PIECES OF THE PUZZLE: STORIES FROM EFL THAI UNIVERSITY

STUDENTS' LANGUAGE LEARNING MOTIVATION,

EXPERIENCES, AND SELF-IDENTITIES

IN THEIR IMAGINED COMMUNITIES

\title{
Sudatip Prapunta
}

A thesis submitted to the Victoria University of Wellington

in fulfilment of the requirements for the degree of

Doctor of Philosophy in Education

Victoria University of Wellington 



\begin{abstract}
Despite the growth of English, the lingua franca of today's world, most Thai undergraduates struggle to attain a high level of communicative skills in environments where English is a Foreign Language (EFL). This thesis explores and reinterprets Thai students' language learning motivation, experiences, and their identity formation and development. The person-in-context relational view of motivation was used to complement Dörnyei's theory of L2 Motivational Self System (L2MSS). These frameworks were used to analyse the multifaceted aspects of individual and contextual influences on the participants' L2 self and identity.
\end{abstract}

This study employs a research methodology with a focus on a narrative qualitative approach. Quantitative data were collected from 356 first-year students at a public and private university in Thailand and four Thai students were purposively selected. These four participants were formally interviewed three to four times about their English learning motivation and experiences. The narrative data were generated by a series of individual interviews and supplemented by stimulated recall interviews, an English diary, and other person-family-and-social artefacts. Their L2 learning motivation and experiences from school to university were presented as unique individual narratives. The interview transcripts were then analysed across the cases to create themes.

The findings indicated that the rote-memorisation, grammar-translation, and examination-orientated methods practised by their secondary and tertiary EFL teachers impacted the participants' language learning motivation and the development of their L2 self-identities. The Thai participants prioritised speaking skills and felt highly motivated to attain communicative English for their future career. Their ideal L2 self appeared to be strengthened by their sustained efforts to communicate in English in both formal and informal learning contexts. Nonetheless, their ideal L2 self and ought-to L2 self seemed to be interconnected and worked together in their motivational system. The participants regulated themselves by using motivational strategies in association with the promotion-focused and preventionfocused instrumentality to maximise their intended effort in learning English. The inclusion of self-efficacy into the L2MSS model yields insights into how the 
participants actualised their self system in their motivational orientation. They pushed themselves to gain more exposure to a variety of learning experiences in both face-to-face and virtual communication in their imagined communities. By investing their effort and time in majoring in English and Business English, they envisioned themselves after graduation improving their parents' and extended family's social status and well-being. Their ideal L2 self and transportable identities were developed to meet Thailand's integration within the ASEAN Economic Community (AEC). For instance, two participants at a public university were able to envision themselves studying English at a Malaysian university. Narrative approaches shed light on the participants' individual motivational orientations and the effects of these on the formation and development of their L2 self and identity in the past, present, and future. This study allows teachers and educators to understand the interplay between in-class and out-of-class learning experiences and the implication of the local, social, and global learning experiences of EFL Thai learners that may have been unexplored and unheard. 


\section{PUBLICATION}

Prapunta, S. (2017). Who am I? "I am a Swifty!" Some Stories from EFL Learners. Universal Journal of Educational Research, 5(10), 1827 - 1834.

Prapunta, S. (2016). EFL learners' stories: Ideal L2 self and their learning experiences. In P. Clements, A. Krause, \& H. Brown (Eds.), JALT2015 Conference Proceedings. Tokyo: JALT. 


\section{ACKNOWLEDGEMENTS}

I am indebted to my supervisors, Dr. Carolyn Tait and Dr. Margaret Gleeson, for their wisdom, constructive feedback, and continued support on my research. They opened the opportunity for me to conduct the narrative research based on my interest and intention. They have extremely played a pivotal role in motivating me to strive for the best.

My special thanks to Prince of Songkla University for sponsoring me the Staff Development Scholarship to pursue my PhD journey in New Zealand. Studying in the foreign country was challenging and could broaden my worldview of being an autonomous researcher and gaining overseas lived and learning experiences. I am extremely thankful to Dennis Dawson, Dalice Sim, and Lisa Woods who kindly gave me statistical help and consulting in the quantitative realm. I would like to thank Thilegawathy Sithraputhran, Thuy Tran, Dwi Agustina, Syerina Syahrin, Raewyn Eden, and other colleagues at Campbell $31 \mathrm{~A}$ and Waiteata 3, for sharing their learning and researching experiences with me.

Special thanks to Ajarn Siriluck Wechsumankalo and Dr. Nattakritta Chotipaktanasook for assisting me to obtain the approval and giving me some constructive advice with administering the online questionnaire at their university. Additionally, I am thankful for the faculty and administrative staff at my home university for their assistances in data collection. I felt grateful for the full cooperation of the undergraduates at both universities who voluntarily participated in this project and actively shared their L2 learning experiences with me all through my research project. Particularly, interviewing the students at my home university strengthened our research relationship and bonds of friendship. Listening to their meaningful stories deepened my understanding of their language learning motivation and L2 self-identity. Without them, this project could not happen.

Since some parts of this thesis are included in the JALT Postconference Publication, I want to acknowledge Professor Stephen Ryan, the content editor, for his valuable comments and suggestions. 
Lastly, I take this opportunity to thank my parents and family members. Their continuous concern immensely encouraged me to push myself to write this thesis. I am grateful for the support of family in my life. 


\section{GLOSSARY}

$\begin{array}{ll}\text { AEC } & \text { ASEAN Economic Community } \\ \text { ASEAN } & \text { Association of Southeast Asian Nations } \\ \text { BE } & \text { Business English } \\ \text { CoP } & \text { Communities of Practice } \\ \text { EFL } & \text { English as a Foreign Language } \\ \text { ELF } & \text { English as a Lingua Franca } \\ \text { ESL } & \text { English as a Second Language } \\ \text { GAT } & \text { General Aptitude Test } \\ \text { GPA } & \text { Grade Point Average } \\ \text { L2 } & \text { Second/foreign Language } \\ \text { L2MSS } & \text { L2 Motivational Self System } \\ \text { M } & \text { Mean } \\ \text { PAT } & \text { Professional Aptitude Test } \\ \text { SD } & \text { Standard Deviation } \\ \text { SLA } & \text { Second Language Acquisition } \\ \text { SPSS } & \text { Statistical Package for Social Sciences } \\ \text { NS } & \text { Native speaker } \\ \text { NNS } & \text { Non-native speaker } \\ \text { O-NET } & \text { Ordinary National Education Test } \\ \text { TOEIC } & \text { Test of English for International Communication } \\ \text { SCT } & \text { Sociocultural theory } \\ & \end{array}$




\section{Definitions of terms}

A brief definition of key terms and abbreviations is presented in Table 1.

\begin{tabular}{|c|c|}
\hline Key term/Abbreviation & Definition \\
\hline Asian Economic Community (AEC) & $\begin{array}{l}\text { In 2015, the Asian Economic Community } \\
\text { (AEC) integrated ASEAN or its member } \\
\text { states of the Southeast Asian region with } \\
\text { the free movement of goods, services, } \\
\text { investment, skilled labour, and free flow of } \\
\text { capital. People from non-English speaking } \\
\text { countries are expected to use English as a } \\
\text { medium of their communication to achieve } \\
\text { these objectives. }\end{array}$ \\
\hline $\begin{array}{l}\text { Association of Southeast Asian } \\
\text { Nations (ASEAN) }\end{array}$ & $\begin{array}{l}\text { The Association of Southeast Asian } \\
\text { Nations (ASEAN) was cooperatively } \\
\text { formed by Thailand, Indonesia, Malaysia, } \\
\text { the Philippines, and Singapore on August 8, } \\
\text { 1967. The aim was to foster the economic, } \\
\text { social and cultural development within the } \\
\text { ASEAN region. The motto is "One Vision, } \\
\text { One Identity, One Community (ASEAN } \\
\text { Secretariat, 2008)". }\end{array}$ \\
\hline English as a Foreign Language (EFL) & $\begin{array}{l}\text { English as a Foreign Language (EFL) refers } \\
\text { to the use of English among speakers of }\end{array}$ \\
\hline
\end{tabular}




\begin{tabular}{|c|c|}
\hline & $\begin{array}{l}\text { other languages in a non-English speaking } \\
\text { country such as Thailand, Japan, or China. } \\
\text { Most of EFL students are likely to have } \\
\text { limited opportunities to communicate } \\
\text { English in their daily lives and learn } \\
\text { English for passing the examinations. }\end{array}$ \\
\hline English as a Lingua Franca (ELF) & $\begin{array}{l}\text { English as a Lingua Franca (ELF) refers to } \\
\text { the communication in English between } \\
\text { speakers with different dominant languages } \\
\text { such as non-native speakers in Asian } \\
\text { countries with diverse linguistic and } \\
\text { cultural backgrounds (Seidlhofer, 2005). }\end{array}$ \\
\hline English as a Second Language (ESL) & $\begin{array}{l}\text { English as a Second Language (ESL) refers } \\
\text { to the communication in English among } \\
\text { speakers who use English as a second } \\
\text { language or an official language, in } \\
\text { addition to their native language such as } \\
\text { Malaysia, Singapore, or the Philippines. }\end{array}$ \\
\hline Integrative motivation & $\begin{array}{l}\text { Students who are integratively motivated to } \\
\text { learn the L2 language in order to } \\
\text { communicate with the member of the } \\
\text { second/foreign language community, } \\
\text { identify themselves with English speaking } \\
\text { people or ultimately integrate within an }\end{array}$ \\
\hline
\end{tabular}




\begin{tabular}{|c|c|}
\hline & $\begin{array}{l}\text { English-speaking society (Gardner \& } \\
\text { Lambert, 1972) . }\end{array}$ \\
\hline Instrumental motivation & $\begin{array}{l}\text { Students who are instrumentally motivated } \\
\text { want to learn the second/foreign language } \\
\text { in order to acquire some advantages such as } \\
\text { getting a good grade or good job (Gardner } \\
\text { \& Lambert, 1972). }\end{array}$ \\
\hline Instrumentality-prevention & $\begin{array}{l}\text { The individual L2 learner is encouraged to } \\
\text { learn English as an obligation or duty to } \\
\text { their parents or family. This is revealed in } \\
\text { the learner's intentions to avoid failing the } \\
\text { examinations or drives towards getting a } \\
\text { degree. }\end{array}$ \\
\hline Instrumentality-promotion & $\begin{array}{l}\text { The individual L2 learner has internalised } \\
\text { an intention to learn English in order to } \\
\text { pursue a personal goal such as attaining } \\
\text { high proficiency in English, becoming an } \\
\text { educated person, or getting a competitive } \\
\text { job. }\end{array}$ \\
\hline $\begin{array}{l}\text { Language Motivation Self System } \\
\text { (L2MSS) }\end{array}$ & $\begin{array}{l}\text { The "L2 Motivational Self System" is a } \\
\text { reconceptualised the theoretical framework } \\
\text { which synthesises some influential } \\
\text { approaches in the field of L2 learning }\end{array}$ \\
\hline
\end{tabular}




\begin{tabular}{|l|l|}
\hline motivation and psychological theories \\
concerning learner's self and identity \\
(Dörnyei, 2005, 2009).
\end{tabular}


TABLE OF CONTENTS

ABSTRACT ….......................................................................................................................

PUBLICATION ....................................................................................................................iii

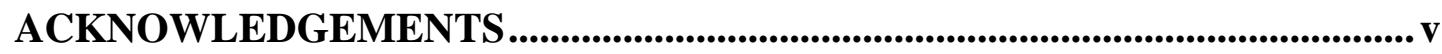

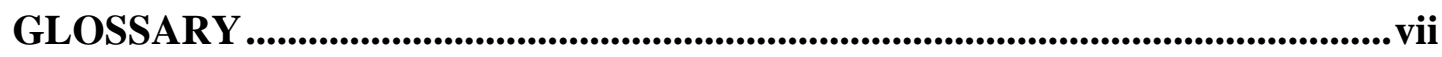

TABLE OF CONTENTS ...............................................................................

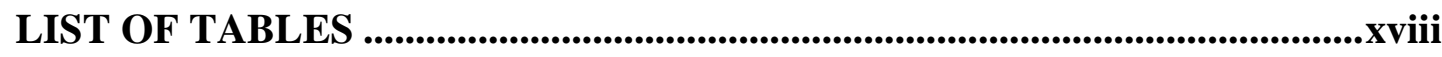

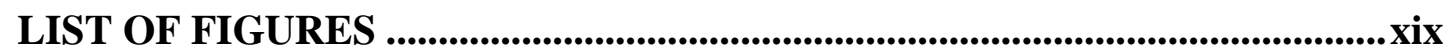

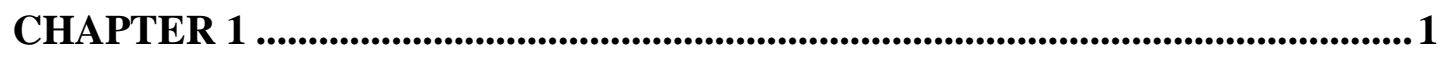

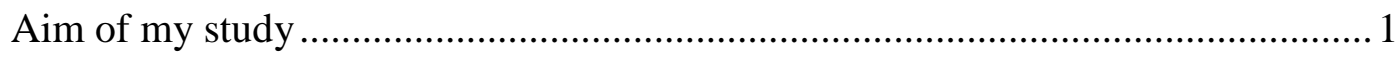

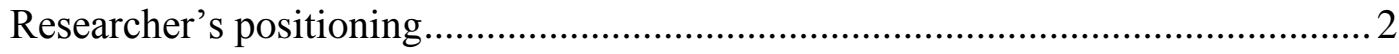

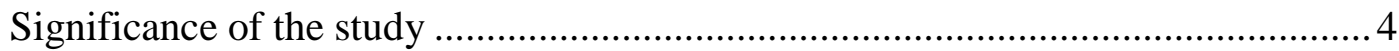

Overview of my methodology and theoretical frameworks ............................... 5

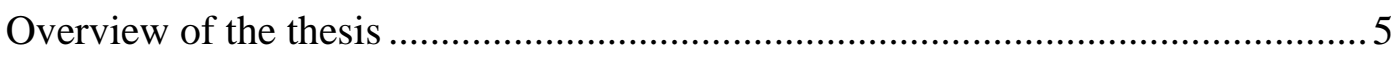

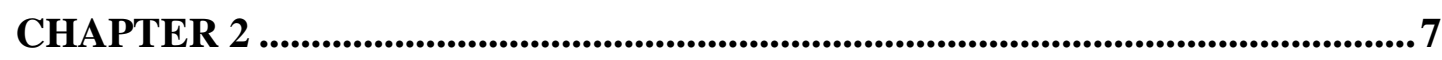

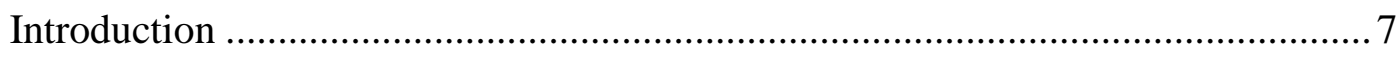

Contextualising the historical background and role of English in Thailand ............ 7

The changing role of English as ELF in the Thai context ............................... 11

English language education and issues of proficiency in Thailand ....................... 13

Thai learners' perceptions of their L2 self-identity ….......................................... 16

Previous studies explored the Thai undergraduates' perceptions of Thai English

Previous studies about the Thai undergraduates' perceptions of learning English

Communities of practice, imagined communities and identities.........................2 21

Communities of practice and multimembership ........................................... 21

Reconceptualising imagined identity as a site of struggle ..........................23

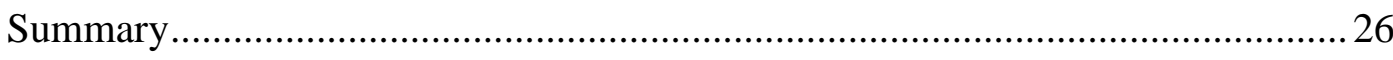

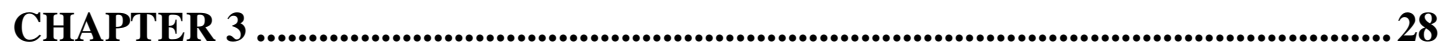

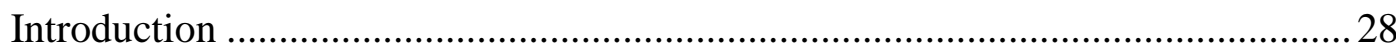


Development of L2 motivation research and self-identity

The conceptual shift of L2 learning motivation research ................................. 28

Methodological shift of L2 learning motivation research ................................. 30

Dörnyei's L2 motivational self system (L2MSS) .............................................. 31

The link between L2MSS and possible selves and self-discrepancy theories.... 32

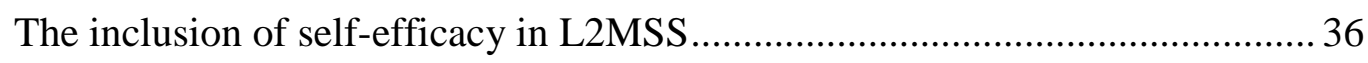

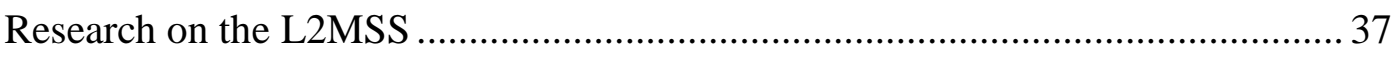

Ushioda's (2009) “person-in-context” relational view of motivation .................... 42

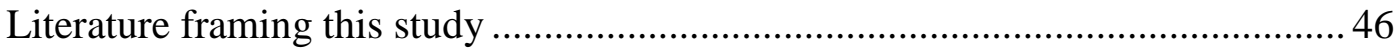

Integration of literature into a theoretical and conceptual framework................ 46

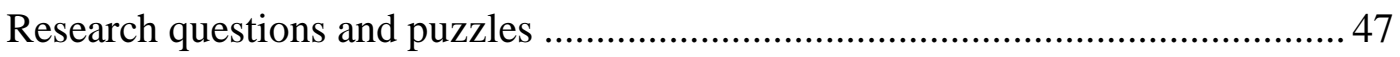

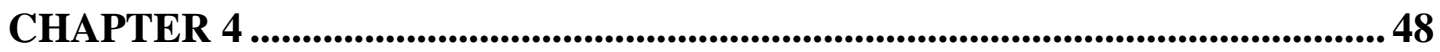

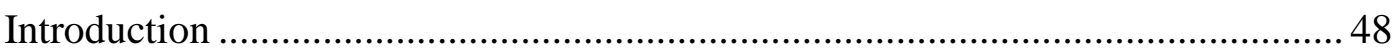

Shifting my worldviews to explore Thai students' L2 motivation and self-system49

Analysis: Aligning my research approach with my worldview ........................... 51

Procedures for selecting eligible participants .................................................... 52

Advantages of using a questionnaire and undertaking narrative research ..........52

Analysis: Recruiting eligible participants through a validated survey ...................53

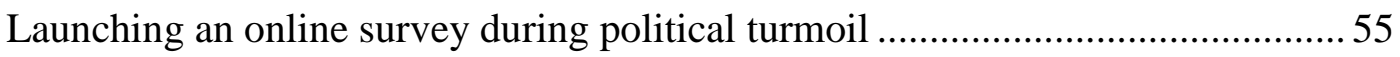

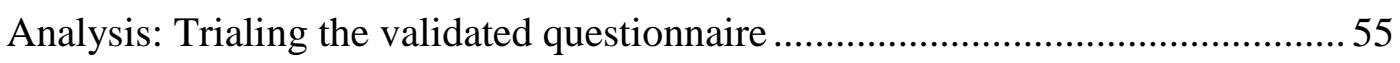

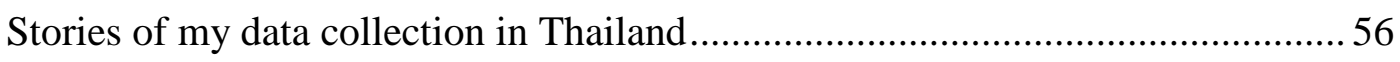

Analysis: Advantages of using convenience sampling for a survey ......................59

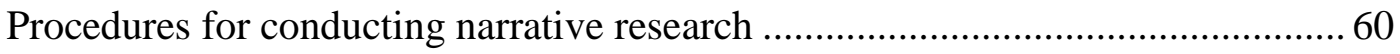

Analysis: Using the quantitative findings to recruit "hard to find" participants .... 62

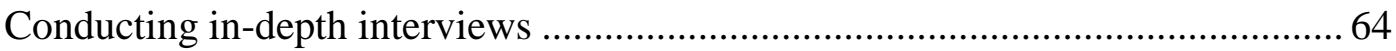

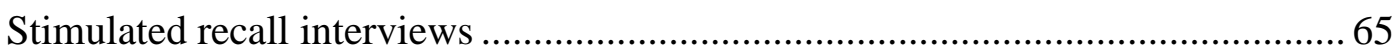

Undertaking narrative research, researchers' positioning, and ethical consideration .66

Analysis: The uniqueness of narrative research .................................................6 69

The ethics of relationships between researcher and participants.......................... 70

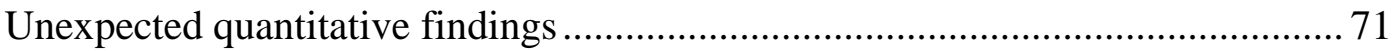

Analysis: The problematic "intended learning effort" variable as a criterion measure 
Narrative analysis, reflexivity, and writing up the narrative report....................... 73

From collecting data to writing up the report ....................................................... 74

Analysis: Decisions during the analysis process ……......................................... 75

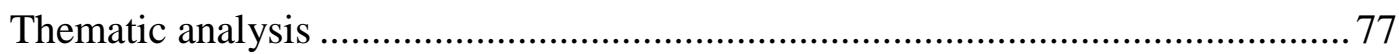

Challenges of translation from Thai into English............................................... 78

Power relationships between my participants and me........................................ 79

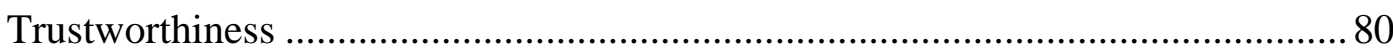

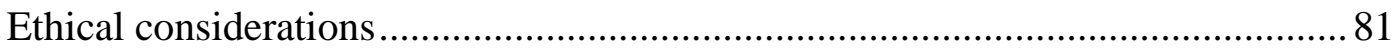

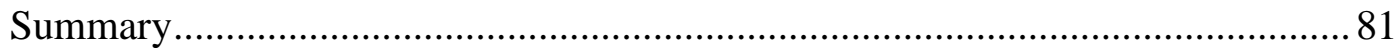

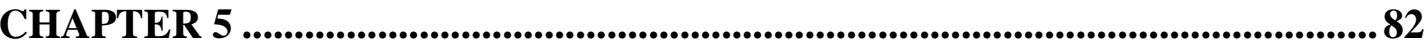

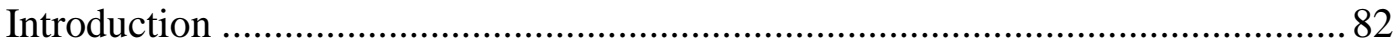

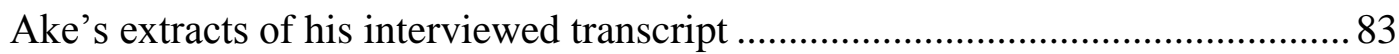

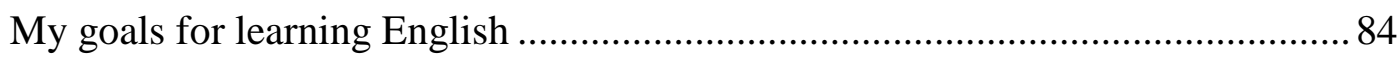

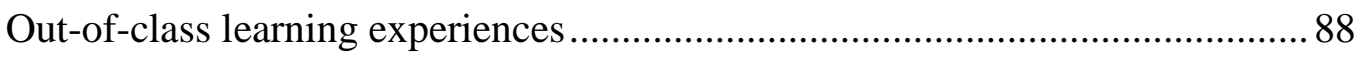

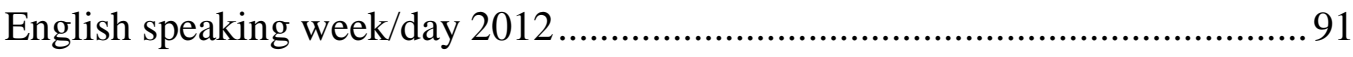

Part-time working experiences at Hat Yai ...................................................... 92

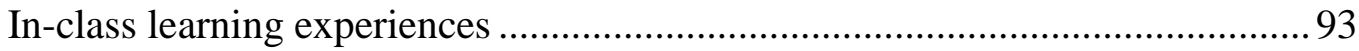

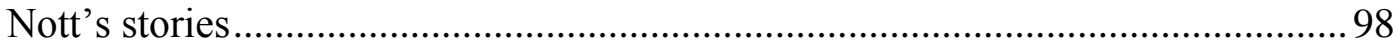

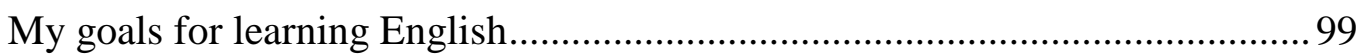

My scholarship for underprivileged students.............................................. 101

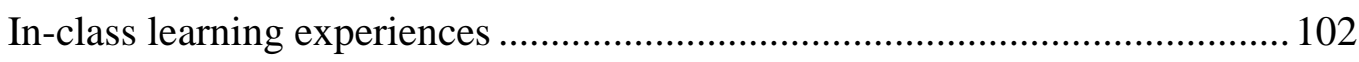

Negative learning experiences at the university ........................................... 103

Out-of-class motivated learning experiences .................................................. 104

His internship at Tourism Authority of Thailand (TAT) ................................ 105

Out-of-class learning experiences from mass media and social networking .... 106

Once-in-lifetime backpack adventure in Myanmar .......................................... 107

My intended effort of learning English from past to present.......................... 111

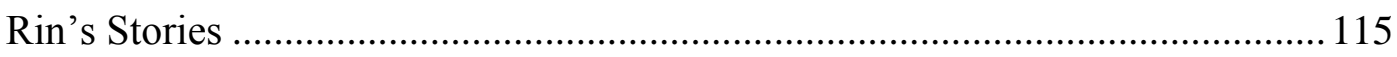

My goals for learning English................................................................ 116

Why did I study at this small university?.................................................. 117

My profile of learning English at a temple school....................................... 124

Foreign friends from social networks from school to university ..................... 128

Thai-Malaysia partnership from school to university ................................... 129 
My aunt has motivated me to learn English

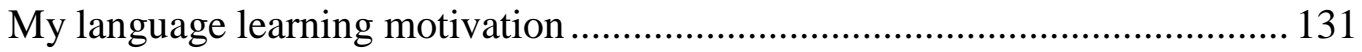

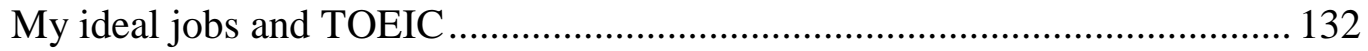

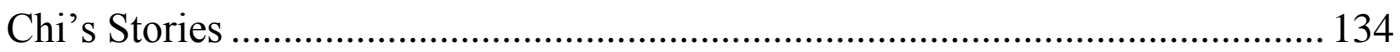

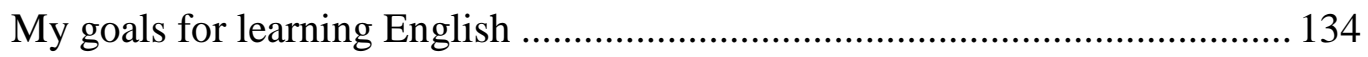

My profile: Private English classes for university entrance exam................... 135

Majoring in Business English (BE) at the southern public university.............. 138

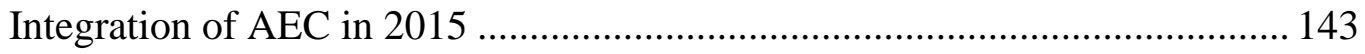

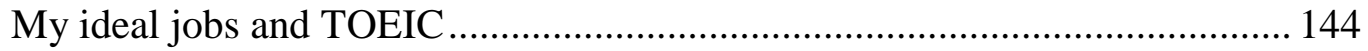

My expectation for the next semester .......................................................... 146

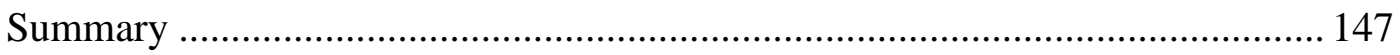

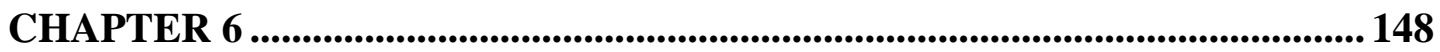

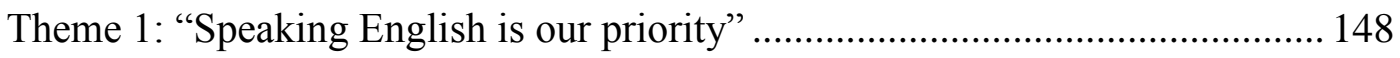

“Speaking fluently or speaking njoo..njoo..pla..pla..?” ................................... 149

"Speaking like "Farang" or speaking as who we are" .................................... 150

“English Speaking year project 2012”: our mission impossible? ..................... 153

"Our memorable second language activity in class" ...................................... 154

Speaking English is a must for our work ……............................................... 155

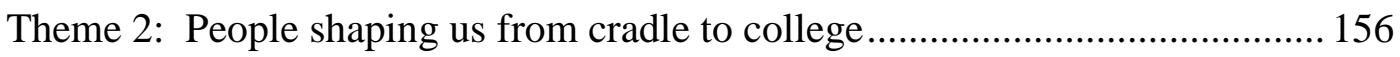

Our parents and family members: encouraging vs. discouraging us? ............. 157

Our teachers: motivating vs. demotivating us?............................................ 160

Our friends: peer networking vs. peer pressure ............................................. 164

Theme 3: Using English to open up our eyes.................................................. 165

"We found our foreign friends on the Internet"................................................ 166

"Our schools and universities broadened our global perspectives"................. 168

"We imagined ourselves studying and working overseas/ in English-speaking

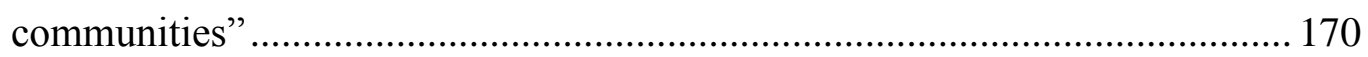

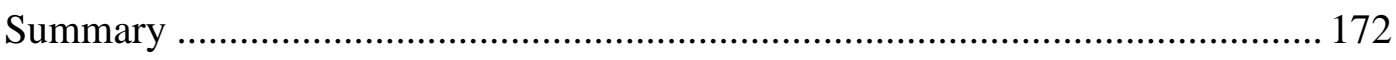

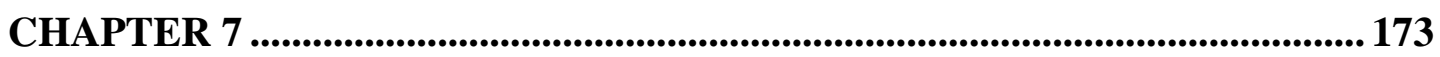

Tensions and dynamic interplay between their perceived skills and experiences 173

Transition from school to university ............................................................... 175

Interwoven relationship between social and psychological aspects................... 176

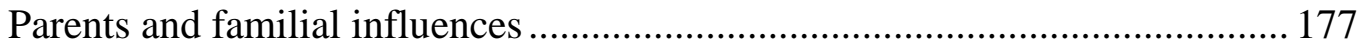


Pedagogical and institutional influences..................................................... 178

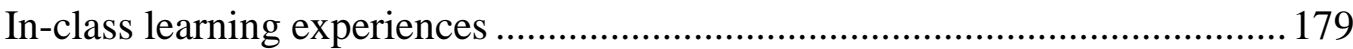

Forging their L2 self-identity in their imagined communities ........................... 182

Out-of-class learning experiences: face-to-face communication..................... 184

Out-of-class learning experiences: virtual communication ............................ 184

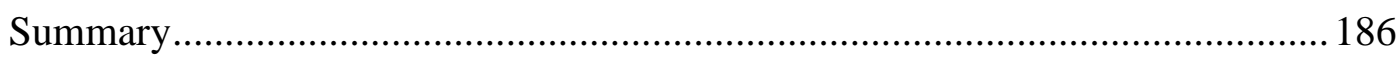

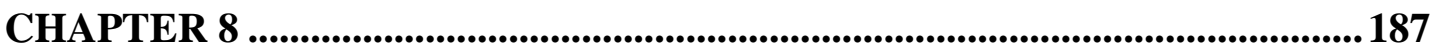

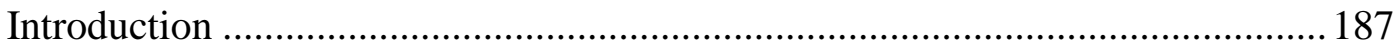

Process of the Thai language learner's L2 motivational self-system ................... 187

Dynamic interplay between the notions of ideal and ought-to L2 selves ......... 188

Dynamic interplay between ought-to and ideal L2 selves .............................. 191

Language learners' LLM and experiences in their imagined communities ......... 193

Multiple membership and reconciliation in AEC integration ............................ 196

Persons-in-global-context model (virtual communication) ............................. 198

Integrating the Thai Learners' L2 self-identities in their imagined communities

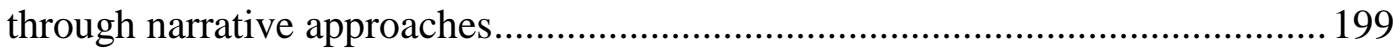

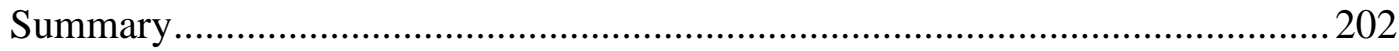

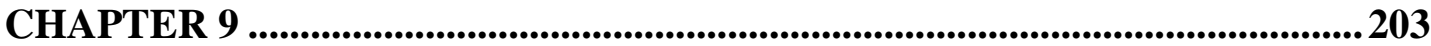

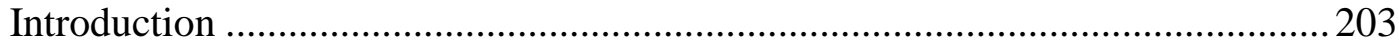

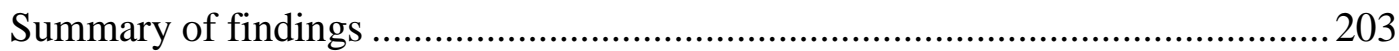

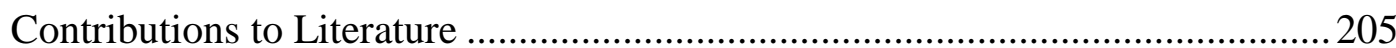

Integrativeness and ideal L2 self of the Thai university students .................... 205

Instrumentality and the Thai university students ..........................................206

Inclusion of the self-efficacy in L2MSS ....................................................... 207

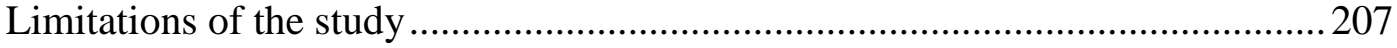

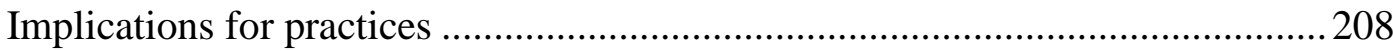

Language teachers and learners .................................................................. 208

Policy makers and curriculum designers ....................................................2 210

Parents and family members ..................................................................... 211

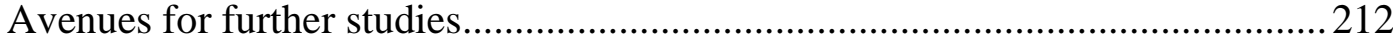

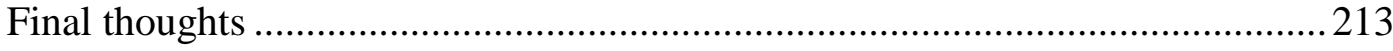

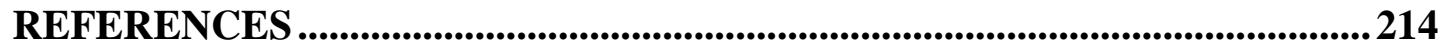


Appendix A: Ethical approval letter 229

Appendix B: Questionnaire 230

Appendix C: Preliminary interview questions 235

Appendix D: Information for the online survey 237

Appendix E: Information sheet for the in-depth interview 239

Appendix F: Information sheet for the dean or head of the department 241

Appendix G: Consent form for the dean or head of the department 244

Appendix H: Consent form for students 246

Appendix I: Sample of my research journal. 248

Appendix J: Sample of the student's English language diary 249

Appendix K: Mean score and SD of the intended effort variable. 250 


\section{LIST OF TABLES}

Table 4.1 Cronbach alpha, mean scores, and SD for each variable ...........................60

Table 5.1 Techniques of presenting the four participants' narratives...............82

Table 5.2 Summary Ake's L2 learning experiences from the past to present........98

Table 5.3 Summary Nott's L2 learning experiences from the past to present .........114

Table 5.4 Summary Rin's L2 learning experiences from the past to present........133

Table 5.5 Summary Chi's L2 learning experiences from the past to present ........... 146 


\section{LIST OF FIGURES}

Figure 2.1 Structure of the Thai educational system .............................................. 9

Figure 2.2 Selection process for university admission in Thailand.......................... 10

Figure 2.3 Outer-circle and expanding-circle societies in Southeast Asia (Thailand),

South Asia, and East Asia

Figure 3.1 Components of L2MSS: ideal L2 self, ought-to L2 self, and L2 learning experiences

Figure 3.2 Conceptual representations of the self (A: independent construal:

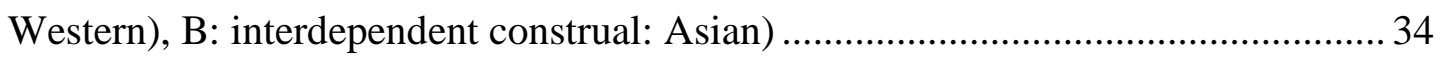

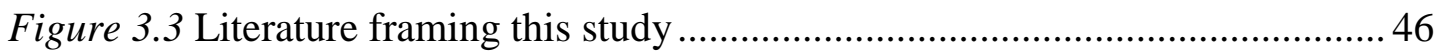

Figure 4.1 Intended effort (as measured by the survey) of the participants selected

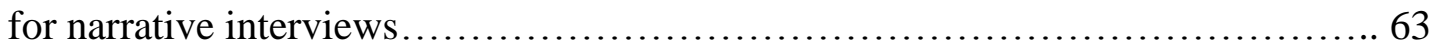

Figure 4.2 Self-efficacy of the participants selected for narrative interviews.......64

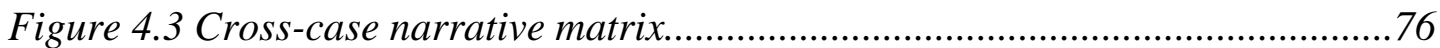

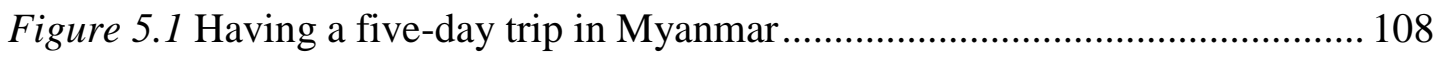

Figure 5.2 Taylor Swift's photo in his mobile phone ........................................... 111

Figure 5.3 Taylor Swift's concert cancellation................................................... 111

Figure 5.4 Sitting for a direct admission ....................................................... 117

Figure 5.5 Doing a multiple-choice entrance examination................................... 117

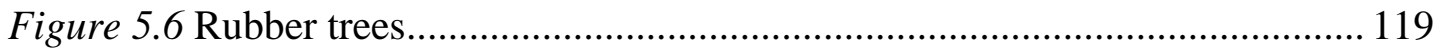

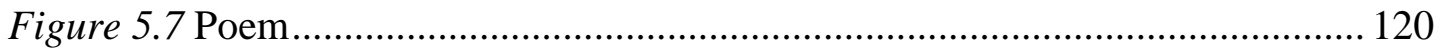

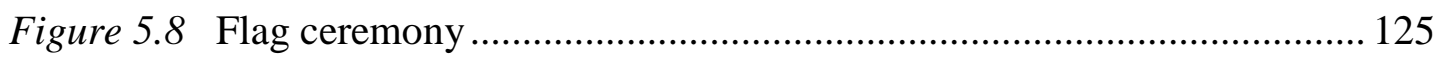

Figure 5.9 Participating in public speaking contest.......................................... 126

Figure 5.10 Receiving a postcard from her British friend ................................... 128

Figure 5.11 Visiting a Malaysian school with her teachers and schoolmates ......... 129

Figure 8.1 Process of the Thai language students' L2 motivational self-system .... 188

Figure 8.2 Model representing the state of consonance between ideal and ought-to L2 selves of the Thai language students

Figure 8.3 Model representing the state of dissonance between ought-to and ideal L2 selves of the Thai language students

Figure 8.4 Persons-in-local-and-global context and persons-in-global-context models of the Thai university students 195

Figure 8.5 Concentric circles diagram of the Thai university students' emerging L2 self-identities 200 


\section{CHAPTER 1 INTRODUCTION}

My study aims to investigate the language learning motivation of Thai tertiary students in the changing sociocultural and economic environments of Thailand. This chapter introduces the aim and significance of the study. The brief description of my methodology and theoretical frameworks are addressed. Finally, I provide an overview of the thesis structure which foregrounds contents of each chapter.

\section{Aim of my study}

Studying English in Thailand is challenging because learning English is different from learning other content-based subjects in the curriculum in contexts of English as a Foreign Language (EFL). The use of English is limited to classroom settings and passing examinations. Thai students study in this EFL context and have limited opportunities to speak English in their daily lives. Students who achieve EFL proficiency need to motivate themselves to learn independently and to seek out opportunities to communicate with foreigners.

Tracing back to its establishment, the Association of Southeast Asian Nations (ASEAN) was cooperatively formed by Thailand, Indonesia, Malaysia, the Philippines, and Singapore on August 8, 1967. The aim was to foster the economic, social and cultural development within the ASEAN region. Its motto is "One Vision, One Identity, One Community" (ASEAN Secretariat, 2008). The implementation of AEC integration since 2015 has created economic and social benefits and strengthened the connectivity among the citizens of the community. The increasing free flow of business transactions and skilled labour in member states has emphasised on the importance of using English in educational and business contexts. This provides Thai students with more opportunities to contact, travel, and even work with people in the member states. As members of a future mobile workforce, it is important to understand whether Thai university students have the English language skills to participate in the global community, and if they perceive themselves as proficient English-users at a time when learning English is not restricted to classroom settings. 
This study examines Thai learners' second language (L2) learning experiences and the process of learning English in a monolingual context. I capture Thai students' motivation and vision of their future selves amid the changing social and cultural contexts in the AEC era. The current social and cultural contexts mean that students have more opportunities to communicate with native speakers (NS) of English and non-native speakers (NNS) in changing sociocultural environments. This study investigates how these new opportunities to use English in this period may strengthen Thai learners' visions of being successful English-users and motivate them to sustain their motivation of interacting effectively with NNS and NS interlocutors in the global community. Technological advances have given students more access to social networks and the Internet to interact with interlocutors virtually in meaningful contexts. This means that it is necessary to explore whether Thai students are be likely to be motivated by learning English out-of-class as well as in classroom settings because accessing these alternative learning spaces may boost their confidence in using English as a medium of communication. Thus, I attempt to explore how Thai undergraduate students push themselves to learn English to ensure teachers and educators in this field may find the insights of L2 learning motivation and experiences in their particular contexts.

\section{Researcher's positioning}

I am ethnically Thai, born of Thai parents. I studied at schools and universities in Thailand. Reflecting on my past, my initial motivation to learn English was profoundly influenced by my father, who attended a southern rural school and obtained a scholarship sponsored by the national airline company to pursue his vocational education in Bangkok. After completing his study, he worked there successfully and occasionally attended professional training programmes overseas. He often took me abroad and exposed me to western culture. Throughout my childhood, I was encouraged to study English attentively at school. Sometimes, my father asked me the meaning of English vocabulary. If I could answer him correctly, I would be proud of myself. I still remember memorising a long list of vocabulary at school. I was convinced if I could speak English, I would be able to travel and work internationally. I believed that English could broaden my horizons and be a springboard to my personal, familial, and professional success. Thus, I was passionate about learning English throughout my entire education from school to university. 
My insider perspective also stems from my professional experiences as a teacher of EFL over the past 10 years, teaching and training Thai students from diverse socio-educational backgrounds. I worked as a lecturer at a public university in the northern province of Bangkok metropolitan area for two years. After that, I worked as a language trainer for seafarers and company staff at a Singaporean-owned shipping company in the heart of Bangkok for six years. I then worked as a lecturer for three years at a public university in southern Thailand where I obtained a scholarship to pursue my $\mathrm{PhD}$. Since my home university aims to be one of the foremost research universities in Asia, they organised a series of research training opportunities for the faculty staff. As a lecturer, apart from teaching, my responsibilities were to conduct research to improve pedagogical practices and to develop courses and curricula.

My research interest stems from the fact that I was normally assigned to teach General English to large classes of first-year students from different majors. Because of the large numbers of students, I sometimes used traditional pedagogical approaches such as grammar-translation in reading and writing classes, and drilling activities in speaking classes. I saw that some students wanted to study simply to pass examinations. They appeared to strive to maintain the motivation to learn English within the constraints of their monolingual context. They did not seem to see the relevance of English to their daily and professional lives. In contrast, other students felt motivated to learn and could sustain their efforts in both academic and non-academic contexts. I was passionately interested in discovering how students were motivated to engage with communicative activities and sustain their English learning experiences efficiently when they saw themselves as having limited background knowledge of English. This prompted me to explore students' perceptions of the influence of their learning context upon their L2 learning motivation during the transition from school to university. Thus, my aim is to capture the stories of these students' diverse learning experiences. From my perspective, understanding their L2 language learning experiences is like assembling pieces of a puzzle. Their success stories could be a model to other L2 students in EFL contexts. Besides, understanding their failures of learning English is also beneficial. As a teacher and researcher, I could understand students' perceptions of ideal linguistic tasks which would enable me to improve my teaching practices and support students to sustain theirL2 motivation and expectations of courses and the curriculum in the future. 


\section{Significance of the study}

Thailand's educational policy has been influenced by its entry into AEC, for instance, “English Speaking Day/Year" project was initiated in 2012. This national educational policy was instigated by the Ministry of Education to encourage primary and secondary students in urban and provincial areas to improve their English skills and become proficient English users. The ministry expected that attaining English proficiency would boost secondary students' motivation, autonomy and agency to communicate with other countries in their academic and professional life. English, thus, plays a crucial role in high school and tertiary levels of the national education system.

The communicative method plays a significant role in national language education. Since the integration into AEC, Thailand's education policy encouraged school teachers to include more speaking activities and conversational practice in their classes (Fredrickson, 2012; Hodal, 2012). These practices have the potential to motivate students to engage with authentic, communicative activities and enable them to see the relevance of speaking skills in their academic and professional lives in the future. In contrast, for several decades, teachers have relied on grammar-translation and rote-memorisation approaches to ensure that their students pass the university entrance or admission examinations. These examination-focused practices have been identified as demotivating to students learning English and may lead to their limited proficiency in English (Draper, 2012). They may not feel adequately equipped with linguistic and cultural competences to participate in the AEC community in which English is regarded as the lingua franca or global language.

My study captures the previously unheard stories of tertiary students' English language learning motivation, experiences, both in class and in out-of-class contexts, and shows how participants; language identity develops in the transition from school to university. I selected this particular period to explore how Thai adolescent students realise the increasing importance and usage of English to their academic and professional lives, sustain their motivation to learn English, and embrace it as part of their L2 self-identities within the ASEAN region and global community. 


\section{Overview of my methodology and theoretical frameworks}

This study draws on learners' development of L2 identity through the L2 Motivational Self System (L2MSS) (Dornyei, 2005, 2009). Although several previous studies (Taguchi, Magid \& Papi, 2009) were conducted employing quantitative methods in various Asian contexts, few empirical studies have employed L2MSS employing qualitative approaches. I applied a person-in-context relational view of motivation (Ushioda, 2009) to complement the model and capture details about the students' L2 learning processes and experiences in the Thai context.

In addition, there is little narrative research of L2 self-identity issues (Benson, 2014). I thus used a quantitative survey to select potential participants and then applied narrative approaches to create "a new sense of meaning and significance" related to the research topic (Clandinin \& Connelly, 2000, p. 42) and "frame a research puzzle" (Clandinin, 2013, p. 42). Applying narrative approaches enabled me to capture the interplay of the participants' perceptions pertaining to their L2 learning motivation and experiences in diverse sociocultural settings. Their stories of learning English reflect some of the realities of pedagogical practices used in Thailand. Thus, applying narrative approaches was crucial for deepening an understanding of the theoretical framework and pedagogical practices in my context.

\section{Overview of the thesis}

The thesis consists of nine chapters. This chapter serves as an introduction to the thesis and highlights the aim and significance of the study. I address my positioning and motivation to conduct the qualitative-oriented study. Finally, the overview of methodology and theoretical frameworks are also addressed.

Chapter 2 contextualises the current role of English in the Thai context. The chapter also addresses the impact of globalisation and Thailand's integration into AEC on the sociolinguistic landscape of Thailand. Literature drawing on imagined communities and identities is reviewed in relation to English as Lingua Franca (ELF). The chapter includes a review of literature pertaining to Thai students' perceptions of roles and ownership of English in their contexts. Chapter 3 presents the theoretical models of L2MSS and the person-in-context relational view of motivation used in the study. The chapter includes links to related theories which are aligned with EFL learners' language learning motivation and L2 self-identities. 
Chapter 4 reviews the qualitative-oriented approach which I employed in the study. The chapter presents the research instruments. It explains the quantitative analysis which led to the selection of the participants. The processes of data collection and narrative analysis are addressed. I present my methodology as a story arising from my experiences of undertaking this research. I have put my story in boxes to indicate the episodes. Then I use research literature to reveal the rationale and impact of the research decisions that were made.

Chapter 5 reports the dialogues between one participant and me, and the narratives of the other three participants' L2 learning experiences. The chapter records how the participants' agency, family, and institution influenced their L2 learning processes and emerging self-identities during their transition from school to university.

Chapter 6 presents a thematic analysis based on multiple cross-case narratives of the participants. Three major themes that emerged are: speaking is our priority, people shaping us from cradle to college, and using English to open our eyes.

Chapter 7 discusses the participants' L2 learning experiences and emerging self-identities based on the major theoretical frameworks used in the study.

Chapter 8 shows how my findings integrate with the theoretical and conceptualised frameworks used in the study. Also, I propose a new integrated model to illustrate the Thai students' learning experiences and the formation of their self-identity in the linguistic and sociocultural landscape of Thailand. The findings and discussion in Chapter 5-8 answer my research questions and puzzle.

Chapter 9 provides a summary, the recommendations, and the limitations of the research. It offers avenues for further studies and identifies pedagogical implications. 


\section{CHAPTER 2 \\ LANGUAGE EDUCATION IN THAILAND}

\section{Introduction}

This chapter contextualises the impact of globalisation and the growth of English as a global language on the linguistic landscape of Thailand. I also review research studies of Thai students' perceptions of their linguistic beliefs and L2 identity development.

\section{Contextualising the historical background and role of English in Thailand}

In this section, I trace the history of English language teaching in the Thai education system. I outline how English proficiency is used to determine entrance to university programmes. I contrast opportunities that Thai students have to use English outside classrooms with the role English plays in language education and business in Thailand.

The history of education in Thailand is set within the wider history of Thailand as an independent country. Thailand has not been colonised by any western countries. Hence, compared to neighbouring countries, its educational system is not strongly influenced by any European or American models. Thailand has a "complex sociolinguistic context" where one must understand "the basic tenets of the culture" to begin to understand its teaching and learning system (Foley, 2005, p. 223). Traditionally, early education was predominantly supported by the monarchy, temples, and missionaries. There is a long history of English language learning in Thailand. King Rama III, who reigned from 1824 to 1851, encouraged the members of his court to acquire English knowledge and modernise the country (Baker \& Phongpaichit, 2005; Foley, 2005). The majority of English learners at the time were from an elite group of people. Originally, some missionary schools and all higher education institutions were situated in Siam or Bangkok, the capital of the country.

The country maintained this status quo until 1960, when an English syllabus was adopted in the educational system of Thailand because there was more international communication with foreigners (Foley, 2005). Despite this change in the 60s, this syllabus did not successfully replace rote-memorisation and grammar-translation, which were deeply embedded in the educational and religious traditions of the country. In late 
1970, the national curriculum introduced English as a Foreign Language (EFL) as an elective subject, at the secondary and tertiary level. The communicative approach to language learning played an integral role in improving the teaching and learning system of Thailand up until the present. Currently, in compliance with the present Basic Education Core Curriculum 2008, English is a compulsory subject for primary to uppersecondary schools. The new curriculum stipulated that all Thai citizens have an equal right to 12 years of free education (primary and secondary school), six years of Prathom (Por. 1-6 or Grade 1-6) and Mattayom (Mor. 1-6 or Grade 7-12). Also, students can choose to study upper secondary education which includes technical and vocational study, or they can enter the labour market. At university, English is regarded as compulsory and/or an elective subject, depending on the students' major or preferences. Opportunities to continue to learn English at university have increased this century but gaining entry into university can be challenging for students.

Increasingly, public and private universities have been established to expand learning opportunities for provincial students in all regions of the country. According to the Office of Higher Education Commission (OHEC, 2009), between 2003 and 2008, a total of 78 public and 69 private universities were opened nationwide in Thailand. Formal education consisted of twelve years of basic and higher education under the Ministry of Education and two mainstream higher education systems: degree and diploma (see Figure 2.1). 


\begin{tabular}{|c|c|c|c|c|c|}
\hline $\begin{array}{l}\text { Aprox. } \\
\text { age }\end{array}$ & $\begin{array}{l}\text { Aprox. } \\
\text { grade }\end{array}$ & \multicolumn{2}{|c|}{ Education Level } & \multicolumn{2}{|c|}{ Degree } \\
\hline 24 & $19+$ & \multicolumn{2}{|c|}{ Doctoral degree study } & \multicolumn{2}{|c|}{$\begin{array}{c}\text { Ph.D. or advanced } \\
\text { professional } \\
\text { degree }\end{array}$} \\
\hline 23 & 18 & \multirow{2}{*}{\multicolumn{2}{|c|}{ Master's degree study }} & \multirow{2}{*}{\multicolumn{2}{|c|}{ Master's degree }} \\
\hline 22 & 17 & & & & \\
\hline 21 & 16 & \multirow{4}{*}{$\begin{array}{c}\text { Undergraduate } \\
\text { program }\end{array}$} & \multirow{4}{*}{$\begin{array}{c}\text { Higher } \\
\text { vocational } \\
\text { education }\end{array}$} & \multicolumn{2}{|c|}{ Bachelor's degree } \\
\hline 20 & 15 & & & & \\
\hline 19 & 14 & & & \multirow{2}{*}{\multicolumn{2}{|c|}{ Diploma }} \\
\hline 18 & 13 & & & & \\
\hline 17 & 12 & \multirow{3}{*}{$\begin{array}{c}\text { Upper secondary } \\
\text { education }\end{array}$} & \multirow{3}{*}{$\begin{array}{l}\text { Vocational } \\
\text { secondary } \\
\text { school }\end{array}$} & \multirow{12}{*}{\multicolumn{2}{|c|}{ 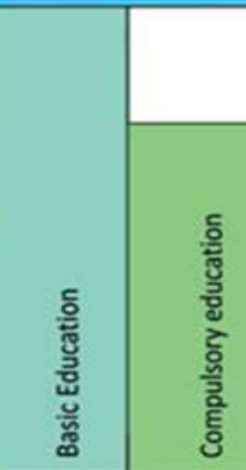 }} \\
\hline 16 & 11 & & & & \\
\hline 15 & 10 & & & & \\
\hline 14 & 9 & \multirow{3}{*}{\multicolumn{2}{|c|}{ Lower secondary education }} & & \\
\hline 13 & 8 & & & & \\
\hline 12 & 7 & & & & \\
\hline 11 & 6 & \multirow{6}{*}{\multicolumn{2}{|c|}{ Primary education }} & & \\
\hline 10 & 5 & & & & \\
\hline 9 & 4 & & & & \\
\hline 8 & 3 & & & & \\
\hline 7 & 2 & & & & \\
\hline 6 & 1 & & & & \\
\hline 5 & & \multirow{3}{*}{\multicolumn{2}{|c|}{ Pre-primary education }} & & \\
\hline 4 & & & & & \\
\hline 3 & & & & & \\
\hline
\end{tabular}

Figure 2.1 Structure of the Thai educational system

(Source: Office of Education Council, 2004)

In the EFL Thai context, there is a focus on exam-oriented English to pass the highly competitive entrance university examination (Fredrickson, 2012; Sanonguthai, 2014). Entering prestigious universities may lead to gaining a good education and job in the future. To pursue tertiary study in public universities, the majority of Thai students are required to take several rounds of examinations. In the centralised admission system, the examination required for almost all universities is the Ordinary National Education Test (O-NET). Its major objectives are to test basic knowledge across several requisite subjects such as English language, mathematics and social studies. In addition, candidates are expected to take another two aptitude tests: the General Aptitude Test (GAT) and the Professional Aptitude Test (PAT). GAT tests the reasoning ability and English proficiency of the candidates. In terms of language proficiency, the PAT tests candidates' ability in other foreign languages such as French, German, Japanese, and Chinese. Students are able to choose to take the particular tests required by specific programs. Hence they do not have to take all tests like the O-NET. The O-NET, GAT, and PAT 
examinations are multiple-choice formats which focus on receptive skills, particularly reading skills (see Figure 2.2).

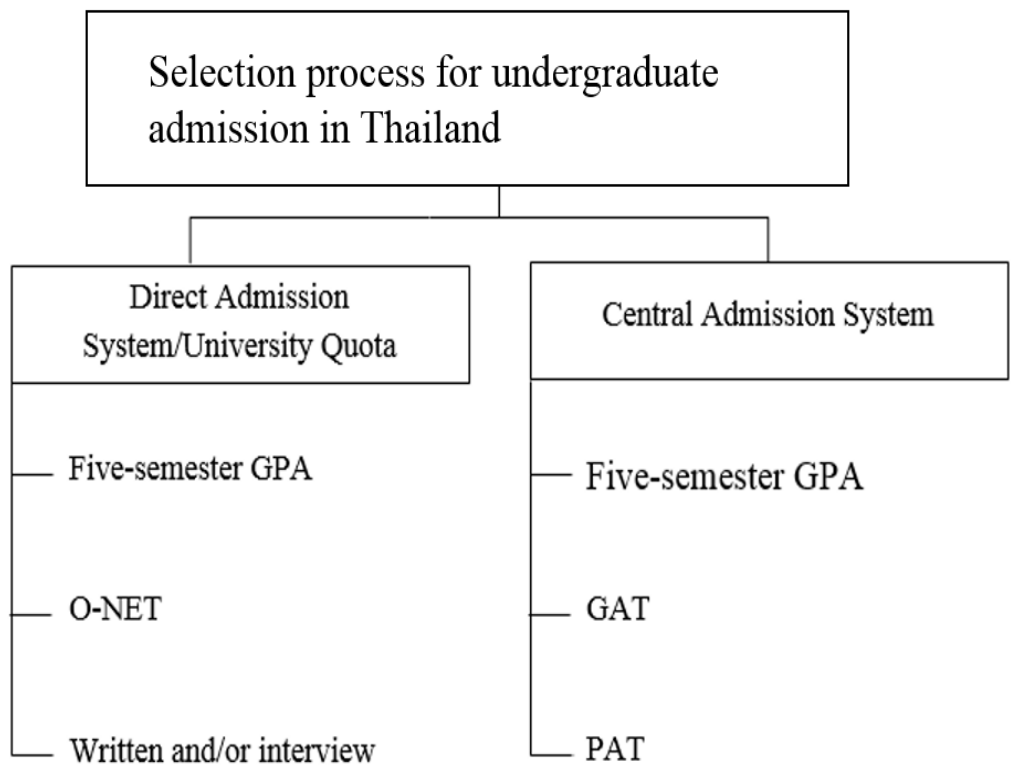

Figure 2.2 Selection process for university admission in Thailand

The application and selection process for English major in universities is multilayered and difficult. In the first round, to apply for the particular program, students are required to submit an O-NET test score, together with the cumulative grade point average from their upper secondary schools, as well as take examinations set by the university. Requirements for admittance into each public university vary greatly. Students can sit for several programs, but they are able to select only one program. Given the fact that majoring in English and Business English is demanding, the competitive ratio is dramatically high and the admission rate is rather low. Likewise, in some universities, students are required to take and pass both multiple-choice and interview examinations to pursue an English major. If they are admitted, they are required to report the results of their five-semester GPA on a specific date or it means they waived their right to apply for entry. If they fail, they can take the examinations at other universities for direct admission or the national round of examinations. In this round, students are required to report all scores to the central admission system. They can choose a program or faculty, based on the ranking of the programs which they are interested in studying. Then, a computed formula is used to weigh students' scores for that program. After the score is weighed, students may be offered a place. This complex process is evidence that, during the transition from school 
to university, Thai students, particularly language students, have to struggle to pursue an English major.

To sum up, Thailand is regarded as a monolingual country where nearly all of the population speaks standard Thai. A small minority speak other languages such as Chinese, Malay, and Khmer (National Identity Board, 2000). In addition to standard Thai, the majority of the population uses regional dialects of Thai in the four regions of the country (Simpson \& Thammasathien, 2007). This means that English education takes place within an EFL context. Baker (2012) indicates that English is regarded as the "de facto" second language of Thailand, compared to the use of other foreign languages. English is used as the medium of communication in various national and international contexts such as international programs, business transaction, and international organisations and conferences in ASEAN. However, Thai students have limited opportunities to communicate in English in their daily lives (Draper, 2012a). They thus struggle to find contexts where they can speak English with foreigners. This is the history and current state of English language education in Thailand.

\section{The changing role of English as ELF in the Thai context}

While it is important to understand the history of English language education in Thailand, it is also relevant to consider how English is used in the wider context of society. English is currently regarded as the Lingua Franca (ELF) in Thailand (Baker, 2012, 2015; Deerajviset, 2014; Kirkpatrick, 2012; Kongkerd, 2013). The term "ELF" is defined as "any use of English among speakers of different first languages for whom English is the communicative medium of choice, and often only option" (Seidlhofer, 2011, p.7). Nowadays, native speakers of English are not dominant in the English speaking global community and could even be regarded as a minority group because of the larger number of non-native speakers in the global community (Bolton, 2008).

In terms of ELF, (as presented in Figure 2.3), Thailand is positioned as an "expanding circle" country (Bolton, 2008; Kachru, 1998) where people primarily use English with other non-native speakers. This use of English has become especially significant since Thailand became a member of ASEAN in 8 August 1997. The ASEAN Charter, Article 34, requires that "the working language of ASEAN shall be English" to promote the 
community's objective of "One Vision, One Identity, One Community" (Asian Secretariat, 2008, p. 29). An estimate of the current number of ASEAN users of English, including South Asia and East Asia, is 812 million people (Bolton, 2008, p.7). The total English users for Thailand is estimated to be 10 per cent of the population (6.5 million out of 65 million). These statistics capture the emergence and development of Asian Englishes which reflect the global story and illustrate the functional role of English in Asian regions.

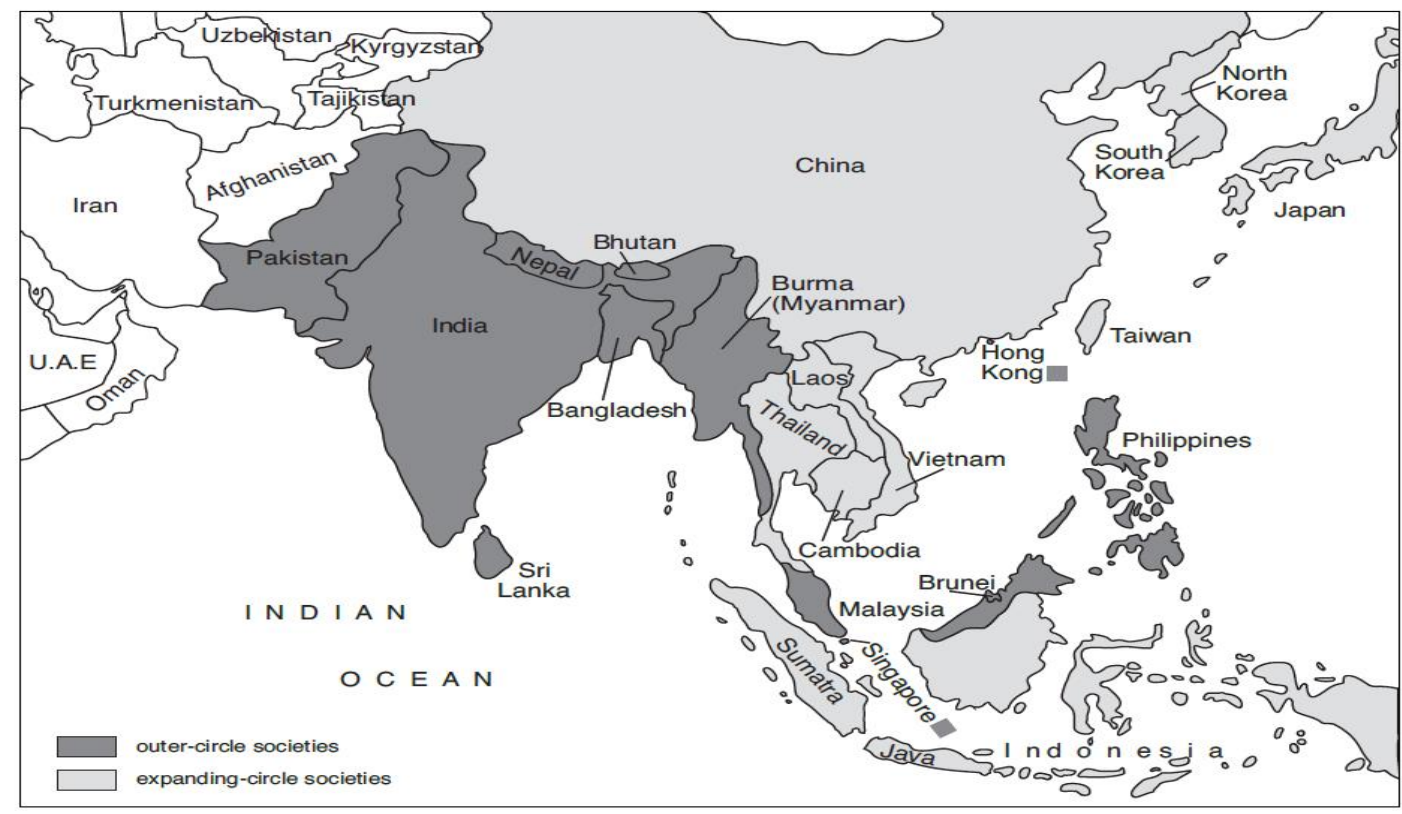

Figure 2.3 Outer-circle and expanding-circle societies in Southeast Asia (Thailand), South Asia, and East Asia

(Source: Bolton, 2008, p.4)

The ELF phenomenon challenges the notion of World Englishes in Thailand and ASEAN. English is globally used as an international language (Graddol, 2006; Jenkins, 2000, 2006). Who owns English internationally? There appear to be conflicting perspectives of the dichotomy between perceptions of standard versus non-standard English, and native speakers (NS) versus non-native speakers (NNS). Kachru (1998) argues that Asian Englishes should be regarded as a local pluralistic linguistic heritage where the norms are necessarily determined by the context in which English is used in each particular country. Jenkins (2006) proposed to include Asian English as part of World Englishes (Kachru's Outer Circle). Expanding Kachru's concept, Canagarajah 
(2006b) indicated that there are at least two major ways to consider ELF: as an historical development of colonisation, and as the result of globalisation. Hence, the emphasis is to move "to alternate models of global English that chart the relationship between communities in more fluid and egalitarian terms" (Canagarajah, 2006b, p. 199). Given these circumstances, the notions of identity, culture, and intercultural communication need to be further explored in ELF contexts (Baker, 2015).

Due to the increasing role of ELF in Thailand and Asia, proficient English language students are likely to achieve their academic and professional purposes. Nonetheless, an educational gap is opening between the rich and poor, and urban and rural students. The Thai linguistic landscape is complicated by language education policies and practices that appear to overlook rural and provincial students (Baker, 2015). English has been widely adopted as ELF by the urban middle classes, but provincial and rural students in Thailand tend to see themselves as having low proficiency in English and feel that the social class system contributes to their limited access to language learning resources (Baker, 2012; Draper, 2012a, 2012b; Hayes, 2010). Provincial students are underrepresented in higher education research in Thailand. My study hopes to capture their unheard language learning motivation and identity.

In conclusion, I provide the brief description of the changing role of English as ELF in the Thai and ASEAN contexts. In the next section, I highlight the language education and Thai students' proficiency.

\section{English language education and issues of proficiency in Thailand}

This section discusses the impact of educational initiatives to improve English proficiency and the effects of different forms of assessment on teaching approaches.

The role of English as an ASEAN language has implications for educational policy and practice. In 2002, the National Education Curriculum shifted the focus from teaching English as an academic subject to teaching English as a medium of communication. The new curriculum prioritised communicative and task-based pedagogical practice, autonomous learning, and self-access learning (Wongsothorn, Hiranburana \& Chinnawongs, 2003). Language learners were now expected to acquire four major 
objectives of: (1) integrating the four skills of English for communicative purposes; (2) harmonising English language and culture; (3) applying English language to link and integrate with other subject areas; and (4) being able to effectively use English language in out-of-class settings (MoE, 2008a, 2008b).

Thailand's educational policy has been influenced by integration of ASEAN Economic Community (AEC) in 2015. The establishment of AEC created a pathway for Thailand's students and graduates to use English as a medium of communication academically and professionally (Sanonguthai, 2014). To promote English in AEC, the Thai Ministry of Education initiated a challenging nationwide project entitled "English Speaking Year 2012" to encourage teachers to explore pedagogies beyond grammar and rote-learning and to encourage students in all state schools to speak in English more frequently with native speakers (Fredrickson, 2012; Hodal, 2012). This policy aimed to reach Thai students from provincial and rural areas by teaching them how to access educational tools through TV, radio, and the internet. To prepare for the AEC integration in 2015, the academic calendar of Thailand was also changed in line with that of other member states. However, it is questionable whether this top-down educational policy has been effectively implemented and how applicable it has been in encouraging authentic communication, particularly in provincial and rural areas (Baker, 2015; Draper, 2012b; Fredrickson, 2012).

Despite these initiatives and an awareness of the importance of English worldwide, it appears that improving the English proficiency of Thai students has not been successful. According to the report of the O-NET (Ordinary National Educational Test), the English average scores of 350,000 upper secondary school students (Mathayom 6) in 2011, were 19.22 out of 100 (Kaewmala, 2012). The results of the tests suggested that Thai students have inadequate English proficiency which may have a negative impact on the country's competitiveness in the region and global market. According to Draper (2012b), achieving high levels of English is problematic for provincial and rural students since English is mainly learned using Thai as the medium of instruction. This suggests that the O-NET is not calibrated appropriately for these students. Additionally, the International Educational Testing Service (ETS, 2015) ranked Thai students in the lower quartile with average scores for the Test of English for International Communication (TOEIC) of 492 out of 
990: 282 for the listening part and 210 for the reading part of the test. These results indicate that Thai students struggle to reach satisfactory English proficiency scores. However, government agencies and educators are uncertain how to best respond to help students enhance their communicative and linguistic skills and later apply these in their future workplaces (Baker, 2008; Draper, 2012a).

These problems appear to be exacerbated by a mismatch between the demands of national educational assessment system and policy expectations. The policy aims to promote the ability to communicate in English yet, there is no listening or speaking test in any of the entrance university examinations. Also, instead of applying the communicative approach, many Thai English teachers continue to use grammar-translation teaching methods due to the backwash from accuracy-focused national or entrance examinations (Fitzpatrick, 2011). So students are taught to pass multiple-choice tests and receptive skills are prioritised over productive ones. This reflects that, in actual pedagogical practice, teachers are likely to mainly use Thai language and focus on reading in class to compensate for their own limited communicative skills in English (Karnnawakul, 2004). Because of financial constraints, there is a shortage of qualified foreign language teachers in schools. Therefore, when students in rural areas wish to apply for an English major at university, they are likely to struggle in their oral interview tests. These conditions may cause rural students to feel unmotivated to study English since they lack opportunities to practise speaking and listening skills in class (Choomthong, 2014). They seem to lack confidence and are afraid of making mistakes when the opportunities to use English arise.

Likewise, there are criticisms of the basic TOEIC test which mainly evaluates reading and listening skills. Although speaking and writing assessments are now available, the new version has still not been widely adopted. Most tertiary institutions and organisations in Thailand still use the basic TOEIC test as the undergraduate entry requirement and the standardised test is commonly used for job applications. This also illustrates how speaking and writing skills are not prioritised in Thailand (Sanonguthai, 2014). Particularly, the International Educational Testing Service continues to emphasise assessing the kinds of English used in the inner-circle countries such as UK, America, and Australia, rather than that used in outer-circle contexts as India, Singapore (Canagarajah, 2006a). Instead of aspiring to a native speaker standard of English, diverse world 
Englishes need to be taken into consideration when assessing English proficiency in ELF contexts.

Differences between EFL and ELF have impacted teaching approaches in Thailand. EFL teaching practices traditionally tend to emphasise correct pronunciation and interpret learners' errors as a deficit in their English proficiency (Jenkins, 2009a, 2009b). In contrast to EFL situations, ELF teaching practices tend to focus on mutual intelligibility among different mother-tongue accents and forms of pronunciation in their communication. Jindapitak \& Teo (2013b) argue that the traditional English language teaching (Native speaker-based) that occurs in some EFL contexts does not gear Thai learners towards the global world of English. As a result, code-switching from one language to another in ELF contexts is more acceptable than in EFL contexts. The implications of espousing ELF were still being developed as AEC integration took place in 2015 (Choomthong, 2014; Geerson, 2013). However, NNS with different mother languages in expanding-circle countries are continually negotiating the kinds of English to be studied. Thus, it is important to capture how Thai undergraduates understand proficiency in English as they use English as a medium of communication with other NNS in neighbouring countries.

\section{Thai learners' perceptions of their L2 self-identity}

This section reviews previous studies exploring Thai participants' perceptions of their L2 identity and preferred models for learning English and using it in EFL and ELF contexts.

\section{Previous studies explored the Thai undergraduates' perceptions of Thai English}

I review previous studies which examined Thai participants' perceptions of a variety of English and Thai English in EFL and ELF contexts.

Based on the in-depth interview, Buripakdi (2012) explored 21 Thai professional writers' perceptions of using Thai English in the Thai context. Using a grounded-theory approach, he explored the participants' in-depth understanding and categorised the emerging English positions into five perspectives, which form a linguistic hierarchy from most preferred to least. Firstly, the participants who wished to use “the Queen's English or standard English" aspired to use grammatically correct and coherent written expression, 
in particular they wished to write accurately. Secondly, they perceived "instrumental English" as functional language use where English was used as an oral communicative device for specific purposes. These preferences illustrate a division between written and spoken users. Thirdly, “cosmopolitan English" was positioned as a lingua franca English which was perceived to be linguistically and culturally flexible, appropriate, and multicultural. The participants prioritised using English in different ways in order to meet local requirements. Next, the participants rated "glocal English" as the harmony between local and global use. The harmony relates to their awareness of combining local and global languages as part of their identity without losing their dignity or Thainess. However, they realised the increasing importance of Standard English. Finally, "Thai English" was positioned as a valid variety of World English, regardless of the Thai accent. They saw Thai English as reflecting the national uniqueness of their linguistic and sociocultural written and spoken competencies. Buripakdi addressed that the majority of the participants prioritised the Queen's English ${ }^{1}$ while others preferred Thai English and perceived it as a legitimate variety of English. Depending on the particular purpose, this category represented Thai participants' diverse perceptions of the hierarchical use of English which was influenced by the internal colonisation. That is, they heavily conformed to Standard English in their communication. Nevertheless, the impact of the AEC integration challenges researchers to consider how Thai undergraduates prioritised varieties of English in their in-class and out-of-class identities.

By exploring perceptions of the standard versus non-standard accent, Jindapitak and Teo (2013a) challenged the views that Thai people have the two varieties of AmericanEnglish and British-English accents which have prevailed for several decades. In their survey, the 52 third-year English-major undergraduates from one southern Thai university identified their preferred English accents and provided a written justification of their responses. The findings revealed that the majority of learners found both British and American inner-circle accents prestigious and felt that acquiring either one would add to their own social status (21.5\%). They described them as "educated" and "high-class", and linguistically (17.31\%), as "most intelligible" and the "correct form of Standard English". However, the researchers in the study argued that students also preferred using Thai English, the expanding-circle accent, to establish their unique Thai identity. The

\footnotetext{
${ }^{1}$ The Queen' English, in this study, refers to the types of spoken and written with the US and UK, which were strict with grammatical rules prescriptive language conventions.
} 
group of participating students did not aspire to speak with a native-like accent. This study portrayed how Thai students perceived the varieties of English usage differently and created a L2 identity using an appropriate model for English language learning and use in their communication.

These findings are consistent with Tananuraksakul's (2012) findings which investigated the intercultural experiences of Thai students and captured a link between their psychological and linguistic identities. This qualitative research required BusinessEnglish Thai undergraduates to interview NS and NSS tourists in Bangkok. At the end of the course, the 36 language learners voluntarily submitted a report about their personal feelings, linguistic anxiety, and self-confidence that they experienced while communicating with foreigners. The emerging themes revealed three different psychological phases: before, during, and after interviewing. Tananuraksakul posited that the participants perceived that they were constructing and negotiating multiple L2 identities while communicating English with NS and NNS foreigners. During the first phase, all of them had positive attitudes and extrinsically motivated themselves to take her Intercultural Communication course for personal and academic interests. They initially were able to maintain their self-confidence, dignity, or security. Nonetheless, they felt worried and shy about initiating the conversation because they thought that their English competency was inadequate. During the second phase, they negotiated multiple identities which related to their self-confidence, courage, and self-worth. When they felt unable to communicate effectively they reported a lack of confidence, limited risk-taking, lack of pride, and face-loss. On the other hand, they felt more confident while conversing with helpful, friendly and smiley interlocutors. During the final stage, they mutually negotiated these emotional identities by using face-saving strategy, establishing friendship, and willingness to communicate in their L2 communication. The findings indicated that, beyond their English proficiency, the effective use of English among them is culturally embedded in the Thai context. Despite living in a monolingual context, they were able to strengthen and mediate their L2 identity by exposing and familiarising themselves through intercultural engagement.

This understanding of Thai English in the ELF context contrasts with the traditional concept of L2 speakers. The major purpose of these studies was to explore global and local identities (Buripakdi, 2012; Jindapitak \& Teo, 2013a; Tananuraksakul, 2012). 
Previous studies raised the question of the status and role of the Thai English accent and whether it was legitimate for Thai students to speak "Tinglish or Thaiguish", to communicate with English users from expanding-circle societies. According to Smyth (2001), some Thai people speak with a Thai English accent because, practically, they attempt to "fit every English word into the Thai phonological system" (p.344). This leads to a peculiar reluctance to shed their accent and a variety of English loan words are commonly used in their daily lives. In addition, some teachers may reinforce this process by providing transliteration in an English-Thai dictionary using Thai script to clarify pronunciation Thai learners may also pronounce English words in the Thai style in order to avoid being misunderstood or sounding pretentious among their friends (Smyth, 2001). Similarly, Jenkins (2000) focused on two-way communication and posited that teachers still tried to maintain the traditionally NS-oriented pronunciation. Additionally, mutual intelligibility is pedagogically restricted only in minority EFL ("NS-NSS") interactions and "learners will not develop the ability to make their pronunciation easily intelligible" in the NSS-NSS communication (Jenkins, 2000, p. 233). She argued that selecting a communicative style based on their preferences gave learners the chance to empower themselves.

Similarly, Trakulkasemsuk's (2012) study assumes that Thai users of English have the right to maintain and present their identity while communicating in English as an international language. Based on written historical and linguistic anecdotes, it is clear that, Thai language developed its own characteristics and was influenced by several linguistic, social, and cultural features of English language, so-called "ThaiE", and transferred Thainess into Thai English, translation, lexical borrowing, and transliteration. However, she argued that there is room for further empirical studies to capture other features of Thai English and Thai learners' attitudes towards using Thai English as part of emerging varieties of English. 
Previous studies about the Thai undergraduates' perceptions of learning English

This section reviews previous studies which examined Thai university students' perceptions of their language learning beliefs, attribution to their successes and failures in learning English in their context.

Fujiwara (2011) surveyed 542 first-year Thai undergraduates' perceptions of language learning beliefs. By using the factor analysis, he made a comparison between Thai and Taiwanese university students' beliefs. He found that Thai undergraduates' language learning beliefs can be categorized into five factors: 1) learning and communication strategies, 2) important aspects of language learning English, 3) expectations and difficulty of learning English, 4) nature and aptitude of language learning, and 5) difficulty and ability of language learning. There were some similarities of language learning belief structures between the two groups of students and this may relate to their shared English learning experiences among university students in EFL contexts. The findings affirmed that the individual's L2 learning experience is the most important variable for the EFL learners' belief development. These five factors affect the individual's learning language beliefs about their L2 learning process and success.

English language learners may possess different perceptions of their success and failure in their English learning contexts. Employing a questionnaire, Wang and Rajprasit (2015) investigated Thai undergraduates' beliefs about their successes and failures in the classroom in English for Specific Purposes courses. High-proficiency students prioritised continuous practice as the key component of their success whereas the low-proficiency ones put priority on acquiring a sufficient amount of vocabulary knowledge. Both groups of students strongly agreed that they could increase their speaking proficiency if provided with adequate time and practice, opportunities to study in native-speaking countries, and if they had access to English resources to enhance their L2 proficiency.

Using quantitative methodology, Hayes (2014) examined Thai university students' values and perceptions of learning English, for example, whether English had a negative impact on their mother-tongue language, culture, and their sense of national identity. The results indicate that the Thai students used English as a tool for personal economic advancement. These Thai respondents agreed that the use of English is important to the success of 
Thailand's development within a globalised economy. They perceived that people all over the world use English for communication and business. However, the majority of the respondents reported that the Thai language is superior to English. From their perspective, using English in their context did not negatively impact their national identity.

\section{Communities of practice, imagined communities and identities}

In August 2015, Thailand entered the AEC community. This transition to the wider international community changed the purposes for learning English for Thai university students. In this study, I use Wenger's (1998) Communities of Practice (CoP) and Norton's notion of imagined communities (2000, 2013a) to understand the impact of Thailand's integration into AEC. In this section, I will explain how learners develop their identity through participation in a CoP. I link this to the work of Norton to situate the participants in this study in a local, national, and global context. Finally, I discuss how English education in the Thai context affects EFL Thai students' varied perceptions of learning and realising their imagined identities.

\section{Communities of practice and multimembership}

Wenger (1998) illustrated that imagination is powerful and regarded as a mode of belonging to CoP which relates to a group of learners who share a passion for something and learn how to improve it by interacting regularly. According to Lave and Wenger (1991), legitimate peripheral participation describes how newcomers become experienced members and finally old timers within a CoP. As newcomers to communities, EFL students initially attempt to gain access to various ongoing activities in class and out-ofclass settings. They want to communicate in English and be accepted by the group as of legitimate peripheral participants. From this aspect, they identify themselves as members of the community by engaging and interacting with NS and NNS, rather than focusing on only NS interlocutors. The imagination is regarded as "a process of expanding our self by transcending our time and space and creating new images of the world and ourselves" (Wenger, 1998, p. 176) and an "experience of identity" (p.215). In addition to directly involving themselves in and engaging in face-to-face communities, learners imagine themselves being part of these communities. Given that they imagine themselves belonging to the $\mathrm{CoP}$ of English users, they will take action to bring about engagement 
and participation. On the other hand, without any imagination, they are not likely to extend sufficient effort to avoid taking any practical and concreate actions to be part of communities of language users or they may even avoid taking any practical and concrete actions to be part of the community. Hence, to some extent, their perceived language beliefs and behaviours impact their imagined identities.

Wenger (1998) defines the term "identity" as: (1) temporal or related to the specific time; (2) ongoing which means learners' perceptions may change; (3) complicated as it is socially situated, linear, and (4) multiple and changeable, depending on the interaction of others in the given time (p. 154). Wenger (2000) further defines an identity/identities as a lived experience of belonging (or not belonging), productively engaging with others through their shared histories, mutual commitment, a as "a living vessel" (p. 239) in CoP such as schools, universities, workplaces, and social networks. The learner's identity is considered the core of the social learning system.

However learners may be situated in multiple communities of practice. In multiple communities, learners can personally develop their identities by experiencing their own boundaries and creating the bridge across communities (Wenger, 2000). Drawing on Wenger's (1998) concepts of multimembership and reconciliation, I expand the scope of imagined communities to Thailand's integration into AEC to understand how they negotiate their local and global identity in this CoP. Recently, they have more opportunities to engage several out-of-class activities and use English as a medium of their communication with other people in member states.

Wenger (1998) proposed that multimembership and the work of reconciliation are intrinsic to our identities. In essence, this concept is applied to understand Thai learners' perceptions of $\mathrm{CoP}$, particularly during the AEC integration. "The work of reconciliation" is regarded as the most crucial challenge encountered by language learners who move from one community of practice to another (Wenger, 1998, p.160). The process of reconciliation relates to identity formation which may not always be harmonious but reconciliation also relates to the effort of maintaining coexistence among other members of people and countries. If the boundaries of practice are part of our personal experiences, we negotiate our activities and identities dynamically in relation to the histories among 
our communities of practice. Thus, the experience of multimembership is not solely related to personal identity, but it also deeply relates to the work of reconciliation within an individual's social world. Learners have to create and cross the social bridge and achieve unique experiences of identity construction process. In the study, I apply this concept of multiple identities to capture how the participants, peripheral to Englishspeaking communities, forge their L2 identity construction, and become part of multiple Communities of Practice using English as a medium of communication. Drawing on Wenger's views, I can capture Thai learners' perceptions of their L2 learning experience which affect their language learning beliefs and behaviours in the ELF context.

\section{Reconceptualising imagined identity as a site of struggle}

In this section, I review the concept of imagined communities to examine how Thai students struggle to learn English in their context. As Thailand takes a role as a social and participating member of AEC, learners empower themselves to acquire the social and cultural capital to influence their language learning process, but at the same time they face barriers in their language learning.

Norton's imagined communities of L2 learners draws heavily upon Wenger's (1998) CoP and Anderson's (1991) concept of “imagined community". Anderson comments that individuals perceive the nation as their collective imagined community and envision themselves belonging to the same community, despite the fact that they have never met or known one another before. Norton (2000) defines identity as "how a person understands his or her relationship to the world, how that relationship is constructed across time and space, and how the person understands the possibilities for the future" (p.5). Bourdieu's (1991) construct of "investment" symbolises the historical, social, and cultural aspects of a learner's relationship to the English-speaking community and their desires to be accepted in their imagined communities. If L2 learners invest in the target language to fulfill their goals, they need to acquire a vast variety of symbolic resources. Resources are a form of capital. For instance, economic resources refers to prosperity and income. Social resources refer to peer networking, mingling with senior friends at schools, universities and workplaces, connection to networks of power. Cultural capital refers to knowledge, such as that inherent in educational degrees. Accessing and acquiring this capital thus empower learners with social and cultural resources, reflecting the 
relationship between the investment and identity in their imagined communities (Norton, 2000, 2013a).

Norton (2013b) argued with the findings of mainstream quantitative research on new constructs of motivation which used Dörnyei’s (2009b) questionnaire and categorised students as more motivated or less motivated, with static and ahistorical identity. She thus reconceptualised motivation as investment to illustrate meaningful interplay between a learner's desire and commitment to learn a language and changing identity (Norton, 2013a; Norton and Toohey, 2011) across time and space. By drawing on sociocultural theory within a qualitative framework, she put an emphasis on learners' desires and commitment to learn English and explored how their L2 identities shifted under a site of struggle (Norton, 2000, 2013a). For instance, L2 learners have to struggle to gain legitimate peripheral participation and speak English in their imagined communities, either in face-to-face or virtual communication, in which they feel supported and unthreatened (Li, 2014; Pierce, 1995; Norton \& Gao, 2008). For this reason, language is acquired not only as a linguistic system, but as a social practice in which experiences are organised and identities negotiated (Norton and Toohey, 2011). Norton argued that, as social beings with contradictory and multifaceted angles shaping their identities, highlymotivated learners could not necessarily be categorised as good language learners. That is, they may not be adequately motivated and committed to acquire English in different stages of their learning process in different contexts.

The shift of focus on identity and investment relates to the imagined communities that learners aspire to when learning a language (Anderson, 1991; Kanno \& Norton, 2003; Norton, 2001). By extending this concept, Norton (2001) reconceptualises and proposes the construct of imagined communities in L2 learning to illustrate the non-engagement and resistance to learning English in L2 classroom settings. Norton and Toohey (2001) encourage researchers to capture learners' investment based on their participants' learning contexts, human agency, and identity. Their research has foregrounded language learners as participating social agents whose narratives are related to sociocultural and historical contexts. The agentic sense of each individual is embedded and mediated through their previous learning histories. They argued that few studies examine the impact of the power relation between language acquisition and social interaction. They suggested that, in 
essence, "the conditions under which language learners speak are often highly challenging, engaging their identities in complex and often contradictory ways" (Norton \& Toohey, 2001, p. 312). Consequently, the Thai EFL context is a unique monolingual setting to capture learners' L2 motivation deriving from in-class and out-of-class learning experiences.

Norton and Toohey (2011) categorised two types of imagined communities which impact the learners' L2 learning motivation and identity: one refers to communities in which L2 learners desire to have contact with people in direct and face-to-face communication; while another refers to the imagined communities in which people have virtual contact among people across space and time through the advancement of technological devices and social media. Kanno and Norton (2003) posited that identity must be understood in terms of our investment both in the real and possible worlds.

However, most of Norton's work and that of her associates (Norton, 2000, 2013a; Norton \& Toohey, 2011) has mainly been conducted and analysed in ESL contexts where participants were either immigrant or international students. Her emphasis is particularly on the impact of migration on identities of language learners with diverse linguistic histories. It is still unclear how imagined communities and identities relate to EFL students who may have limited opportunities to communicate in English in their daily lives such as students in Thailand.

The concept of imagined communities is broad, not limited to any target language communities. Hence, Norton and Gao (2008) encourage researchers to "theoretically validate" the possibilities of the identity research on EFL learners (p. 118), in an array of face-to-face and virtual communication. This challenge raises the question of whether the L2 identity of Thai university students may be influenced by their different educational and socio-cultural backgrounds and whether these may influence their aspirations, needs, attitudes, opportunities and motivations (Draper, 2012a). Drawing on a sociocultural theory (SCT), Yashima (2013b) argues that the notion of participating in imagined communities can bridge the gap between SLA and participation in Asian EFL settings. She used the metaphor of participation and concept of imagined communities to explore 
EFL Japanese learners' identity and agency. Similarly, I capture how my Thai EFL undergraduates exercised their agency and imagined identity in ELF.

In conclusion, with the impact of globalisation and the dominant status of ELF in Asia, imagined communities (Norton, 2000, 2013a) are applicable to two aspects of my study. First, I aim to capture how Thai undergraduates' perceptions and imagination affected their English learning motivation and self-identity during the period of the AEC integration in 2015. This integration mandates English as the official language among people in the member states and provides a means of embracing their local identities within a wider imagined global community. This phenomenon opens up the possibility of forging a global identity. Second, there is potential to see how the learners invest in and commit to acquiring English learning proficiency to achieve their imagined identities. Technological advances and the influence of virtual communication offer opportunities for students to access, invest, and acquire English proficiency and skills through the Internet and social networking. There are no longer any geographical boundaries among English language users in the digital age. Ryan (2006) addressed how these temporal and spatial barriers may be overcome by EFL learners' social imagination. Hence, I argue that Thai learners' perceptions of imagined communities need to be studied and re-evaluated.

\section{Summary}

This chapter has provided an overview of the background of teaching and learning English including its role as a compulsory subject in schools in the monolingual context of Thailand. However, due to the impact of globalisation and internalisation, the roles of language education in school and tertiary level have changed from an EFL to ELF focus. Thai students are encouraged to improve their English proficiency and gain more exposure to English in both local and global contexts. Due to the impact of AEC integration, they tend to have more opportunities to communicate with NS and NNS interlocutors in diverse contexts than in the past.

Qualitative studies in Thailand reveal undergraduates' varied beliefs and attitudes towards roles and varieties of English in the Thai context. These beliefs about learning and using English contribute to an understanding of Thai students' motivation and identity as 
language learners. The theoretical framework of motivation will be covered in the next chapter. 


\section{CHAPTER 3 \\ LITERATURE REVIEW AND THEORETICAL FRAMEWORK}

\section{Introduction}

In this chapter, I summarise the development of motivation research and discuss the key theoretical framework and conceptualization of L2 self-identity. I review L2 learning motivation research and the social and cultural perspectives in EFL contexts. I explain the two major theoretical and conceptual frameworks upon which my analysis is based: Dörnyei’s (2005, 2009) L2 Motivational Self System (L2MSS) and Ushioda's (2009) person-in-context relational view of motivation. To illustrate the frameworks, I review the seminal research underpinning my study.

\section{Development of $\mathrm{L} 2$ motivation research and self-identity}

In this section, I trace the history of research on L2 motivation to describe how the concept of the L2MSS evolved. I also consider how the self-concept may relate to LLM and self-identities of L2 learners.

The connection between L2 identity and motivation has been explored in second/foreign language learning contexts for over five decades (Gardner, 1985; Gardner \& Lambert, 1972). A dichotomy of integrative and instrumental motivation was initially proposed based on the hypothesis that the motivation to learn and acquire a second/foreign language (L2) has distinctive social, cultural and psychological dimensions, compared to other academic subjects (Gardner, 2001, 2010). Integrative orientation refers to an interest in learning the other language to acquire knowledge of and to integrate with the target language community, while instrumental motivation refers to acquiring a new language for practical reasons such as getting a good grade or getting a good job. These complex psychological, behavioural, social, and cultural elements have frequently resulted in controversial findings and debates in SLA.

\section{The conceptual shift of L2 learning motivation research}

One of the earliest challenges to Gardner's social-psychological notion of integrativeness was the critique of Crookes and Schmidt (1991), who introduced a cognitive perspective to language learning motivation. They focused on the significance of the learning 
environment as a motivational influence particularly in EFL contexts. They claimed that the term "motivation" needed to be reconceptualised in second language learning for two reasons. Firstly, Gardner's notion of integrativeness suggested that learners are static rather than multifaceted social beings, and secondly, most of his research in this field had been conducted in ESL contexts. Extending these criticisms, Dörnyei (1994a, 1994b, 2009, 2010) also challenged the relevance of Gardner's concept of integrativeness within the EFL context because most of the early studies advocating this concept were carried out in bilingual or English as a Second Language (ESL) contexts, such as Frenchspeaking communities (e.g. Gardner, 1985; Gardner \& Lambert, 1972). Dörnyei drew attention to the lack of studies supporting the theory of integrativeness in an EFL context.

Within the past decade, perspectives in the field of the motivation research have moved away from a cognitive-orientation towards the socio-dynamic (Dörnyei \& Ushioda, 2011). This is a significant change because cognitive studies were able to decontextualize the internal processes of language learning and did not consider the social processes of language use (Dornyei \& Ottó, 1998). The traditional conception of motivation as relating to individual differences in the classroom expanded to integrate the notions of self and social context (Dörnyei, 2009, 2010; Dörnyei \& Ushioda, 2011). Block (2003) reviewed literature in the field of SLA that used a lens of sociocultural theory and suggested that SLA research would benefit from a more interdisciplinary and socially informed approach. Current studies focus on investigating the integration of the self/identity system with social and contextual factors to understand language learner behaviour within the setting of the globalised world. Block (2003) suggests that researchers should capture how students' detailed life stories and identities are constructed through linguistic development over time, particularly in naturalistic settings. This aligns with Pintrich's argument (2000), who considered that instead of separately considering cognitive, or motivational, or social aspects of learning, research should capture multiple aspects in a multidimensional framework. Likewise, Zuengler and Miller (2006) identified that there were two paradigms of cognitive and sociocultural perspectives in SLA. They argued that the context impacts language learning in a manner that cannot be captured by traditional cognitive paradigms and computational models of motivation. Hence, there has been a movement towards conducting studies using sociocultural theory in an attempt to integrate people and social context in motivation research and SLA. Block (2007) extends 
this social turn to include the narrative approach SLA research, which is gaining increasing popularity.

\section{Methodological shift of L2 learning motivation research}

The field of L2 learning motivation has a methodological shift in recent years. Researchers have taken more holistic perspectives to counter traditional motivation research studies which were heavily dependent on questionnaires as instruments to gather students' attitudes, feelings, and goals (Campbell \& Storch, 2011; Lamb, 2013; Magid, 2009). In an effort to capture the complex and locally grounded aspects of individual learners, there is a trend towards exploring the attitude and the L2 motivation of language learners by using qualitative or mixed methods approaches. These approaches which incorporate a qualitative aspect can explore the broader and deeper perspectives of human experience of language learning (Lamb, 2012, 2013; Magid, 2009).

Ushioda (2001) pioneered a qualitative-oriented approach to language learning motivation by using open-ended and semi-structured interviews with 20 English-speaking students who were taking French in their undergraduate program in Ireland. The key objective of her study was to use qualitative methodology to explore language learners' motivational perceptions and to identify effective thinking patterns and belief structures that sustained and optimised involvement in learning. The results suggested that students with positive L2 learning experiences were likely to possess internalised motivational influences relating to L2 perception and a personal desire to master and achieve a high level of L2 competence.

However, Ushioda (2001) cautions that the differences between the home language and the target language (French) in her study may not be challenging for English speakers. This is in contrast to other students (like Thais) who learn English as a historically and globally influential language and whose home language has a completely different syntax, pronunciation and written script (Trakulkasemsuk, 2012). In addition, the emphasis on the

culture underlying a new language plays a vital role in the motivation of Asian students whose cultures are very different from Western ones. Due to cultural differences, I examine Thai learner' distinct motivational components and L2 self-identities. 


\section{Dörnyei's L2 motivational self system (L2MSS)}

It is uncertain whether EFL students feel motivated to learn English to integrate into particular target language communities and how they might do it. The key issue is the connection between the self-concept and L2 motivation. Dörnyei (2005, 2009) reconceptualised L2 motivation by integrating the self-perspective as part of a learner's L2 identity in EFL contexts. This is illustrated in Figure 3.1. The L2MSS model synthesises several influential approaches in the field (Gardner, 2001; Noels, 2003; Ushioda, 2001). It consists of three components: the ideal L2 self, the ought-to self, and L2 learning experiences.

First, the ideal L2 self (also known as instrumentality-promotion, see the section of the link between L2MSS and possible selves and self-discrepancy theories for a fuller explanation) describes the L2-specific facet of a person's ideal self or "a desirable selfimage" of L2 users for their personal, social, or professional purposes (Dörnyei \& Ryan, 2015, p. 87). For instance, if students have an ideal of being proficient speakers of English, they feel motivated and attempt to reduce the discrepancy between their actual self and ideal self by regulating themselves to achieve their communicative goal. Hence, the motivation to fulfil the learners' idealised goals is internalised within the self. The ideal L2 self is repeatedly correlated with the variable of intended learning effort (Taguchi, 2010; Taguchi, Magid, \& Papi, 2009). However, it is not clear how the ideal L2 self and intended learning effort are qualitatively related and constructed for Asian students.

Second, the ought-to L2 self (also known as instrumentality-prevention, see the section of the link between L2MSS and possible selves and self-discrepancy theories for a fuller explanation), relates to the imposed self-image that an individual believes they ought to possess to gain L2 proficiency to avoid negative outcomes or to meet expectations of others such as parents, family members, teachers, peer and social pressures (Chen, 2012; Lamb, 2013; Magid, 2009). Thus, the motivation originating from the ought-to L2 self is less internalised within the learner's self-concept, compared to the ideal L2 self. Theoretically, it is not clear how ought-to and ideal L2 selves are connected in the learners' L2 learning motivation and process. This connection, and the impact on L2 learners' identities, will be explored in my study. 
Third, L2 learning experiences refer learners' situated learning motives arising from their own previous learning experiences. The experiential component involves students' perceptions of their successes and failures, such as the impact of teachers, peer groups, and learning conditions. These aspects have an integral impact on L2 learners. However, the learning experiences component is conceptualised at a different level to the two future self-guides (ideal and ought-to L2 selves) because it is external to the notion of self and influenced by a learner's learning process and experiences in the past or present.

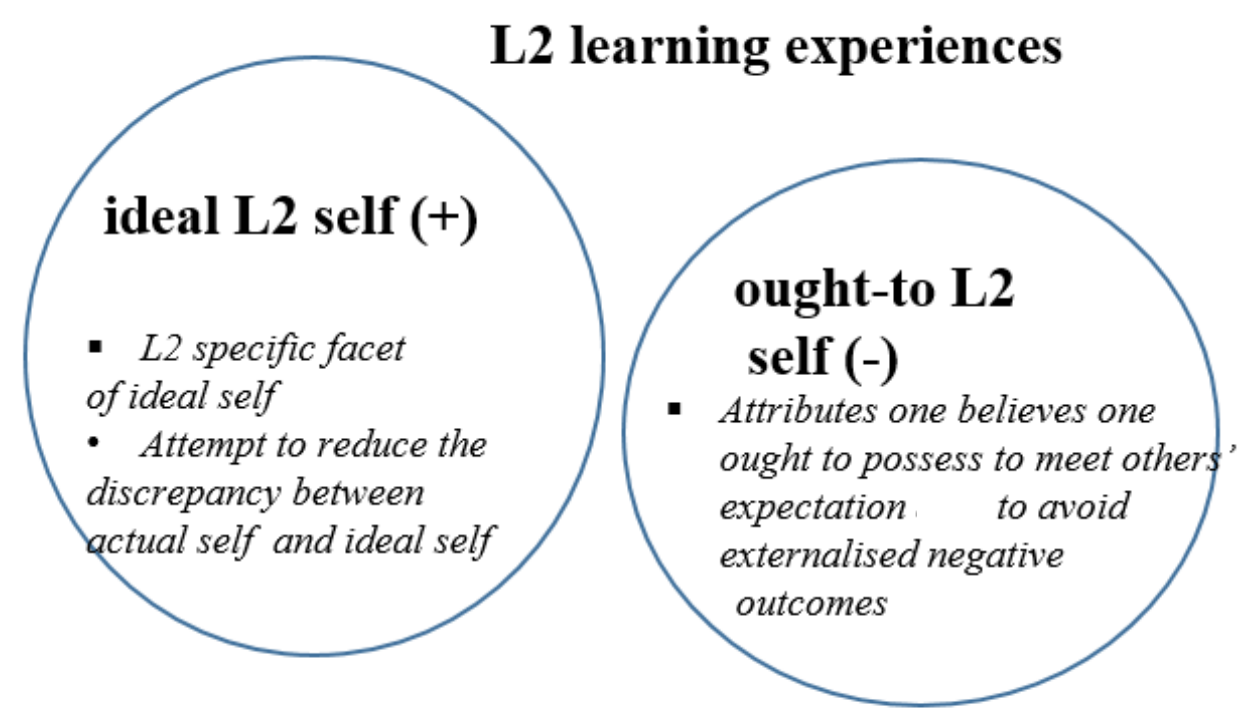

\section{L2 learning experiences}

Figure 3.1 Components of L2MSS: ideal L2 self, ought-to L2 self, and L2 learning experiences

To sum up, there are three fundamental sources of the motivation to learn L2 language: the learner's vision of oneself as a proficient L2 speaker and social pressure arising from the learner's environment, and positive learning experiences.

The link between L2MSS and possible selves and self-discrepancy theories

The components of L2MSS broaden the understanding of L2 motivation by reconceptualising the two theories of self-concept. First, drawing on the psychological aspect of possible selves (Markus \& Nurius, 1986), "future self-guides", the future self within the learners' self-system represents the idea of who the learners might become, 
who they would like to become, and who they are afraid of becoming. The notion of ideal self guides an individual who aspires to become (a hoped-for self) and who avoids being a person whom he/she is afraid of becoming (a feared self). For example, a learner hopes to become an effective communicator and is afraid of becoming an unsuccessful learner. This theory reflects the learner's ideal self, positively and negatively, as foreseen by visions, images, and senses. While self-concept refers to the current state, it is also related to the past and future states of experiences. However, whether the individual's dream and imagination become true or just a fantasy depends on how realistic they are (Oyserman \& Markus, 1990).

Second, drawing on Higgins's $(1987,1998)$ self-discrepancy theory, individuals compare themselves to three internalised aspects of "self-guide": the ideal self, ought self, and actual self. The concept of ideal and ought selves as desired end-states was developed from the link between self-regulation and motivation. In this theory, the ideal self is the most crucial motivational component of self. The ideal L2 self has a "promotion" focus concerning hopes, aspirations, advancements, and accomplishment. The instrumentalitypromotion refers to the regulation of the personal goal to approach English-speaking communities and become a successful language learner by using promotion-focused strategies. For example, motivated language students can create their vision of being fluent speakers and regulate themselves to communicate in English in diverse contexts. On the other hand, ought-to L2 self has a "prevention" focus concerning security needs, responsibilities and obligations. The instrumentality-prevention refers to the regulation of duties and obligations by using prevention-focus strategies. For example, L2 students tend to avoid making grammatical errors while speaking English or avoid engaging with the target language community. The actual self relates to the attributes which the individual learner believes that they actually possess and who they are at a given time. Higgins proposed that the individual learner is motivated to reduce the discrepancy between the actual self and the other two selves.

However, Ryan and Irie (2014) argue that the ideal self and ought self overlap because individuals belong to several social groups. In particular, an adolescent learner's behaviour and identity are likely to be influenced and imposed by peer pressure, social obligations and group norms. According to Marcus and Kitiyama (1991), the differences 
in self-construal between Western and Asian impact on the individual's self-concept (p. 226) are shown as follows (see Figure 3.2).

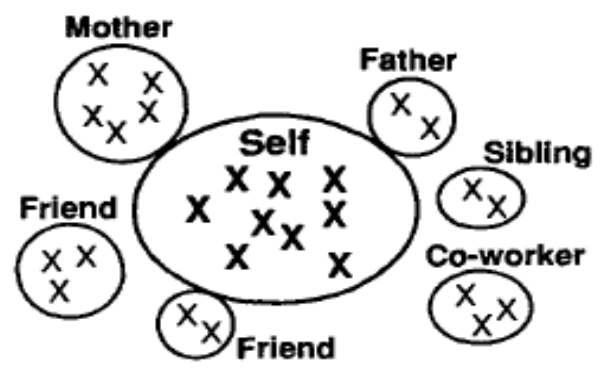

A. Independent View of Self

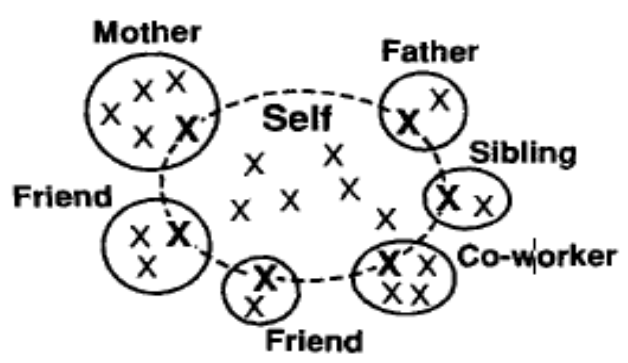

B. Interdependent View of Self

Figure 3.2 Conceptual representations of the self (A: independent construal: Western), B: interdependent construal: Asian)

For instance, American views of self, or "independent self" are likely to relate to individual desires and preferences in regulating their own behaviours. In contrast, the Japanese views of self are likely to be an "interdependent self". Thai students, like Japanese students, are likely to relate to external or social relationships with parents, family members, and friends. It is unclear at what point the individual learner negotiates between collective, imagined identities and their internalised dreams and aspirations.

In line with the L2MSS model, traditional integrative instrumental motivation, known as instrumentality-promotion is one construct of motivation. Recent studies of self-system (Csizér \& Dörnyei, 2005a, 2005b; Dörnyei, 2009, 2010; Taguchi et al., 2009), divide instrumentality into instrumentality-promotion and instrumentality-prevention, depending on the extent to which individual learners internalise and regulate their motives or instrumentality. Instrumentality-promotion is equivalent to ideal L2 self and involves a promotion focus. For instance, when our idealised image is associated with being 
professionally successful, "instrumental" motivation with promotion is internally related to the ideal L2 self, such as studying English to get a well-paid job. In contrast, instrumentality-prevention is equivalent to ought-to L2 self and involves a preventions focus such as studying English not to get a bad grade or not to disappoint one's parents.

Self-regulation is defined as the learner's ability to use appropriate strategies to plan, monitor, and complete a designated task (Zimmerman, 2000). The ability to self-regulate is thus the characteristic of learners who drive and evaluate themselves towards their attainment. Dörnyei (2005) defines the term "self-regulation" as "the degree to which individuals are active participants" (p.191) who make their own choices and take responsibility for their own learning process. He indicates that the focus of L2 motivation is shifted from L2 learning strategies (product) to a degree to which learners take responsibilities for their L2 autonomous learning (process). In relation to the L2MSS model, Dörnyei (2009) illustrates six integral steps to fulfil ideal L2 self of learners in the language learning process in class. First, constructing vision. Second, strengthening the vision. Third, substantiating the vision. Forth, activating the ideal L2 self. Fifth, developing an action plan or roadmap. Finally, considering the prospect of failure. These steps portray how L2 learners develop their L2 language learning motivation in their L2 learning process as part of their self and identity. Dörnyei and Ushioda (2011) agree that sociocultural factors and contexts affect individual motivation and are aligned with learners' collective goals and values.

In L2MSS, the key crucial component is the notion of ideal L2 self. Previous studies (Dörnyei \& Chan, 2013; Dörnyei, \& Kubanyiova, 2014; Takahashi, 2013) have emphasised language learners' creation of a vision for their desired future language self. It has been suggested that learners create their visions only in certain conditions, not automatically. These conditions are as follows:

- The learner has a desirable future self-image. While some learners can easily generate a successful possible self, others do not. This means that some learners develop an ideal L2 self and ought-to self, and others may not.

- The future self should be sufficiently different from the current self. If these two selves are positioned close to one another, no increased, intended effort is likely to be extended. 
- The future self-image is elaborate and vivid. If not, learners are not able to evoke their ideal L2 self.

- The future self-image is perceived as plausible and possible. Otherwise learners will not sufficiently extend their intended effort and finally their future self-image will become a fantasy.

- The future self-image does not clash with the expectations of the learners' parents, family members, teachers, peers, and other social learning conditions.

- The future self-image is regularly activated in the learner's working self-concept through multiple L2 learning activities.

- The future self-image is aligned with meaningful "procedural strategies" that act as a "roadmap" towards the goal.

- The desired future self-image is offset by a countering "fear possible self" which has a negative or undesired consequence on learners' possible self.

(Hadfield \& Dörnyei, 2013, p. 4)

\section{The inclusion of self-efficacy in L2MSS}

Self-efficacy underpins my study because this concept captures the interplay of learners' personal, behavioural, and environmental influences (Bandura, 1993, 1997, 2000). Selfefficacy is an individual's belief that he or she can perform and succeed at tasks and activities. To become a successful learner, he or she must have a strong sense of personal efficacy about their performance of a task (Bandura, 1993). He states that agency is the "power to originate actions for given purposes" (Bandura, 1997, p. 3). He assumes that self-efficacy has a major impact on creating the learner's imagination and acting on their goal. That means, learners with a stronger sense of self-efficacy seem able to envision themselves performing the task and thus become more motivated in their learning. Thus, agency plays a crucial role in students' self-regulating learning and engagement.

The learner's self-efficacy is based on the following sources: mastery experiences, vicarious learning, verbal and non-verbal persuasion, and physiological and affective reactions. First, mastery experiences refer to the degree of success that the learner interprets from their past learning experiences. As a language learner, these mastery experiences play a significant role in learners' self efficacy. Bandura (1997) states that 
mastery experiences are the most important source of self-efficacy beliefs, impacting on almost all aspects of what learners do, how they think, feel, and behave.

Second, vicarious learning refers to learning by observing other people's behaviour and attempting to perform like their role models. Seeing others who are close to the learner's age, level, and ability is regarded as a powerful influence and this may raise learners' efficacious beliefs about their own success. Third, verbal and non-verbal persuasion refers to the moral support and encouragement from others such as teachers' feedback on the assigned task. This component may have a big impact on how learners assess their own capabilities. Finally, physiological and affective reaction means that the learner who is under pressure or anxious may produce unproductive behaviours while performing tasks. In contrast, positive emotion can raise efficacy belief. By synthesizing relevant evidence pertaining to self-efficacy in the L2 settings, Raoofi, Tan, and Chan (2012) reviewed 32 empirical studies published between 2003 and 2012. They found that selfefficacy beliefs play a crucial role in the language learning process. Their most consistent findings revealed that the learner' efficacious beliefs have a major influence on learners' intended effort and pursuit of self-directed learning. However, few studies capture the interplay of students' envisioned future-self and self-efficacy in EFL classroom settings.

\section{Research on the L2MSS}

In this section, I review and summarise previous studies which advocate the L2MSS theory and the importance of exploring students' attitudes towards their L2 motivational self-system in different contexts. There has been little previous research on L2 learning motivation using a mixed-method approach in the Thai context. I focus on the L2 motivation and self-identities of Thai learners during the transitions from high school to university. During a critical period, they have to adjust themselves and develop their way of learning in a new learning environment.

Busse (2013) developed a questionnaire to investigate the L2MSS by exploring the connection between a student's ideal L2 self and actual self, that is, their self-efficacy for their L2 learning motivation. Using mixed methods, she investigated 59 first-year university students' motivation for studying German as a foreign language over one academic year. The findings indicated that, regardless of the students' integrative 
orientation, self-efficacy was consistently related to students' ideal L2 self and selfperceived effort in learning L2 language. The qualitative data provided evidence that the students' low self-efficacy beliefs may undermine the development of an existing ideal L2 self. However, their sense of task-based self-efficacy in each skill is likely to change during one academic year. Yet, compared to English, German is not regarded as such a powerful, international language. This may affect the way the students expended their intended effort and envisioned themselves speaking with German native speakers. This suggests that it would be useful to capture the self-efficacy beliefs and ideal L2 self of students performing task-based activities in learning English. By applying the concept of self-efficacy in the questionnaire of this study, I capture learners' linguistic self-belief and the self-evaluation of their capability to exercise their agency to achieve their learning goals.

Employing the L2MSS questionnaire, Taguchi et al., (2009) conducted a comparative study of nearly 5,000 secondary pupils, university students, and adult learners in Japan, China, and Iran. They explored the impact of different cultural backgrounds and educational stages on students' L2 motivation in these EFL contexts. They pointed out that the findings from several of Dörnyei's large-scale Hungarian nationwide studies (e.g., Dörnyei \& Csizér, 2002; Dörnyei, Csizér, \& Németh, 2006) were not countryspecific because similar patterns were also found in other EFL contexts. Their key results indicated that the notion of integrativeness should be relabelled as the ideal L2 self, and instrumentality divided into promotion and prevention. Unlike Kormos and Csizer's (2008) findings, they found a relationship between the ought-to L2 self and learning motivation. They claimed that this relationship was connected to family values within Asian contexts although the education systems seemed to be strongly influenced by cultural differences. They suggested that the cultural background of L2 learners should be taken into consideration more to broaden insights into how the L2MSS works within a specific cultural context, particularly in other Asian EFL countries. Thus, I applied some items of this study in relation to self and identity to explore how Thai learners felt internally motivated to learn English and how their families and social expectation affected and shaped their L2 identities. 
In a longitudinal mixed-method study using the L2MSS survey, Lamb (2004) explored the impact of globalisation on integrativeness particularly on the motivational changes of middle school Indonesian students, aged 11-12 years old, who studied English in an EFL context. He revealed that highly motivated students held both integrative and instrumental learning goals. Thus it was difficult to identify the boundary between these two aspects. Importantly, their intended effort appeared to evolve in line with their own identities. That means there were clashes between their local and global identities which may have impacted their English learning motivation. They had to strive to exert their intended learning effort to enhance their English proficiency despite experiencing contextual constraints. He found that "English may not be associated with particular geographical or cultural communities" (p.5). Instead, it seems that the teenagers shaped their identities through impact of mass media, widespread music, pop culture, and advanced technologies. Lamb's findings are consistent with Murray's (2008b) EFL learners' language learning stories, where adult Japanese students were able to enhance their fluency in English from intermediate to advanced level through pop culture and mass media in spite of studying English solely in a monolingual context. To conclude, globalisation adds a new dimensions of integrativeness among EFL learners, particularly in Asian contexts.

Using Dörnyei's self-reported survey, Li (2014) investigated the differences in motivation between 132 EFL Chinese undergraduates in China and 122 in an ESL context in New Zealand. Li found that Chinese learners in New Zealand expended more intended effort in learning English, developed a stronger sense of ideal L2 selves as competent users of English, and had more favorable attitudes towards learning English, than the EFL learners in China. It seems that the ESL learners invested more in studying overseas where a high proficiency in English was essential for them to achieve their academic goals. On the other hand, EFL students tended to expend less intended effort and had a higher level of prevention-instrumentality than the ESL ones. For these two groups of Asian students, English learning experience and instrumentality-promotion are the two key factors which determined their motivated learning behaviour.

To become successful learners, age may not be the only defining factor for LLM. Lamb (2012) conducted a comparative study by employing L2MSS as the framework of an 
investigation of 527 junior high school students' L2 motivation in three contexts in Indonesia: a city, provincial town, and a rural district. The objective of the study was not only to investigate the students' motivation to learn English, but also to clarify the components of the ought-to L2 self. The findings indicated that the level of motivation for the urban students was higher than that of the students in the rural area. The ideal L2 self was only significant among the urban group. In terms of validating L2MSS, the findings were consistent with Kormos and Csizer's (2008) which also failed to elicit the ought-to L2 self, possibly due to the young age of the respondents and the compulsory nature of English as a school subject. He recommended further qualitative studies to explore the indepth story of ideal L2 selves with regard to when and how the ideal self-guide motivates an individual as part of their L2 identity.

Magid (2009) used a mixed method approach to do a comparative study of 1,154 middle school and university students (employing L2MSS), and ten case studies of Chinese university students. The interview data indicated the importance of contextual issues of family, face, responsibility, and pressure. This study clarified the motivational role of the Chinese family and described relationships among the L2MSS and the two types of instrumentality (promotion/prevention) and the ideal L2 self. He concluded that the ideal L2 self of the university student is more specific and well-rounded than that of the middle school students. Consistent with Chen's (2012) interview findings, personal self and family/collective self internally coexisted among these Asian students in EFL contexts. Contrary to L2MSS' traditional concept, it appeared that ought-to L2 selves internally and positively combined both preventional and promotional instrumentality. The L2MSS model effectively represented the differences in motivational orientation between these two different age groups. The study took the temporal aspects of motivation into account because undergraduates' L2 selves and their attitudes towards learning English may change over time. Hence, it is important to consider the motivational role and impact of parents, family members, and the social environment on learning English, particularly during the transition between high school and university.

Lamb (2013) used mixed methods to provide evidence that rural Indonesian students tended to develop their ideal L2 self as part of their motivation in spite of encountering contextual constraints in EFL contexts. In the study, L2 learners' learning motivation was 
regarded as part of their agency which was internally and externally shaped by their personal, familial, and contextual factors. Through interviews, both the learners and their parents were well aware of limited resources and limited exposure to English in their monolingual context. Additionally, parents were aware that they could not financially support their children to take costly private courses or to provide adequate learning. They could not be their children's role models in studying English. These scenario could illustrate why these marginalised students made slow progress in spite of envisioning themselves as proficient learners. This study confirmed that learning outcomes stem from the interaction between an individual learner's agency and social structure.

By using multiple case narratives of three English-major students in China, Gao, Li, and Li (2002) indicated the crucial role of individual agency to shape L2 self-identities and learning environment. The key themes were: (1) pre-college language learning orientation; (2) interaction between college input and personal effort; (3) identity conflicts; (4) future direction of development; and (5) core identity. The findings indicate that the EFL learners exercised different amounts of individual agency to forge their L2 self and identity in the particular context, depending on the learning environment. Gao (2010) analysed learning stories to investigate one learner's agency. Zhang was a disabled EFL learner in China. By collecting her diaries, letters, and narratives, the findings reflected her unique learning strategies to shape and harmonise her ideal L2 self with her language beliefs, intended effort, and self-regulatory learning. Regarded as a role model for EFL learners, she had a strong sense of self-efficacy and extended full learning efforts despite experiencing socio-economic and contextual constraints. Hence, these two studies could be applied with my English-major participants in provincial and rural contexts in Thailand.

Employing L2MSS in a longitudinal mixed-methods study, Irie and Brewster (2013) captured the stories of how three first-year Japanese students developed their identity using ideal L2 self to regulate their L2 learning processes. The findings indicated that the power of imagination and rich exposure of experiences could effectively develop the students' ideal L2 self. A variety of vivid and concrete imagery motivated students to regulate themselves to pursue and persevere in studying English continuously. However, the findings applied solely to mature undergraduates, not school students because they 
tended to have clearer academic and professional vision than school ones. Similarly, Boonchum (2010) examined differences in self-identity changes between English-major students in Bangkok and ones in a northern province of Thailand. He found that there was no difference in their self-identity changes. In addition, English-major Thai undergraduates both in urban and rural areas were likely to positively change their L2 self-identity and felt more confident when they had foreign friends and experienced different norms of behaviour and cultural values. These two studies reflect the power of the ideal L2 self and the value of language learning experiences in motivating EFL university students.

Due to the inconclusive results about the ought-to L2 self in previous studies, Teimouri (2016) investigated L2 learners' emotional experiences (anxiety, joy, and shame) through the lens of L2 future self-guides employing L2MSS model. The findings of the study support the unique, interconnected nature of ideal L2 self, ought-to L2 self/own, and ought-to L2 self/others. He proposed that the notion of ought-to L2 self could be divided into two aspects and the learners' obligation to learn L2 could be separated based on the degree of their internalisation of English learning motives. The L2 learners' promotionfocus and prevention-focus were connected. The inclusion of emotional motivation in his model has potential to understand different types of L2 learner's motivated behaviours in attaining their L2 learning goal in the particular context.

Findings from these empirical studies indicated that the L2MSS model has been widely used as a tool to explore EFL's LLM and self-system. However, there are limitations in validating the L2MSS model using a quantitative study alone Therefore, I propose to undertake a to enrich the understanding of L2 Thai learners' intended effort and unique motivational profiles in achieving their goal of learning English and forging their selfidentities in the monolingual context.

\section{Ushioda's (2009) “person-in-context" relational view of motivation}

In this section, I justify the use of a second framework in my study. To complement the L2MSS and capture holistic and naturalistic aspects of learners' self and identities, Ushioda's (2009) "person-in-context" offers a relational view of motivation that can offer a new perspective to my study. This model captures L2 students' perceptions of their 
identities and their English learning experiences within their sociocultural context. Her model builds on the theories of Russian educational psychologist, Vygotsky (1978), whose sociocultural theory of mind explains how learners are influenced by social interaction which enhances their cognitive skills. Sociocultural theory plays a crucial influence on her work (Ushioda, 2008, 2009, 2011a, 2011b, 2011c) and provides a broad framework explaining the concept of social motivation mediated and shaped by an L2 learning environment. Likewise, in this model, Ushioda prioritises the learners' agency and how they initiate and regulate themselves to achieve their learning goals. She argues for an emphasis on:

"real persons, rather than on learners as theoretical abstractions; a focus on the agency of the individual person as a thinking, feeling human being, with an identity, a personality, a unique history and background, a person with goals, motives and intentions; a focus on the interaction between this self-reflective intentional agent, and the fluid and complex system of social relations, activities, experiences and multiple micro-and macro-contexts in which the person is embedded, moves, and is inherently part of'. (p. 220)

Drawing on Lantolf and Pavlenko (2001), she advises that language learners should be treated as real people, social human beings, who "actively engage in constructing the terms and conditions of their own learning" rather than "processing devices" (p. 145). These learners develop their learning processes of behaving socially, physically, and psychologically as a mediating outcome accessible for or by them. Ushioda (2009) uses autonomy theory and practice in her model. She argues that motivation needs to be regarded as an organic process which emerges through the multifaceted system of social interrelationships and places the notion of motivation within a particular context.

In line with Ushioda's holistic model, Mercer (2012) showed that EFL undergraduates' personal sense of agency appeared to intertwine closely with their cognitive and affective senses of self-belief. These beliefs emerged from the complex interaction of interpersonal and intrapersonal environmental impacts on their identities. Consequently, Mercer argues that learners' agency needs to be captured as a whole within the environment. The nuances of the learning environment are thus considered the most important influence on 
EFL learners' multifaceted motivation (Campbell \& Storch, 2011). Motivation is not simply situated within the learner but can be beyond the control of learners themselves. The personal agency and the dynamic interaction of a learner's self-beliefs in their context are at odds with each other because of the internalised and multifaceted dimensions. Additionally, several studies increasingly recognise the importance of agency in L2 learners' identity and SCT in diverse learning contexts (e.g., Davin \& Norton, 2015; Gao, 2010; Lamb, 2013; Ushioda, 2009).

Ushioda (2009) focuses on identity-oriented components of "persons" (p. 216). She captures how language learners develop agency and self-regulatory skills in their L2 learning process. Drawing on Richards (2006), she analyses learners' social and discourse identities in different contexts, both in class and in out-of-class contexts. The three components of identities that she identifies in relation to the L2 learning contexts are:

- Situated identities are explicit and refer to the context of communication, such as teacher and student identities which are situated in classrooms;

- Discourse identities refer to a scenario in which students orient themselves to particular discourse roles during the classroom interaction such as being "listener" or "questioner" in a given situation;

- Transportable identities are implicit. Teacher and students may bring these with them and they may be brought outside the classroom during the teacher-student interaction.

She argues that transportable identities are an integral concept which can be applied to meaningful learning process (Ushioda, 2011a). Engaging transportable identities during teacher-student interactions in the language classroom necessarily "involve[s] an investment of self, with all the emotional, relational and moral considerations that this invokes" (Richards, 2006, p. 72). Consequently, teachers play a vital role, promoting and facilitating the interaction with L2 learners. In reality, they have several transportable identities such as being a daughter, student, and part-time staff member in their daily lives. By considering the legitimacy of their L2 self-identities, learners could be promoted to possessing the autonomy to speak as themselves by using English as a medium of communication in their social participation and negotiation (Ushioda, 2011b). Motivated 
students can be regarded as autonomous learners. If they feel unmotivated, they may not regulate themselves to perform target language tasks. Using this model, she posits that teachers play an important role in evoking and stimulating students' transportable identities and autonomy. When teachers treat them as "real" people, students feel more engaged and involved with activities, and sustain their intended effort more than when they are taught using a traditional approach. The relationship between classroom practices and the world of learners' transportable identities "emerge[s] as dynamically coconstructed process" (Ushioda, 2011b, p. 22) and allows for interplay between in-class and out-of-class learning. She captures the shift of learner's self and identity and captures how learners perceive and transport their personal and social identities. An example of this theory is advocated by her argument that L2 learners increasingly are increasingly motivated to use mobile technologies to transport their identity and sustain their personal meaningful casual learning in out-of-class settings (Ushioda, 2011a, 2013). She also addresses the importance of focusing on the interplay of the learner's personal and social identities in classrooms and diverse non-academic contexts. In EFL contexts, acquiring English in out-of-class contexts is necessary, particularly for university students in the current digital age (Richards, 2014; Stockwell, 2013). Ushioda applies the notion of transportable identities to extend the scope of autonomy and motivation into the digital world. Ushioda (2011a, 2011b, 2013) argues that students' transportable identities are not grounded only in physical boundaries and social relations with new people, but also increasingly expand in the virtual world of cyberspace, mobile communication, and entertainment technologies. According to Stockwell (2013), EFL learners are motivated to use technology for language learning in two ways. First, they take ownership of a form of language learning controlled or assigned by teachers in class and out-of-class settings. Second, they may spontaneously extend their intended effort and act on their own volition. Still, it is questionable how they sustain their motivation to regulate themselves. 


\section{Literature framing this study}

Integration of literature into a theoretical and conceptual framework

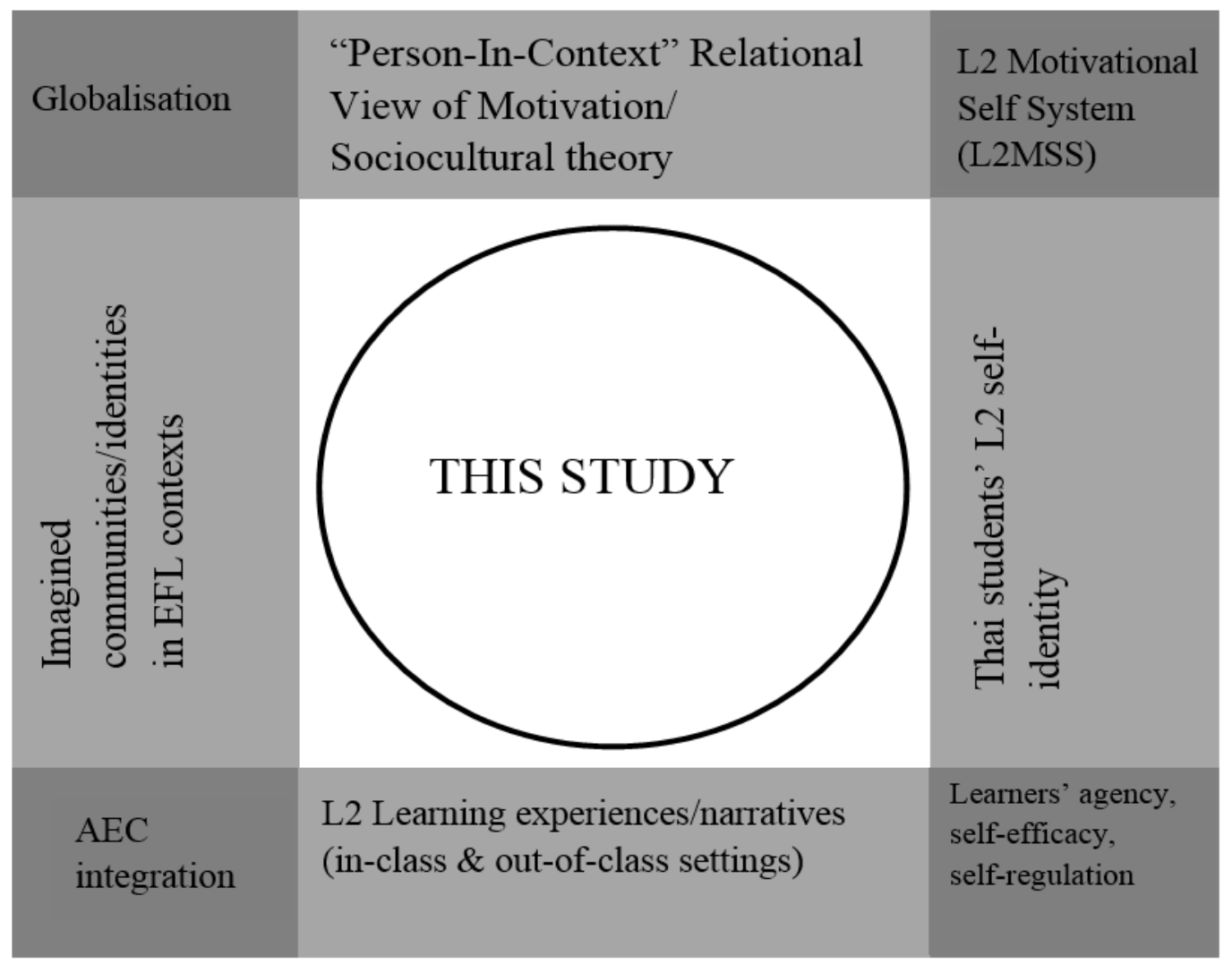

Figure 3.3 Literature framing this study

The theoretical and conceptual framework for this study draws on both quantitative and qualitative literature. This fits with a pragmatic approach to gain insights regarding the particular scenario. According to Creswell (2014), pragmatist researchers use research to explore what works practically at a particular time and place within the social, cultural, historical, and political context. The description of this research approach and its justification are incorporated in the Methodology Chapter.

The conceptual framework of this study is presented in Figure 3.3. There are four streams of research which support the framework of this study: Person-in-context relational view of motivation, Thai students' L2 self-identities, their learning experiences, and imagined communities. Research at the intersection between these main areas is of particular interest. This is presented in the darker grey areas in the corners of frames. Although extensive research has been carried out applying the L2MSS model in quantitative 
studies, there is a need to explore the interconnection between language learners' ideal and ought-to L2 selves using a person-in-context model, particularly during a significant event in globalisation in Asia such as the integration into the AEC in 2015. Understanding learners' narratives in relation to their own country and identity is meaningful since their national and historical stories "[are] interwoven as part of the fabric of the individual life" (Andrews, 2007, p. 499). Hence, I capture and analyse identity-oriented components of "persons" instead of focusing solely on "individual differences in an abstract theoretical sense" (Ushioda, 2009, p. 216) through the real-life learning stories of purposively selected Thai university students. The emphasis is on the contextually-related dimensions, both in-class and out-of-class settings, using narrative approaches.

\section{Research questions and puzzles}

The overarching research questions and puzzles that frame this study are as follows:

1. To what extend do the selected highly-motivated participants perceive that they exerted their intended efforts and have self-efficacy in learning English?

2. How do they report their past and present learning motivation and L2 experiences from school to university?

3. How do they report their in-class and out-of-class learning experiences of their English learning at their university? 


\section{CHAPTER 4 METHODOLOGY}

\section{Introduction}

This chapter explains the research approach and processes used in my study. I begin the chapter with a justification for undertaking L2 motivation research and present reflections on the stories of my methodology. I justify the instruments and procedures involved in the participant selection and discuss the data collection and narrative analysis processes.

Throughout this chapter I draw on place, sociality, and temporality which are aspects of three dimensional narrative inquiry (Clandinin, 2013; Clandinin, Personal Communication, 17 October, 2016). I describe the socio-cultural place in which stories occurred at a particular time. I consider the social relationships among my participants and me, and between the institutions involved and me. In addition, I look at my own interpersonal and intrapersonal positions in my research: how I moved back and forth in time; and how I employed different methods such as a survey followed by narrative interviews. The specific approach to reflexivity within narrative research and narrative analysis is discussed.

I present my methodology as a story that arose from my experience of undertaking this research. I have put my story in boxes to indicate the episodes. After each episode, I then reflect on the story of my research by using research literature to reveal the rationale and impact of the research decisions that were made. By presenting my methodology in this way, I aim to provide a transparent recount of the processes of undertaking this research and to demonstrate my reflexivity in considering the impact of the decisions on the trustworthiness of my research. 
Shifting my worldviews to explore Thai students' L2 motivation and self-system

My intellectual journey began a couple of weeks after enrolling in a $\mathrm{PhD}$ methodology course at Victoria University of Wellington. Initially, I was unsure of my capabilities to conduct a qualitative study due to my limited background knowledge and research experience. I took one course entitled "Advanced Qualitative Research and Analysis in Education" (FEDU 512) based on my supervisors' suggestions. I learned about a variety of philosophical concepts in this course. I felt that, to obtain a prestigious academic title of "Dr.", I had to be a well-rounded person with a deep understanding of terminology and the concepts of ontology (the nature of being, existence or reality), epistemology (the study, theory, or process of knowledge and knowing), and axiology (the domain of values and ethics that influence a researcher's perception, decision, or action). The key message I learned from this course was that foregrounding the identities of researcher and participants is paramount when undertaking a qualitative study. For several months, I attempted to make sense of these concepts in connection with my research topic of L2 motivation and self-system.

I read earlier studies in the field of L2 motivation which were positioned within the positivist paradigm. This approach puts an emphasis on measuring individual differences. These studies suggested that an L2 learner's motivation orientation was either through a desire to integrate into the target language community or arose from an instrumental aspiration to achieve well-paid jobs. Initially, I studied Gardner's (2010) questionnaire "The Attitude/Motivation Test Battery" which is regarded as the standardised test to measure learners' attitude towards learning English in specific contexts. However, most previous research using this survey had been conducted and validated in ESL contexts. Therefore, I concluded that these clear-cut interpretations of motivation were unlikely to help me understand my students' complex L2 motivations and self-identities, in particular, because they learn English as a foreign language in a monolingual Thai context. 
After reading more widely, I came upon the L2 Motivational Self System (L2MSS) theoretical framework conceptualised by Dörnyei. This had been widely validated in EFL settings, including Asian contexts. In my view, this survey offered the potential to understand Thai students' self-systems. However, his model focuses on the ideal and ought-to L2 selves, rather than the actual self. I felt that the actual self was an important concept to include as I wondered how Thai students imagined themselves to be part of English-speaking communities, particularly during the period of integration into the ASEAN Economic Community in 2015. As EFL students in this new political and economic context, I thought they tended to drive themselves to become proficient English users, rather than just learning English to pass examinations. I thought that these students might drive themselves in this way because they aspired to gain experiences of using English as a medium of communication with people in the other member states who are also non-native English speakers in an ELF context. As I related these ideas to what I had learned in FEDU 512, I realised that these concepts of learning motivation in imagined communities could structure my research questions.

After consulting with my supervisors, I felt more confident about including contextual elements of students' language learning motivation and identity development. I wondered what made Thai students push themselves to gain L2 learning experiences in Thailand, a largely monolingual environment. I found that none of the existing studies had undertaken research into L2 motivation during the transition into AEC integration yet integration seemed to be a hot issue among national policy makers, educators, teachers and students in Thailand during this period.

Dörnyei's L2MSS framework was originally established in the west. I wondered what the term "self-system" might mean in an interdependent or collective society like Thailand. As a Thai, I am well aware of how Thai people take mutual obligations into account. The mutual duty of parents and children in Thailand, as in other Asian contexts, involves perceptions and behaviours that span their whole lives, whereas parents in western contexts expect their children to become independent and more autonomous. I assumed that the self-system in western culture would relate closely to an individual's aspirations and achievement. In contrast, in eastern cultures, the individual's aspirations and achievement are based on group/collective goals. 
I was really interested in exploring the actual self of Thai students and how it interplays with an Asian learning environment. As a result, I wanted to investigate the component of actual self that relates to self-efficacy so that I could explore learners' agency. I included the construct of self-efficacy to gain insight into first-year students' self-reported beliefs about their linguistic capabilities. Additionally, one of the key contributors to selfefficacy is mastery experiences of L2 learning, the third component of L2MSS. By using a survey alone, I suspected that I would gain limited insight into their successful L2 learning experiences yet I strongly believed that a variation of this model would enable me to capture how students gained successful L2 learning experiences in the monolingual context of Thailand.

\section{Analysis: Aligning my research approach with my worldview}

Post-positivists focus on testing well-defined variables, regardless of any social and cultural influences on the inquiry, whereas interpretivists focus on contextualising any understanding of a human's lived experiences (Green, 2007). A study that was both quantitative and qualitative had the potential to foreground all the key concepts in the field of L2 motivation and identity. According to Creswell (2014), quantitative research (from a post-positivist worldview) is an approach suited to examine the relationship among three variables. These were, in my study, the ideal L2 self, the ought-to L2 self and self-efficacy. This quantitative approach would enable the different constructs related to the L2MSS to be measured drawing on a large sample and using statistical procedures. To balance this, a qualitative approach (from a constructivist/interpretivist worldview) allows an exploration and understanding of the causes of human action and social problems from participants' perceptions. Thus, with a post-positivist lens, the questionnaire used in my study drew on an objective and measurable view of reality. In contrast, the interpretivist lens, allowed me to interpret the participants' perceptions of their experiences and tap into their subjective knowledge. To conclude, the two research approaches are distinctive and complementary in their natures, investigative approaches, and philosophical assumptions. This led me to see the possibilities of using one methodological approach such as a survey to select participants for a qualitative study. 


\section{Procedures for selecting eligible participants}

\section{Advantages of using a questionnaire and undertaking narrative research}

In my study, I used both quantitative and qualitative approaches for two reasons. First, I strongly believed that Dörnyei's framework could help me analyse my data and explore Thai students' multi-layered self-systems. Second, I intended to apply Creswell's sequential explanatory approach, and results from the survey would allow me to purposively select highly-motivated participants for in-depth interviews. I could then analyse these interview data using narrative methodology.

To complement Dörnyei's model, I used Ushioda's person-in-context relational view of motivation. I focused on a holistic view of self-and-identity-oriented components of a language learner. I wanted to hear the students' voices which were still unexplored. I was well aware that, by using only a survey, I would miss an opportunity to understand the contexts of the participants' learning which shaped their L2 identity. I knew that L2 learners are not robots. They can develop their agency and identity themselves but may be influenced by parental, familial, institutional, and other social aspects.

During my research proposal process, I found that this approach seemed to fit my research project and answer my research questions and puzzles. Initially, I assumed that a mixed methods study would enable me to combine research methods, and collect and analyse a variety of data to capture multifaceted perspectives of students' language learning motivation and identity development.

Taking a pragmatic-oriented perspective, I realised that my priority was to apply the appropriate approach to answer my research questions and puzzles. To achieve that, as a qualitative researcher, I had to be flexible, transparent, and able to adapt to any unexpected results. 


\section{Analysis: Recruiting eligible participants through a validated survey}

In this study, the aim of using the survey was to recruit potential participants for interviews. The online survey used in the study was mainly based on the questionnaire (Taguchi et al., 2009) to explore Thai students' perceptions of their English learning motivation and identity. This instrument has been widely validated with participants in several Asian countries (Lamb, 2012, 2013; Magid, 2009; Taguchi et al., 2009). However, none of these studies had used this validated questionnaire to recruit potential participants in Thailand. I selected six variables, rather than using all 16 variables in the original questionnaire. These 27 items with a 6-point Likert scale were selected because they related to self and the identity of L2 learners. These relationships (for example, ideal L2 self and ought-to L2 self) are ambiguous and need to be explored in other different EFL contexts (Islam, Lamb, \& Chambers, 2013; Kim, 2009; Magid, 2009). However, the actual self was not a significant component of the L2MSS model and was not part of the original questionnaire. The learners' actual self underpinned my research questions. Thus, I adopted eight items about self-efficacy with a 5-point Likert scale from a validated questionnaire (Busse \& Walter, 2013). This meant that all seven variables (listed below) had the potential to contribute to the motivational patterns which reflect the actual self and identity of Thai university students. The details of the 35-item questionnaire (see Appendix B) are as follows:

1. Intended learning effort (Criterion measure). The term "Criterion measure" (Taguchi et. al, 2009) is used as a primary criterion for the selection of the participants who perceived themselves as high-motivated students of learning English. The four items $(2,8,13$, and 20) were designed to measure the learner's effort and motivation towards learning English such as Item 20, "I think that I am doing my best to learn English".

2. Ideal L2 self. The four items (4, 10, 16, and 22) were developed to measure L2specific facets of one's imagined self to reduce the discrepancy between the actual and ideal selves. For instance, Item 16 "I imagine myself as someone who is able to speak English". 
3. Ought-to L2 self. The four items $(6,12,18$, and 24) were used to assess the attributes that one believes that one ought to possess such as obligations or responsibilities to avoid negative outcomes or external pressure from parents and social environment. For instance, Item 18 "Learning English is necessary because people surrounding me expect me to do so".

4. Familial/parental influences. The four items $(1,7,14$, and 19) were developed from Gardner (1985) to measure active and passive familial support or influences on learners' learning English. For instance, Item 7 'My parents encourage me to take every opportunity to use my English such as speaking and reading”.

5. Instrumentality-promotion. The six items $(3,9,15,21,25$, and 26) were designed to measure the regulation of personal goals to become a successful person such as attaining high proficiency in English or attaining higher social respect. For instance, Item 3, "Studying English can be important to me because I think it will be useful in getting a good job".

6. Instrumentality-prevention. The five items $(5,11,17,23$, and 27) were used to assess the regulation of duties and obligations such as studying English in order not to get bad marks in the university or to avoid failing the examination. For example, Item 5, "I have to learn English because without passing the English course I cannot graduate”.

7. Self-efficacy. The eight items (28-35) were used to measure the self-perceived belief of an individual's capability to reach a certain level of performance (Bandura, 1989) in four skills. For example, Item 34, "How confident do you feel in speaking about a film with a native speaker?"

According to Johnson and Christensen (2014), researchers normally adhere to one particular paradigm. However, they can thoughtfully and strategically combine quantitative and qualitative methods which balance strengths and weaknesses of both methods. In this study, I employed a quantitative survey to recruit eligible participants and to inform a qualitative study that explored Thai students' L2 learning motivation and 
multidimensional self-identities. I looked for any congruence and ambiguities and clarified them by conducting a series of in-depth interviews. The subsequent storying offers a robust and trustworthy methodology. To assure the trustworthiness of my analysis, I articulated my standpoint and used a research journal for self-reflection to ensure open and honest narratives with my participants and readers (Malterud, 2001) (see Appendix I).

\section{Launching an online survey during political turmoil}

In April, 2014, my journey was complicated by political unrest. While studying in New Zealand, I had kept up with news about the Red-shirt uprising in Bangkok. At that time, there had been a period of Red-shirt versus Yellow-shirt conflict for several years. In a sense, Thailand's monarchy system, the heart or identity of Thai people, was being questioned by the Red shirts which included students, businesspeople, left-wing activists and rural people who called themselves "grassroots" who were mostly from the northern part of Thailand. They tried to support an amnesty for Thaksin, the exiled ex-prime minister, with the hope of letting him return home again. The Yellow-shirts, who claimed themselves to be loyal to the King, marched the streets to protest the election's invalidation and vote-buying of Yingluck's government led by Thaksin's younger sister or political puppet. The political unrest was on-going during the period when I returned to Thailand for my data collection.

With this in mind, I selected the research sites for convenience, located on the outskirts of Bangkok. I kept contact with my friends, the lecturers at those two universities, and they confirmed that everything would be fine. So I was not concerned much with the political turmoil at the beginning of my study. I returned to Bangkok in April, 2014. Before administrating the survey, I conducted a survey trial by emailing a link to 18 undergraduates' personal email addresses at a well-known public university.

\section{Analysis: Trialing the validated questionnaire}

Trialling the survey ensured that the translated version of each item was understandable and allowed the functions of the Qualtrics Survey Tool to be tested prior to the actual launch. In the small trial of the survey, I did not test the reliability (Cronbach Alpha) of 
each variable because this kind of analysis is not reliable with the very small number of respondents who participated in the trial (Creswell, 2012). Also, the survey had already been validated (Magid, 2009; Taguchi et.al, 2009). I intended to use a quant-QUAL selection process which is a variation of a sequential quantitative-qualitative mixed methods study (Creswell \& Plano Clark, 2011). However, I did not aim to compare or integrate the two data sets. Instead, I prioritised the interpretative approach to focus on the qualitative study to recruit eligible participants in the in-depth, narrative interviews. I triangulated the interviews by integrating multiple written sources such as an English Diary and personal-familial-social photos to stimulate and complement the participants' narratives within the L2MSS and sociocultural framework. Thus, I aimed to achieve a more holistic understanding of the participants' L2 learning experiences by exploring their narratives through a qualitative thematic analysis.

\section{Stories of my data collection in Thailand}

After obtaining ethical approval from Victoria University of Wellington, I embarked on my data collection. At the private university, I contacted my friend who worked as a lecturer and was the acting Assistant Dean, and also sought approval from the Dean of the Faculty of Arts. Initially, I had intended to email the invitation to the students' university or personal email addresses. However, my friends informed me that first-year students normally do not access the university emails as a medium of communication. Rather, they suggested that I set up a link to an online questionnaire at the Testing and Learning Centre where the students had to complete an online course evaluation in the last week of the semester. So, I changed my initial plan and followed my colleagues' suggestions. 
Because I had strong relationships there, I was able to obtain permission to set up a link to the survey in a short period. After gaining approval from the university, my friends helped me coordinate with the faculty and IT staff and selected the specific date and time when all three groups of the English-major, first-year students would attend the lab. On that day, I helped the IT staff set up the link in the morning. Also, my friend introduced me to students in her class and told them that they could ask for information about the instructions and question items. I quickly felt connected with the students through my relationship with their lecturer. Everything went smoothly. The students appeared curious and motivated to complete my online survey, spending 10-15 minutes doing so. At the end of the day, I de-activated it and checked the initial findings through the output function in Qualtrics.

My first mission was successfully completed. In total, 233 respondents out of about 300 respondents at the private university fully completed the online survey in that one day. Then I imported the Qualtrics data into the quantitative analysis straightaway. Using the online survey was convenient and time-saving despite having a large number of respondents participating in the quantitative study. However, I was most concerned about the small number of potential participants who were willing to attend the in-depth interview. Even my offer to provide them with a movie voucher as an incentive was not enough. Only 20 students, or less than 10 percent of the respondents, provided me with their personal contact details at the end of the online survey. I started contacting these 20 students to invite them for an interview. 
During that period, I also had submitted the required documentation to a prestigious public university to gain approval to gain access to students' university email addresses for three months. A problem emerged because the students there seldom used the university's email communication in their daily lives. A contact, who works as a lecturer there, said that she would try to help me. As an English lecturer there, she informed her students on a Group Facebook page about my project and invited them to provide their personal email addresses. Eventually, I got about 20 email addresses from potential participants. In addition, my documentation was slow to be processed because I had intended to carry out my research during a summer semester and this coincided with ongoing political unrest. I felt rather stressed after continually trying to follow up with the staff there. Eventually, I decided to cancel data collection at this site because of the redtape and paperwork. I thanked the lecturer and also those students who had volunteered their help.

My journey was becoming tricky and problematic. Next, on May 22, 2014, I heard the announcement of martial law and curfew. I felt worried about whether I would be able to complete my task within the six-month period allowed.

I went to Plan B. I flew to my home university in the southern region to gain the approval of the Dean of the university to undertake my research there. There were neither political demonstrations nor a military presence in this rural area. In contrast to Bangkok, the atmosphere at the university was very quiet during the summer break. To gain access, everything seemed to be much easier than at the public university in Bangkok. As a teacher at the department of Foreign Languages there, it was very convenient for me to gain the approval and directly contact the faculty and administration staff there, even students.

I encountered several challenges. First, I wanted to collect data during the summer break when few students were taking summer courses. Second, like the students in Bangkok, they seldom used their university accounts for email communication in the holidays. Rather, their channels of communication were Group Facebook (FB) and Line applications. Initially, the administration officer recommended that I post a link through their FB which was their normal channel of communication. 
However, I decided that there were privacy and confidential reasons to avoid using FB in case other members of the FB community saw who had volunteered to participate in my narrative research. Then the officer provided me with the personal email addresses of students majoring in Business English, Tourism, and Accounting who were taking courses during that summer. To supplement this, I personally contacted the lecturers and student representatives in the particular majors and asked them to provide me with updated student contact details. Another problem emerged: that some students did not have a Wi-Fi signal at their houses in remote, rural southern areas. Despite this, the students assured me that they could complete my online survey at local Internet cafés. Eventually I obtained almost 250 email addresses. I negotiated with the heads of each major subject area and specified the actual date for sending a link to their personal email address, and the date on which I would de-activate my link in the system. Also, I added information about where and when I would conduct the interviews to ensure that students understood the time constraints. This was important because most students came from other provinces in the southern region. Finally, 123 respondents out of 250 fully filled out the online survey within a one-month period. Success at last!

\section{Analysis: Advantages of using convenience sampling for a survey}

During this period, I used convenience sampling to launch the online survey at two universities to purposively recruit students to participate in narrative interviews. This approach allowed me to purposively select eligible participants for narrative research. According to Creswell (2012), narrative research has the potential to explore one or a few individuals' experiences and gain deep insights into the individual stories and identities. I planned to select a small number of participants who reported that they were highlymotivated to learn English. The criteria for recruiting the participants for narrative interviews were as follows: (1) they were first-year students who had completed the survey, who expressed an interest in being contacted for narrative interview, and provided their contact details such as mobile phone numbers and personal email addresses, (2) their mean score for all the items on the "intended effort" scale was at least 4 out of 6 which showed that they perceived themselves as highly-motivated students in learning English. I analysed the data using SPSS Version 20 and used descriptive statistics which indicate general tendencies in the data such as mean scores and medians. 


\section{Table 4.1}

Cronbach alpha, mean scores and SD for each variable

\begin{tabular}{lllll}
\hline Variable name & Number of item & Cronbach Alpha & Mean & SD \\
\hline 1.Intended learning effort & 4 & 0.39 & 4.55 & 0.6 \\
2. Ideal L2 self & 4 & 0.80 & 4.72 & 0.82 \\
3. Ought-to L2 self & 4 & 0.67 & 4.15 & 0.92 \\
4. Familial influences & 4 & 0.77 & 4.85 & 0.77 \\
5.Instrumentality-promotion & 6 & 0.78 & 5.32 & 0.54 \\
6.Instrumentality- prevention & 5 & 0.66 & 4.86 & 0.70 \\
7. Self-efficacy & 8 & 0.90 & $3.87 / 5$ & 0.77 \\
\hline
\end{tabular}

Using an online survey had several advantages. First, using the Qualtrics program was time-saving and convenient. That is, a large quantity of data and initial findings were easily exported and analysed automatically through Excel and SPSS programs. Second, respondents who lived in areas away from the university could access the survey link through the Internet and complete it at a time that suited them. Access to potential participants for the survey had been more complex than expected. Even in my home university where I had assumed access would be unproblematic, some students still struggled to access my online survey.

\section{Procedures for conducting narrative research}

I did my best at the time to contact potential participants for the narrative phase and to assist them to understand my research project. Those students who provided their mobile phone numbers at the end of the survey seemed most likely to want to participate in the interviews.

In reality, the political conditions in Bangkok were chaotic during the military coup. It was very challenging for me, as a researcher, to recruit potential participants and undertake multiple interviews at their university during the political transition of our country. I found it a bit traumatic while commuting from my house to the university when I encountered military camps and armed soldiers patrolling and standing on the streets. 
At the private university, fortunately, I interviewed three students who were on campus because they were organising the first-year welcoming party and worked part-time at the university. This seemed to indicate how out-going and active they were and may explain why they decided to allocate some of their precious time to sharing their experiences with me. Finally, I selected two English-major students, rather than the non-English major student who took only one English course at the university. The English majors were more likely to be motivated to learn English and to have diverse L2 learning experiences in academic, non-academic contexts, and through social networks. In addition, their actual self and linguistic self-efficacy also related to the construction of their L2 self and identity. At the public university, I interviewed a total of five participants majoring in Business English and two participants who appeared to have gained much more exposure in English beyond the classroom than the other potential participants.

I completed three interviews with each of the two participants from the private university and four in-depth interviews with each of the two participants from the public university until it appeared that no new ideas were forthcoming and it seemed data saturation had been achieved. Finally, I was able to gain insights into these Thai university students' language learning motivation and multifaceted L2 identity development at school and university.

I found that despite the high response rate to the online survey, 356 respondents from two universities (236 from the private and 123 from the public university), this did not lead to large numbers of potential participants for the qualitative phase. Actually, this would have been a serious matter for several research designs, but my emphasis on gaining in-depth data through a narrative inquiry meant that it was credible to concentrate on these few participants. Less than 10 percent of the respondents were interested in attending in-depth interviews. 
The context and the timing provided challenges to recruiting potential participants for the qualitative phase particularly since this coincided with the proclamation of martial law in Bangkok. Students returned to their home towns or worked part-time jobs during the summer break. When I contacted those who had expressed an interest, most refused me straightaway, or did not reply to my email invitation, or did not show up even if we had already made an appointment.

\section{Analysis: Using the quantitative findings to recruit "hard to find" participants}

Using quantitative data from an online survey allowed me to locate a "hard to find" qualitative sample (Hesse-Biber, 2010, p. 137). These were the participants who had reported high levels of intended effort in the survey (see Figure 4.1). Under these circumstances, the focus of my research shifted from a pragmatic towards a largely qualitative approach through which I could explore the purposively selected participants' L2 self-system through narrative research. Creswell (2013) and Clandinin and Connelly (2000) recommend that narrative researchers interview only a very small number of participants to explore elements of participants' identity in depth. By shifting my focus to this approach, I aimed to capture students' motivational profiles and capture the breadth and depth of their identity development. Finally, I selected four rather than eight participants to increase the likelihood of gaining a deep understanding of the distinct motivational patterns influenced by their individual contexts.

I examined the quantitative data about each participant to inform my understanding of their motivation compared to whole sample of participants who took the survey. The following section discusses this and relates it to their selection as participants in the qualitative research. 


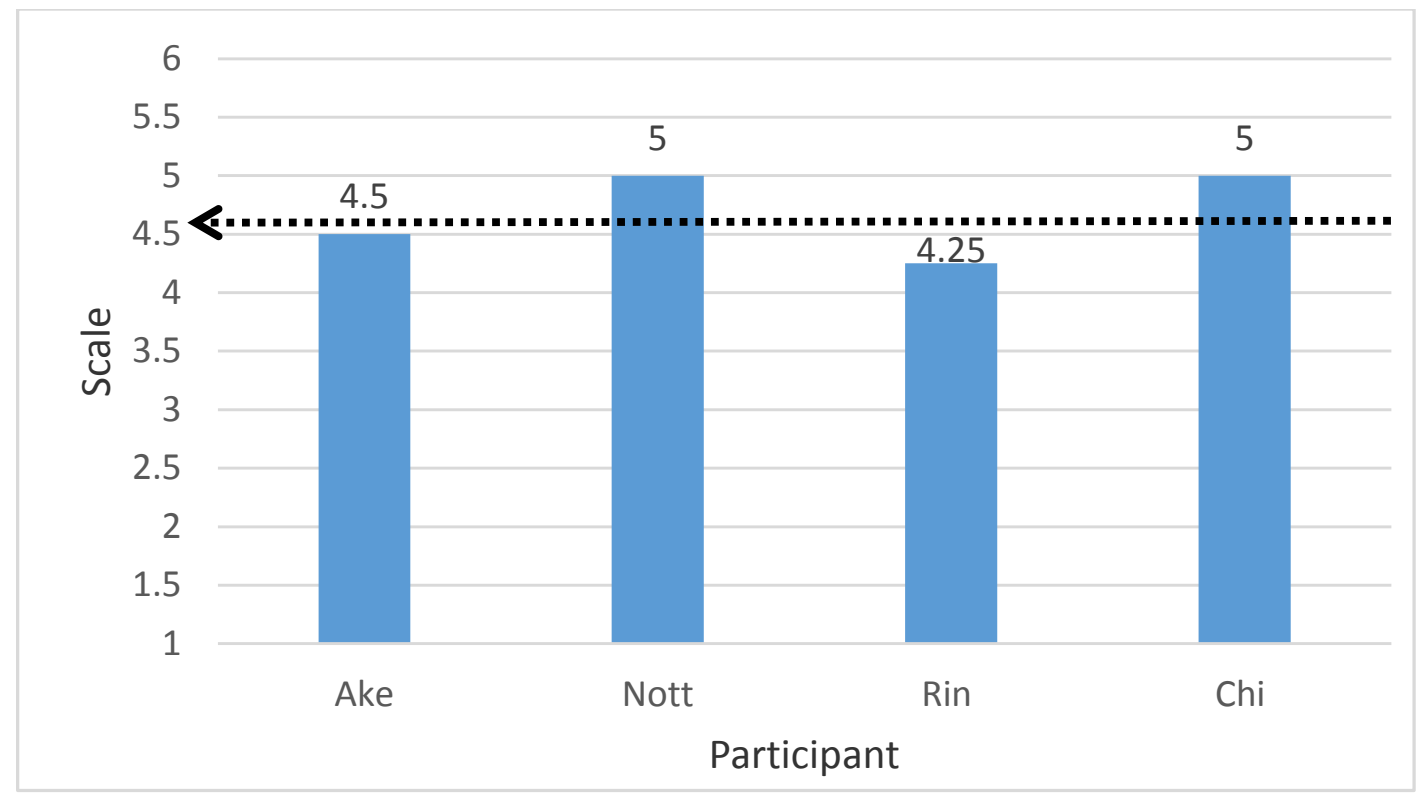

Figure 4.1 Intended effort (as measured by the survey) of the participants selected for narrative interviews

Figure 4.1 shows the mean scores of the four items from the survey for intended effort for the four participants' selected for the qualitative phase in comparison to mean scores for intended effort from the entire quantitative sample of 356 participants. The mean scores for the four intended effort items of these participants were greater than 4 out of 6 , and over the mid-point of 3 on the scale, indicating that they considered themselves to be highly-motivated students. The broken line indicates that the mean score of the whole sample was 4.55 out of 6 . Nott and Chi had similar mean scores for intended effort which were above the mean score of the whole cohort for this construct.. Ake's mean score for intended effort was 4.5 which equated with the average score of the whole sample. Rin had the lowest mean score for intended effort among the four participants. However, I included her as a participant because she met the critierion of having a mean score over 4 for intended effort. One point of particular interest was that her mean score for the selfefficacy items was the highest among the four participants. This allows some insight into the diversity of Thai students' L2 motivation and self-identity. 


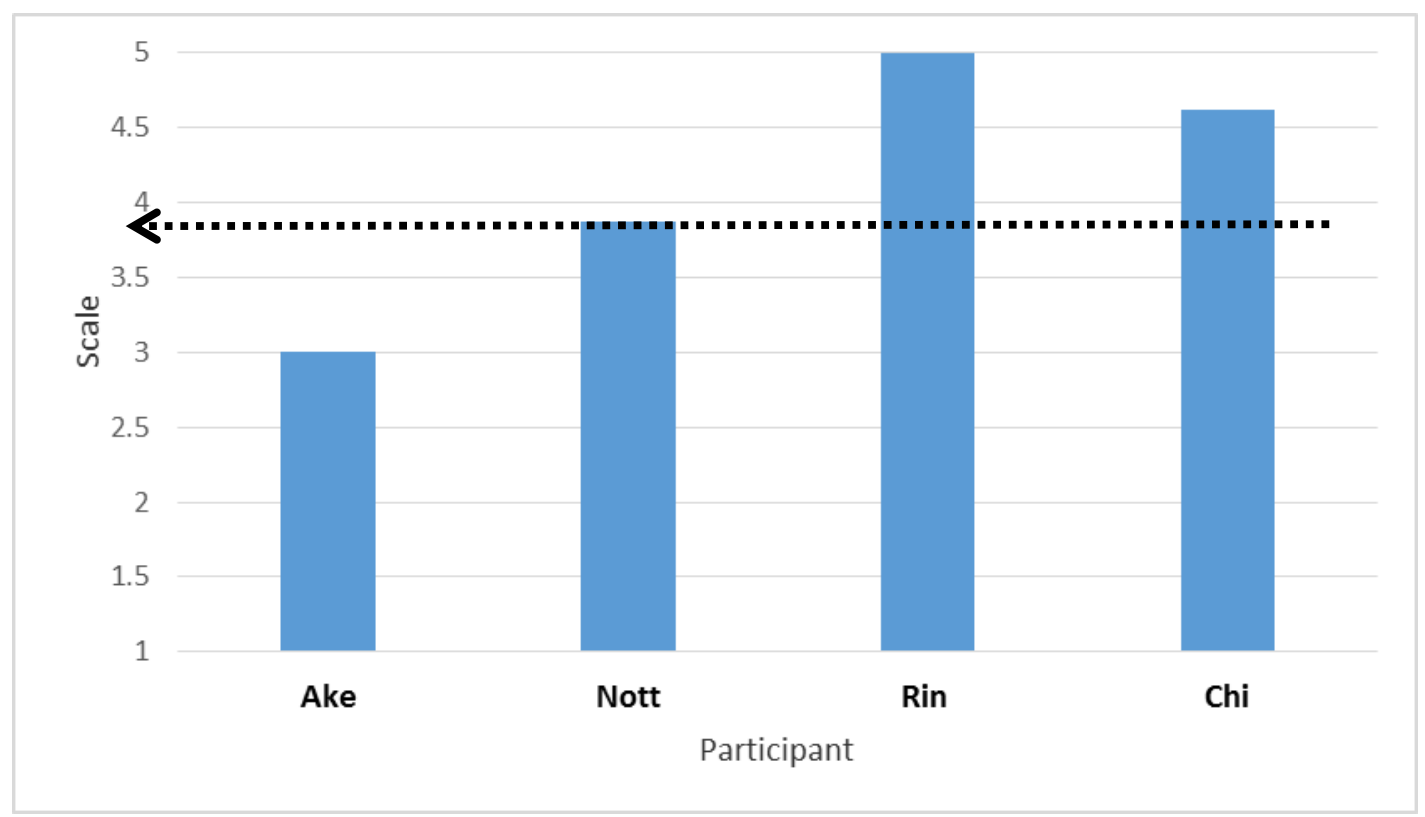

Figure 4.2 Self-efficacy of the participants selected for narrative interviews

As illustrated in Figure 4.2, three of the participants seemed to have a high level of selfefficacy. The broken line indicates that the mean score for the eight items in the selfefficacy scale of the whole sample was 3.87 out of 5. Rin and Chi's self-efficacy mean scores were higher than the mean, (4.62 and 5 out of 5 respectively), Nott's score equated with the mean score of the whole sample. Compared to the other participants in the qualitative phase, Ake had the lowest mean score in self-efficacy at 3 out of 5 .

\section{Conducting in-depth interviews}

In the qualitative phase, narrative data were formally collected through three semistructured interviews. I talked with the individual participants three or four times in indepth interviews which took from 30 minutes to 1.5 hours a session. Each question prompted them to reflect on a set of issues relating to their English learning motivation and contexts for learning. After completing each round, I transcribed the interview straightaway and sent a copy to the participant.

In my study, the first interview was designed to elicit comprehensive stories and experiences that shaped their LLM and their self-identity as language students. The interview prompts were adapted from the studies of Ushioda (2001) and Busse and Walter (2013) which provided a theoretical framework of LLM and self-identity (see Appendix C). The second, third, and/or fourth interviews aimed at burrowing (Connelly 
\& Clandinin, 1990) or digging deeper into their experiences based on the L2MSS theoretical framework and explored the tensions involved in being language students. I digitally recorded each interview and transcribed it immediately afterwards, partly because this allowed me to highlight the participants' answers to the probing questions which allowed me to ask them to make further comments in the next session. These semistructured interviews were conducted in the participants' preferred language (Thai) on the dates in the table below.

\section{Table 4.2}

Description of the four participants selected for narrative interviews

\begin{tabular}{|c|c|c|c|c|c|c|}
\hline Pseudonyms & Gender & Age & Major & Hometown & Date & $\begin{array}{l}\text { Total hours of } \\
\text { interaction with } \\
\text { the researcher* }\end{array}$ \\
\hline Ake & Male & 19 & English & $\begin{array}{l}\text { Hat Yai } \\
\text { (southern) }\end{array}$ & $\begin{array}{l}3 \text { Jun,14 } \\
17 \text { Jun, } 14 \\
29 \text { Aug, } 14\end{array}$ & $3.98 \mathrm{hrs}$. \\
\hline Nott & Male & 19 & English & $\begin{array}{l}\text { Hat Yai } \\
\text { (southern) }\end{array}$ & $\begin{array}{l}3 \text { Jun, } 14 \\
17 \text { Jun, } 14 \\
22 \text { Aug, } 14 \\
5 \quad \text { Sep, } 14\end{array}$ & 3.37 hrs. \\
\hline Rin & Female & 19 & $\begin{array}{l}\text { Business } \\
\text { English }\end{array}$ & $\begin{array}{l}\text { Hat Yai } \\
\text { (southern) }\end{array}$ & $\begin{array}{l}9 \text { Jul, } 14 \\
12 \text { Jul, } 14 \\
15 \text { Jul, } 14 \\
30 \text { Jul, } 14\end{array}$ & $4.29 \mathrm{hrs}$. \\
\hline Chi & Female & 19 & $\begin{array}{l}\text { Business } \\
\text { English }\end{array}$ & $\begin{array}{l}\text { Phuket } \\
\text { (southern) }\end{array}$ & $\begin{array}{l}9 \text { Jul, } 14 \\
16 \text { Jul, } 14 \\
30 \text { Jul, } 14\end{array}$ & $3.10 \mathrm{hrs}$. \\
\hline
\end{tabular}

*The total hours do not include time chatting in virtual communication.

\section{Stimulated recall interviews}

The stimulated recall interview is an introspective method of "eliciting data about thought processes involved in carrying out a task or activity" (Gass \& Mackey, 2000, p. 1). All participants were asked to bring artefacts as a stimulus for the interview. I brought along the English textbook used in the Listening and Speaking course at my home university, which I had also used in teaching, to prompt the participants to articulate their L2 learning 
experiences. This textbook prompted them to remember and articulate specific experiences in their immediate learning environment. After returning to New Zealand, I continued to chat regularly with them and asked them to respond in more detail to their transcripts, photographs, and artefacts via phone calls, Facebook, and Line, an application which offers free voice calls and instant messages. I used this approach to identify contextual aspects which were salient to the individual participants and this enabled me to narrow the scope of contextual factors during the analysis (Ushioda, 2015). Thus, the stimulated recall process allowed me to capture a detailed picture of their L2 learning processes and experiences.

\section{Undertaking narrative research, researchers' positioning, and ethical consideration}

During data collection, after completing each interview, I jotted down my thoughts and feelings regularly in a reflexive journal. When my supervisors asked me to summarise and talk about my thoughts, I reflected further on these ideas in my journal. I found that this process led me to think deeply about the participants' stories and I added some excerpts from my research journal when writing their narratives.

At the private university, I found it most challenging to interview Ake. During the interviews, I could sense the tension between us. This seemed to arise when he was reluctantly sharing with me his experiences of failing to pass English examination at his university. In our first interview, I raised general questions to prompt him to tell his stories such as, "Could you tell me about your stories or experiences?" I summarised key points with him to ensure what I interpreted and understood was accurate and comprehensive. After finishing the interviews, I transcribed these detailed interviews in Thai straightaway. Then I carefully analysed the questions, how I asked for more detailed information and dug deep to gain more clarification of the participants' detailed stories. A sample from my research journal is presented as follows: 


\section{Excerpt from my research journal}

"Reflecting on interviewing my first participant, Ake preferred the speaking course which had a less rigid structure and supplementary materials designed by the teacher. It appeared that he did not share many in-class and out-of-class linguistic capabilities and learning efforts in learning English, compared to Nott. I am not sure whether I should include his learning stories in my study."

"I felt a bit embarrassed when he frankly confessed to me that he preferred to study English with native speakers to Thai lecturers. Specifically, his disappointing learning experiences in reading courses reminded me of my previous pedagogical practices. Sometimes, I lectured large-sized classes orienting with a commercial textbook. Despite the fact that I explained sentence structures and reading strategies, they were not motivated to read passages by themselves in out-of-class settings. English is different from other content-based subjects. To understand texts, learners have to be adequately equipped with linguistic knowledge, sufficient background knowledge, and integrated skills in critical reading. Interviewing him reminded me of teaching low-proficiency students at my home university."

(My research journal, 17 June 2014)

From the reluctant way he responded, I thought Ake found it hard to share his learning experiences with me after finding out that he had failed two subjects in English. As an English-major student, he felt very discouraged by his failure and this experience appeared to lower his confidence and self-efficacy in contrast to his positive responses to the survey.

While interviewing, I asked myself "Should I stop asking?" Should I continue asking?" Because of my concern for ethical practices, I was reluctant to dig deeper and unsure of my position as a researcher because I was afraid of causing him to lose face and selfesteem, because of some of my direct questions. I could feel how he felt at that time. If I were him, I may not have shared my disappointing stories to a stranger. 
Still, I was curious. Some parts of his L2 learning experiences were rather negative and could not be reported completely in narrative reports. Still, his stories portrayed the reality of the English learning environment in Thailand and shared some similarities with other participants. Could I include his stories in my thesis? His stories were very different from those of the other three learners. If this was to be a trustworthy study, I felt that I had no choice. Even though he was not willing to discuss his failure to pass English at university, I decided to include his stories in my findings to represent the diversity and richness of Thai participants' L2 motivation and identity development.

My original plan was to have a stimulated recall interview where the artefacts could be both a source of data and a prompt to share and encourage the participants to talk in detail. Although this was not successful in the early stages of the narrative process, using artefacts to stimulate the participants' recollections enabled me to gain insights into their narratives in the later stages of the storying process.

Initially, only one student, Nott, shared any artefacts. Nott showed me a Taylor Swift photo and his caption entitled "I am a Swifty" and some memorable Myanmar-trip photos on his mobile phone. The other three students did not bring any artefacts. It was also likely that in the early stages of our relationship they may not have yet trusted me as their friend/sister, and they may have felt unsure of the research confidentiality. I asked myself: "If I were them, I wonder whether I would bring my personal artefacts and share them with the researcher (stranger). Maybe not. This was a problem and I thought about solutions.

I believe that sharing the English textbook, our mutual artefact, encouraged participants to share personal artefacts. Additionally, having a series of interviews allowed us to develop a stronger relationship and established trust among us. Eventually, I convinced them that their artefacts were important in helping my foreign supervisors in New Zealand to understand the particular contexts. Pictures are more powerful than thousands of words. The participants seemed to open up as they shared their personal artefacts with me. For instance, Rin shared with me her photos, poems, and postcards through email communication and Line application. Chi shared with me her photos through Facebook. 


\section{Analysis: The uniqueness of narrative research}

Fundamentally, we human beings make sense of our lives through our stories and experiences (Clandinin \& Connelly, 2000). The narrative approach is a unique form of qualitative research which investigates individual stories (Creswell, 2012). Stories emerge from the interaction of social influences on a person's personal life history in a particular context (Clandinin \& Rosiek, 2007). Individual experiences should be "studied narratively because narrative thinking is a key form of experience and a key way of writing and thinking about it" (Clandinin \& Connelly, 2000, p. 18). As a narrative researcher, I valued the particularity of students' stories and experiences, rather than attempting to generalise from the experiences of multiple participants. For each of my participants, I attempted to situate their stories within the L2 learning environment to ensure readers could visualise and interpret these students' narratives. In this study, each story is presented using a different narrative style as a way of revealing the social influences on the participants' experiences of language learning. Clandinin \& Connelly (2000) suggest that narrative researchers write participants' stories with several forms of narrative reports. Therefore, I reported the participants' narrative accounts in different styles to represent these individuals' diversity and to illuminate the uniqueness of each participant's stories (Clandinin \& Connelly, 2000). For instance, a dialogue and conversation technique was employed to present the utterances from one of the interviews (Riessman, 2008) to represent some of the participant's responses. I used a zoom-in and zoom-out technique by asking the participants to identify both personal (zoom-in) and contextual (zoon-out) aspects of their life experiences (Denzin, 1989) to understand how the participants interacted with NS and NSS in various contexts. Additionally, metaphors and transitions (Clandinin \& Connelly, 2000) were used to illustrate the participants' L2 transitional experiences from school to university.

The additional strength of undertaking narrative research is that I could ask my participants to share their personal-familial-social artefacts because these artefacts constitute memory boxes or "collections of items which trigger memories of important time, people, and events" (Clandinin \& Connelly, 2000, p. 114). Artefacts used in my study included the participants' postcards, poems, photographs of their personal, familial, and social lives, and a personal journal. One of my participants, Rin, shared with me her English diary which was part of a two-semester university project. Learner diaries are "autobiographical, introspective documents that record the experiences of language 
learning from the learner's perspective" (Barkhuizen et al., 2014, p. 35). Some parts of her diary assisted me to understand her perceptions of her L2 learning experiences.

Visual images can contribute to analysing narrative data (Riessman, 2008). However, Nott was the only participant to bring photos and artefacts to the face-to-face interviews. As time passed the other participants became more forthcoming and so after my return to New Zealand, I selected some digital photos they sent me via email and, with the participants' consent, chose similar images from online newspapers and websites to illustrate the sociocultural contexts they described. Presenting photos in the findings allowed me to represent the interface of the visual and written texts and illustrate the participants' L2 learning experiences and some of the social influences on their L2 learning.

\section{The ethics of relationships between researcher and participants}

As I reflected on the ethics of my study, I realised how the relationships between my participants and me had changed over time. If they had come to perceived me as a friend or sister, what were my ethical responsibilities toward them then? I decided to clarify this and repeatedly asked them for permission to refer to their artefacts. That was my solution. It became clear that, in time, they trusted me enough to continue to share their artefacts with me.

After completing interviews, all participants gave me access to their FB page and Line. I reflected on my position when participating in their virtual communities. This magnified the dual identity I was developing of being both a researcher and a person with a warm relationship (being a virtual friend) with my participants at the same time. In our virtual relationship, the participants had the power to avoid communicating with me or, even unfriend me at any time. However, I became part of their lives because, to gain access to their Facebook page, I shared my own Facebook page and followed up their stories over time. Therefore, the participants and I got to know each other well and developed a more balanced and reciprocal relationship during the storying process.

Understanding values, beliefs, and assumptions of researchers is at the heart of conducting all research, particularly interpretative inquiry in which a researcher is considered a human research instrument (Lincoln \& Guba, 1985). So, while I worked to story each individual participant's experiences and stories from their points of view, I did 
not avoid including my personal interpretation influenced by my own situation and environment as a relational research (Clandinin, 2013). As the storying process evolved, because narrative inquiry is non-linear, I was able to identify a series of small stories from the reported experiences of each participant, and choose appropriate forms to present each final report.

\section{Unexpected quantitative findings}

After completing the data collection and returning to New Zealand, I consulted with statistical experts and reported the mean scores and reliability of the constructs from the survey to my supervisors. Then I was asked to find the Cronbach Alpha of each variable in the survey. I consulted Dalice Sim at the School of Mathematics to learn how to find and analyse the Cronbach Alpha level of each construct. It appeared that the Cronbach Alpha of the intended effort variable was lower than the standard. I felt shocked in the sense that I had used intended effort as the primary criterion measure to recruit participants who perceived that they were highly-motivated to learn English. The low score meant there was inconsistency among the items in this construct. The items did not fully represent a single construct. Initially, I felt concerned that this finding would negatively affect my data analysis. I felt unsure how I would explain this to my supervisors. However, I had always aimed to orient towards the qualitative or narrative data.

Unexpectedly, the construct of intended effort had emerged in the quantitative findings with a surprisingly low reliability in my study despite being at an acceptable level in other published studies and this part of my research puzzle needed to be explored further. This puzzle suggested that narrative processes might provide a way of discovering the individual's perceptions of their own effort in language learning in their individual context. It appeared that this group of students may have interpreted this construct differently compared to participants in other published research. I carefully examined the items that contributed to this construct for clues to assist me to see why. The construct of intended effort had not only been pivotal in selecting students to participate in the indepth interviews, but had also become a significant part of the research puzzle that required in-depth analysis and further exploration. 


\section{Analysis: The problematic "intended learning effort" variable as a criterion measure}

The criterion measure of intended learning effort had been validated in previous studies (Taguchi et al., 2009) by examining the Cronbach Alpha coefficient to examine whether the items in each scale were internally consistent in an analysis of reliability (Dornyei \& Taguchi, 2010). In contrast to earlier studies, the Cronbach Alpha value of the scale "intended effort" was 0.39 which is considered unacceptably low (George \& Mallery, 2011). The low reliability of the intended learning effort scales used in the quantitative study was problematic since I had planned for this scale to represent the core of the quantitative analysis. I had planned for it to serve as the foundation for the subsequent qualitative research. However, this scale did not explain why these participants reported that they could not do their best in their English learning (see the details in Appendix K). I needed another approach to reveal how different sociocultural backgrounds including the impact of familial and social expectations were likely to influence these participants' self-system (ideal L2 self and ought-to L2 self) (Taguchi et.al, 2009). To summarise, the low reliability of this variable indicated that "intended effort" could not reveal the complexity underpinning this construct. In response to this lack of reliable evidence from the survey, I placed greater emphasis on the narrative inquiry. This allowed me to prompt the participants to articulate and share their motivations and L2 learning experiences in detail.

In addition, I needed to consider other aspects such as the time period of data collection which may have impacted on the data. One of the challenges was the time lag between collecting data for the two phases (Hesse-Biber, 2010). Each data set needs to be considered within the temporal period that it was gathered. For example, at the private university, I launched the online survey during the last week of the semester. At that time, the respondents had not received the results of their English assessments and so may have felt motivated at the time to attend the interviews. If they later received negative results, they may have become reluctant to share their stories with me. I recognised that I was investigating the participants' experiences of a process of learning English rather than just the snapshot provided by the survey. A narrative approach enabled me to see how Thai students made sense of and interpreted their L2 learning experiences and self-identities 
over the period of the qualitative phase. This approach enabled me to explore their lived experience (Clandinin \& Connelly, 2000). Thus, I could capture both their general and particular English learning experiences as they reflected on their transition from school to university.

My approach changed and I placed greater emphasis on the interpretative paradigm using narrative methods than I had originally planned. I decided it was not appropriate to hypothesise and test the variables of L2MSS. Instead, I attempted to achieve a profound understanding of the micro-and-macro phenomena affecting how provincial participants drove themselves to learn an L2 and seek opportunities to interact with NS and NNS interlocutors in diverse learning contexts. I sharpened my focus on interpreting the qualitative data to gain a full picture of the participants' L2 motivation and learning experiences. Themes emerged from "in vivo" codes or the wording and key phrases which participants used in their in-depth interviews (Saldana, 2013, p. 91). The small number of participants, the gathering of rich qualitative data from multiple interactions over time, and the use of coding that emerged from the data suggested that this study was now exploratory, rather than explanatory. The new emphasis on exploring the deep, rich qualitative data collected from the four participants enabled me to construct a rigorous narrative inquiry (Creswell, Hanson, Plano Clark, \& Morales, 2007).

\section{Narrative analysis, reflexivity, and writing up the narrative report}

At the public university, I felt privileged to listen to my students' stories of their language learning both in class and outside class. In particular, the participants at my home university and I were able to share and co-construct our values, beliefs, and identities because of our shared familiarity with that context. Although the relationship between me and students at the private university may not have been as strong as that with students from my home university, I was still able to position myself as an "insider" who grew up and was also shaped by familial, institutional, and sociocultural values in Thailand. Both groups of the students called me "Ajarn" or teacher. However, I felt that the participants at my home university and I established a warm relationship as a teacher and student at the same university, in addition to the researcher and participant relationship. This is not an unusual situation in narrative research where the researcher is also regarded as part of the research process since its objective is to understand relational aspects which shape the 
participants' identity. In this study, the participants at my home university and I shared several things in common such as lecturers we knew and English learning environments they experienced. Thus, it was especially important for them to know that I would treat their narrative data with confidentiality and would not share any negative stories with their lecturers who were my colleagues.

\section{From collecting data to writing up the report}

Initially, I wondered whether there was a conflict of interest between us in their participation. Yet, even if I had authority at my university, my participants, first-year students, did not personally know me since I had started my PhD in New Zealand at the time they began studying at the university. Therefore, participating in my study did not affect their grades or GPA. It was also unlikely that I was in a position to exercise power or coerce them to fill out the online survey or could influence them to provide their personal contact details at the end of the survey for individual in-depth interviews. Rather, I clearly specified in the survey that participating in the project was voluntary. After experiencing up and down moments occasionally, I was able mitigate these ethical challenges with a sigh of relief.

While collecting data in Thailand, I translated and emailed my supervisors the Englishtranslated version of interview transcripts of one participant to ensure that I was on the right track of interviewing and translating. I found it challenging to translate from Thai into English and still capture the cultural nuances. However, I received constructive feedback from my supervisors; I felt more confident to dig deeper into the issues raised, transcribe, and translate raw data further.

Moving from collecting data to writing up research is a tense and uncertain period for a researcher. I spent a lot of time reading, rereading, and analysing the narrative accounts. I re-listened to the digitally-recorded scripts. If there was anything I did not understand, I contacted the participants through Line and asked them to clarify the issue and provide me with some additional artefacts or photographs. 
I found writing the narrative reports complicated and time-consuming. The most challenging part was how to create narrative reports which would vividly illuminate the multiple layers of the participants' experiences to readers or outsiders with different worldviews and learning experiences. I experimented with different writing techniques to ensure that my foreign supervisors who held western perspectives could make sense of these Thai students' learning experiences and stories situated in the Thai context. I questioned how I could analyse narrative data and clearly illustrate my inner feelings and thoughts, and the emotional moments that arose while interviewing my participants. Finally I decided upon presenting a series of small stories for each of my participants. Entering this stage enabled me to re-visualise and re-analyse their narrative accounts. I hoped that through my research I could make some contributions and differences to teaching practices at my home university.

\section{Analysis: Decisions during the analysis process}

I recorded my observations, reflections, and research experiences in my research journal throughout the whole process of undertaking narrative research. It is common for narrative inquirers not to know how to analyse and present data until they start analysing in depth (Creswell, 2013). The narrative process establishes the relationship, mutual trust and respect between a narrative researcher and participants (Clandinin \& Connelly, 2000), and this demands reflexivity. Reflexivity in narrative studies refers to the dynamic process of interaction and co-construction between the researcher's and participants' values and experiences (Clandinin \& Connelly, 2000). The process of reflexivity and continuity of contact with the participants at two universities, particularly the ones from my home university, enabled us to establish trust and sustain a relationship, and this lent integrity to the narrative inquiry.

Reflexivity, more generally in qualitative research, also refers to how a person's values, beliefs and interests influence his or her research and how he or she identifies the foundation of knowledge (Creswell, 1998). As a primary instrument of data collection and analysis (Merriam, 1998), I had to be aware of my assumptions, behaviors, and biases which might have affected this inquiry. In presenting narrative data in the findings, I included my reflexive personal commentary and made interpretations in different sections to ensure that narrative data were presented more transparently. My personal, reflexive journal included reflections about my personal narratives, and allowed me to voice the 
research experience. It became an artefact that captured my developing relationship with the participants both during and after undertaking this study. I included excerpts from this research journal, so that others might see the fine details of the participants' (and my) stories and make their own judgement based on participants' (and my) teaching and learning experiences. This illustrated how we established mutual trust and increased the value of member-checking. It also tracks and assures the adequacy of the analysis (Cohen, Manion, \& Morrison, 2005).

Additionally, to see the overall picture of my developing analysis, I constructed a crosscase narrative matrix for the four participants (see Figure 4.3) by placing the period of time and their positive and negative attitudes in the first left-hand columns. In the toprow, I identified five key aspects of their L2 learning perceptions and experiences in different colour keys: goals of learning English, in-class and out-of-class learning experiences, examinations, role models, and work-experiences. In each participant's narratives, I coded and highlighted the key words of each dimension with the colour key as illustrated in Figure 4.3 (see the details in the Findings chapter).

\begin{tabular}{|c|c|c|c|c|c|c|c|}
\hline \multirow{2}{*}{\multicolumn{2}{|c|}{ Nott's narrative }} & \multirow{2}{*}{$\begin{array}{l}\text { Goals for } \\
\text { learning } \\
\text { English }\end{array}$} & \multicolumn{2}{|c|}{$\begin{array}{l}\text { Attitudes towards their L2 } \\
\text { learning motivation }\end{array}$} & \multirow{3}{*}{$\begin{array}{c}\text { Exam } \\
\mathbf{s}\end{array}$} & \multirow{3}{*}{$\begin{array}{c}\text { Role } \\
\text { models }\end{array}$} & \multirow{3}{*}{$\begin{array}{c}\text { Work } \\
\text { experiences }\end{array}$} \\
\hline & & & in-class & out-of-class & & & \\
\hline \multirow{2}{*}{ Present } & $\begin{array}{c}\text { Positiv } \\
\text { e }(+)\end{array}$ & & & & & & \\
\hline & $\begin{array}{l}\text { Negati } \\
\text { ve }(-)\end{array}$ & & & & & & \\
\hline \multirow{2}{*}{\multicolumn{2}{|c|}{ Ake's narrative }} & \multirow{2}{*}{$\begin{array}{c}\text { Goals for } \\
\text { learning } \\
\text { English }\end{array}$} & \multicolumn{2}{|c|}{$\begin{array}{c}\text { Attitudes towards their L2 } \\
\text { learning motivation }\end{array}$} & \multirow{2}{*}{$\begin{array}{c}\text { Exam } \\
\mathbf{s}\end{array}$} & \multirow{2}{*}{$\begin{array}{c}\text { Role } \\
\text { models }\end{array}$} & \multirow{2}{*}{$\begin{array}{c}\text { Work } \\
\text { experiences }\end{array}$} \\
\hline & & & $\begin{array}{c}\text { in-class } \\
\text { experiences }\end{array}$ & $\begin{array}{l}\text { out-of-class } \\
\text { experiences }\end{array}$ & & & \\
\hline \multirow{2}{*}{ Present } & $\begin{array}{c}\text { Positiv } \\
\text { e }(+)\end{array}$ & & & & & & \\
\hline & $\begin{array}{c}\text { Negati } \\
\text { ve (-) }\end{array}$ & & & & & & \\
\hline
\end{tabular}

Figure 4.3 Cross-case narrative matrix

Then I transferred information into the appropriate cells. By constructing this matrix, I was easily able to move backwards and forwards across the interview transcripts, and see 
big picture differences and similarities. To conclude, I analysed the particular scenario/aspects of their narrative transcripts systematically.

\section{Thematic analysis}

To strengthen the rigour of the narrative approaches, I employed thematic analysis which “is probably best suited to multiple case studies" (Barkhuizen et al., 2014, p. 77). My focus was to analyse identity-oriented components of "persons" instead of focusing solely on "individual differences in an abstract theoretical sense" (Ushioda, 2009, p. 216) which has been the preferred focus in previous studies (e.g. Islam, Lamb \& Chambers, 2013; Taguchi et al, 2009; Teimouri, 2016). The thematic analysis allowed me to establish shared themes in my study and enabled me to search for and present themes in conjunction with the theoretical framework (Braun \& Clarke, 2006). In particular, this approach captured themes across different L2 learning stories which unfolded both individual and collective L2 identities of these Thai undergraduates.

I applied Braun and Clarke's (2013) seven stages of thematic analysis: (1) coding and analysing transcription systematically; (2) reading and rereading the data to become familiar with and immersed in data that might relate to the research questions and puzzles; (3) coding and identifying aspects of the data in relation to the research questions and puzzle; (4) searching for themes and identifying salient aspects of data and patterns within the dataset; (5) reviewing themes and determining whether the particular themes match the coded data; (6) defining and naming themes which are unique and distilled to phrases or short sentences to reflect my participants' perceptions and voices, and (7) writing the report and including selecting vivid, compelling extracts as examples of data that are congruent with the final analysis of the literature, and addressing the research questions and puzzle of the study (p. 202).

Therefore, to find the missing pieces of my research puzzle, I grouped similar themes emerging from all participants' transcripts using coding techniques. I coded and recoded raw data from the transcripts by using one word, short or long phrases as themes to open up and represent the essence and meanings of a code (Saldana, 2013). For example, I selected "process coding" using gerunds ("-ing" words) to connote the action in the data (Charmaz, 2002). By probing into the grounded data in the interviews, all participants 
prioritised "SPEAKING" as their goal of learning English. Hence, "Speaking is our priority" became the major theme within their LLM. I also applied "in vivo", "literal", or "inductive" coding since I "prioritised and honoured the participant's voice" (Saldana, 2013, p. 91). Under this major theme, "versus coding" was used to identify dichotomous terms used by individuals, groups, or contexts in direct conflict with each other (p. 115). This contributed to an authentic interpretation of the participants' meanings. I thus labelled the sub-themes using in vivo codes such as "Speaking fluently vs/or speaking Njoo..Njoo..Pla..Pla..?" and "Speaking like "Farang" (westerners) vs/or speaking as who we are".

During the data collection and analysis, I used a process of broadening (generalising), burrowing (deepening), and restorying (Connelly \& Clandinin, 1990). These analytical models deepened my understanding of the participants' emerging stories. Broadening allowed me to portray the individual participant's characteristics and perceptions and to set up the social and contextual backdrop for their stories. I attempted to elicit and broaden stories that shaped their language learning motivation, experiences, and their self-identities. Burrowing was used to capture their perceptions and emotions at that particular time and place. Using these techniques enabled me to develop probing questions to dig deeply and focus on their perceptions and emotions. Finally, by collating and triangulating across a wide range of data, I could restory specific critical incidents and transitional experiences in the narratives. This allowed me to understand how they developed and reconstructed their L2 learning process and self-identity. In the process of interpreting each participant's experiences, their L2 self-identity resonated with my previous learning and teaching experiences, as well as previous studies related to L2MSS and person-in-context models. During the data collection in Thailand, I contacted them through email, FB and Line about 10-15 times depending on each different relationship.

\section{Challenges of translation from Thai into English}

$\mathrm{Li}$ (2011) discussed the influences of translation on the findings, analysis and presentation of narratives. She suggested narrative researchers should take ethical and relational issues into consideration when translating texts and learners' experiences simultaneously. I did not translate all of the Thai transcriptions into English because I was concerned that my translation and interpretation might have interfered with the participants' review of their 
interviews. After completing data collection, I coded the Thai transcripts to maintain a close understanding of the participants' meanings. Then I translated the transcripts from Thai into English and emailed the final translated narratives to the participants. However, none of them made any major changes probably because they had already had opportunities to check the Thai-version transcripts. Because the participants had checked the English version of their transcripts, I did not change the grammar from that point on. Some of the transcripts and quotes contain grammatical inaccuracy for this reason. The challenge of translating the interviewed transcripts from Thai into English was to translate slang and capture subtle cultural differences. I thus decided to translate and illustrate the concepts explicitly in English. Since my topic of my master's thesis related to translation analysis, I applied Larson's (1998) meaning-based translation techniques in my work to illustrate complicated ideas. For example, the term "Kradaae" (กระแดะ, slang), means trying to show off by pretentiously speaking English with a foreign accent and native speaker intonation. Translating the concept of an unknown word from their mothertongue or L1 into L2 allowed my supervisors and readers with a western lens to make sense of students' situated learning experiences. To ensure the accuracy and trustworthiness of the translation, I emailed translated transcripts to my colleagues who specialise in language and translation to cross-check the translated narratives.

\section{Power relationships between my participants and me}

According to Clandinin, Pushor and Orr (2007), it is challenging to explore how students, teachers, and researchers' identities are constructed within the context of cultural, social, and institutional narratives (p. 25). As a narrative inquirer, I did not try to ignore the fact that I played a crucial role as a teacher and researcher. Consequently, I could be myself and be part of this research but it was important to make this process as transparent as possible. My values and interpretation yielded insights into students' L2 motivation and learning experiences. Undertaking narrative inquiry was an appropriate method to answer my research questions exploring Thai students' complex and fluid identities. This approach allowed them to retell their L2 experiences/stories and articulate who they were and what they would like to be as English-users. However, the participants are not intended to be a representative of the whole population in general. Findings from narrative inquiry are layered and textured by particularity and incompleteness-- 
knowledge that leads less to generalisations and certainties (Clandinin \& Murphy, 2007). As a narrative inquirer, I value the importance of the particularity over the generalisation.

Having a close relationship with the participants' lecturers at both universities minimised problems in accessing documentation, and reduced time constraints in collecting data. My relationships with related authorities were crucial in gaining access to potential participants. My participants were provided with information about the interviewing process and were assured of the confidentiality of their identities and data. My priority was to safeguard the participants' identity and treat them respectfully. Importantly, the participants had the right to refuse to participate in my study or withdraw at any stage.

\section{Trustworthiness}

Trustworthiness refers to the "complex question of the relationship between the findings of narrative inquiry studies and the underlying "realities" they represent" (Barkhuizen et al., 2014, p. 90). I was aware that I might have unintentionally imposed my values and biases when presenting my participants' narratives since I conducted the research at my home university and was familiar with the context. My own stories had the potential to influence and overlay the interpretation of the participants' experiences. To minimise this threat to trustworthiness, I presented their stories as a compilation of transcripts to minimise my interpretation. Additionally, I reported the individual narrative accounts in different styles to represent these individuals' diversity and to illuminate the uniqueness of each participant's stories (Clandinin \& Connelly, 2000) (see the details in Chapter 5 Findings).

To triangulate my data, I used multiple sources of information and examined evidence from such various sources as narrative interviews, stimulated recall interviews, an English diary, and photos to build a coherent justification for narratives and thematic analysis. To assure trustworthiness, I used a research journal for self-reflection to ensure open and honest narratives with my participants and readers and including excerpts of my thoughts and interactions in the final report (see Appendix I). I also assured the participants from my home university that their identities would not be disclosed to their lecturers (my colleagues). 


\section{Ethical considerations}

Victoria University of Wellington emphasises the ethical conduct of research. All procedures in the study strictly adhered to the requirements of the Faculty of Education's Human Ethics Committee. After gaining ethical approval, I submitted the documentation (see Appendix A-H) to authorities at the two Thai universities. Having a close relationship with the lecturers at both universities may have reduced unforeseen problems pertaining to documentation and time constraints of collecting data and were crucial in supporting my access to potential participants. My participants were provided with information about the interviewing process and were assured of the confidentiality of their identities and data. My priority was to safeguard the participants' identity and treat them respectfully. Importantly, the participants had the right to refuse to participate in my study or withdraw at any stage (Dörnyei \& Taguchi, 2010). Additionally, they were informed that any chat messages, personal and family photographs would not be presented in the thesis.

I was also aware of my position in the narrative interviews. I was a lecturer and they were students. This was particularly evident in the university where I had been teaching. I needed to ensure that the participants felt at ease, and did not feel coerced into providing data. I did this by allowing the relationship to develop gradually and by reminding them of their options to withdraw from the study at any stage.

\section{Summary}

In this chapter, I presented stories of my methodology. I explored the implications of using the L2MSS model as a major theoretical framework and selecting eligible participants who perceived themselves as highly-motivated learners through the online questionnaire. The qualitative-oriented study involved a series of individual interviews, stimulated recall interviews, and personal-familial-social artefacts. I reflected on my relationship with the institutions and participants and how this influenced the narrative research process. In the following chapter, I present the four participants' narratives that show how each individual participant's L2 learning motivation and experiences affected the formation of their L2 self-identities. 


\section{CHAPTER 5}

\section{FINDINGS}

\section{Introduction}

This chapter presents the four participants' narratives. The findings are derived from multiple sources of data as illustrated in the section on Procedure for conducting the narrative research in the previous chapter. The narrative data were generated by transcripts of interviews, an English language diary, photos that held meaning for the participants, and artefacts selected by the participants and shared with me. Each of the students' narratives include the individual learners' perceptions of their language learning capabilities and experiences, as well as the major influences of familial, institutional, and social environments on their language learning motivation and L2 self-identities. Their stories capture their learning experiences during the critical period of transition from high school to university, in-class and in out-of-class settings. However, as illustrated in Table 5.1 , I present the data of the four different narratives in four different ways to uncover the uniqueness and diversity of the individual participant's narratives.

\section{Table 5.1}

Techniques of presenting the four participants' narratives

\begin{tabular}{|l|l|}
\hline Name & Narrative presentation techniques \\
\hline Ake & $\begin{array}{l}\text { Ake's findings are presented by using a compilation of extracts from his in- } \\
\text { depth interviews. I present his narratives in this way to show that he was } \\
\text { reluctant to express his L2 self and identity. His narratives reflected the } \\
\text { mismatch between his efficacious belief and unsuccessful learning } \\
\text { experiences. To contextualise the scenarios, I also add my reflections to show } \\
\text { how tense I felt while asking some prompting questions and how difficult it } \\
\text { was to play the role of the narrative researcher in this case. }\end{array}$ \\
\hline Nott & $\begin{array}{l}\text { Nott's findings are presented by using the zoom-in and zoom-out techniques } \\
\text { (Denzin, 1989). His unique stories illuminate readers insight into the } \\
\text { multidimensional nature of his L2 self-identity. By using this technique, } \\
\text { readers see the tensions between his internal and external aspects of self. This } \\
\text { technique can help deepen readers' understanding of the interface between his } \\
\text { in-class and out-of-class learning experiences and shows how he interacted } \\
\text { socially with his foreign friends. }\end{array}$ \\
\hline
\end{tabular}




\begin{tabular}{|l|l|}
\hline Name & Narrative presentation techniques \\
\hline Rin & $\begin{array}{l}\text { By combining the raw data of her interview transcripts, her narratives were } \\
\text { presented without my additional interpretation. Since she is one of my } \\
\text { students at my home university, my intension was not to impose any values on } \\
\text { her L2 learning experiences at the university. I will present her L2 self- } \\
\text { identity by capturing her transitional experiences of becoming a BE-major } \\
\text { student by using metaphors and transition (Clandinin \& Connelly, 2000). Her } \\
\text { narratives are presented based on her interview transcripts without adding my } \\
\text { interpretation. }\end{array}$ \\
\hline Chi & $\begin{array}{l}\text { Her narratives were thus presented similarly to Rin's. However, I will add } \\
\text { some parts of my reflections in my research journal because her stories } \\
\text { resonated with me in terms of my own parental and familial expectations and } \\
\text { influences on my L2 learning experiences in my childhood. In addition, her } \\
\text { narratives could illustrate how her learning motivation has been developed } \\
\text { from the past up until the present. }\end{array}$ \\
\hline
\end{tabular}

\section{Ake's extracts of his interviewed transcript}

During the summer break, I made an appointment and met him at his university. This private university is a large one in Bangkok with undergraduate Thai programs and International College (IC), English and Chinese programs, as well as graduate programs. The total enrolment of students at all levels is approximately 20,000. The campus is situated on just over 40-acres of land, including a beautiful green environment which accommodates new buildings, modern teaching and learning facilities and student clubs.

At the time, my journey was rather tricky due to the political unrest, announcement of martial law and curfew, and the military coup of May 20, 2014. I felt uncertain about completing my data collection within the six-month period I had committed to. On June 3, 2014, I interviewed the first participant named "Ake" at his university library. He seemed friendly and cooperative. He helped me reserve the private study room at the library to conduct the narrative interviews. 


\section{My goals for learning English}

Interviewer: Why are you interested in learning English? What are your goals?

Ake:

First, I would like to speak English well and express myself bravely and confidently in speaking. Second, my family will support me to stay overseas with my aunt who is settled in Australia at the moment. They told me if I graduated with a BA, I can pursue my study there. But I was unsure about this.

Interviewer: Why not? It would be awesome if you had a chance to study overseas.

Ake: Even though my aunt could provide me with food and accommodation, my family's is not well-off, financially. The major obstacles are an expensive air fare and other expenses. Also my vocabulary is limited. I could not grasp rapid speech, shortened words and phrases or slang. And I spoke haltingly, making grammatical mistakes.

Interviewer: How did you improve your skills?

Ake: I listened to foreign news, movies, and music continuously-kept practising.

Interviewer: That was why you chose to major in English.

Ake: $\quad$ Right. I developed a clearer goal. Choosing an English major made me feel more motivated. Actually my parents asked me why I did not choose to major in Mass Media and Communication since I was an active student who preferred learning-by-doing and hand-on experiences ("Activity Kid"). It would be better than studying English in class, which I had already done for ages. But I preferred English for my future career so I could work overseas. My parents and aunts also supported me.

Interviewer: I see. Anyway, I was wondering why you studied at a private university. The tuition fees are much higher than at a public one.

Ake: $\quad$ Right, but I asked for a loan from a government scholarship named "Income Contingent Loan". In contrast to other universities, here they provide you with a $100 \%$ tuition-fee scholarship if you choose a major which is scarce in the specified job market. Also, I didn't have to take any exams.

Interviewer: Good on you. You had an opportunity to major in English as you expected. 
Ake:

They just allowed me to learn what I wanted-public or private, depending on myself. If I had passed an exam, I would have studied at the public. But if not, I could study at the private. Actually I took an admission exam at a prestigious southern Thailand university for the quota of students from 14 southern provinces. I sat the Tourism major because my friends encouraged me and since my vocational study. I really wanted to be a guide. However, I still failed it. They selected only five students from that round.

Interviewer: Why didn't you choose to sit for the English major?

Ake: $\quad$ The scores required for an English major were very high.

Interviewer: Apart from being a guide, what would you like to be?

Ake: In the future, I would like to work at jobs using English, such as a guide or an interpreter. Actually, I would like to work as a flight attendant like other kids. The problems were (1) my height was only 168 but they require 170-175; and (2) they required a high score of TOEIC. I had to study more about tourist attractions in each country.

Interviewer: Hope you reach your goal. Anyway, to wrap up, you did not care whether you were at a private or public university?

Ake: $\quad$ Yes. It depended on me and social factors.

Interviewer: So what do you think about learning conditions in EFL contexts?

Ake: Usually, most Thai teachers still use textbooks which I find boring. Learning with foreigners, as you know, they were punctual and involved us in a variety of activities such as singing songs. Sometimes they taught interestingly, sometimes, boringly. However, studying English at university focused separately on particular skills such as English for speaking and listening, reading, and writing. That was good since I clearly understood more techniques in each skill. Most teachers used power point as a key instructional media.

Interviewer: What about studying at a vocational school?

Ake: $\quad$ The teachers taught general English, four skills in one subject.

Interviewer: Why did you choose the vocational school, instead of the high school?

Ake: $\quad$ After finishing Matthayom 3, I reckoned I wanted to pursue Matthayom 46 (Grade 9-12) but the problem was I failed an entrance exam. Initially my 
parents worried about me. They were afraid that I couldn't study there since I was not attentive enough and was addicted to playing games. Then, my mom who worked as a teacher at a vocational school asked me to study at her school.

Interviewer: Did you have any troubles while studying there?

Ake: $\quad$ I had to learn new subjects such as Accounting and Finances. They were rather complicated. However, I chose to major in foreign languages. To me, English was tough, very tough. Additionally, I had to study Chinese in my second year. Everyone had to learn Chinese in this major. While learning, I did not like memorising vocabulary much but had to do so, difficult to read Chinese alphabet, very difficult.

Interviewer: How did you sort things out?

Ake: $\quad$ Fortunately, my good friends helped tutoring me. I studied only one subject in Chinese. Besides I studied three to four subjects such as Conversation English and English for Work, focusing on functional English used in the office.

Interviewer: Could you share with me any memorable English classes?

Ake: $\quad$ No.

Interviewer: Did you feel inferior as a vocational student?

Ake: $\quad$ We did not learn much about such general subjects as math, science and Thai language subjects. Rather, we focused on commercial knowledge and a hands-on experience, or learning-by-doing, which was the strength. Considering English, I did not feel inferior because I thought it depended on me. If I needed to study and search for unknown vocabulary, I would know the stuff.

Interviewer: From your view, which skills do you prioritize: listening, speaking, reading, or writing?

Ake: I prioritise speaking. Then it would be listening, reading, and writing respectively.

Interviewer: Which skills do you feel confident or good at?

Ake: $\quad$ Speaking and listening. But I am not good at writing and reading. I liked speaking subjects/courses the most because I wanted to improve my speaking skills, accent, and dared to express and converse in English. 
However, sometimes, I felt pressured because my classmates were better and had better accents. I felt like I wanted to speak well like them because I was not outstanding. I was not that good. I needed to improve my very weak grammar which I did not like. You know, I just found out the results last week. I failed two subjects this semester.

Interviewer: Really? Sorry to hear that. Could I ask how you felt once you knew about that?

[I was rather surprised. Initially, I expected to hear positive English learning experiences from a highly-motivated language student in a top class. I was not prepared to handle this situation. On the surface I looked normal but inside I felt uncertain about asking for more detail in our first interview. I did not want to harm his L2 self-identity. I was curious, though.]

Ake: $\quad$ I asked myself "Hey! Did I pay enough attention to them?" This made me lose my confidence.

Interviewer: Did your parents know about that?

Ake: $\quad$ Yes.

Interviewer: What were their responses?

Ake: When knowing the results, I was disappointed and thought that my parents would absolutely blame me. They called me up and I confessed to them I failed the two subjects, English for Reading and English for Writing. They consoled me that was fine. Failing was like an experience which could help me become more active and pay more attention to my studies.

Interviewer: You are lucky to have such caring and understanding parents!

Ake: $\quad$ Actually it is my fault. I did not pay attention to my studies. I sometimes played and sometimes studied. I hardly did any assignments or read textbooks despite the fact that my parent told me to do so. My parents may realise this. After listening to them, I felt motivated to be more focused than this. I felt more motivated since my family always SAID...SAID...SAID:

If you don't graduate or study well, you may not be able to go overseas; 
If you want your family $\mathrm{Sabai}^{2}$, you will have to pay more attention to study;

To me, these kinds of saying make me feel more motivated. Previously, they would say:

If you are addicted to playing games or could not focus on the study, you will not be able to go overseas.

[What his parents and aunt said could reflect the clash between his L2 self-identity and self-efficacy. I really understand how much pressure he felt.]

Interviewer: Did you feel under pressure?

Ake: $\quad$ My parents did not put pressure on me much whereas my aunt was rather tough. She told me if I was not attentive, I shouldn't go to Australia. But I was not worried about their comments. I know that if I do not do well, the consequences will be like that.

Interviewer: They do worry about you, don't they?

Ake: $\quad$ Absolutely yes. My parents told me if I liked it, I should do my best. They would support me absolutely. This was the major reason why I moved to Bangkok. I wanted to experience the wide world, open up my eyes and ears, since for the past eighteen years I lived only in Hat Yai. I wanted to stand on my own and stay with friends, away from my family.

Interviewer: Did you think you did your best here?

Ake: $\quad$ No

Interviewer: Why not?

Ake: $\quad$ Difficult to answer. Probably I was not attentive enough and had limited background of this English knowledge.

Out-of-class learning experiences

Interviewer: In your opinion, what is the difference between studying in Hat Yai and Bangkok?

Ake: Not that different. Most foreigners in my hometown, Hat Yai, were Malaysian and Singaporean, only a small number of Europeans. But when I moved to Bangkok, I met a lot of foreigners in and out of my university.

\footnotetext{
${ }^{2}$ Sabai is a generic word with several positive meaning in Thai such as physical well-being, financially stable.
} 
For instance, while traveling to Kao San Road, I saw a lot of foreigners walking and passing by. I felt like I was staying in a foreign country.

Interviewer: What did you do there?

Ake: $\quad$ Last year, I went there with P' David, 29, my aunt's son, who studied in Thailand until Matthayom 1, resigned and transferred his study to Australia. He came here to visit us, go sightseeing, and wanted to travel to Kao San Road. There were a dozen stalls running this sort of business there. I went inside and the shop assistant asked me in English: "Can I help you?" I replied in English that "I would like to have ... (He said this sentence in English). I was not sure if they knew I am Thai. From that experience, I felt like I dared to speak but not that much—still speaking haltingly. But I was not afraid of speaking English with Thai people.

Interviewer: Why not?

Ake: $\quad$ Initially I was afraid of speaking in public like others. But I changed my behaviour because, during my primary school, I liked doing school activities such as dancing and doing a stage performance. That helped me dare to act out more.

Interviewer: What did you perform?

Ake: $\quad$ On my Prathom 5-6, my favourite teacher organised the school's stage performance entitled "Snow White and the Seven Dwarves" on the English Day. I acted as one of the dwarves but did not say anything much, just supporting ideas with the other six ones. We rehearsed it for a few months because it was our first big show. On that day, my parents, sister, and a relative attended it and my parents complimented me, saying that I had done well.

Interviewer: Could you describe your teacher?

Ake: $\quad$ I studied with her from Patthom 3-6. I was motivated to learn English. She graduated from overseas. But she is retired. Her teaching style was easy to understand with teaching gimmicks (techniques) such as switching on music and singing songs together.

Interviewer: Anything else?

Ake: $\quad$ She showed us her memorable photos taken overseas and told us about her life experiences there. I liked to listen to those kinds of stories. I could 
imagine myself speaking English there with a lot of Farangs ${ }^{3}$ surrounding me.

Interviewer: From your perspective, was it necessary to speak English like foreigners?

Ake: To me, I did not imitate them much. The most important thing was, while speaking English, they understood me and we understood them. That was it. Whether we would have a better accent mostly depended on how often we kept practising.

Interviewer: What do you think about the Thai- accent speaking people?

Ake: As usual. They may not be highly educated and did not mind about accents. They just focus on understanding. We understood them. They understood us. To me, I spoke in my own style, both Thai and English—no matter what, it was English similarly.

Interviewer: Could I ask whether your parents could speak English?

Ake: $\quad$ My mom couldn't but my dad could speak a bit. They travelled to Australia once to visit my aunt before I was born. I saw some photos of my dad playing the guitar with his foreign friends.

Interviewer: Good on you. As you told me, you felt confident in your speaking skills.

Ake: I could communicate in English bravely and confidently. However, at my university, one Thai teacher, graduated from Chula and overseas, said my English was okay but I need to improve my weak grammar.

Interviewer: Could that compliment boost your confidence?

Ake: $\quad$ Sort of. When assigned to speak, I would speak automatically and confidently without any preparation.

Interviewer: How about your friends?

Ake: $\quad$ Some of them were good but dared not speak in front of the class. But I was not afraid since I dared to speak out.

Interviewer: Good. Have you ever taken any extra private class?

Ake: I used to take a one-month remedial class with that Thai teacher-free of charge, three hours a day, twice a week.

Interviewer: What did you learn?

Ake: I learned grammatical rules from exercises and basic sentence structures, loaded with grammar first.

\footnotetext{
${ }^{3}$ Farang is commonly used to refer foreigners, westerners or native-speaker interlocutors. It does not include non-native speakers or interlocutors.
} 
Interviewer: Did you use that much?

Ake: $\quad$ Not really - hardly ever use it, maybe in writing.

English speaking week/day 2012

Interviewer: I see. Tracing back to your vocational school, do you remember the policy named "English Speaking Week/Day 2012”?

Ake: $\quad$ As I remembered, at our flag ceremony, the principal encouraged us to use more English in our daily lives in compliance with the policy of Ministry of Education. Sometimes a Thai teacher spoke in English and translated it into Thai there.

Interviewer: How could you practise speaking?

Ake: $\quad$ Greeting friends.

Interviewer: Did you have a chance to use it in reality?

Ake: $\quad$ Hardly ever. Normally I did not. I spoke Thai.

Interviewer: Did it work?

Ake: $\quad$ To some extent, if we wanted to improve it, we would dare to make friends and approach them.

Interviewer: How did your friends interact or engage with activities based on these policies?

Ake: $\quad$ Differently, depending on the individual.

Interviewer: What did you think about entering the AEC in 2015 (next year)?

Ake: $\quad$ Basically we had to communicate in English since it was the second language besides our language. But I was not sure whether it could help improve our quality of life since I had attended the training at Hat Yai. Students from the fourteen provinces in the south brainstormed and discussed basic knowledge about AEC. I thought it might be good but not sure in what way.

Interviewer: At your university, was there any campaign about AEC?

Ake: $\quad$ Yes, in our major, we did the vinyl boards introducing some basic greetings among neighbouring countries.

Interviewer: Personally, to become a proficient learner, how do you learn and access English? 
Ake: $\quad$ My friends suggested I watch soundtrack foreign movies and learn from YouTube and other media because we were in the Information Technology, "IT" era. Sometimes I try to improve by imitating the original and could speak better. I like downloading MP3 in my mobile phone and sang to myself. My favourite song is "My Love, West Life" because this was the first song my teacher taught me. I started reading lyrics and studied unknown vocabulary, accents ("He used this word in English"), and pronunciation. Then I joined the music club, playing the drum.

\section{Part-time working experiences at Hat Yai}

Interviewer: Could you share your work experiences with me?

Ake: $\quad$ Sure, during my vocational study in summer, I worked as a part-time waiter at a small restaurant in Hat Yai. One day while I was preparing some food in the kitchen, the two staff standing in front ran into a kitchen and excitedly shouted "Hey!! Farangs... Farangs have come in". They asked me if I could speak English. I replied I would try taking an order.

Interviewer Had you done that before?

Ake: $\quad$ No, I just spoke with my foreign teachers in class. Initially I was afraid and unsure if my grammar and accent (The participant tended to use accent and pronunciation interchangeably) were wrong or not good enough. But I thought I should try since I did not have a chance to meet foreigners frequently.

Interviewer: How did you feel?

Ake:

At the moment, I felt numb and so excited because I was afraid of not using correct grammar-uncertain if I had to use "past tense" or took any wrong orders.

Interviewer: What did you say?

Ake: While taking the order, Farang customers asked me what do you "recommend" (he said this word in English). I recommended Tom Yum Kung and other dishes. They understood me and ordered them. After finishing serving, they started chatting with me, "How are things? Are you tired?" I asked them where they came from.

Interviewer: How many people? 
Ake: $\quad$ As I remember, there were five foreign teenagers, one British couple, and Australian and Singaporean tourists.

Interviewer: What did you learn from that?

Ake: $\quad$ After gaining this experience, I felt good. I could make friends, dared to speak in English, and felt more confident.

\section{In-class learning experiences}

Interviewer: Could you please tell me about your memorable classroom?

Ake: I was impressed with a Filipina teacher, in the Basic Speaking subjectthe way she taught us was very enjoyable. Probably, because of her ages 30 s, this made her like one of our friends in class. She got good feedback from us. Everyone in class enjoyed studying with her.

Interviewer: How did you know?

Ake: I noticed from our facial expressions-students and the teacher, all connected, in class. She was very friendly and did not stick to content much and there was a variety of activities in class. I felt that Ajarn ${ }^{4}$ was happy and we were happy as well.

Interviewer: Could you describe one class?

Ake: $\quad$ Each class was different. I was impressed with several classes but will share with you one scenario. In that class, the teacher would ask us to describe each photo out of five to six photos on the power point. We did not have to prepare beforehand, sort of impromptu speaking. All of us had to speak out, describe the photo in detail. We were very attentive and engaged. She did not time or ask any particular students. Whoever wanted to describe it, just spoke out.

Interviewer: Really? So most of you were good at speaking, right? Did anyone keep quiet?

Ake: $\quad$ Hardly anyone. The opposite! Most of us competed in speaking.

Interviewer: Probably it was a top class. What if you used the wrong order or made grammatical errors?

\footnotetext{
${ }^{4}$ Ajarn means teachers or lecturers.
} 
Ake: If so, she would not correct you but she would say it the other way round. We then realised we made wrong word orders or grammar. Besides she would describe more or add vocabulary to the parts we did not touch on.

Interviewer: From your view, what are the advantages of these kinds of activities?

Ake: $\quad$ Firstly, this kind of activity made me witty. I could think and speak rapidly. Secondly, I could speak without caring much about grammar. I could say what I thought right away. Ajarn was not serious. Although my vocabulary was limited, I could use the basics.

Interviewer: How would you score her out of 10 ?

Ake: $\quad$ I gave her 10 .

Interviewer: Wow...

Ake: $\quad$ Personally I liked a teacher with a sense of humour (He used the word "Hey-Ha" in Thai). We had a lot of fun and jokes and did not get bored at all. That was the reason why students had no stress in class.

Interviewer: What kinds of techniques or strategies did she use in class?

Ake: To me, she was "the best teacher who teaches from her heart, not from the book." I could feel she gave us her heart. Then we would give her our hearts. (Literally translated)

[I was impressed with his idea. I felt that he really meant what he said, with a firm voice and serious face. This could also mirror my identity and hit my heart. I ask myself whether I fitted this definition and how to improve my teaching practices to meet the students' needs and expectations in the future.]

Interviewer: Thanks for sharing your memorable class with me. Could you talk about any class you didn't enjoy?

Ake: $\quad$ Reading class, absolutely. I felt disappointed to be studying with a Thai female teacher. Initially I did not understand what she taught at all. I never experienced anything as difficult as this before. Personally I did not like reading. I was not good at it. Also, vocabulary was too advanced such as medical terms without any exam samples. I did not understand her. I think she preferred us to study on my own.

Interviewer: Why? Please give me one example. 
Ake:

At the beginning, Ajarn would talk about a particular topic, open her slides in power points, and stick to her supplementary sheets. Time us to read for 5-7 minutes. Then skimming, scanning and translating general ideas. Then read and answer the questions. Period.

Interviewer: Did she assign you to read and translate passages beforehand?

Ake: $\quad$ Yes. But I translated only unknown words, opening from English-Thai dictionary and jotting them down in Thai.

Interviewer: Any problem? From my experience, in my reading class, some students share their problems with me. For example, if they do not know which word to choose from since there are several different meanings. Or even when they have tracked all unknown vocab. in the dictionary, they still do not know how to translate the whole message.

Ake: I did not read them seriously-just opening the $\operatorname{dic}^{5}$ and sometimes translated sentences in wrong orders. I did not understand the whole message or main ideas. I knew limited grammar and vocabulary since I hardly recited vocabulary. I learned here was totally different from that at my vocational school. Reading for a while, I fell asleep.

Interviewer: Have you ever forgotten reading or translating before taking her class?

Ake: $\quad$ Yes, frequently.

Interviewer: Did she know that?

Ake: $\quad$ No. She did not walk around the class. She just checked attendance and asked us to translate some vocabulary or words simultaneously before reading. We just answered.

Interviewer: How many students?

Ake: $\quad 40-50$ students.

Interviewer: Did she use any commercial textbooks?

Ake: $\quad$ No. She would use excerpts from textbooks and her supplementary sheets.

Interviewer: Has she taught you the basic sentence structure-how to find the subject and verb?

Ake: $\quad$ Never.

Interviewer: Did you have any accumulated scores before taking the final exam?

\footnotetext{
${ }^{5}$ Dic is commonly used to refer a dictionary.
} 
[Actually I did not want to focus on this detail but it is important, for me as a teacher, to critically analyse his problem. I questioned myself if he himself deserved this failure or if maybe there was something wrong with his teacher's teaching styles, materials, or examinations.]

Ake: $\quad$ Yes, but I couldn't remember. What I remembered was whether I would fail or not.

Interviewer: Why? What about other subjects? Did you think like that?

Ake: $\quad$ Compared to other subjects like a speaking subject, I felt confident and would think in an opposite way. I had to do my best to get a good grade.

Interviewer: Tell me more about the final exam? How many passages? How long?

Ake: $\quad$ It was a three-hour multiple-choice exam with five to six passages and 5060 items. I completed it in one hour.

Interviewer: How fast!

Ake:

As usual. While doing exams, if I felt confident that it was a right answer, I would stick to it without any change. Done-no need to revise. Otherwise, it would be wrong.

Interviewer: Really? And after finishing, did you think that you would pass or fail? Ake: $\quad 50-50$.

Interviewer: What is the criterion of grading " $\mathrm{F}$ "?

Ake: $\quad 50-60$

Interviewer: What did you think about this grading system?

Ake: $\quad$ I was not serious.

Interviewer: Any advantages or disadvantages?

Ake: $\quad$ It could measure whether and to what extent we understood key contents of the subject. But I was pressured to make it. I had to make it-I felt all this tension.

[His response seems to express his self-contradiction]

Interviewer: Did this affect or diminish your performance?

Ake: $\quad$ Sort of.

Interviewer: Anyway how did you improve your reading skills for the next semester? 
Ake: $\quad$ Firstly I had to adjust my attitude. Personally I did not like reading but I needed to get more motivated or find any interesting reading stuff in the next semester.

Interviewer: Is that easy? As you told me, you did not pay much attention to your study-playing and studying. Changing attitudes was not sufficient. You needed to change behaviours or learning habits, practically speaking. [I was not sure if he felt offended but I would like to know about his concrete actions and firm resolutions.]

Ake: I was an adult and grown-up. If I could not handle with this, what would my future be like? I had to experience something tougher than this. If not, I would be the weak or low-immunity person (literally translated). Now I still did not know what to do.

Interviewer: What about a writing course?

Ake: $\quad$ He coldly stared at me and did not answer.

[I did not ask him about the writing course until our last interview, the third session. I just tried to prompt it. Then I realised that I should close the case here. No matter what, I was very grateful that he voluntarily participated in this study. Without him, this project would not be completed with the meaningful and insightful stories representing different facets of language learning motivation and L2 self-identity.]

After interviewing him several times, I asked my friend to keep an eye on him due to his poor performance. Interestingly, she shared with me that a lot of language students also received low GPA like him. That was the reason why the number of the English-major sections was reduced from three to two sections in the second year. Actually I do not aim to compare participants' performances between private and public institutions. However, I assume no matter what university they study at, they should have motivation and persistence in learning English. However, Ake decided to pursue this major, though it seems doubtful whether he could improve his performance. So the stories go. 


\section{Table 5.2}

Summary Ake's L2 learning experiences from the past to present

\begin{tabular}{|c|c|c|}
\hline L2 learning experiences & In-class activities/tasks & Out-of-class activities/tasks \\
\hline $\begin{array}{l}\text { Present } \\
\text { (university) }\end{array}$ & $\begin{array}{l}\text { - Felt motivated to do } \\
\text { impromptu speaking } \\
\text { activities such as speaking } \\
\text { in front of class and } \\
\text { describing pictures in group } \\
\text { - Felt unmotivated to take } \\
\text { Reading course which } \\
\text { focused on grammar- } \\
\text { translation, textbook- } \\
\text { orientation, and rote- } \\
\text { memorisation } \\
\text { Solely expected to pass } \\
\text { examinations only } \\
\text { Failed Reading and Writing } \\
\text { courses and lost his self- } \\
\text { efficacy in pursuing his } \\
\text { English major and worrying } \\
\text { about being "Dek Sil" }\end{array}$ & $\begin{array}{l}\text { - Downloaded and listened to } \\
\text { foreign music and movies } \\
\text { - Confidently spoke English } \\
\text { with a Thai shop assistant at } \\
\text { Kao San Road in Bangkok }\end{array}$ \\
\hline $\begin{array}{l}\text { Past learning experiences } \\
\text { (vocational school) }\end{array}$ & $\begin{array}{l}\text { - Learning four skills in one } \\
\text { subject } \\
\text { - Impressed with the English } \\
\text { teacher who taught him to } \\
\text { sing English song named } \\
\text { "My Love, West Life" }\end{array}$ & $\begin{array}{l}\text { Gaining speaking experiences } \\
\text { with foreign customers while } \\
\text { working as a part-time waiter } \\
\text { at his hometown, Hat Yai } \\
\text { - Joined a one-day trip to } \\
\text { Malaysia with his teachers and } \\
\text { schoolmates }\end{array}$ \\
\hline
\end{tabular}

\section{Nott's stories}

On the day I met Nott, the atmosphere in the campus was relaxed and peaceful in contrast to the chaotic conditions outside where soldiers were patrolling on main roads after the announcement of martial law for national security. Before the interview, we had lunch at a restaurant in front of his university as he recommended. While walking there, he proudly pointed to his team photo posted on a board, which he considered to be his first artefact. "Look, that's my team member named Dek-D, (Decent Kids). We joined the project Backpack to Asia 2014. You could google and learn more about us on Youtube”. I 
felt somewhat surprised and nodded with a smile. Even though my visit there was during the summer semester, I still saw many students doing a variety of enjoyable activities to welcome first-year students. This is regarded as a tradition for most universities in Thailand to encourage freshmen to make new friends, chat with senior friends about university learning experiences, and build relationships among them in the long term. My participant, Nott, as a sophomore, was responsible for organizing recreation activities for freshmen. That was the reason why he did not return to his hometown and could share with me his English learning experiences. He answered most of my questions confidently and energetically.

\section{My goals for learning English}

To zoom in on his initial, personal interest in learning English, he explained:

"I started learning English during kindergarten. At the beginning I did not like English. I was so afraid of Farangs due to their big and tall figures. But my sister had a foreign boyfriend working in Singapore. They stayed together at our house. Sometimes I felt like an outsider. While my sister could converse with him in English, I could not. I felt stressed when we sat together, had a meal, and her boyfriend turned his face to speak to me in English. But I dared not to chat with him because I could not do so. That was why I started learning English. I believed one day I could speak English like foreigners.

I wanted to speak English like a native speaker. I hoped I could converse and communicate in English. That was my main goal. I really liked English. Speaking skills were my priority, then listening. If we learned English, we should speak like native speakers. Also, I wanted to work overseas. Even if I did not reach my goal, I intended to work hard towards it."

Zooming out for his perspective on the obstacles of learning English in the EFL context like Thailand, he explained:

"The major problem was that we stayed in a learning environment where most people did not speak English. We should study in the International Program or pursue our study in foreign countries. We studied only in classroom contexts. When classes finished, we switched into Thai. Actually it should not be like that. 
Let me give you one example. While I was studying in the vocational school in Hat Yai, there was one initiative project called “English Speaking Day 2012”. We were encouraged to speak English every Friday. It appeared that most students did not talk to one another". Most people complained: "We have been learning English from the kindergarten to present". How come we could Speaking Njoo..Njoo..Pla..Pla ${ }^{6}$. Without doubt, that was why we could not.

In my view, if you speak in English, most Thais would say: "Look at that person. $\mathrm{He} / \mathrm{she}$ is so "Kradaae" ${ }^{\text {7 }}$. So it was difficult to improve. Actually if we speak with native-speaker or foreign accents, we could practice and improve. It was good for us. I did not care about them, anyway. But most people saw that others did not speak. Neither did they! Normally, Thais would behave and follow others. The other reason was that teachers were not very strict. During studying at my vocational school, teachers did not speak English in class at all. But at this private university, some teachers lectured in a bilingual language by switching from English to Thai. If they noticed that we did not understand them, they would switch into Thai. Probably this was because of the AEC.

Before the AEC, I thought I had to learn English to work overseas. However, now I thought we learned English to accept the AEC as part of our community, since we would have more opportunities to use English as a medium of communication. I had noticed an advertisement with a message: "If you spoke three languages, you would earn a competitive salary and would be desirably considered". So, in my view, if you were a bilingual or trilingual person, you would gain more special opportunities."

Particularly, he illustrated why he decided to major in English during his transition from vocational school to university.

"Essentially, I did not stick with studying at the public university and did not mind learning at the private university. To me, I just wanted to learn English, no matter where it was. Before studying here, I took the admission exam to major in English

\footnotetext{
${ }^{6}$ Speaking Njoo..Njoo.. Pla..Pla means that they can speak English just a little bit.

${ }^{7}$ Kradaae, (กระแดะ, slang, negative and sarcastic term), means trying to show off by pretentiously speaking English like foreigners with foreign accents and intonations.
} 
at one public university but I failed. Only two scores were at the entry level. I felt disappointed and cried. Again, I tried to apply for the International Program, at the same university. This time I did not have to take a written exam and only had an interview test with a foreign teacher. One night before, I could not sleep and asked my friend to conduct a mock interview in English with me until 2-3 a.m. On the day, I was so excited, submitting my portfolio. When he spoke to me, I was shaken and could not answer in long sentences, only short words or broken English. Then he asked me to read one passage about the internship. I did so and he asked what the word "intern" means. "A trainee," I replied. He asked me to summarise and translate it. I thought about it for a while and summarised in simple English. I could answer him in short phrases or fragmented sentences. I did not understand why I could listen and understand most of what he said but I could not answer or string long sentences together. I could answer him right away, though. Besides he asked, "Why don't you study at Hat Yai? Why did you choose Bangkok?" I replied, "Here is famous. So I want to study here." Finally I made it. However, tuition fees and expenses there were costly and my family was rather poor. When I told my sister that I was accepted at first she felt delighted. But once she received the tuition bill worth about 55,000 Baht (NZD 2,000) for the first semester, she realised that, as a single mom, she could not shoulder this burden. I begged her, "Please pay the first-semester tuition for me. I would work part-time and earn a living by myself after that". She refused and I felt so disappointed. I thought at that moment that I would have to stop learning for a year. Then I googled and searched for information about scholarships for underprivileged students, and this university name popped up."

Based on his stories, it was not unusual that he was eligible for tuition-free financial assistance from the university, but he struggled with paying for his accommodation and monthly allowances to survive in Bangkok, where the cost of living is continually increasing.

My scholarship for underprivileged students

"Initially I did not expect to obtain a scholarship here. I just tried and wrote a twopage essay with my portfolio. In the essay, I quoted the King's speech: "People...if they did not have their own nation, no land to live, they could not pursue 
happiness. So we could maintain the stability of the country. Hence, we had to exercise our body and soul, particularly lifelong learning because individuals with no knowledge could not find true happiness". I could remember the quotes by heart since during his first year at the vocational school all students had to recite it out loud at the flag ceremony every morning. In addition, I told my desperate life stories. My father, a construction worker, was dead due to alcoholism, and my mom died of a kidney failure. So I intended to lessen my elder step sister's burden by asking for the university scholarship. Finally, I got it."

He spoke with a strong voice without any hesitation. To him, the speech reflected that our king has encouraged Thai people to seek and gain knowledge to improve themselves and finally develop our country.

\section{In-class learning experiences}

\section{My favourite English learning experiences}

"I felt happy with an American lecturer, Ajarn Barron. I liked his teaching style. He used supplementary sheets and outside-class materials, not simply the textbook. Suppose I wondered and asked what the term "ain't” meant. He replied, "is, am, are + not". He did not teach like other teachers who kept explaining subject contents on the power point, with loads of content and lots of slides. No. He did not teach like that. He just started with the topic and explained how the words are collocated. Personally I did not want the teacher to bombard him with overloaded content from textbooks or slides in the power point. In this course, his objective was to encourage us to speak English as much as we could after finishing this course. The advantage was that we had the conversation tests frequently. When he asked questions, I could automatically answer him without waiting. For instance:

Teacher: "What would you like to have for dinner?"

Nott: "Would you like to eat with me this evening?"

Teacher: "What country would you like to travel to?"

Nott: $\quad$ I replied, "Myanmar". 
Teacher: "Why would you like to travel there?"

Nott gave him the reason and asked him:

"Would you like to travel with us?"

While having the individual speaking test, I did not perceive Ajarn Farang as a lecturer while speaking. I did not feel that he was my real teacher, just like my friend. If he asked anything, I really enjoyed keeping on answering and asking questions continuously. I had a fun and smooth conversation. Normally, the test took about two minutes. He would give us the topic "Follow-up Questions." While some friends spoke only a few minutes and then finished, others enjoyed it and spent more time than that."

\section{Negative learning experiences at the university}

"There was one subject, Reading Class. Once the teacher came to class, she would ask us to read one or two passage(s) in the sheet, about seven minutes in reading...skim, scan, find the topic or main idea. Answer the questions. Finish. Finish class. My classmates felt the same. She did not academically tell about reading strategies or techniques. For instance, "You see this word. It would be the main point. You do not have to read all words but you could guess from topics, key words, or bullets". She might assume we already knew. Probably we learned only new vocabulary. She would ask us what the word means while checking student attendances. If possible, I wanted her to provide us with more reading techniques on how to find the main idea in the passage. It should not just start with: READ. Read in your sheet for seven minutes. Then answer the questions."

\section{Learning with a foreign teacher at his vocational school}

"Normally we hardly had any native speakers to teach us English. However we heard that there would be a new English teacher that semester. I was so excited to learn with him. I checked with my accounting friends studying with him before us. What they told us was: "Not fun. The way he taught was not fun". On that day, when he came to our class, everyone was quiet. Before teaching, he asked us to stand up, move and dance, and say "Who, What, When, Where, Why, How (W5H1). He said, EXPLAIN to one side and GIVE AN EXAMPLE to the other 
side of the class". Then he explained to us if anyone asked us in English, we should have W5H1 in our answers. This was the easy way to practise speaking English. So far, I still remembered the way he moved and danced with his chubby figure. Initially I thought it was not fun but it was actually. The reason my accounting friends did not like him because maybe they did not understand what he asked them to do. But I, as a language student, wanted to learn with foreign teachers."

\section{Out-of-class motivated learning experiences}

In Thailand, parents and family support have a major influence on a student's English language learning (Choomthong, 2014). They encourage and financially support their children to take extra classes after class or on the weekend. They want their beloved children to spend valuable time for studies and gain sufficient knowledge in order to pass the competitive university entrance examination. However, Nott's father was totally different.

\footnotetext{
"When I was in Grade 7 (Mattayom 1), I asked my dad if I could take an extra class in English but he refused. My dad commented: "It was not our language. Why did "Mueng" (Kim) have to study? Were you stupid? The persons taking extra courses were the weak". My dad believed that only weak students should study more so it was not necessary. He also did not want my sister to have a foreign boyfriend either. Fortunately my sister had a foreign boyfriend and realised that English was really important. She paid for the English private course with a special discount because she knew the owner of the institute. The other reason was that my parents did not expect much. I had studied to the highest level, the Bachelor Degree, compared to others in my family."
}

He said "sorry" to me before saying a pronoun "mueng" which is regarded as an impolite word in Thai. As a hierarchical society, there are a variety of pronouns used with people from different social statuses, ranging from the monarchy, monks, commoners, and lower-class people. However, this could represent that he grew up from a low socioeconomic family background and his father may have had a negative attitude concerning learning English and foreigners. His father did not realise its importance and relevance of learning English. In particular his family had struggled financially. However, as a child, 
he really felt motivated to learn how to converse in English with foreigners without considering his financial constraints. Fortunately his sister realised its importance and supported him financially. When asked to compare the difference between studying at his school and the private language centre, he replied that:

"It was totally different. For instance, at that language centre the teachers switched on the tape or VDO. At the first round, there was no subtitle. They asked us to guess vocabulary meanings. At the beginning it was very slow and gradually became faster and faster. They taught us how to speak and pronounce words and phrases. Different from English classes at my school, there were a lot of language games and activities at the private course I took. Also, as I remembered, during the Christmas period, the teacher dressed up like Santa Claus and taught us the history of Christmas Day. When we studied with enjoyment, we liked learning it. This experience may encourage me to speak like native speakers, I reckoned. There were many levels. But I took only one course."

Interestingly when I asked him to share with me his memorable learning experiences during his primary and secondary schools, he could not remember them. However, after taking the 12-hour short course, he still recalled and shared with me his vivid impressive learning experiences and the teaching styles of two friendly foreign teachers. This influenced him to speak and learn English by himself in both in-class and out-of-class settings later.

\section{His internship at Tourism Authority of Thailand (TAT)}

While most mainstream students have decided to study at high schools (Matthayom 4-6) and pursue their bachelor degree at the university, Nott was different.

"In my view, studying at high school (Mattayom 4-6), I would have had to learn maths and science which are too general. Studying at the vocational school, I could practically use English in my future career such as a tour guide or flight steward. When I graduated, I wanted to use English in the workplace. So I decided to major in a foreign language there. Actually I started working as a part-time waiter in Hat Yai when I was 14. Initially, to take an order with foreign customers, I was anxious. Then I learned how to take orders in English by noticing the way a 
manager communicated with them. Finally I could do it and felt proud of myself. Also, I had a good opportunity to be an intern for two months at the Tourism Authority of Thailand (TAT), Hat Yai Office. At the time, bombings happened there. For a week due to a shortage of manpower I was assigned to help foreign tourists who had lost their passports. I could speak, listen and understand English but it did not sound like a native speaker. However, I listened to several accents such as ones from Singapore, Malaysia, and Russia. If possible, I would like to work with TAT again since I could travel to several new places, meet a lot of Farangs and get some allowances".

This could reflect that he really wanted to gain hands-on experiences which could open the opportunity for him to work in the future.

\section{Out-of-class learning experiences from mass media and social networking}

"I really liked to see foreign movies. Now I had several foreign friends. Sometimes we saw foreign soundtrack movies together. Initially I could not listen and understand them clearly. Although we got Thai subtitles, it was not fun because it is not our language. However, I wanted to be like others. If others could listen and understand them, I would have to do that as well. Recently I saw a foreign movie named "Maleficent" in the soundtrack version. I like Angelina. I saw it twice. They spoke in this accent. I really liked it. I liked to listen to it...feeling relaxed. I still remembered some dialogues. You could also see the phrase, "Well...Well," in my Line status. I would like to speak English with a British accent. In my view, it sounded smooth and beautiful—sort of Noble/Posh English accent.

Sometime I downloaded western movies and programs from internet. I was addicted to a foreign series named "Walking Dead". I watch it frequently. Supposing I knew it was launched on the internet at 8 pm., I would rush home and watch it. Even though there are Thai subtitles provided in some websites, I thought the way it was translated was not fun, like listening to it by myself. The word choices in translation are not "O" (Okay). I'd rather listen to it by myself. Sometime I used "Scotch Tape" (Sell tape) or my hand covered the subtitle on the 
TV/computer screens. I'd rather listen to it by myself. If I could not catch words, difficult vocabulary and slang while watching movies, I would rewind them until I understood, four to five time maximum. If I did not know vocabulary, I would guess them from context clues. It should be like this...like that because the meanings of slang were not included in the dictionary (English-Thai).

I started chatting on social networks, HI5 and MSN when I was 13-14 (Grade 78). I liked chatting with foreign friends. So far, I kept chatting with Indian and Indonesian friends. But I hardly had any western ones. My Indonesian friend liked Thai culture and wanted to learn the Thai language. He asked me how to speak and translate Thai words. The advantage was that I could practice using English. I taught him Thai language and communicated with him in English. He was good at English. In early September, he planned to travel to Hat Yai, not Bangkok. So I could not be his guide but gave him advice through Line Application instead."

\section{Once-in-lifetime backpack adventure in Myanmar}

"My three friends and I were one of the winning teams taking part in a university project which encouraged students to gain memorable backpacking experiences in Asian countries such as Malaysia, Singapore, Vietnam, Myanmar and Laos. We selected Myanmar due to the lower cost of living compared to Thailand. We received a supporting allowance worth 20,000 Baht. After travelling there, we had to share our travelling experiences on blog. If we were voted as the winner, we would receive 5,000 Baht. I was the person who initiated the idea, wrote the proposal, and asked my English-major friends to join this project—only our team were the first-year students. However, none of us had ever been overseas before. Except me, I had a one-day field trip to Alor Setar, Malaysia, while studying at the vocational school. Anyway I asked information from our Myanmar friend studying at International College before. He said to me: "Don't worry that you might not survive there since a lot of people in Yangon (city) could speak English. Just don't look down on them and do not think they could not speak in English". 


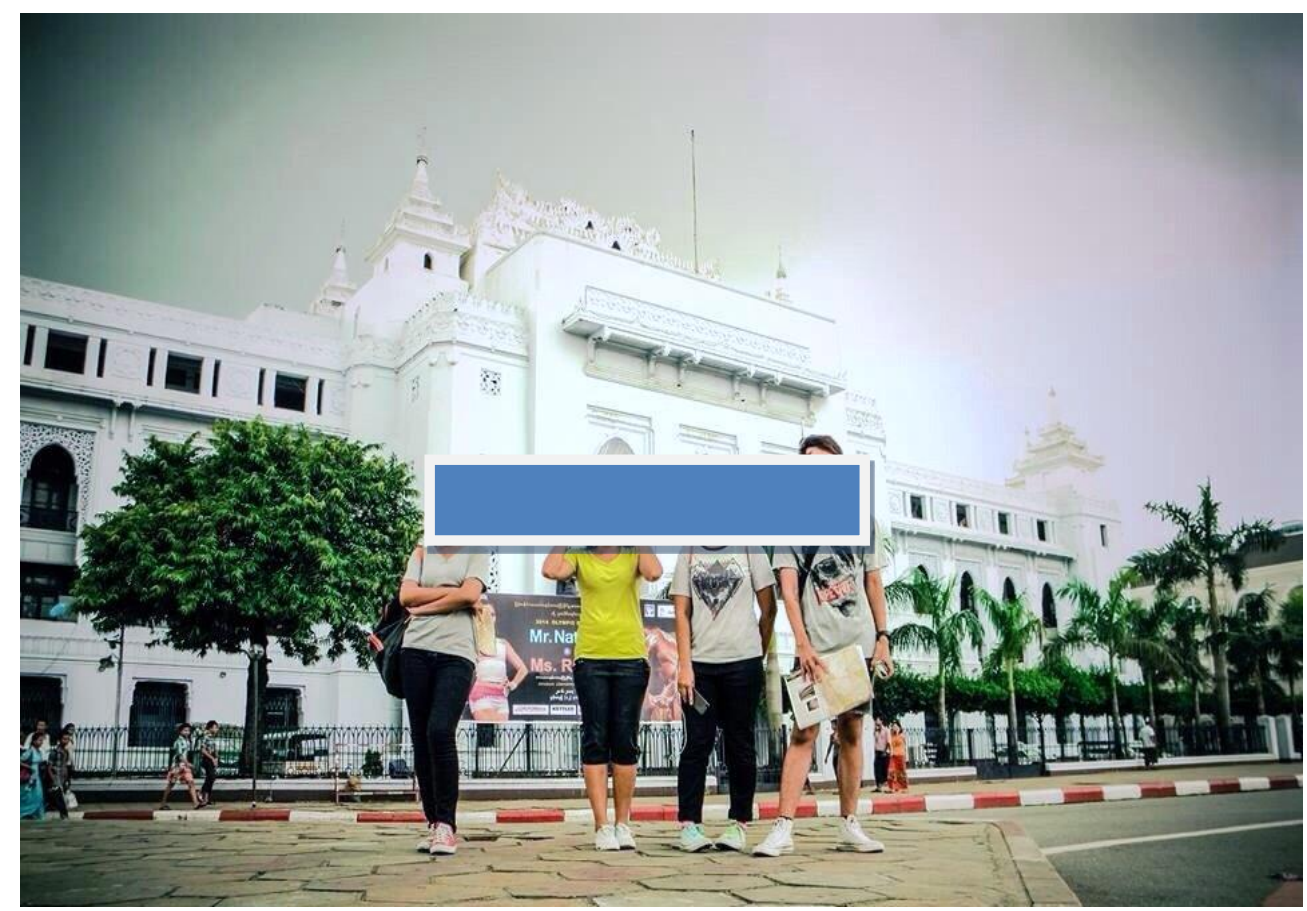

Figure 5.1 Having a five-day trip in Myanmar

When I reached there, I tried to speak English as much as I could. I felt motivated to speak English. I really dared to speak English as much as I could. I really dared to speak English while travelling there while I had not risked speaking like that in Thailand. I could speak what I thought right away. Since we changed guesthouses every day, both in the city and rural areas, I felt happy to meet and make new foreign friends from European countries such as Austria, Russia, and Poland. Most of them were friendly and really liked travelling to Asia. They approached and chatted with us, asking where we came from. They told us that they would travel in several Asian countries and maybe in Thailand. Then we exchanged our Skype ID. However, some local people in some areas could not speak English with us. We had to use the sign language or draw pictures to illustrate our ideas."

He asked me whether I noticed his Line status “BE BRAVE”. I gave him one book about how to speak basic Myanmar but suggested to him that, if possible, he should try to speak English as much as he could. We also kept in touch on Line about his journey and I realised that he tried to communicate in English as suggested. He was able to practice speaking English, make friends with foreigners, and expose himself to intercultural experiences while travelling overseas, even in neighbouring countries. 


\section{My role models}

\section{My elder sister}

"At that time, my sister was 24-just graduated. She was older than me. We were a sibling with different mothers. During studying the primary school (Prathom 56), my sister usually turned on foreign music. She really liked listening to Tata Young music, international albums. She usually turned on foreign music and I kept listening to music like her. She really liked listening to Tata Young musicinternational albums. As I listened to her music almost every day at the time, I eventually liked several songs._Then I printed the lyrics, read, and translated them. Sometimes I asked her to teach me how to read and translate them. I liked to sing along and incredibly felt the charm of pronouncing English such as /t/ sound. I felt impressed with it. I asked her to teach me English to ensure I could converse in English with foreigners someday."

When asked if he could communicate in English with his sister's boyfriend fluently and automatically, he told me that they broke up but he had a chance to speak with foreigners while working part-time.

\section{My senior friend}

“Thanks to P' David Nut (In Thai, the pronoun, P', is used to call senior friends or people who are older than you), I had a chance to work as a part-time staff for a foreign music organizer in Bangkok. He majors in English here and likes doing several kinds of activities so he is very popular. Still he has not completed his study since he both studies and works part-time. I met him first at a party organised by IC. Probably he saw me chatting with a Vietnamese friend in English so he told me: "I am looking for an English-speaking person. You would work with Farangs. They were rather strict and punctual". Initially, I felt childish, not ready to work. However, after he invited me several times, I decided to try working there. I worked as a coupon staff at a four-star hotel. My duty was to sell coupons to foreign customers buying food and beverages. Initially I lacked confidence but he encouraged me, "Just do it. Try working with Farangs, the key persons. He shared with me the story that previously he was not good at English at all. But after he had a lot of foreign friends and they taught him how to speak 
English. Finally he could speak English. He suggested to me it was such a great chance for me to work and practice speaking at the same time. Learning English in the academic context could not guarantee a one-hundred-percentage success. I believed him. His stories were similar to my sister's ones. Initially she could speak English a bit... "Snake Snake Fish Fish (Thai slang) like me. But she was good at speaking English". But once she had the foreign boyfriend, she could do it fluently."

\section{Who am I? I am a Swifty}

"During studying at vocational school, I listened to Taylor Swift's music almost every day. From my view, she was a talented song writer, guitarist, and singer. I printed her song lyrics, translated, and sang along. I followed, read her messages, tried to tweet her in English-“'I'm your biggest fan, I will follow you, until you love me." Initially my dream came true once she organized her tour concert “Taylor Swift Red Show 2014" in Bangkok. I tweeted her: "I am your Thai fan". And she sent me a smiley emoticon. I was so happy. With a limited budget, I could not afford a ticket, just intended to meet and greet her at the airport with my friends. However, I felt disappointed and almost cried once I knew her concert was cancelled after the military coup took control in May."

He then showed me a lot of his photos loaded in his IPhone and one of the photos was on his wallpaper previously. As an optimistic teenager, he said, "I understand that, and I still have a lot of chances to meet her. He tried to position himself as a member of globalised pop culture by using English as a tool of communicating with his favourite American pop singer through his cell phone, IPhone. "I got and paid it by cash by myself when I was 17-18", he proudly admitted to me and showed me his favourite photo, "I am a Swifty," as shown in his mobile phone. 


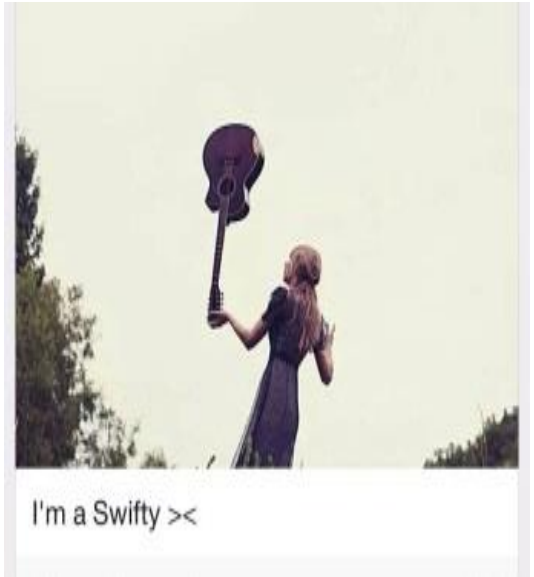

Figure 5.2 Taylor Swift's

photo in his mobile phone

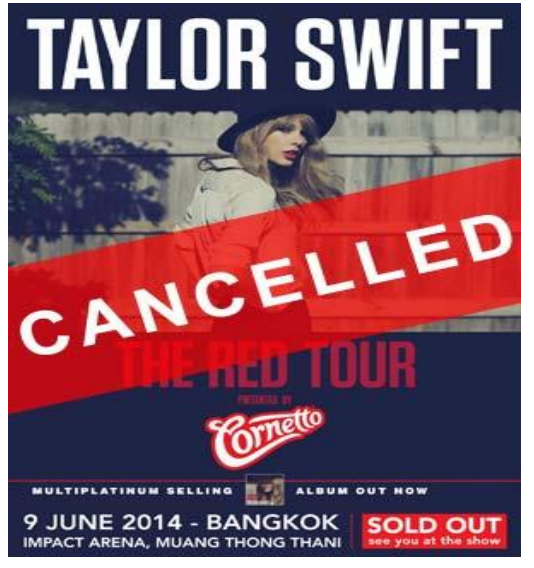

Figure 5.3 Taylor Swift's concert cancellation

(Source: http://www.thaiticketmajor.co $\underline{m / \text { concert/concert }- \text { php? } \text { sid }=2265 \&}$ $\underline{l a=e n)}$

\section{My intended effort of learning English from past to present}

"From my viewpoint, I could not identify that I have improved from that period to this period exactly. But it had gradually improved. I started practicing speaking bit by bit. It took time. Tracing back to the moment that I could not converse with my sister's boyfriend, this made a major difference to me while studying Pathom 6 . During my secondary study, I had continuously improved. My English was better. I learned from my sister and listening to English songs almost every day. I kept asking her what the particular word means and she told me its meaning. Then I asked what the whole sentence means and she suggested to me how to translate. She told me that I could ask her. Then I asked her what I should say if I would like to invite others to have meals in English. She kept telling me.

However, compared to my past, I thought my English had changed a lot. I had improved my speaking skills a lot. In the past I could speak English a little bit like Snake Snake Fish Fish. I could not string words in sentences. But as I got older and gained more experiences. I felt I was much better than the past. Recently I met up with my old friends at Hat Yai. I could converse with foreigners in English. I felt that I became a bit superior to my old friends who used to study at the same level as mine. I was proud of myself. 
However, if you asked me about my future career, it changed continuously. So far, I would have really liked to work as a flight steward. It was my dream job. I would like to work on an airplane, wear the smart uniform with a good-looking image, earn a high salary, and have a chance to travel to several countries. But I was still not "Pae"8 like that. I had read a job advertisement. They required goodlooking people with tall and well-built figures. I could not reach that point. Possibly, I wanted to be a tour guide. You could travel, talk with a lot of people and earn a lot of income. I liked travelling and I did this project "Backpack to Asian: Blog Contest 2014”. I travelled to Myanmar with other three friends. No matter what, after graduating, I would absolutely try applying for all the jobs I was interested in".

He felt that after working in part-time jobs and studying the English major, "Learning English in the classroom and using English outside are totally different. A lot of slang is used outside. But in the classroom we learn some academic content and we don't use it much in our daily lives". However, he thought that his English is better after working and speaking with foreigners. Initially he worried since he could speak English but not very well. Even though he could not understand everything and say Aha....Aha... (English phases he said with a smile), he was impressed with this experience.

However, it was just a short-term part-time job. During our interviews, the military announced martial law and demanded that we got home before midnight. I asked him whether the curfew affected the business. He reflected that this incident had a major impact on the hotel and tourism business since most parties or pubs usually finished late at night, around 1 or 2 am.

He wanted to speak like a native speaker. However, once he was asked if he thought he had done his best, he replied without hesitation.

"I did not think so. The problem was that I did not know whom I could practice speaking English with. There were a small number of foreign teachers here. If we knew foreign teachers, we could practice speaking and learn how to use lots of slang. Also, I could not listen to IPhone only because I'd prefer listening to the

\footnotetext{
8 "Pae, Thai slang, means exactly right or perfectly.
} 
living person, face-to-face. If I spoke or pronounced wrongly, they would give me some advice. There are some foreign teachers there but they teach at IC. Last semester he learned English with only one native speaker, only twice a week. "To achieve my goal, there should be five to six speaking classes. Also, I did not want to learn grammar. I thought I did not have to use all tenses in reality. Why did we have to learn repetitively?"

\section{My expectation of learning English}

"To me, English was very useful for promotion in the future. While working at TAT, I was rotated to work at the call centre and met one new talkative officer. At the moment she waited for the TOEIC results. Finally she got 600 something and got promoted as an accounting officer. I still wondered why working as an accountant required the TOEIC score. In the future I would take the TOEIC examination to apply for a job. It could prove to me whether what I learned was good enough. But I was unsure of my listening skill—only one-time listening, as I knew. I could read but some words were difficult and made me translate wrongly. If I took the exam in the future, I expected a good score. So I had to be wellprepared".

Probably this was one of the reasons that motivated him to work in part-time jobs and gradually save his money. Providing he was given a chance to trace back to his past and create a new story about himself, he may not change much since he felt satisfied with his speaking skills to some extent. In the future, he still dreamed of being a proficient speaker of English in his professional path. Hopefully it may not be beyond his expectation and control. 
Table 5.3

Summary Nott's L2 learning experiences from the past to present

\begin{tabular}{|c|c|c|}
\hline $\begin{array}{l}\text { L2 learning } \\
\text { experiences }\end{array}$ & In-class activities/tasks & Out-of-class activities/tasks \\
\hline $\begin{array}{l}\text { Present } \\
\text { (university) }\end{array}$ & $\begin{array}{l}\text { - Felt motivated to have } \\
\text { impromptu individual speaking } \\
\text { tests with his NS teacher } \\
\text { - Enjoyed studying with his NS } \\
\text { lecturer who encouraged him to } \\
\text { speak English automatically and } \\
\text { creatively } \\
\text { - Felt unmotivated to take } \\
\text { Reading course which were } \\
\text { based on textbooks and } \\
\text { overloaded content through } \\
\text { slides }\end{array}$ & 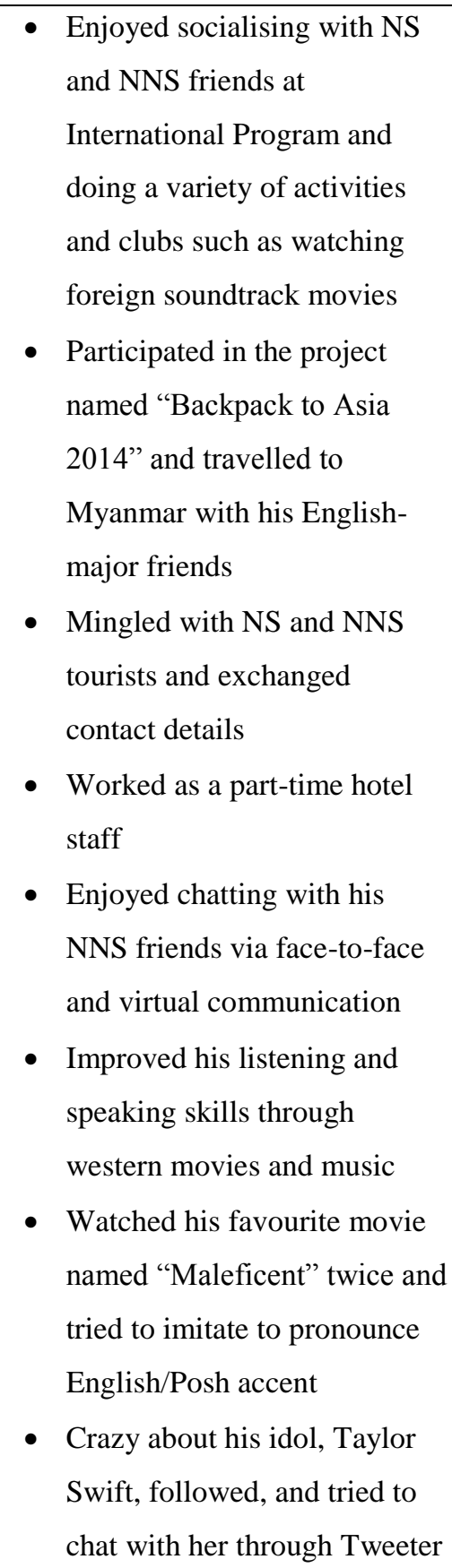 \\
\hline $\begin{array}{l}\text { Past } \\
\text { (vocational school) }\end{array}$ & $\begin{array}{l}\text { - Preferred speaking activities } \\
\text { which related to his job and } \\
\text { real-life communication } \\
\text { - Impressed with the foreign }\end{array}$ & $\begin{array}{l}\text { - Be an intern at Tourism } \\
\text { Authority of Thailand at Hat } \\
\text { Yai, his home town and } \\
\text { gained speaking experiences }\end{array}$ \\
\hline
\end{tabular}




\begin{tabular}{|c|c|c|}
\hline $\begin{array}{l}\text { L2 learning } \\
\text { experiences }\end{array}$ & In-class activities/tasks & Out-of-class activities/tasks \\
\hline & $\begin{array}{l}\text { teachers who taught how to } \\
\text { make questions by using Who, } \\
\text { what, when, where, why, and } \\
\text { how } \\
\text { - Felt unmotivated to study } \\
\text { English in a large class at his } \\
\text { school } \\
\text { - Enjoyed studying with the } \\
\text { foreign teachers who introduced } \\
\text { tapes and video to improve } \\
\text { speaking and listening skills at a } \\
\text { private language center }\end{array}$ & $\begin{array}{l}\text { with NS and NNS tourists } \\
\text { - Worked as a part-time waiter } \\
\text { and had an opportunity to } \\
\text { speak English with foreign } \\
\text { customers } \\
\text { - Participated in a one-day trip } \\
\text { to Malaysia with his teachers } \\
\text { and schoolmates } \\
\text { - Took a Basic Conversation } \\
\text { course at a private language } \\
\text { center } \\
\text { Improved his communicative } \\
\text { skills through listening to } \\
\text { western movies and music }\end{array}$ \\
\hline
\end{tabular}

\section{Rin's Stories}

On July 7, 2014, I made an appointment with the participants at the dorm of my home university. My home university is regarded as one of the prestigious public universities of which there are five campuses all over southern Thailand. This university aimed to expand academic opportunities and support long-term development in the region of southern Thailand.

However, my campus, surrounded with rubber trees, is the newest and smallest, with around 3,000 students, without any international or graduate program. Before embarking on my journey as a doctoral student in New Zealand. I was part of the implementation of the new Business English (BE) curriculum. While other campuses offer only English majors, my campus initiated and launched this unique major (BE) to tap into the undergraduates' language learning motivation to effectively use business and linguistic knowledge in their future professions. Based on the number of applicants during the first year, this program had gained considerable interest due to Thailand's entry into the AEC, 2015. Its strength is that the third-year students would be enabled to pursue overseas study either in Malaysia or China for one year. This was the first year that students from 
my university, the juniors, had a chance to study overseas and gain more exposure to intercultural experiences.

I was excited to have an in-depth narrative interview with these students in the $\mathrm{BE}$ programme. Despite having no class during summer, they voluntarily staffed the recreation team to organise freshman-welcoming activities. Both of the participants confessed to me that they felt excited to share their stories with me. Rin, the first participant I interviewed, was very eager to share with me her meaningful stories and experiences of learning English.

\section{My goals for learning English}

I would like to speak with foreigners since English is an international language which people all over the world use in their communication. This was an important reason. Particularly, "If a Farang (NS) asked and chatted with me in English, I could fluently converse with them. I felt like I was extraordinary and so proud of myself". Besides, I liked learning English since my primary (Prathom) and kept learning continuously in the secondary (Matthayom) level. To me it was fun (Sanook) to learn and use it more. However, I still had some problems in speaking. Currently, I chatted with my British friend, Tom, 19, via Facebook. During the beginning of military coup, he asked me what had happened in Thailand. I explained to him what was going on at the time. But he was puzzled and asked me to clarify some words. I wondered: "Did I make some mistakes?" Probably I beat around the bush, cautiously giving him too many details or using the wrong vocabulary. Actually, I did not have to elaborate like that-maybe, or using English in a Thai style. 


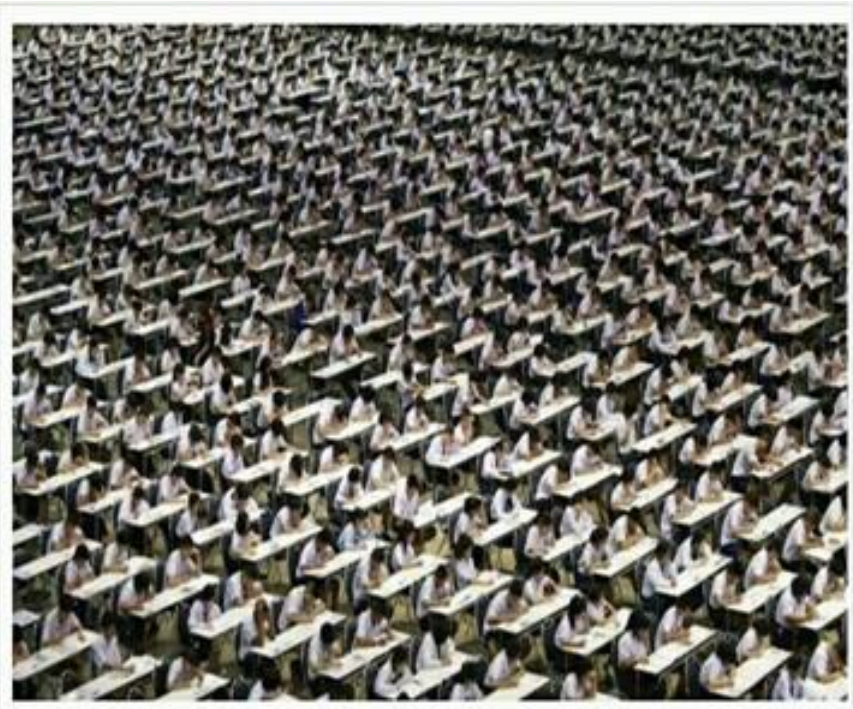

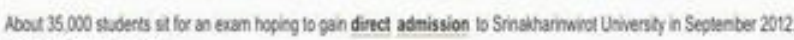
(Banglod Post fle photo)

Figure 5.4 Sitting for a direct admission

(Source:

http://www.bangkokpost.com/print/416894/)

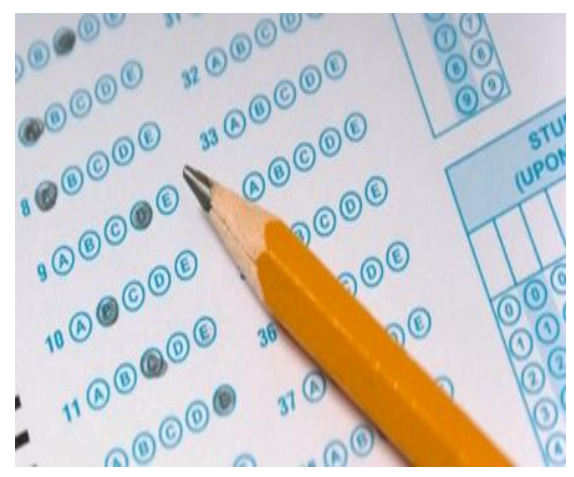

Figure 5.5 Doing a multiplechoice entrance examination

Why did I study at this small university?

Before studying here, I had taken an examination, majoring in English for Communication at the prestigious public university in Bangkok. There were a large number of students taking the written exam there because it was the first university to organise a direct admission exam (See photo). I had to travel from my hometown to Bangkok. While taking the exam, I felt very sleepy and could not really think. Finally I could not make it, but I was not disappointed. I just wanted to try taking the exam and only a small number of students, less than 100, were admitted. After that, I knew that there were some quotas (from my school to this university) during the second semester. Initially I considered two majors-Tourism Management and BE. Then I decided to choose BE because I had a chance to study overseas. This was a major reason. On the interview day, Ajarn asked me in Thai what kinds of job that BE students could work in after graduation. I replied, "Air hostess and businessperson", with a smile. Then she asked me in English whether I used to travel to Trang and how I felt when I was in PSU, Trang. After finishing the interview, Ajarn told me straight away that I was admitted. Finally I got in the quota for high-achievement students to study here. The total of my 
GPA ranged at 3.5-4.0 in average. I felt so happy that I no longer had to take the exam anywhere else. If that had not been the case, I would have to take EXAM...EXAM...EXAM. Once confirming the seat, I was not eligible to apply for other universities. Actually my friend was also admitted but waived it because she preferred to study and live in her hometown. Personally I preferred to study in this small, quiet university, instead of Songkla, my hometown, because, actually, my school and house were located in the suburbs and very far from the city so I got used to this kind of surrounding. I did not want to study at Hat Yai (the biggest city in Songkla) which was more modern and convenient because I was afraid I would end up too frequently hanging out with friends. My parents would like me to study at a public university, instead of public, to save a lot of money for them.

However, when taking an accounting course, I wondered why I had to study calculus. Why did I learn English only? To me, it was too difficult. Particularly, before taking an exam, I was very stressed and worried that I would fail it so I kept reading until 3 a.m., sleeping on a textbook. However, I understood that learning BE is supposed to relate to Accounting and Maths. I could not avoid them. My friends also complained about this. Actually, if I really did not like anything, it meant I would not want to adjust myself to its demands. However I had to read and reread it to pass through this situation. I never thought about "Sil" since it was just a few non-majored subjects. If I gave up or stopped studying too soon, it would not be right. However, a few BE friends changed to majors in Public and Enterprise Management because initially they just wanted to study overseas but they realised later that they did not like studying English.

\section{Tiring moment while studying at the university}

Whenever I felt tired or disappointed, I would think of two persons, my mom and my granddad (her mom's dad and mom). I phoned my mom, chatted and complained about what was going on, "Mom, I felt lazy, really lazy. Studying and doing activities was very tough”. My mom told me briefly but clearly: “..., you just want to come back home and tap our rubber trees instead". Her comment opened my eyes. After listening to that, I

\footnotetext{
${ }^{9}$ Sil is derived from fossilised. It is usually combined with kids/dek. The combined word, "Dek Sil" means a group of the first-year students who change their major or university due to their low performance/GPA. Some of them may perceive that they did not fit the major, were in a critical probation status, or were expelled.
} 
realised that I would rather study further, more relaxed, Sabai Sabai. I thought all parents wanted to see their children live a better life, compared to them. If I had been a rubber farmer, it would be uncertain-some days I could make money, others I could not, depending on the uncertain weather and season. That was why they would like me to get a good, secure job and salary.

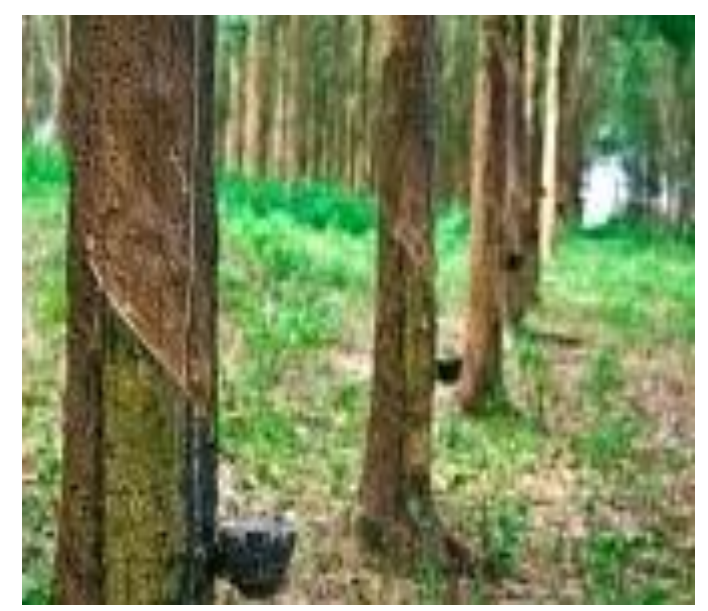

Figure 5.6 Rubber trees

My granddad also has a major influence on me in several aspects of my life. When I was a little kid, I was raised up by my grandparents. I spent most of my time with them. I felt close to my granddad. He was a clever person. He could speak English. During P.3-4 (Grade 3-4), he took me to Sand Stone Castle in Buriram province. I saw him chatting with one Farang and took their photos. I would like to speak English like him. However, he passed away and I had only my grandma. He was very diligent and thrifty. He worked as a government officer but did rubber farming when he was available. Sometimes, even now, I still take his photos with me, stare at his face, and talk to him, "Granddad, I (Noo) am so tired".

His photos reminded me of his teaching since he always read me a poem during my childhood. I still keep it at my house (She could not exactly recite all the poem while being interviewed but sent a copy of the poem to me via Line later). 


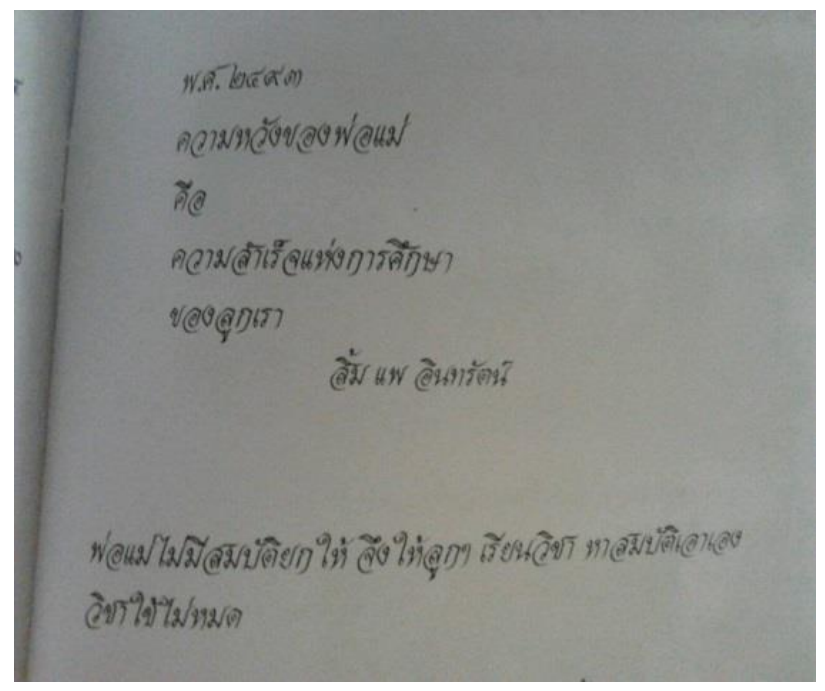

Figure 5.7 Poem

\section{Poem (In 1974)}

The hope of parents

is

the educational success

of their children

... Composed by Lim Pae Intarat

Parents have no will to give away

so support their children to study.

With this hope,

the children will earn their living

by themselves.

Education is an endlessly usable asset

which will stay with them forever.

This poem and his teaching had a big influence on me. He taught me to be diligent and economical. I was not in fashion like others. I tried to study hard not to disappoint them and get a good job so that my family would be "Sabai" in the future.

\section{Memorable experiences in learning English at the university}

I liked to study the Listening and Speaking course, which was taught by a female Thai lecturer. Her accent was good, clear, and easy to understand - not too fast or too slow. Her teaching style was totally different from what I learned during my high school. She focused on some details such as explaining how to use different words in both British and 
American styles. I liked that. She understood students, gave us homework, but not too much. I liked a teacher who was kind but a bit tough so that we felt more motivated and energetic in class. I gave you an example of my favourite class. The topic on that day was about "Going Shopping". On that day, Ajarn brought her own clothes and accessories as a prompt in our speaking lesson and asked us what we thought about them. We replied: "Cool, stylish". After finishing the class, she asked us to do a role play in a small group in class or the next period. We prepared, applied, and memorised content in a textbook. On that day, we dressed up and did a role play in front of the class. For instance, some friends bought the shirt from Korea and those earrings from England. That class was very enjoyable and colourful because the topic related to shopping. I hardly saw anyone bored. If they were, Ajarn asked some questions to keep us focused and motivated. From my viewpoint, if we did that frequently, we would get used to our classmates' eyes staring at us. The problem was some weeks, on Monday, we forgot so we had to help brainstorm, THINK...THINK...THINK...about a script and memorise it in a short period. While doing that in front of class, we forgot it but fortunately heard some whispering sounds from the friends sitting in a front row. It was fun, though. Normally, we had to memorise key phrases and structures from a textbook and need to take time to understand them. Finally we could speak English in sentences. While doing scripts, I told them: "Please memorise content in Thai, know what other friends talked about, and how it was translated into Thai. In case we forgot, we could still think about content in Thai and kept continuing our conversation in English". I thought it "worked" and my friends felt happy.

Besides, we were assigned to perform the two speaking tests before mid-term and final exams. Based on what we learned from a textbook, I created a script by myself for about one hour and then shared with my friends. While creating it, I did not ask anyone to share ideas since it took a lot of time to complete it. If they had any questions or wanted to add more information in their parts, they could discuss or add it later. The advantages of doing this kind of activity were that, besides getting a good mark, I could improve my speaking skills and enhance my bravery and confidence. I would boldly speak in a foreign accent and expressed my feelings and body language based on a real context. From my view, boldly speaking and expressing my ideas (Fully, literally translated) made my friends understand what I was doing or talking about. Ajarn liked that and complimented us. But during high school, sometimes while conversing with foreign teachers, I spoke in 
my style, but my friends mocked and nagged me. Probably they would not themselves dare to speak like that and thought it was too much. I did not care if others thought I was "Kradaae". For instance, imagine if I had a job interview in English in the future and the recruiter had to evaluate my speaking skills. So I had to speak out clearly in an English

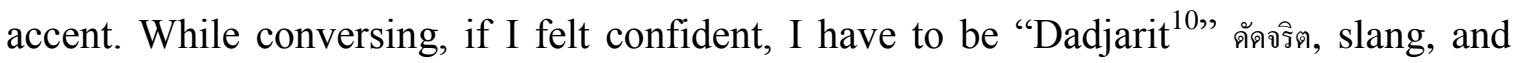
spoke out in foreign accents. To me, if it did not cause anyone trouble, I should just do it and be myself. On the contrary, it would be tasteless and sound strange if we spoke in a Thai style and stressed wrongly, like Good Morning instead of Good Morning, in English. If we spoke in the Thai style, we could understand each other. But if we conversed with foreigners, they could not understand and may puzzle over us because many words were pronounced similarly. If we pronounced some English words indistinctly, we may unintentionally mislead them. This was why they could not pronounce the consonant "L" or "R" correctly. To me, I did not have that kind of problem. To solve the problem, we had to be braver. Most of our BE friends did not have any overseas experience so they may feel embarrassed and shy while speaking English with someone. By contrast I actually dared to speak English but could not respond or communicate automatically as expected.

\section{Demotivating learning experiences at my university}

I did not have any favourite subject. I liked them all. But I felt anxious about the Reading and Writing course. I had few problems with reading. Normally, Ajarn would assign us to read first and suggest we guess unknown words from context clues and not rely too heavily on a dictionary. She told us that the less we open it, the more we could improve our skills. Sometimes I could not really guess the word so I would check in my EnglishThai dictionary to find out several words. I did that at home and Ajarn did not know. My problems were that I did not know how to pronounce a word and what its correct meaning was, since one word could have different meanings and parts of speech-noun or verb. Sometimes after finishing translating, I felt puzzled and wonder whether it should be translated that way, so I had to wait for Ajarn to give answers. In class, she would randomly ask us to translate individually. Then she summarised the key content and explained how it should be translated.

\footnotetext{
${ }^{10}$ Dadjarit (ดัดจิต, slang) means fully speak out with foreign accents. Dadjarit and Kradaae could be commonly used interchangeably.
} 
In writing class, I had to be more careful to get grammar right in matters such as article usage, gerund, and tenses. In high school, teachers would not focus much on writing and editing. But here we had to write based on the topic and pattern in a textbook, submit, rewrite our writing assignments, and resubmitted assignments. It was useful if we learned our grammatical mistakes and tried to avoid making them again. But I had to practice writing continuously otherwise I would forget. Also, the problem was that after learning a lot of grammatical rules, I had to think carefully whether I had written correct sentences with correct grammar. For instance, there is a need to put "adjective" in front of "noun". Sometimes I mixed everything up in my head. I often made changes from right to wrong ones. Maybe, there are a lot of grammar rules which made me think too much and feel uncertain whether or how to use them correctly. Most of my friends also have these sorts of problems. It was not a teacher's fault but mine. Actually the lecturer taught clearly and I could understand her well. Normally I was a quick thinker writing fast without careful checks so I made mistakes. Still, I remembered well about my embarrassing story in writing and editing class. The teacher had been correcting our writing tasks individually for some periods and maybe we made a lot of grammatical errors. So she took a break and asked us to check carefully by ourselves before submitting to her. Then she started correcting in the second round. I was the first student, walked confidently out in front of the class and submitted my task on her desk. It appeared that after she read it for a few seconds, she spoke out loud to the class: Look! Making a grammatical mistake from the first sentence! How had I checked my work? When I walked back to my seat, I felt like I badly "failed" (She used this word in English) and my face was shrunk two inches whereas at the beginning I felt very confident. Her words hit my heart. Maybe I was too confident or careless.

However, generally, I preferred to study English at the university which focused on each skill more in-depth. During my high school, I studied in the Science-Math program, not the Art-Language one, so I studied fewer English classes than others. Apart from studying in class, I participated in the English Diary Project. Initially I kept wondering whether or not I should attend this project. I felt lazy...too lazy to write and had no idea what topics or stories I should write each week. Then I thought it would be useful and better than doing nothing. I convinced them that it would not take a lot of time, simply writing one or 
a few pages a week. While writing, I did not think too much about grammar, kept writing, expressed my true feelings and shared my personal stories with my teachers. I just tried to use simple vocab. It took me only 20-30 minutes since it was very small. It might have taken time if I had some stories to share and had to find unknown vocab in both ThaiEnglish and English-Thai dictionaries. My problem was that I made sentence errors with word order and could not think of vocabulary in English while writing, so I had use both kinds of dictionaries. Still, I did not have or use an English-English dictionary since I did not understand definitions in English and had to find out more in a Thai dictionary again. To me, it was quite complicated and time-consuming. Yet, we would be forced to use an English-English dictionary this year (as a sophomore.)

\section{Participating in the English diary 2013 project}

While attending the English Diary project, I just wrote my stories in English and submitted them to teachers for correction every Monday for two semesters. After Ajarn finished correcting my diary, I would collect it from their offices at the end of that week. Then I read their previous comments and tried not to make errors again. However I learned that I still made the same kinds of errors because I just wrote it in a short period before submitting without checking much. Some weeks I had a lot of homework and forgot about writing it. However, it was useful since I tried not to make mistakes in my writing class. I also got a consolidation prize. From my view, I got it because I just wrote how I really felt while doing a particular activity, and did not "fake" (She used this word in English). I tried to be myself as much as I could. When I felt sad, I expressed my true feelings through writing. If I stressed, I talked to myself, “Keep fighting," and expressed my stressful feelings in my diary. I felt happy to do so.

\section{My profile of learning English at a temple school}

I graduated Grade 12 (M.6) from a small school located in a small town in Songkla province. There are about 400 students from M. 1-6 (Grade 7-12). The monks donated a piece of 60-Rai land from a temple to build this school. (In Thai, it is called "Temple School", for underprivileged kids or students). The school are surrounded with rubber trees and my house is not far from it. 


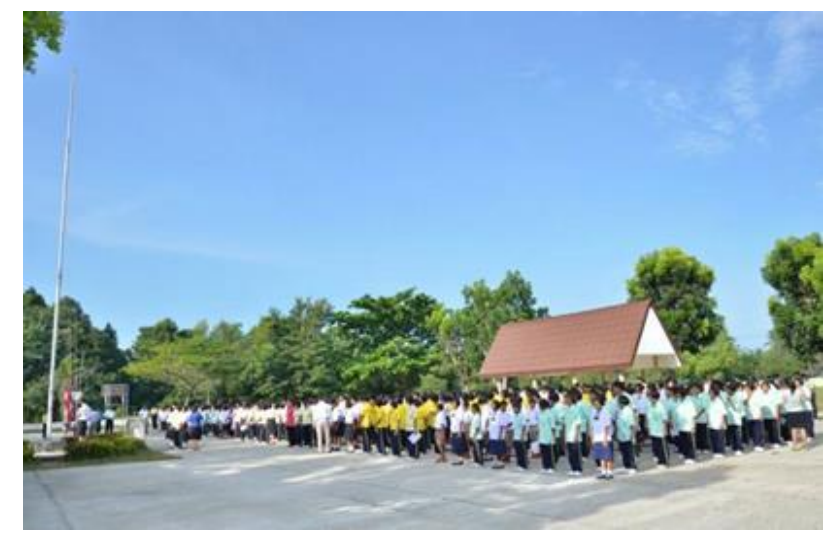

Figure 5.8 Flag ceremony

\section{In-class learning experiences at my school}

Ideally, I liked to learn in a quiet, very quiet classroom. So while studying, I could listen attentively to my lessons. I did not easily get distracted or let my mind wander. Importantly teachers are supposed to "entertain" us (She used this term in English). The weather was not too hot. Otherwise I could not focus on my study. To be honest, I accepted that I hardly had memorable learning experiences during my high school and the way teachers taught was quite boring. I remembered one foreign teacher who would teach only one period a week whereas a Thai teacher taught two periods or two hours a week. I preferred the foreign teacher. For example, in that class, she would write on a board...today we were going to travel to this place so what should we bring for this trip. Then we started THNKING...THINKING...THINKING. If anyone could not remember vocab in English, he or she would speak out in Thai first. Then we would help each other thinking in English later. We could speak a lot in class.

In contrast, studying with a Thai teacher was quite boring. When she came to class, she rarely entertained us but just kept teaching continuously and assigned us to do grammatical exercises. Sometimes she wrote some sentences in Thai and asked us to translate into English, for example, ฉันกำลังจะไป (I am going to). Then we just wrote them in English and submitted to her. Most of them were simple sentences, not complex ones so we could do that. I felt like I wanted something deeper or more difficult than that. I did not want to learn repetitive and simple contents. After she retired, a new young Thai teacher, early 20 s, replaced her but still did not have teaching experience. 


\section{Becoming a school representative for a public speaking contest}

During M. 6, I was selected to take part in a Public Speaking Contest organised by Thaksin University, Songkla. I had two foreign teachers, one was British and another was American-Japanese. After selecting me as a school representative, the British teacher trained me whereas the American one would comment on my speaking. While practising, I tried to ดัดจริต, speak and fully imitate foreign accents but the teacher commented that I did not have to stress and add too many "s" or "ch" sounds. The teacher explained it to me to ensure that I could understand and follow his/her suggestions. Then I tried to adjust it as suggested. They selected me because I was friendly and dared to approach and chat with both Thai and Farang teachers. I was asked to participate in several language activities or contests such as being the Master of Ceremony in special events such as Teacher Day. As I remember, before the contest, my foreign teachers wrote me a script which related to the ASEAN Community and the reasons why we have to pay attention to it. I had to practise speaking and rehearsing with them one hour a day, almost every day, for one week.

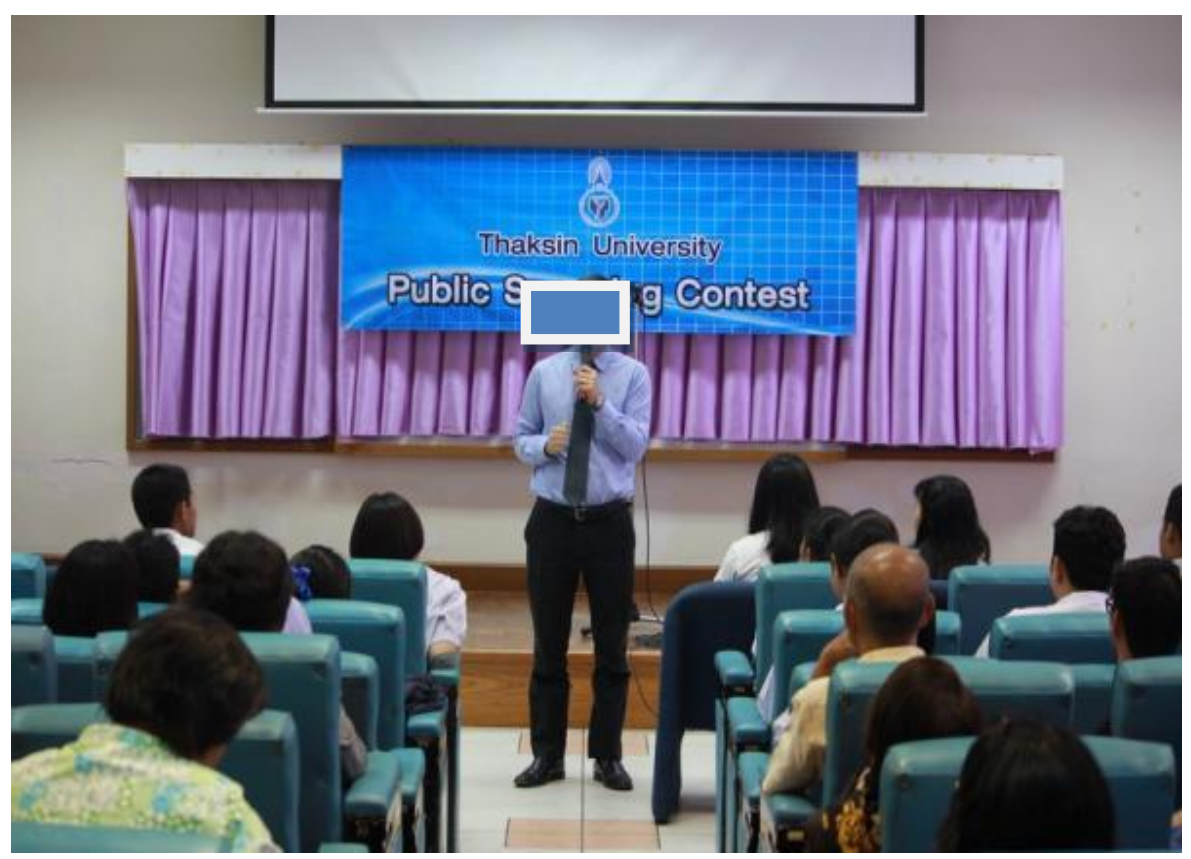

Figure 5.9 Participating in public speaking contest

On that day, I went to the university with the two foreign teachers, one sitting with me and another one taking a student to the Spelling Bees contest. Before the contest, I felt nervous, as did others. While speaking, I glanced at my palm card due to my nervousness and posed my expressive gestures as practiced. If I could not think, I smiled, glanced at 
my card again, kept speaking and moved my hands whereas some students were excellent and could fluently speak in public without glancing at any palm cards. They spoke confidently with clear voices, moved around the stage and used nice gestures. I felt like, "Wow. They were "perfect" (she used this word in English) with good accent/pronunciation." Finally I could not make it but my teacher gave me moral support and complimented me: "Very good". You know, when I saw my raw score result, I realised that Ajarn Farangs rated me higher in general, compared to Ajarn Thai. From my view, Ajarn Thais may think too much or they may have high criteria or standards which Thai students could not meet or do "Pae" (exactly right) as they expected. On the other hand, Ajarn Farangs were not serious like that. To me, beyond the prize, it was an opportunity. Even though I could not make it since there were only three winners whereas more than 40 students attended the contest, I was glad to be part of it. If I had studied at a big school, I would not have gained this kind of experience for sure. Because I studied at a small school surrounded by rubber trees, I felt thankful that the teachers gave me a chance to compete. What I had learned from attending this activity was that if I would like to master speaking like others, I had to improve much more than this.

\section{English Speaking Project 2012 at her school}

During high school, I remembered that a teacher in charge of a social subject announced at a flag ceremony that, due to the entry of AEC in 2015, the government initiated the English Speaking Day in 2012 and encouraged us to speak English every Monday. After that, for some weeks, my foreign teachers spoke in English during special occasions such as telling us the history of Christmas day and asking us some questions. We just spoke in English a bit in front of the flag ceremony. In my opinion, this policy was not fruitful because nobody monitored us to speak in English. That was why Thai students could not speak well compared to others in our neighbouring countries. We were not colonised by western countries. We had to learn English by ourselves. But we are the typical Thai people so we have to learn by ourselves. There was an inequality between urban and rural students. In the case of urban students, they would be better because they had access to better education. In contrast, rural or jungle students ("Dek Ban Nok") would struggle more since some families do not support or shape their children. For instance, children in my community are not interested in learning English. Their parents are similar to them. They were rubber farmers, hardly using English and in reality so it was not related to their 
daily lives. But because we were entering the AEC, the lack of English would cause some problems. Maybe I should study a third language such as Bahasa, Laos or Myanmar.

\section{Foreign friends from social networks from school to university}

During M.5-M.6, after travelling to several islands in Phuket, I saw a lot of foreign tourists and really wanted to have foreign friends so that I could brag/talk positively about our country. First, I searched for information and finally found the website called "Interpal". Then I started sending messages to foreign friends to greet them and finally made new friends from several countries such as China, Russia, and Poland. However, Tom, 19, a British friend sent me greeting messages first and we still keep contact until today via FB. Initially, he wanted to chat with me via skype but I did not have the program at my house. Normally we shared stories about our countries, food, travel, and sports. As a Buddhist, he was very interested in our culture and did not perceive Thailand and Thai ladies in the same negative way that others did. He really liked Thai boxing and wished to travel to Phuket once in his life (see the sample of her English language diary in Appendix J). I told him that if he travelled here, I would be his guide. He also learned Thai language and sent me a postcard with his handwriting in Thai.

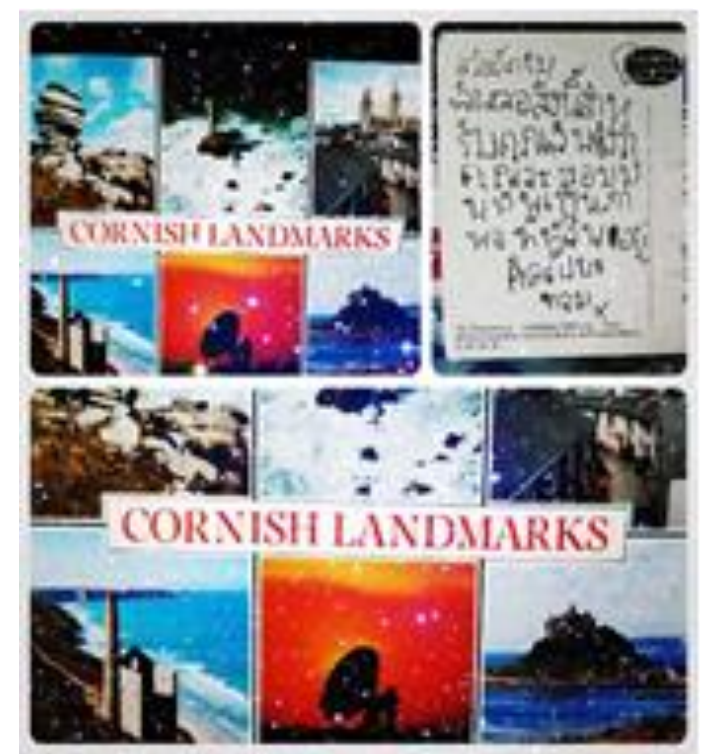

Figure 5.10 Receiving a postcard from her British friend

During my high school, I sent him a few pieces of my writing assignments via $\mathrm{FB}$, and he made some corrections and gave me suggestions. If I had any questions about English, I would ask him for advice. But sometimes it was quite complicated due to different time 
zones and I had to wait for his answers quite a long time. However, it was useful since I could make friends with him, and we could chat, share experiences, and help each other.

\section{Thai-Malaysia partnership from school to university}

In relation to the AEC entry, my school has established a partnership with a Malay school so we had a chance to have a field trip there and did a lot of cultural activities together such as performing traditional dances and playing sports. While travelling there, if my friends did not understand English, I would interpret from English into Thai to them. Malay students also visited our school. We had memorable experiences sharing languages and cultures.

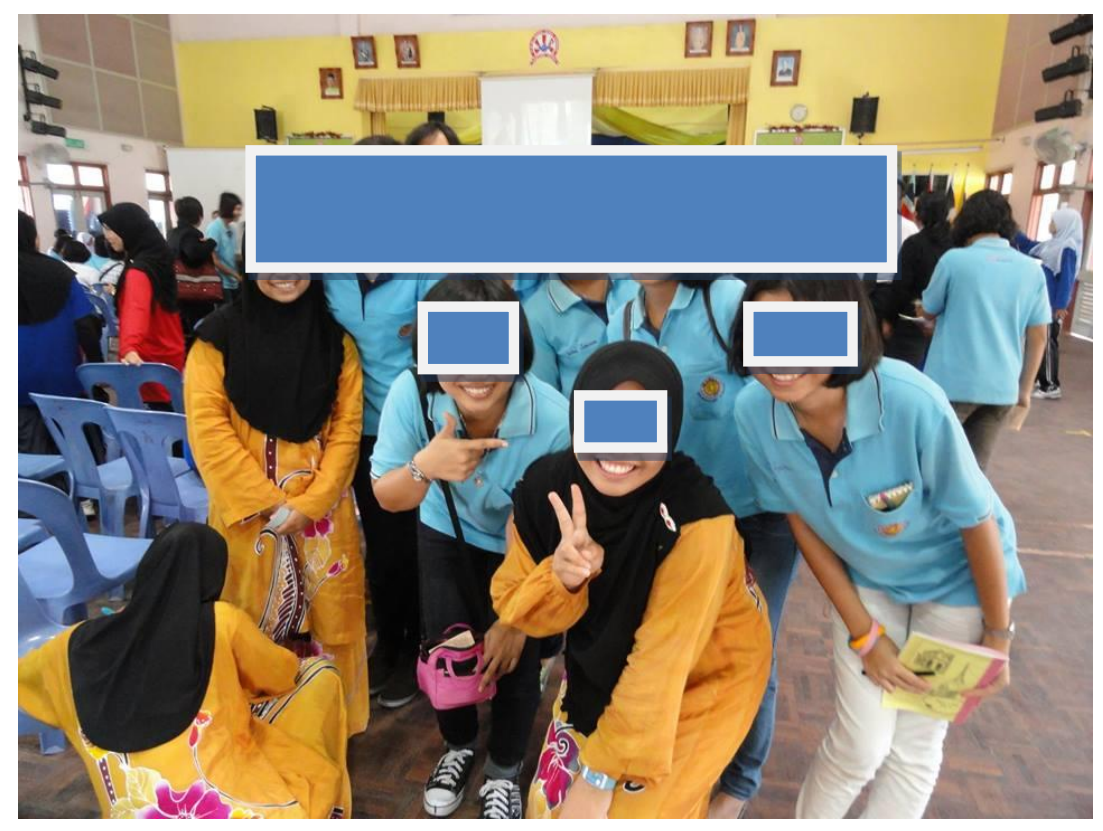

Figure 5.11 Visiting a Malaysian school with her teachers and schoolmates

My dream of studying overseas would come true. In my third year, I would have a chance to study in Malaysia. My priority was to communicate with them and understand their accents. At the beginning, we may still chat with our Thai friends using one Thai word and one English word style. But after that we could make friends with students there so we could learn language and travel together. Last year, a group of lecturers and students from a prestigious Malaysian university visited our campus and gave us an orientation which assisted us in adjusting to the new academic environment during my third year there. While sitting at the auditorium, I chatted with Chinese-Malay students sitting next 
to me. I wondered and asked them whether most of the students there could speak English. They replied, "Yes." I could understand their accent quite well-not too difficult. But my problem was that I could not fully listen to and understand the lecturers who guided us through the instructions, rules and regulations. They spoke very fast so I just quickly looked over content from the power point slides instead. However I would try to practice listening more. From my view, even though their accents are different from the native speakers, we could communicate and understand each other. We have to communicate and understand them whereas accents/pronunciation could be trained.

After studying here for one year, I thought I had made a right decision. I chose what I liked and what suited me the most. Normally, if I was passionate for something, I would be happy to do it continuously. Next semester, I would enrol for seven major courses in English. I imagined myself sitting and working on a pile of English textbooks, supplementary sheets and assignments. I would try to study harder. To me, as an Englishmajor student, gaining good grades in English was very important. If I got a low score or less than half, it would reflect that I could not achieve my goal or show my lack of understanding of key content or English proficiency. Thus, no matter what, I would try to do my best.

\section{My aunt has motivated me to learn English}

My aunt had a major continuing influence on my L2 learning. Up to now, if I had any questions about English usage, I sent her messages or made phone calls. She graduated from our university in a different campus, majoring in Chinese and minoring in English. Currently she works in the Department of Foreign Business at a bank. During my Grade 1-6, my aunt initially bought me cartoon CDs. While watching movies with her, I had to listen to English soundtracks and read Thai subtitles. The first one was Stuart Little. If I could understand, I would SPEAK...SPEAK...SPEAK and imitated an original. If not, I would read Thai subtitles instead. Initially she suggested that I watch cartoon movies because it was easier to catch up than watching action or fantasy ones. Then I started doing that. While watching, she imitated pronouncing some words to me and I just nodded. But I tried practising later. Sometimes during my childhood, I watched movies with my elder sister at my house. After listening, I jotted down what I heard and wrote transliterations. I often did that as a child. I did not know why I did that. But I felt happy. 
Nobody gave me any compliments. I did that alone or with my elder sister. Then, at school, I just said that in English with my friends but they did not understand what I said. I felt good, anyway. Also, I liked watching romantic comedy movies. During my high school, I bought fairy tales books with listening CDs inside at a bookstore. Then I imitated pronunciation and read out loud...once upon a time. It was Sanook (fun) and partly helped me improve my English. When we really liked doing something, our passion would shape our behaviours progressively. I liked imitating sounds from what I heard and felt proud of doing that.

\section{My language learning motivation}

In terms of priorities, I rated speaking first, then listening, reading, and writing. If we met anyone, we had to converse with them first, listen and understand them. Also, we had to read and understand. If we made little mistakes, they could still understand us. But if we said something wrong, they could not understand us. Based on my capabilities, I rated reading first because I could read and understand better than speaking. I hardly ever spoke English with anyone in reality. Sometimes I used to chat with friends in English but could not remember vocabulary and speak automatically so I had to speak Thai. In class, we did not speak English frequently. Although I chatted with foreign friends via Facebook, sometimes I preferred typing to speaking. I kept smiling and typing instead. Maybe I was embarrassed with guys. In case of chatting via typing, if I knew that I made some mistakes, I was still okay, not that serious. But in case of a "face-to-face" (she used this word in English) communication, I would feel embarrassed if they did not understand. Perhaps I was not familiar with their accents.

Tracing back to my past, I started learning English through reading and transliteration by comparing Thai vowels and consonants to English ones. I had to memorise, and practise reading and pronouncing words from a young age. I tried to read fluently and constantly since then. I did not have a chance to speak much. If so, I spoke only formulaic sentences. That was why I was still not satisfied with my speaking skills. When I wanted to speak, I could not think and speak automatically. That was my problem, despite that fact that actually I knew the meaning of vocab I would like to say-probably due to my embarrassment as well. I felt embarrassed since I had to converse with the owner of the language or native speakers. When I made some mistakes or they did not understand what 
I said I felt like I had done something wrong or I had to correct them, like this...like that. Did I make some mistakes? That was why I tried to make it short and easy to understand. I did not chat in long sentences-I was not that good. The solution was to building my confidence. If you asked me if I tried to do my best, I did so. I was attentive while learning and revised lessons before taking exams. But if you asked me whether I actually did my best, I thought probably not. In term of autonomous learning, I should have studied by myself more than this. Sometimes, if I wondered or puzzled over anything, I would search for YouTube teaching video clips from the internet such as the ones taught by Ajarn Adam. One of the foreign teachers opened his clips in class when we did not understand some lessons or got bored in his classes. I liked that but I did not have internet/Wi-Fi at my house. Also, the signal at my dorm was very slow. That was why I preferred the teachers or experts to teach me because I did not want to search for information by myself and randomly guess whether it was correct. Also, my problem was that I always wondered about things that others did not. If I watched teaching clips and had some questions, no one could give answers right away. So that meant that I had to keep wondering. That was why I preferred to learn and interact with teachers.

From my viewpoint, if we would like to have a lot of life experiences, get a good job, and travel around the world, we have to open up, learn new foreign languages - second or third languages. There is nothing to lose. However, the question was to do with the fact that that we had learnt English from the primary to university level, right? It was unusual for us to speak English even a little bit. To me, it was a negative aspect of our educational system. Maybe because we had not been shaped since our childhood about why we had to learn English and what it was used for. Perhaps some people may question why they had to learn and feel unsure whether they would have a chance to use it or not. Others may think that learning English was difficult so they stopped learning. Each student had different background knowledge. But I liked learning English.

\section{My ideal jobs and TOEIC}

During my childhood, like other kids, I dreamed of being an airhostess, wearing a beautiful uniform and make-up. But my height is only $156 \mathrm{cms}$ so I stopped dreaming about it when growing-up. After that, I dreamed of being a guide. I would travel around the world and use English with them. To me, it would be challenging if we could 
communicate with people with different accents, visit several interesting tourist attractions in each country, and learn their cultures. Besides, during M.6, my school took me to a field trip at an aviation control tower in Hat Yai. To work there and meet their requirements, I will obtain high TOEIC scores, ranged at around 700-800. To me, I admire anyone who passed it at that level-I supposed them to be an awesomely clever person. I have never tried taking an exam. But I just examined some very thick practice test books at a bookstore and I think they were difficult. I am still unsure about my capabilities at the time since I had never tried taking an exam yet. Probably I will get a higher score in reading than listening since, as I knew, we have only one chance to listen to a tape. But I have never listened to it before and may not get used to foreign accents. I am not ready now but if I plan to take an exam to work there, I will have to prepare my reading from now on to the fourth year.

\section{Table 5.4}

Summary of Rin's L2 learning experiences from the past to present

\begin{tabular}{|c|c|c|}
\hline L2 learning experiences & In-class activities/tasks & Out-of-class activities/tasks \\
\hline $\begin{array}{l}\text { Present } \\
\text { (university) }\end{array}$ & $\begin{array}{l}\text { - Felt motivated to do role- } \\
\text { play activities and speaking } \\
\text { tests with her peers } \\
\text { - Preferred doing the scripts } \\
\text { and using the rote- } \\
\text { memorising strategies } \\
\text { - Felt confident to speak } \\
\text { English and do not care if } \\
\text { being perceived as Kradaae } \\
\text { or Dadjarit } \\
\text { - Preferred to study English at } \\
\text { the university which focused } \\
\text { on each skill more in-depth } \\
\text { - Felt puzzled in translating } \\
\text { some reading passages } \\
\text { - Lost her face and confidence } \\
\text { because of making } \\
\text { grammatical mistakes in } \\
\text { writing class }\end{array}$ & $\begin{array}{l}\text { - Participated in the English } \\
\text { Diary } 2013 \text { project } \\
\text { - Enjoyed chatting with NS and } \\
\text { NNS friends via Skype and } \\
\text { Facebook frequently } \\
\text { - Kept in touch with her British } \\
\text { friend, Tom, from school to } \\
\text { university }\end{array}$ \\
\hline
\end{tabular}




\begin{tabular}{|c|c|c|}
\hline L2 learning experiences & In-class activities/tasks & Out-of-class activities/tasks \\
\hline $\begin{array}{l}\text { Past learning experiences } \\
\text { (high school) }\end{array}$ & $\begin{array}{l}\text { - Felt demotivated and tense } \\
\text { to learn complicated } \\
\text { grammar rules (e.g., if- } \\
\text { causes) for quiz and } \\
\text { examination without real } \\
\text { understanding }\end{array}$ & $\begin{array}{l}\text { - Being selected as a school } \\
\text { representative of Public } \\
\text { Speaking Contest } \\
\text { - Being trained by two native } \\
\text { speakers on how to pronounce } \\
\text { English correctly } \\
\text { - Joined a one-day trip to } \\
\text { Malaysia } \\
\text { - Searching for foreign friends } \\
\text { via the website called } \\
\text { "Interpal" and started chatting } \\
\text { with her NS and NNS via } \\
\text { virtual communication }\end{array}$ \\
\hline
\end{tabular}

\section{Chi's Stories}

I made an appointment with her at the dormitory of my home university in the afternoon of June 7, 2014. Similar to Rin, she was friendly, active, and engaged in the Freshywelcoming activity during summer break. However, she revealed that initially she worried about having the interview since she had never experienced it before. Nevertheless, after she was convinced that it would not be that difficult and she could freely share her own stories and visions of learning English, she felt relieved and smiled. She is an articulate participant who moved from her hometown to major in Business English at my home university.

\section{My goals for learning English}

Firstly, I would like to study Business English (BE) for a career to expand my parents' business in foreign countries. Currently they are in the frozen seafood business, only in Phuket, not export. But I would like to run our business like PFP (Pacific Food Processing Company, Thailand's leading company exporting frozen seafood products locally and internationally). My brother and I could help to grow our family business in the foreign market. After taking business courses here, I started thinking and chatting with my family at home while having dinner. My parents, who could speak English, were neutral/indifferent, and did not pressure us to expand our business overseas. I made a decision by myself. I just initiated the idea and chatted with them. 
Secondly, I would like to speak English fluently since I could not speak out and catch the word when I met and listened to Farangs/foreigners. Also, while speaking, I could not use the words I wanted to express. I could not speak fluently. I sometimes stopped speaking, and always kept quiet. I could speak a little bit. But if you asked me to tell a story stringing long sentences together, I could not do that. Perhaps I may not feel familiar with "speaking Farang" (Literally translated).

[While transcribing and translating her field notes, I felt like we have so many things in common and I would say her stories could mirror my L2 self-identities in several aspects such as being influenced by familial expectation and taking extra courses in English since my childhood.]

\section{My profile: Private English classes for university entrance exam}

As I remember, I did not like learning English during Grade 2 because I had negative experiences with my English teachers. Initially I felt pressured and stressed so I could not fully focus on studying. For instance, when assigned to do homework about simple grammar/tenses, I could not get it right. I remembered well that Kru (Teacher) hit me. I did not want to study this subject and do homework. I did not catch words and understand her at all. It was too fast. But my attitude changed when my mom took me to have a private course in English with Aunty Ya. Firstly I told my mom that I did not want to do so because I did not like it and could not understand it. My mom suggested that I had to already take an extra class in maths so could just continue learning English further since a location was quite close. I had to take it then. Once I took the class with her, I liked the way she taught us - explaining slowly, step-by-step, emphasising key words, and proving easy to understand. There were about ten students in the class. If anyone did not understand anything, she would teach us individually. I studied with her the longest, from P.3-M.3 (Grade 3-9). I learned many things such as grammar and vocabulary. I realised that learning English was not that complicated. I noticed that my grammar was better than other friends during high school. Studying there was fruitful. I did not credit any teachers there since I had no memorable experience. The reason I did not study with her further was because my parents started talking about the university admission exams so I decided 
to study at famous English tutoring centres in the Phuket branch. Most of my students took extra tutoring classes like the ones in Bangkok. I studied in rerun VDO courses with the popular tutor of the country (Normally she recorded her live teaching from the headquarters branch in Bangkok and distributed tapes to other branches nationwide). The advantage was if I missed any classes, I could attend them on other days freely and as I wished. However, she spoke very fast. Finally, I could not complete the whole course and stopped halfway through. To me, taking extra courses was necessary since it could widen our knowledge. In my view, taking extra classes could help us save time. We studied, understood the contents, and spent only a short period. When learning by ourselves, we had to spend a lot of time searching for information and we did not know if it was really correct.

\section{Negative learning experiences at my high school}

When asked about memorable experiences at high school, I automatically want to say, "No", but I can vividly recall many stories of negative experience. For instance, on one day, during M.4, the teacher came to class and told us she would teach us how to use "if clauses" and we would have a quiz at the end of the class. I thought to myself, "What? Crazy?" The topic itself sounded difficult and I felt it was worse than normal. The worst was that we had to do this quiz because she wanted to accumulate scores for us before our mid-term exam. This was quite unusual since it was only 50 minutes a period". It happened only once, though. Then she started teaching the three types of using "ifcauses" writing on a board and taught/spoke very FAST...FAST...FAST. Normally she spoke very fast but on that day she spoke faster since we had the quiz after that. Other friends and I could not catch the lesson at all. While teaching, she would write on the board and explained to us about each type of "if-causes" by giving examples based on a textbook. I did not read it in advance because she did not follow the chapters in sequence in the textbook, "flip and flop teaching" (literally translated). She never told us before about this - just telling us on that day. That was why I remembered vividly "deep in my heart" (literally translated), learning "If-causes". After studying for 30 minutes, we took a 20-minute quiz. In a 40-item exam, the subjects were provided and most sentences were short. We had to change a verb to the right tense in a blank given. Finally I got 21 and then it was divided by two, a full score of 20. If you asked me about the advantages and disadvantages of taking the exam, I thought it made me more active and energetic to read 
and revise lessons but I did not understand lessons and key contents. If we had the exam tomorrow, I would keep reading. It would be better than just learning without any assessments. Some teachers spoke very slowly which made feel sleepy sometimes, but not all periods. I sat in front, put my head on a desk, and closed my eyes. Normally it would happen after having lunch. I felt full and asleep. But most of my classmates liked chatting and made noises. Only a few students took a nap in class.

\section{Admission Examination}

I had taken an admission examination at a prestigious university in northern Thailand. My school seniors suggested me that majoring in English, International Program there was awesome and academically rigorous. I wanted to try and study there despite locating in the north and far from my hometown. After graduating Grade 12, my two friends and I took the admission examination organised by the particular university or "direct exam". At that round, about 700 students sat for the exam but the university admitted only 60 . Suppose today I took an exam, tomorrow the result would be announced. After finishing I was not sure anyway because there might be many people better than me for sure. I was not sure if I was significantly equal or inferior to them. Finally I passed it but my friends did not. The university screened 400 students for the interview. The moment I knew the results, I felt numb, excited and proud of myself. This was the first time I took an important exam in my life like this. Then I had to have the interview next morning. On that day, the staff gave me a queue number and I sat with all the students in a big auditorium room. They would call us, a group of ten students, to have the interview in the other room. I got a queue number, ranging from No. 30-40 in the morning session. In the smaller room, there were about ten tables and two lecturers for each. While sitting there under the air conditioner, I felt very cold. When they called my name, I introduced myself in English and felt very nervous because I had never been interviewed in English before. They asked me why I was taking the exam there despite living in Phuket (the south). I replied that majoring in English there is cool. My voice was shaking...so shaking. I started sweating. I could not speak out initially...then spoke haltingly. I had never done this before. They asked me another question what I should do if I stayed at a dorm there and had some problems with my roommate. I could not get it right. I just gave them a short answer that I would move my room, just only this, due to my nervousness. Then they said, OK. That's it. I knew right away that I had not made it. It took about five 
minutes. Actually I took my port (portfolio) there but they did not ask me to present it. But here at PSU, Trang, the teacher asked me to do so and I also submitted my portfolio which represented the school and extracurricular activities I had done during M.4-6, for example, I had taken part in the Southern Spelling Bees 2012 contest at one southern public university. But I passed only the first round. After one month, the result was officially announced and I had failed. I was so disappointed. I could not make it. I passed the written exam but could not succeed. I did not fully do my best. But I did not know what else I should prepare for, besides introducing myself. I had no experience of taking an interviewing test before.

\section{Majoring in Business English (BE) at the southern public university}

Currently I am majoring in BE at PSU, Trang campus. Actually I submitted my score at PSU, Trang campus twice. Firstly, I applied in the quota round for the 14-province southern students. But I failed it because my scores did not meet the criteria. (The written exam was prepared and sent from PSU, Hat Yai campus.) They admitted only 30 students. I was disappointed because one of my close friends passed but I did not. I tried again in the second round by submitting my GAT-PAT score. I came here for an interview exam and the teacher asked me what country I would like to pursue my study in. I replied, "Malaysia". In this round, 20 students were admitted for this major and I finally passed it. But I was not that clever. Probably there were a small number of students submitting in this round or most of the clever students were accepted already in the first round. Initially, I was interested in Tourism, International Program, in Phuket. However, I preferred to study here since I have an opportunity to study overseas and the tuition fee is not costly (less than NZ\$ 1,200-1,600). It would be worth more. I knew about this curriculum from a manual provided when I took an exam in the first round, the 14-province quota. I did not talk about this with my parents. I chose it by myself. When my parents knew my results, they were delighted but worried about me since I had to stay away from them. After taking courses here I felt disappointed because I had to study several subjects I was not good at such as maths and accounting. I did not understand why I had to study them despite having chosen to major in BE. Why didn't I study only language? I started thinking about "Sil". I often heard about this word and realised it was quite normal as a university student but I did not want to become "Dek Sil" or waste my time. 
I worried that I had not passed the examinations. I was stressed and under pressure so I phoned my mom and told her, "Maths was tough. Accounting was tough. I failed the means (literally translated)". She consoled me, "No worries. Just study these two subjects only". Then I chatted with friends that I was afraid of being "Sil". But they also consoled me, "Don't worry. We will give you moral support and tutorials. Actually we just have to learn math and accounting this year and semester, only this year. You just have to put up with learning them for one year". Even if I did not understand these subjects, I kept fighting and everything was better, from 2.5 to 3 something. I surmounted these obstacles because of my mom's and friends' moral support. However, in my view, it was quite competitive in my first semester because sometimes, while studying, I asked my classmates about content I did not understand. They just told me, "We do not know either". At the end, it appeared that they got GPA 3.00 something. I wondered why they told me that and I started realising that I had to compete with others.

\section{Memorable in-class learning experiences}

My favourite course was Business Grammar. Initially it was still easy and gradually became more difficult. We not only learned grammar but did role plays as well. Our British teacher assigned us to do two projects: a three-minute individual speaking test with him and having a four-minute pair dialogue. But there was one student left in class so my group had three persons. For my first task I had to suppose that I was an employer and Ajarn was an employee. I had to talk and persuade him to work with me. Ajarn would determine what chapters in the textbook and what tenses could be used in the dialogue. I was an owner of this brand (She used this word in English). I had to convince my friends to work with me by offering them a lot of fringe benefits and no pressure. Each student would be given the topic and had to think more about it. Initially, I did not remember everything. I wrote my script but Ajarn told us that we had to memorise it all and speak to him naturally. So I tried to imagine that I spoke in a real scenario. Suppose that I had a speaking test tomorrow, I would memorise and recite it three to four times, only one day before the test. On that day, I sat and chatted with him in front of the class. Initially, I felt very excited and my voice was shaking. After speaking halfway through, my voice became normal. And I could remember it all-"Pae", nothing was different from my prepared script. I had a dialogue with him—only two of us. My friends did not pay 
attention to me because they were memorising and reciting their own scripts. For the final role play assignment, our role play would be a conversation at the office between a new recruit employee, aged 30 years old, and a boss, CEO or Managing Director, aged 50 years old of the company. My friends and I helped to share ideas and create the dialogue together. We brainstormed about questions the new recruit could ask from the boss and what was expected from the boss. Also we prepared reasonable answers to tell our boss about ourselves, our work experience, or related training. We would try to apply grammar that we had learned to our conversation as much as we could from our textbook. I acted as a boss and had to memorise that part whereas my friends who acted as a newly recruited officer had to prepare their parts. Finally we practised making a conversation together.

I liked these assignments because I could speak English more. It was different from what I had done at my school. I enjoyed learning grammar with the foreign teacher. Previously I thought that learning tenses made me tense since it was very difficult, but actually it was not difficult and I could apply them in my dialogues. Also, I liked learning with him because he was kind and did not put us under pressure. He made us learn happily. Sometimes, he applied "magic tricks, real-life activities, video clips" to motivate students before beginning his class or when students got bored. I did not have any negative learning experience with him. During the final exam, as I remembered, I thought I tried to do my best and put a lot of effort into this subject by repetitively reading and revising several chapters. The major reason was that I had not learned with a foreigner in a formal context before so I had no idea if he "presses" the grade (a tough grader) or not, whereas I took the other two English courses with Thai teachers. To be honest, I preferred to study with Ajarn Farang since they taught "Chill Chill” (Teenager's slang: sanook, relaxingly) while most Thai Ajarns were quite strict. However, I only improved a bit (10-20\%) since I was not regularly exposed to speaking, only two days a week. I thought it was not enough. We should have spoken English every day.

Personally, I did not like speaking in front of the class since a lot of my classmates stared at me. I felt so anxious that I could not memorise my prepared scripts. I had to memorise them because I had to prepare our script with 4-5 other friends as a group work. For instance, at the time, while taking a final speaking role play in front of the class, my friends asked me a question. Suddenly my mind was blank and I stood puzzled, froze, and 
said Um...Ah... for a short period. Then one friend in our group helped me solve the problem by answering the particular question instead of me. I felt my major problem was my nervousness while speaking. Speaking English everyday would be a possible solution and it would gradually improve, I think. Or we should have taken at least two classes a day. I would try anyway.

However, I also liked writing but, in the writing class, I realised that I made many grammatical mistakes and corrections whereas some of my friends were very ready to write and good at it already. I noticed that from the moment a teacher asked us to summarise reading passages. They could complete the task in a short period while I thought to myself, "Had they done? Had they submitted the task?" Even if I felt confident and rate it as most important, I could not do as rapidly as them.

\section{Out-of-class learning experiences}

When asked about outside classroom experiences, I did not have enough time to do any. When I woke up, I went to study. After that, I went to sleep at my dorm. I was so tired. I had to do a lot of assignments in the first semester and a lot of activities in the second. I hardly had my free time. However, I saw some of my university friends chatting with foreign friends. One suggested a website so I tried entering online chat rooms. Firstly, I met a lot of bad people from different ages who chatted for other sexual reasons. Then, I had one good Chinese friend. I asked him for his Skype. We practised English by chatting. He was 21 years old, working at the petroleum company. But I could not remember his hometown and its name did not sound familiar to me. Normally we chatted about general matters, travelling, and current news. I invited him to travel to Phuket, my hometown. Recently he asked me about political unrest. He asked me, "How about our country?" He felt unsafe and scared after watching global news broadcast. I replied to him, "No worries. It did not happen all over the country". After chatting, I felt like I felt more confident to practise my speaking in English. To me, his English was average. I noticed he used basic vocabulary and his accent was normal, similar to me. I could speak as who I am. I did not feel inferior. We were not different. 
Sometimes, I downloaded music and foreign movies. But initially I did not understand the songs I listened to. It was fast...too fast. I could not catch key meanings so I opened the Youtube and selected the ones with lyrics. But I did not do it frequently.

\section{My aunt, my role model for learning English}

Normally my parents were not available since they had to run the business. When I was free, I would visit my 40-year-old aunt. She had a major influence on my learning English in several ways. She always told me that I had to speak English since I was young. Previously she worked at the Gibbon Rehabilitation Project in Phuket. Each month, there would be a lot of foreigners rotating and working as volunteers such as British and Scottish. Before working, she told me that she could not speak English, just opened the dictionary and jotted down unknown words in her note books. However, she had a chance to work with a lot of foreigners for several years and learned English through that. Finally she could speak English and had many foreign friends. Occasionally she tried to take me to her foreign friends' parties. However once I was there, I just sat and kept quiet. I did not know who I would talk to and what I should say. Probably I was still young, only nine. Recently I went to the Christmas party with her. I kept quiet and played with kids instead of speaking English as my aunt suggested. I was very shy and not familiar. I only chatted with kids and Thai people. But she just chatted with their friends. I wanted to have foreign friends with different nationalities like her. To solve this problem, I determined to approach foreigners more. Last semester, when studying with one British teacher, I sometimes asked him the questions I did not understand about my assignments. By doing that, I felt more confident but did not do it frequently.

During M.5-6 (grade 11-12), while sitting in my aunt's car, I listened to foreign music. I liked its beautiful melody, like Thai music. Sometimes she asked me what movies I liked-Thai or soundtrack movies. I tried watching soundtracks once and it appeared that I did not understand them at all. After that, I downloaded them from the internet for free. Mostly I watched cartoon movies and the first one was Tinkerbell (She pronounced "Jingabell" in Thai.), Disney Fairy Tale. I thought it was not difficult to listen, and I could learn new vocab. Then I started downloading cartoons and animation. Usually I saw them once and did not rewind them. 


\section{Volunteer at the gibbon rehabilitation project}

My aunt suggested I work as a volunteer during summer at the Gibbon Rehabilitation Project at Bang Pae Waterfall, her previous workplace. Currently my aunt works as a coordinator at reception with foreigners at a ferry dock in Phuket. I worked part-time there because of her. My duties were to give out leaflets to local and foreign tourists. I gave information about the project and showed them around the site. Sometimes foreigners asked me some details, such as project profile and a number of gibbons there. Maybe they wanted me to chat with them. Initially I felt nervous and blank and I could not speak out. I just took them to a directory board and read some information to them. I felt like I could not improve my speaking skills much, saying the same thing for two weeks. However, one Farang suggested me that "If you practise speaking English every day, one day you could finally speak English”.

\section{Integration of AEC in 2015}

When we entered AEC in 2015, English would become crucially important. We would have to do business with neighbouring countries. If we did not speak, listen, and understand it, it would not be successful. Anyway it might not be good for Thai people because most of us could not speak English. I knew that since working as a volunteer at Phuket, I heard Farangs chatting with their friends and commented that Thais were afraid of speaking English. So I wanted to learn it more. Our country was close to Malaysia and I would study at the prestigious university in my third year so I would learn a Bahasa language as an elective subject in the next academic year. If I studied in Malaysia, I hoped I could speak English every day in my daily life. Before that, I had learned Chinese since Matthayom 2 at the public provincial school because initially I just followed my friends. Then I felt like it was not difficult so I kept learning until Matthayom 6. But I hardly used it now so forgot some. In our university, I did not think we were well prepared since students majoring in BE and tourism were mostly interested in English subjects (while other students from other faculties may not). From my view, Thai students could not speak English despite studying it for ages because we do not familiarise ourselves with foreigners. Most Thai students hardly used English at home. I would give you one example of my friend who had a stepfather as a foreigner. She had spoken English every day since she was young so she could communicate it fluently and automatically whereas we could hardly do so. She did not have to struggle to study 
speaking it like me. Although we were in the global media world, we hardly used it in our daily lives. It would be better if we had a chance to speak in a face-to-face communication/real context. We could frequently chat with them and listen to their accents in reality. If I had the chance again I would have familiarised myself with foreigners more than this, perhaps, since I was young. I should have taken the International Program (IP) since M. 1 (Grade 7) since my parents asked me about that, but I preferred a Thai program at that moment. But probably if I could retrace my steps I'd have been better to have studied IP. I did not want to speak haltingly like this.

If you asked about the government policy entitled "Speaking English 2012" as I remembered, while studying Matthayom 5 (Grade 11), a school teacher announced at a flag ceremony that, due to the entry into AEC in 2015, we were encouraged to speak English more frequently. I think it did not work. At the flag ceremony, one leading student spoke Thai words and switched to English words or "Speak one Thai word and one English word"11. But they did not ask us to say anything. To me, it did not work because the only ones who could understand listened to him/her whereas most students could not understand. I could listen and understand a bit.

Based on the priority, I rated speaking first, then listening, reading, and writing. First, speaking. If Farangs chatted with us, we could not speak any word. Period. Secondly, listening, if we conversed with them, we could not catch the words and reply. They may assume that we could not communicate with them. However, when you asked me to evaluate my capabilities, I rated writing, listening, reading, and speaking, because I did not like speaking. I did not dare to speak. I was not confident while speaking. It would take time for me because I was a shy person.

\section{My ideal jobs and TOEIC}

When I was a child I wanted to be a guide, since I saw a lot of tourists taking ferries at the port near my house. To me it would be awesome if I could travel around the islands and use English at the same time. There were still many tourist attractions and islands I had never been before. But as I told you, I did not like studying English during my childhood. My language learning motivation had been continuously changing, as I told you, and my

\footnotetext{
11 "Speak one Thai word and one English word" is commonly used to illustrate that some Thais always switched between two languages while speaking to make them look cool and educated.
} 
future plan also changed once studying here. After graduating, I would like to pursue my study in International Business, like my brother, at a local public university. The reasons that I would not pursue my study overseas were that I was afraid and not sure if I could stay alone and survive there or not and wondered how I could sort things out if I had any urgent problems. I just "Mano" 12 by myself, but next year I would study overseas with my friends at UM, and could stay there safely, I reckoned. Actually, my dad told me he would financially support me to study overseas. If so, expenses of our family would be costly. My parents had to pay a lot of money for our studies, three of us. My siblings were still studying; one elder brother has just graduated from the same university, majoring in Marketing and was currently pursuing his Masters in International Business. My younger sister was only nine years old, studying in P. 4 (Grade 4) at the international school in Phuket and her tuition fees were very expensive. After graduating my Masters, I reckoned that I would start working at other companies first so I could learn how to run their business from them and apply what I had learned to ours. Particularly, if I communicated in English effectively, it would be my strength. Then my brother and I would manage our family business together. I would graduate in BE while he graduated in Marketing so we could help penetrate foreign markets in the future.

From my view, TOEIC was an important exam since, as a language student, we had to take this kind of exam. I had never taken the exam before but I used to buy a test sample book during my high school during M.5-6 (Grade 11-12). But it was too difficult...difficult, one-round listening and, particularly an error identification part. I just wanted to try and needed to practice more.

What had I learned from telling my stories? I knew more about myself in the aspects that I had never pondered before. From my view, I still needed to continuously improve my English skills. I would try harder, particularly with speaking skills. While working at the Gibbon Campaign, one Farang told me if I continuously practiced speaking English every day, one day I could finally speak English. So I believed I could make it one day if I got rid of my nervousness and embarrassment.

\footnotetext{
${ }^{12}$ The term "Mano", teenagers' slang, means imagine.
} 


\section{My expectation for the next semester}

Next semester I will take seven English courses. That is what I initially expected. But after checking the schedule, I found that I will not study with foreigners in all subjects. Actually I think I will be okay. But our senior students told us that one Thai lecturer is a hard grader. Many students, even smart ones, who took her course still ended up withdrawing from her class or getting bad grades. I felt afraid of that a bit but I had not tried yet, just heard a rumour. To me, if we majored in English and ended up with getting a bad grade, we will not achieve our goal or will not be successful. However, I never imagined I would get a grade C in any English subjects. English is my favourite subject, the only one I am good at. I have to fight for it and will do my best.

\section{Table 5.5}

Summary of Chi's L2 learning experiences from the past to present

\begin{tabular}{|c|c|c|}
\hline L2 learning experiences & In-class activities/tasks & Out-of-class activities/tasks \\
\hline $\begin{array}{l}\text { Present } \\
\text { (university) }\end{array}$ & $\begin{array}{l}\text { - Felt motivated to do } \\
\text { individual speaking tests } \\
\text { with her NS teacher } \\
\text { - Preferred memorising scripts } \\
\text { before having speaking } \\
\text { tests/activities to be "Pae" or } \\
\text { perfect or avoid making } \\
\text { grammatical errors } \\
\text { - Felt anxious to speak in front } \\
\text { of class } \\
\text { - Experienced peer pressure in } \\
\text { writing classes }\end{array}$ & $\begin{array}{l}\text { - Started chatting with her } \\
\text { foreign friends via virtual } \\
\text { communication } \\
\text { - Be a volunteer at Gibbon } \\
\text { Rehabilitation Project in } \\
\text { Phuket, her home town to } \\
\text { interact with NS and NNS } \\
\text { tourists during summer } \\
\text { semester }\end{array}$ \\
\hline $\begin{array}{l}\text { Past learning experiences } \\
\text { (high school) }\end{array}$ & $\begin{array}{l}\text { - Felt demotivated and tense } \\
\text { when learning complicated } \\
\text { grammar (e.g., if-causes) for } \\
\text { quiz and examination } \\
\text { without real understanding }\end{array}$ & $\begin{array}{l}\text { - Felt motivated to study English } \\
\text { in small classes with her } \\
\text { personal tutor } \\
\text { - Enjoyed studying speaking class } \\
\text { with NS teachers at a private } \\
\text { language center } \\
\text { - Participated in the Southern } \\
\text { Spelling Bees } 2012 \text { contest } \\
\text { - Listened to foreign music and } \\
\text { soundtrack movies due to the }\end{array}$ \\
\hline
\end{tabular}




\begin{tabular}{|l|l|c|}
\hline L2 learning experiences & In-class activities/tasks & Out-of-class activities/tasks \\
\hline & & influence of her aunt \\
\hline
\end{tabular}

\section{Summary}

Through the language learning narratives of these four participants, we have seen their highly-contextualised transitional experiences from school to university. They expressed their positive and negative perceptions of applying their intended effort of learning English in the past, present, and future. In particular, what emerged from their narratives was how they perceived themselves as EFL learners and users and they self-evaluated their abilities in communicating with NS and NNS interlocutors in diverse learning environment. In spite of encountering tensions and linguistic anxieties, three participants strove hard to exert their intended efforts to learn and use English as a medium of their communication. Nonetheless, they still perceived that they could not do their best in learning environment. 


\section{CHAPTER 6 THEMATIC ANALYSIS}

In this chapter, I aim to examine the narratives for the missing parts of my research puzzle and discern resonant threads across their transcripts and plotlines. I present three themes emerging from the participants' perceptions of their L2 learning stories and experiences. The three major themes highlight the cross-case variation among participants. The data from these themes emerged from indicative codes from their narrative interviews, excerpts of one learner's English diary, and other relevant artefacts. Indicative codes are presented to support the themes and some of the themes are named using "in vivo" codes: the wording or key phrases that participants used in their mothertongue language interviews (Saldana, 2013, p. 91). The participants' key wordings and phrases related to these themes become the nested threads running through their narrative interviews and represent the "big" pictures of their episodes. The categories (themes) are illustrated by the four participants' voices echoing repetitively across the dataset. I analyse their similarities, differences, and contradictions, and interdependencies. In presenting and illustrating these themes, some portions of participant quotes may be repeated from the previous chapter. They are presented in both places to provide coherence to the individual participants' stories and then support for the further analysis of these stories.

The key themes emerging in the findings are:

1. Speaking English is our priority

2. People shaping us from cradle to college

3. Using English to open up our eyes

\section{Theme 1: "Speaking English is our priority"}

The similarity among all learners was that they prioritised speaking skills over other skills. They desired to improve their speaking for reasons arising from their personal characteristics and their language learning needs. These categories are presented in this section as follows:

- "Speaking fluently or speaking Njoo..Njoo..Pla..Pla..?"

- "Speaking like "Farang" (westerner) or speaking as who we are" 
- “English Speaking Year Project 2012”: Our mission impossible?

- "Our memorable Second Language Activity in class"

- "Speaking English is a must for our work"

"Speaking fluently or speaking njoo..njoo..pla..pla..?"

They desired to "speak English fluently" and "express themselves bravely" in English. English was perceived as an "international language" that people all over the world use as a medium of communication. They could imagine themselves conversing with foreigners successfully. When this happened, they would be part of the L2 global community which would strengthen their future self-esteem and open the success door for them. One participant stated: "If a Farang (NS) asked and chatted with me in English, I could fluently converse with them. I felt like I was extraordinary and so proud of myself'" This reflected that speaking English was perceived as a meaningful and empowering experience for her at that moment.

However, the participants were not satisfied with their own abilities and assumed that it would be difficult for them to achieve this goal of English fluency in their real-life communication. In particular, they were conscious of their personal constraints and critical of their own linguistic competence. They felt anxious and seemed to be held back by their "limited grammar and vocabulary". While speaking English, they were aware that they "use wrong grammar". They tended to use "short phrases or fragmented sentences" or "broken English" with "basic vocabulary". For example, one student (Chi) said: "While speaking, I could not use the words I wanted to express". Sometimes they could not automatically respond to their interlocutor in the real time during the interactive process of communication. If they "listened to something very fast, shorten[ed] words, phrases or slang", they could not catch key messages. Or even if they understood the message, they could not construct their ideas or "string long sentences", with correct grammar, thus ending up "speaking haltingly" or "keeping quiet" in some cases. One student reported that she felt embarrassed while conversing with "the owner of language" or native speakers (NS). She illustrated her meaning by explaining that if the English speaker did not understand what she said. She felt like she had done something wrong. Then she questioned herself: "Did I make some mistakes?" All of them realised they still lacked linguistic competency. 
They shared similar perceptions about the institutional and familial constraints at the root of this particular problem. Nott, the first participant to use the metaphor or sarcastic term of "Speaking Njoo..Njoo..Pla..Pla..", described this phenomenon as "Thai students who started studying English from the kindergarten to university levels", but still made slow progress, who "speak English a little bit", or not as fluently as they expected. "Thai students studied English only in class. When the class finishes, we switched into Thai", they noticed. They rarely used English or applied what they learned in class in their daily lives. In addition, one student (Chi) spoke about learning English outside school, as "most Thai students hardly use English at home" with their family. She compared her English competence with that of her close friend whose step-father was a foreigner. Her friend had spoken English every day since her childhood so she could "communicate it fluently and automatically" whereas Chi could not. She perceived that her friend "did not have to struggle to study speaking like her". Chi assumed if she had spoken English at home every day, she would be able to speak English more fluently too. From the perspective of these participants, the opportunities to use English in their daily lives were important as observing and socialising with others could lead to successful communication skills.

\section{"Speaking like "Farang "13" or speaking as who we are"}

After analysing across the narratives, it appeared that individual students held different perceptions of what it meant to be able to speak English with foreigners in their daily lives. While some of them desired to speak fluently, other students specifically mentioned that they aspired to speak English like Farang. They valued speaking English with foreigners differently. Ake and Chi wanted to "speak as themselves" and did not expect to speak to NS foreigners with the levels of accuracy desired by the other two students. In contrast, Nott and Rin shared something in common. They envisioned themselves speaking "Pae ${ }^{14 \text { " }}$ perfectly like Farang and tried to struggle and regulate themselves to speak with both NS and NNS friends in varied contexts in class and beyond classroom settings. The different perceptions impacted strongly on who they wanted to speak with, where they intended to speak, and why they wanted to speak English in a particular

\footnotetext{
${ }^{13}$ Pae, in Thai, means "to do or perform it exactly and perfectly".

${ }^{14}$ Farang means westerner or NS.
} 
context. To some degree, these perceptions also influenced their language learning process with specific purposes and different learning contexts in mind.

Ake and Chi perceived that they wanted to "speak in their own style", or "speak as who they are", they did not take "accent" into account. (The participants in the study tended to use the terms "accent" and "pronunciation" interchangeably). They were focused on mutual understanding between themselves and interlocutors and achieving authentic communication. From their perspective, it did not necessarily mean that they had to imitate native speakers and speak like Farang. They prioritised communicating in English successfully, with the NS and NNS speakers. The most important thing was: "While speaking English, they understood us and we understood them. That's it. Whether we would have a better accent, mostly depends on how often we kept practising”. No matter how they sounded, using Thai-English or foreign-sounding accents, they regarded the result as "speaking English" as long as they could be understood.

Both of them had similar kinds of speaking experiences which boosted their confidence and made them prioritise speaking for communicative purposes. While traveling to Kao San Road in Bangkok, Ake saw a lot of foreigners passing by and felt like he "was staying in a foreign country." He had never had this kind of experience before while living in his home town. While shopping in Bangkok, a shop assistant assumed he was a tourist and asked him in English: "Can I help you?" He replied in English: "I would like to have ..." (He said these sentences in English). While communicating, he proudly stated that he was "not afraid of speaking English" with Thai people- "we are not different". He simply wanted to speak English and achieve successful communication. Similarly, Chi vividly illustrated the scenario of chatting and skyping with her Chinese friend in virtual communication. She noticed that "his accent was normal", similar to hers. Importantly, she "did not feel inferior" to him and did not experience any linguistic difficulties or barriers while communicating with him. In addition, after observing English in a real-life context, she felt "more confident to practise speaking in English" than she had in the past and so felt delighted to make a new foreign friend online.

However, Nott and Rin's perceptions and expectations contrasted with these language learning goals, but were strikingly similar to each other's. They struggled to acquire effective speaking skills. They wanted to speak English, "Pae," perfectly or fluently, like 
Farang. They "did not care" or were not deterred if other people perceived them as "Dadjarit" 15 " (ดัดจิต) or "Kradaae" (กระแดะ) or "trying to show off" by speaking like westerners. Other students "may not dare to speak like that", Rin assumed. Nott supported this idea: "If Thai people did not see anyone speaking English, they would behave like that as well". Both of them perceived that Thai people could not develop their speaking skills because they hardly practice speaking English. On the other hand, they were different from other Thais because they did not care much about others' opinions as they strove to reach their communicative goal of speaking like Farang.

Their perception of enhancing their speaking skills helped them struggle and sustain their L2 learning effort to "improve their speaking skills" in part. Rin revealed that her friends "mocked and nagged" her while she tried to converse with foreign teachers with her foreign-sounding pronunciation at her high school. However, she proudly stated that her teachers "gave me some compliments" and finally "selected me to be a school representative" to attend the "Public Speaking Contest." She felt impressed to be trained by the two foreign teachers. "They taught me how to pronounce correctly and appropriately". She thus improved her speaking skills and knew how to give a speech confidently and naturally in public. Interestingly, while practising, she clearly stated that she tried to speak "Dadjarit" and carefully imitated foreign pronunciation. Despite not winning the contest, she realised that thinking differently and learning from others could open new learning opportunities for her.

Rin vividly recounted her ideal scenario: "Imagine if I had a job interview in English in the future, the recruiter had to evaluate my speaking skills". While speaking, if I felt "confident", I had to be Dadjarit and "be myself", instead of speaking in the Thai style. Although Thais can understand each other, Farang "could not understand and may puzzle over us". Many words in English are pronounced similarly. She claimed: "If we pronounced some English words unclearly, we may unintentionally mislead them". She strongly believed that being brave and confident is a key element in becoming a proficient speaker of English.

\footnotetext{
${ }^{15}$ Dadjarit or Kradaae refers to people who try to show off by pretentiously speaking English like westerners.
} 


\section{“English Speaking year project 2012”: our mission impossible?}

Nott initially related this national challenge to the controversial policy initiated by the Ministry of Education. Schools and teachers were expected to provide more opportunities for students to practise speaking instead of implementing a grammar-translation approach to teaching. However, all participants reported different real-life learning experiences of the implementation of this policy. One participant (Chi) illustrated: "As I remember, a school teacher announced at a flag ceremony that, due to the entry into AEC in 2015, we were encouraged to speak English more frequently". After that, foreign teachers "spoke in English on special occasions" and asked them questions in English. Sometimes Thai teachers "spoke in English and translated it into Thai". The leading students were criticised for "speaking Thai words and switching to English words". Chi's account echoed a common practice in Thai society and mass media which is sarcastically known as "Speak[ing] one Thai word and one English word". This metaphor illustrates how some Thais use English loan words in speaking to make them "look cool and educated". However, they may not be able to string words into sentences. Interestingly, Nott reported: "We were encouraged to speak English on every Friday. It appeared that most students did not talk to one another". Their illustrations reflect their direct experiences during the period of implementing the idealistic nationwide campaign.

When they were asked whether this policy helped them improve their speaking skills, all of them agreed that it did not work as expected. They said that they were not really encouraged to speak English and their teachers did not monitor them speaking it. Even if they had opportunities to listen to English outside class, they could only understand some parts of the conversation. Rin felt this policy illustrated the "inequality of urban and rural students". She reflected that while urban students gained more access and achieved better levels of education, rural or jungle students, like her, would be "more struggling". She noted that her school classmates and children in her community were not interested in learning English at all. They followed their parents' footsteps. As rubber farmers, they rarely needed English and "hardly used it in reality and [it was] not related to their daily lives". However one participant was concerned that as Thailand entered AEC, this inconsistent use of English might become a problem. Based on these scenarios, the 
participants did not benefit much from campaigns to speak English but they gained awareness of their capabilities and the national problem.

Most of the participants valued the importance and relevance of this project and the integration into AEC. Chi envisioned Thai people, just like herself "doing business with our neighbouring countries", but she worried what would happen if Thais still could not speak, listen to, and understand English. She was afraid that Thai people might lose the opportunity to do business with other member states. One participant thought the issue of the poor English proficiency of Thai students compared to other member states occurred because Thais, "were not colonised by western countries. We had to learn English by ourselves". Unlike the others, Ake could not imagine himself gaining much benefit from this integration and stated: I was uncertain whether the integration would improve my quality of life. However, most participants perceived that they had to improve their English proficiency to adjust to Thailand's integration into the AEC.

\section{"Our memorable second language activity in class"}

The participants' statements reflected that their experiences at university were totally different from their previous experiences at their schools. They all felt more motivated and engaged in communicative and task-based activities such as "doing role plays" and "having individual speaking tests" with their friends and lecturers. Rin remembered her lecturer whose accent was clear and easy to understand and whose teaching style "was totally different from" her negative experience at high school. Similarly, Chi felt that tertiary classes were enjoyable and reported: "We not only learned grammar but did role plays as well". All of them perceived that these meaningful activities within an interactive learning environment could maximise their L2 learning acquisition. They benefited from performing "communicative and task-based" activities and could envision applying them to "real-life communication" in the future.

However, Nott and Ake shared different perceptions and expectations of classroom tasks at university. They felt demotivated by "grammar-translation" and "rote-memorisation" approaches. Instead, they preferred speaking "impromptu" or engaging in fluencyoriented activities. They reflected that this kind of activity made them smart and enabled them to speak automatically without preparing a script in advance. They just "kept 
speaking" and "continuing interactive dialogues" without caring much about grammar. If they used incorrect grammar while speaking, they liked their lecturer to recast their statements correctly or add more details or let them speak freely without correcting their grammar. They preferred speaking and learning from their grammatical errors naturally. This approach motivated them to engage with in-class activities without provoking any linguistic anxiety about communication. These two male students shared similar perceptions in this sense.

In contrast, Rin and Chi were more concerned about engaging in form-oriented activities. Particularly they valued speaking English with correct grammar. They were much more inhibited and anxious about grammar. Hence, they preferred preparing the scripts and happily rehearsing and then performing role plays. Chi explained how, like most of her classmates, she memorised and recited her script three to four times one day beforehand. While performing, initially she felt very nervous. But eventually she could memorise it all, "Pae". Nothing was different from her prepared scripts. She proudly stated that she did not feel choked up, or frozen, and memorising scripts allowed her to cope with her linguistic anxiety which frequently happened because of her personality and previous negative experiences. Her statement suggested that she relied on memorisation to reduce her grammatical errors and to simultaneously boost her speaking self-efficacy. Similarly Rin also created a script for group work and illustrated her learning process: "Normally, we had to memorise them from a textbook but needed to understand key phrases and structures. Finally we could speak English in sentences". While preparing scripts, she told her friends: "Please memorise content in Thai, know what other friends talked about, and know how it was translated into Thai. In case we forgot, we could still think about content in Thai and kept continuing our conversation in English". From her perspective, this approach "worked" and her friends were satisfied with their performance. Their statements reflected that they benefited from integrating grammar rules and rotememorisation with understanding of content while performing communicative activities.

\section{Speaking English is a must for our work}

All participants were well aware of the importance of learning English for their future professions. They all affirmed that they had imagined themselves using English as a medium of communication in their imagined workplaces since their childhood. As active 
and out-going people, they envisioned themselves working as an "air-hostess," "flight attendant," and "tour guide" in the service or hospitality industry. These kinds of job would reflect their people-person personalities. Their visions of becoming Englishspeakers and workers were inspired by seeing foreign tourists in their hometown, listening to their relatives' stories and mass media, or attending the field trips organised by their schools.

At the time of my study, all participants tried to seek opportunities to work part-time while studying or during the summer break. They realised the importance of gaining English-speaking volunteering or work experiences and practising speaking skills. As vocational school graduates, Ake and Nott paid more attention to instrumental purposes for English rather than simply focusing on content in class, which seemed different from real-life usage. Nott stated: "Learning English in the academic context could not guarantee a one-hundred-percentage success". They valued the notion of "learning-bydoing" and "hands-on" experiences. Both of them used to work as part-time waiters in their home town and successfully spoke English with foreigners. As a part-time waiter, Nott felt brave enough to take orders in English from his English native speaking customers. He confessed that initially he felt "anxious," but finally could do it and "felt proud of himself". He perceived working with foreigners as a "fruitful" experience which helped him not only "achieve his communicative goal" but also helped him to realise the value of money. He felt that he "could speak in English more fluently than the past after working with foreigners". Similarly, Chi was influenced by her aunt and worked as a volunteer at a non-profit organisation. While working there, Chi gained more opportunities to chat with foreigners and vividly remembered one Farang teacher saying: "If you practised speaking English every day, one day you could finally speak English". To sum up, all participants strongly agreed that frequently chatting with foreigners in outof-class settings would assist them in acquiring speaking skills.

\section{Theme 2: People shaping us from cradle to college}

This recurring theme emerged from their interviews and unfolded the relationships each participant had with influential people in their learning contexts such as at home, school, and university. Their parents, family members, teachers and friends had both a positive and negative impact on their language learning process at different periods of their lives. 
Additionally, they had a major influence on how the participants remembered their learning experiences. These people shaped them as language students. The impact of other people is presented in this section as follows:

- Our parents and family members: encouraging or discouraging us?

- Our teachers: motivating or demotivating us?

○ "The best teacher teaches from the heart, not from the book"

- "Learning tenses made us tense"

- Our friends: peer network or peer pressure?

Our parents and family members: encouraging vs. discouraging us?

None of the participants reflected that they used English as a medium of communication at home which was to be expected in the monolingual context of Thailand. Their parents worked as "a rubber farmer", "construction worker", and "business owner" in provincial and rural areas. They rarely used English in their daily lives and were not involved with their children's L2 learning directly. However, living within extended families meant that most participants' language learning processes and experiences were influenced by their wider family members from their childhood. The participants could thus envision themselves as a user of oral English who worked in an academic or professional context because of these familial influences. Chi vividly remembered her aunt's advice to her as a child: "You could speak English one day". There were differences in the way the individual participants were inspired to learn and speak English at the early stage at a pivotal point. Nott was initially inspired to speak English because he could not communicate in English with his sister's Farang boyfriend at his home. "I felt like I was an outsider". This meaningful incident prompted him to change. Subsequently, his sister also invested her money to provide an opportunity for him to take a conversational course with foreigners. He felt motivated to study English with the belief "One day I could speak English like foreigners". Likewise, Chi changed her negative perceptions of learning English after her mother financially supported her to take private classes from primary to secondary school. She then realised: "Learning English was not that complicated" after she could understand the lessons better and improved her achievement at school. Unlike other students, Ake was not influenced directly by his relatives, but he enjoyed listening to western music and downloaded it for pleasure. 
Apart from that, their relatives tried to provide them with multimedia and written language resources at home such as cartoon CDs, Disney fairy films, and western songs to achieve the goal of learning English from a young age. Rin reported: "During my Grade 1-6 period, my aunt initially bought me cartoon CDs. She suggested to me that it was easier to catch on, compared to watching action or fantasy ones. While watching movies with her, I had to listen to English soundtrack and read Thai subtitles". Her aunt showed her how to pronounce or imitate some words and phrases in English. She reflected that it helped her improve her English gradually and made her feel passionate about learning English that way. Similarly, Chi reported that her aunt encouraged her to listen to Farang music and movies. "While sitting in her car, I listened to it. I liked its beautiful melody, like Thai music". Like the others, Nott remembered: "During studying the primary school, my sister usually turned on foreign music. She really liked listening to Tata Young music", an international album. Also, he "listened to her music almost every day at the time and eventually liked several songs". These kinds of authentic learning experiences seemed to help the participants to drive themselves to practise whenever they had free time.

After the initial influence from their relatives, it appeared that despite experiencing linguistic difficulties, they made an effort to continue to practise during their free time. Rin still remembered her first movie named "Stuart Little". She found it was difficult to understand but she tried to "speak...speak...speak and imitate the original". She even used these words to talk to her classmates at her primary school even though they had no idea what she was talking about. "I did not know why I did that". She confessed that she felt happy, though. During her high school years, she bought fairy tale books with listening CDs inside. Again she "imitated pronouncing and read out loud...once upon a time..." I liked doing that since it was "Sanook" (fun). Similarly, Chi also echoed that initially she "did not understand soundtrack movies at all". She then tried to sort things out by "downloading cartoons and Disney fairy tales from the internet" for free and finally felt that it was not that difficult. Likewise, Nott vividly recalled how he printed the lyrics, read, and learned new vocabulary. Sometimes he asked his sister to teach him how to read and translate difficult words or slang. "I liked to sing along and incredibly felt the charm of pronouncing English such as /t/ sound". He felt impressed with it. 
Additionally, their family members had a major influence on shaping their vision of being English-speaking users and workers. They were aware that that would be difficult. Nott remembered well that actually his sister "spoke English..Ngoo.. Ngoo..Pla..Pla.." not fluently, like him. However, once she had a "Farang boyfriend and spoke in English frequently, she improved it dramatically". Chi also repeated her aunt's account: "Initially she could not speak English, just opened the dictionary and jotted down unknown words in her note books". However, her aunt learnt and improved English automatically while working and socialising with foreigners. Finally she could speak English and had a lot of foreign friends". Occasionally her aunt also took her to "Farang" parties and she socialised with them too. Currently her aunt worked in a new English-speaking workplace where she could upgrade her salary scale and gain higher bonuses, compared to other staff who could not communicate in English. In addition, sometimes, Rin and Chi shared that whenever they did not know how to communicate in English, they asked her aunt for suggestions and assistance. These examples show that their relatives were not only considered role models but also played a key role in providing them with linguistic support and resources.

Analysing across all narratives, it appeared that three participants had a role model from within their family who could boost their linguistic competence and self-efficacy. Their family members were seen as a visionary group of people who had forged their perceptions and language learning behaviours throughout the participants' lives. The participants thus could use them as a resource when they needed and hold them up as role models of using English academically and professionally.

Some of them perceived that their parents or family members held expectations or imposed their own values on the participants' academic and professional success. These expectations may be regarded as the other side of the same coin. Ake reported that he was bombarded with his family's advice: "If... not focus on my study and graduate...not be able to go overseas", if you wanted family Sabai ${ }^{16}$ (financially stable), pay more attention to the study; if... addicted to playing games..., not able to go abroad". These warnings made him feel motivated to major in English for his future and family. Similarly Chi and Rin frequently complained to their mothers about their academic problems. Chi also

\footnotetext{
${ }^{16}$ Sabai means well-being or financially stable.
} 
expressed her concern over her achievement and the negative effect that studying Accounting would have on her total GPA at the end. She sadly expressed: "I did not understand why I had to study it despite choosing majoring in BE. Why didn't I study only language?" She sadly expressed that she did not want to be "Dek Sil"17" "because it wasted my time". She worried about her GPA which was the major assessment requirement used to apply for a job in the future. Importantly, if she got a low GPA and decided to quit, she would have to not only resit the entrance exam but her parents also would have wasted a lot of their money on her tuition fees. Similarly, Rin expressed in her English diary how stressed she felt while taking an Accounting course: "I did not like this subject...I felt lazy...I called my mom and told her I hate this subject, well my mom said "don't give up.” Besides, her mom frankly warned her: “..., you just went back home and tapped our rubber trees instead". Her mom's words opened her eyes since she appreciated how hard the rubber farmers' lives were, particularly during the current economic downturn. It was common for parents to expect their children to have a bright future with secure jobs, compared to theirs. However, she could not envision herself as a rubber worker like her family members and chose to study harder without any further complaints.

\section{Our teachers: motivating vs. demotivating us?}

Teachers can shape learners' belief in their ability to learn English. They have the power to boost or hinder learners' self-efficacy and self-confidence. However when the participants entered the university, they were no longer under the direct control of one particular teacher. They were obliged to regulate themselves to be more autonomous learners.

\section{"The best teacher teaches from the heart, not from the book"}

The participants all reported they enjoyed studying English with teachers who basically were "Chill Chill" or did not "put them under pressure", "Sanook" (enjoyable), and "Heha (funny)". Ake perceived that his classmates and he could identify which teacher taught from the heart, and they also gave their heart to them as well (literally translated) in return. Rather than "bombarding them with overloaded content from textbooks or slides in the power point", Ake and Nott echoed that they preferred studying English with

\footnotetext{
${ }^{17}$ The term Dek sil means a group of the first-year students who change their major or university due to their low performance/GPA. Some of them realised that they did not fit in the major or were expelled.
} 
teachers who deeply cared about their language learning needs, particularly those who focused on communicative purposes. In particular, they mentioned: “The teacher's major teaching objectives was to encourage them to speak as much as we could and had the conversation tests frequently". They did not like the lecturers who just lectured and talked at them about complicated ideas as if their brains were empty. In terms of linguistic competency, they preferred teachers who could speak English "clearly and were easy to understand". It did not matter if their teachers would switch from English to Thai or from Thai to English as long as they could understand key content.

All students felt impressed by teachers who created meaningful interactive tasks and empowered them to "engage with meaningful activities" which they could relate to "their real-life communication". Nott reflected that while performing "the individual speaking test, I didn't feel that Ajarn Farang was my real teacher, just like my friend". He had an enjoyable and smooth conversation and could answer the teacher without any pauses. While chatting with him about the trip in Myanmar, Nott could envision himself travelling there with his friends. Also, these students highly valued the teachers who could change their negative attitude towards learning English. Particularly, Chi claimed that she eventually changed from holding negative to positive perceptions of learning English. She frankly confessed to me that initially she felt unmotivated to take a course named "Business Grammar", based on what she had experienced at her previous school. Nevertheless, her perception changed after taking the course. This teacher was renowned for applying "magic tricks, real-life activities, video clips" to motivate students before beginning his class or when students got bored. She appreciated this teacher because he could always motivate her to engage in "meaningful task-based activities and individual test" which boosted her confidence, particularly while having individual tests with him. As a result, she invested a lot of her time and effort in studying in class, practising speaking and rehearsing dialogues beyond class to achieve her learning goal. Her teacher successfully used scaffolding strategies both in the class lessons and speaking tests which were rewarding for all involved and met their language learning needs.

To conclude, while taking English courses at their universities as language students, the type of activities and the attitude of the teacher impacted on their motivation. These communicative and task-based activities may have had an impact on how they could 
envision who they would like to become in their future professions or conversely undermined their confidence about whether they could reach their goal.

\section{"Learning tenses made us tense"}

From their primary school years, all participants had been "grammar-translation", "rotememorisation", and an "exam-oriented approach". These threads ran deeply through their academic life. Chi strongly remembered that her school teacher taught three types of "ifcauses" within one period with a quiz after class. She recalled how stressful it was when the students realised they had to take a quiz. She did not remember learning any key content from the quick lesson and did not engage in any communicative activities to practise speaking skills. These negative experiences had an impact on her L2 learning process, linguistic anxiety, and speaking self-efficacy at university. Rin also experienced few opportunities to participate in interactive tasks. She remembered her school teachers' "spoon-feeding ${ }^{18 "}$ styles of teaching. She reported that the teacher "just kept explaining continuously and assigned us to do grammatical exercises". Sometimes she "wrote some sentences in Thai on board and asked us to translate into English", for example, “ฉันกำลังจะ ไป..." or "I am going to..." She perceived these activities as repetitive and would have preferred doing more challenging activities. These activities demotivated her and these unfavourable high school learning experiences affected her writing skills in the long run.

Similarly, at their university, Nott and Ake complained: "Why did we have to learn repetitively? We wanted to learn speaking so we could speak". They did not see any relevance to real-life usage in the workplace. They valued learning-by-doing and "handson" experiences as vocational school graduates. They questioned why they had to still learn grammar despite not using all tenses in real life. They felt "bored" and "suffered from learning it". They felt that they were learning grammar rules without applying them in communicative activities. Even worse, Ake's lecturer criticised him and told him he "need to improve his very weak grammar" which he did not like. "My teachers told me I dared to speak out but my grammar was poor".

\footnotetext{
${ }^{18}$ Spoon-feeding teaching approach refers to simple and repetitive grammar-translation drills without initiating any communicative activities in class.
} 
In addition, they faced grammatical problems in the reading and writing courses. Ake and Nott felt disappointed in their reading course lecturer since she did not teach them reading techniques, just skimming, answering some questions by giving their views. However, Ake confessed that he did not read seriously_just opened the English-Thai "dic"19", and sometimes translated sentences in the wrong order. "I did not understand main ideas". He explained that personally he did not like reading and reciting vocabulary. He felt bored and sleepy doing this. These negative experiences made them felt stressed, demotivated, and finally led to a negative impact on their L2 achievement.

However, Rin and Chi did not directly complain about learning grammar or even English language teachers at their university. They just reflected that they made a lot of grammatical errors in their writing assignments. Chi illustrated: "During my high school, teachers would not focus much on writing and editing, only teaching reading and basic grammar-translation". However her learning process changed at the university because she was expected to write based on the topic in a textbook, submit, edit and rewrite assignments. Rin and Chi valued studying grammar and found it useful if "we learned our grammatical errors and tried to avoid making them again", in contrast to Ake and Nott's perceptions. However, sometimes they felt confused, "made changes from right to wrong ones", and made "a lot of grammatical mistakes on all pages". Their narratives reflected that they did not have opportunities to practise writing skills at school and faced linguistic difficulties and grammatical confusion in their writing class. In particular, they tried to think in the mother-tongue and translate word for word in their process of L2 learning.

Rin shared with me her face-losing experience in a writing class. She reported her teacher's criticisms guiltily: “....after she read my writing task for a few second, she spoke out loud to class: "Look! Making a grammatical mistake from the first sentence! How did you check your work?" She felt like she badly "failed" (she used this word in English) and described: "my face was shrunk two inches ${ }^{20 "}$. She also questioned to herself whether she was too confident or careless. Normally the teachers expected their students to carefully revise and edit their writing before submitting to avoid making any minor errors.

\footnotetext{
${ }^{19}$ Dic shorts for a dictionary which is commonly used among Thai people.

${ }^{20}$ My face was shrunk two inches is a slang which reflects the face-saving value among Thai people. If translating literally, this metaphor described the scenario which he or she feels embarrassed or loses face after doing something seriously wrong.
} 
This was designed not only to benefit and improve the students' writing process but also to lessen the teachers' burden, particularly in large-sized classes. As a language student, however, these negative messages from teachers seemed to damage Rin's writing selfefficacy. However, she persevered because she valued grammatical correctness and desired to improve her writing process. She was the one student who decided to participate in the English Diary Project and shared her diary with me.

To sum up, all participants' perceptions echoed that teaching grammar at their school was form-focused and they did not regard this as a suitable means towards the end of communicating in English. They could not relate drilling exercises to their real-life purposes. However, after engaging in a wide range of university activities, they proactively invested their time and effort and committed themselves to meaningful activities, more systematically and interactively than when studying at school.

\section{Our friends: peer networking vs. peer pressure}

When they entered the university, they were likely to influence others or be influenced by their friends and senior friends to some degree. The participants all affirmed that they positioned themselves as active people who engaged in a variety of university activities to make new friends, learn from one another, and belong to a group. To achieve certain objectives, they had to manage their time effectively and cope with demanding requirements of academic work and activities effectively.

Nott was the only participant at his private university who had foreign friends from the International Program and worked part-time. During his free time, he saw foreign soundtrack movies with them. Initially he openly admitted that he could not understand much. However, he wanted to be like his foreign friends. "If others could listen and understand them, I had to do that as well". His perception echoed how determined he was to achieve his goal of socialising with English-speaking users and immersing himself in English-learning contexts. Additionally, he had a chance to work as a part-time member of staff in Bangkok after his senior noticed that Nott was speaking in English with Vietnamese friends at a party. His senior advised him: "Try working with Farang, the key persons. ... such a great opportunity to work and practise speaking at the same time". Nott took this advice and realised that: "Learning in the classroom could not guarantee one-hundred-percentage success". He perceived that he had something in common with 
his sister in the sense that initially they spoke Snake Snake Fish Fish ${ }^{21}$ but eventually improved their speaking skills after mingling with foreigners. Socialising with his senior helped broaden his viewpoint, and Nott was able to build his own connections and network. Importantly, he imagined himself gaining L2 learning experience from Englishspeaking workplaces where he could improve his speaking skills and boost his selfefficacy.

However, on the other side of the coin, it appeared that another participant, Ake, despite studying at the same university as Nott, could not share Nott's experiences mingling with foreign students at International College. Rather, he felt inferior to his classmates while performing speaking tasks in a group. He confided: "Sometimes I felt pressured because my classmates were better and had better accents. I felt like I wanted to speak well like them because I was not outstanding or not that good". Ake and Chi had similar perceptions and considered they were under "peer pressure", in the classroom context where they felt inferior to others. Likewise, Chi compared her speaking ability unfavourably to that of her classmate who had a foreign stepfather and was surrounded by users of English. Additionally, in the reading and writing courses, Chi compared her writing skills to those of other classmates. She noticed that when her teacher asked all students to summarise reading passages, they could complete the task in a short period while she thought to myself, "Had they done? Had they submitted the task?" She perceived that she "could not do as well and rapidly as them". Her narratives reflected the BE students had a lower level of English proficiency and background knowledge which sometimes made her feel inferior to them.

\section{Theme 3: Using English to open up our eyes}

This overarching theme presents a wide array of the students' L2 learning experiences beyond the classroom settings. As language students, most of the students struggled to broaden their worldviews and experiences, initiate friendship with foreign friends, and participate in target language communities. These categories are presented in this section as follows:

- "We found our foreign friends on the Internet",

\footnotetext{
${ }^{21}$ Snake Snake Fish Fish refers to a sarcastic slang which illustrates that people could speak English only a little bit, despite studying since the childhood.
} 
- "Our schools and universities broadened our global perspectives",

- "We imagined ourselves studying and working overseas/ in English-speaking communities".

\section{"We found our foreign friends on the Internet"}

All participants, except Ake, had experienced using English to initiate a relationship with their foreign friends through social networks. However, Nott and Rin seemed to maintain a higher level of communication and contact with their NS and NNS friends since they had started chatting with them during their school days. Tracing back to his past, Nott "started chatting on social network, HI5 and MSN when I was 13-14 (Grade 7-8). I kept chatting in English with Indonesian friends but hardly had western one". Similarly, Rin tried to find foreign friends through virtual communication. She still vividly recalled seeing a lot of foreign tourists while travelling to some of the islands in Phuket. She felt motivated to find foreign friends through the program called "Interpal". She was successful and she made friends from several countries such as England, China, and Russia. In her English diary, she confided: "I love my Chinese friend very much. Her name is Xiu. I met her on the Internet. We have something in common". Up until the time of this study, Rin still kept in touch with her friends, exchanging snacks and souvenirs by mail. Unlike Rin and Nott, Chi had just started chatting with English speakers at university after noticing her friends' skyping with their foreign friends in the dorm during their free time.

They explained that their major reason for initiating and maintaining friendships through virtual communication in out-of-class contexts was the intense feelings they experienced while chatting with foreigners. They enjoyed "sharing both linguistic and cultural knowledge and experiences". Nott, Rin, and Chi had similar perceptions and positive experiences of continuously keeping in touch with their friends through social networks. Nott revealed that his Indonesian friend asked him to translate Thai vocabulary from English into Thai language and also to recommend some interesting tourist attractions in Thailand since he planned to travel to Nott's hometown. Nott clarified that his NNS friend was really interested in Thai language and Thai culture. "Sometimes, I had to reply his messages late at night after hearing beeping sounds from my phone". However, he realised the advantage: "I could practise using English and teaching him Thai language. 
He is good at English". Likewise, Rin's diary clearly illustrated: "My English friend learns Thai language and Thai culture. He asks me many questions about sentences, and I always tell him. I was happy to help him". However, she also confessed sometimes: "If I had any questions about English usage, I would ask him for suggestions through sending a message via Facebook". Even though she could not receive real-time answers straight away due to different time zones, she mentioned that it did not matter as long as her foreign friend and she still maintained the meaningful relationship and helped each other in different ways. Not surprisingly, three of them illustrated: "We tried to encourage our foreign friends to visit Thailand and also "volunteered to be their guide". To sum up, they perceived that maintaining a relationship with their NS and NNS friends gave them opportunities to broaden their linguistic and cultural competencies mutually. Particularly, Nott and Rin had been pushing themselves to be part of the L2 global community by using English to communicate with their foreign friends all over the world for several years.

In addition, sometimes they used messages as if they were a national representative or ambassador for young people. While chatting online with their foreign friends, they sometimes had to clarify some unrealistic, exaggerated statements and questions arising from misleading news and incorrect perceptions about Thai people or their country. Rin and Chi had unexpectedly negative experiences of accessing online chatrooms where they could not see and communicate with others through face-to-face communication. They vividly remembered unpleasant online encounters with foreign men. Both of them reflected: "It was difficult to find good friends online since some guys negatively perceived Thai women and aimed to chat with them for sexual reasons solely". Their sad remarks reflected their internet participants' negative stereotypes of Thai women. Surprisingly this did not put them off or stop them from accessing online chat rooms. Instead, to solve this particular problem Chi mentioned that she had to be more cautious and "screen their online friends more carefully". However, they realised the benefit of online chatting and still felt motivated to maintain the relationship with their foreign friends. Rin echoed that her British friend was different: "As a Buddhist, he was very interested in our culture and did not perceive Thai ladies in the negative way like others". She clarified to him that the majority of Thai women, including her, did not fit the negative expectations held by some foreign men. Both Rin and Chi elaborated that their 
foreign friends "expressed their concern about our safety and well-being after listening to international news regarding the announcement of martial law" at the time of my study. However, Chi lessened her friend's concern by clarifying that "It was not as serious as broadcast and the political turmoil did not happen everywhere". Also, it did not have a negative effect on her much since her hometown and university were situated in the southern part of the country. Instead, their messages helped the participants broaden their worldview and realised that sometimes the way foreigners interpreted the news and even positioned them may be different from what was happening in reality. They felt that they had a great opportunity to clarify and convey messages to their friends who lived on a different side of the world by using English as the medium of their communication.

\section{"Our schools and universities broadened our global perspectives"}

None of the participants had ever travelled or had overseas experiences with their parents and family. However, they had all, with the exception of Chi, had the opportunity to have a field trip in Malaysia with their teachers and friends while studying at high school. Rin explained: "my school established the partnership with the Malay schools due to the integration of AEC. I travelled overseas for the first time with our teachers and friends. Malay students also visited our school". Her photos illustrated her engaging in a lot of cultural activities together with her Thai and Malay friends such as performing traditional dances and playing sports. She reflected: "we had memorable experiences sharing languages and cultures". Nott still remembered his first experience in Malaysia: "At a canteen, one Malay seller approached, chatted with me and wanted to learn some words in Thai". Despite having limited time, he pointed to "water" and spoke in Thai language. After experiencing this, he realised that perhaps he might teach Thai language to foreigners in the future. To him, having this memorable experience also tied in with his vision of a future profession. While Nott and Rin similarly saw that they would gain more professional opportunities to use English communication in their future, Ake reacted differently to a similar experience: "I had a chance to speak English while having a trip in Malaysia. But I am unsure if the quality of my life will be better after the AEC integration". Although individuals had different perceptions towards the integration, the trip to Malaysia made them more aware of the relevance of English in their daily life and future. 
While studying at their universities, all students observed: "We had more opportunities to have a face-to-face communication with their foreign friends and lecturers than studying at their schools". In particular, the International College (IC) was launched at the private university. However Nott and Ake responded differently. While Ake spent most of his free time rehearsing western music instruments at Music Club, Nott "attempted to mingle with their international friends" by doing several kinds of extra-curricular activities organised by his university and spending his time with them. Nott clearly appreciated that: "To improve my speaking skills, I had to be part of their group and do what they did". Similarly, Rin and Chi also valued the advantages of being part of the Englishspeaking communities. In particular, their Business English program provided them with a one-year learning experience at a prestigious university in Malaysia. As a result of this partnership, both of them had a chance to welcome and chat with a group of lecturers and students during their field trip and orientation at their campus. They were motivated to make friends and practise speaking with them. Rin recalled: "they gave us an orientation to ensure we could adjust to new academic environment if we had to study there as a junior student". While sitting in the auditorium, she chatted with the Chinese-Malay student sitting next to her and found that "her English was easy to understand". She also wondered whether "most of the students there could speak English". Eventually she realised they could. As EFL students, these Thai participants had limited opportunities to communicate in English in their daily lives. However, their institutions were concerned with such constraints and initiated programs or projects and supported the cooperation between universities for the benefit of students.

Additionally, Nott and Ake's university also organised the "Exploring ASEAN: Blog Contest" aimed at encouraging students to explore Asian countries by going backpacking. While Ake did not pay much attention and did not even apply for it, Nott seized the opportunity to engage in overseas experiences with his friends. "I was the person who initiated the idea, wrote the proposal, and asked my English-major friends to join this project". The major reason that he chose to travel to Myanmar was: "It was colonised by a western country and local people were supposed to speak English". He gained some memorable overseas experiences there. Since none of them had travelled abroad by themselves before, "we needed to be brave". When he arrived in Myanmar, "my friends and I had a deal that we had to try to speak English as much as we could. Personally I felt 
motivated to speak English. I could speak what I thought straight away". He felt especially proud of his linguistic competency since he did not dare to speak English like that in Thailand. Apart from exploring interesting tourist attractions there, he felt delighted to make new foreign friends from European countries such as Austria, Russia, and Poland. He vividly remembered his experiences: "Foreign tourists were interested in Asian culture and countries. While staying at guesthouses, they approached us. We chatted in English and exchanged ID skypes". In some cases, his expectations may have been different from reality since local people could not communicate in English with him and he had to draw and use sign language instead. He had successfully sustained his motivation since school and his imagined fluency had a positive impact on his intended effort. However, sometimes, he had to struggle to create out-of-class learning experiences to enhance his speaking and communicative skills and move towards a L2 global identity as a language student.

\section{"We imagined ourselves studying and working overseas/in English-speaking communities"}

All these students realised the importance of having academic experiences abroad and imagined themselves studying overseas in the future. However, some of them felt unsure of their future. Despite having relatives living overseas, Ake felt uncertain: "Even if my aunt could provide me with food and accommodation, my family's economic status is not quite good". He was aware of his financial constraints and likely expenses while living abroad. Despite their own concerns with financial matters, Rin and Chi seemed more likely to achieve their academic goal than Nott and Ake. Rin proudly asserted: "My dream of studying overseas will come true during my third year". They agreed: "We decided to study Business English because we would have an opportunity to study in Malaysia", with the partner of their home university. Rin's priority was "to communicate with them and understand their pronunciations or accents". Initially, she perceived that most of her friends were likely to "speak Thai one word and English one word". However, eventually she would make friends with others. "As a result, we could learn language and travel together". Her viewpoint echoed that she realised the variety of English usage in the new learning contexts. She was willing to learn, adjust, and familiarise herself with different varieties of English in order to initiate friendships and explore new cultures as she used to do during her high school. Together with these 
friends, she imagined herself speaking in English every day in their idealised academic settings across time and space. "Although we are different, we could understand each other". Importantly to achieve the goal, they were willing to open up their mind and learn linguistically and culturally.

As first-year students, they were uncertain about their future careers. Nott was aware of this: Rin understood that this might not be easy: "To me, it would be challenging if I could communicate with several groups of people who speak English with different accents or pronunciations, visit several tourist attractions in each country and learn their cultures". During her childhood, Chi dreamed of doing this job since her house was located near tourist attractions. Yet, she changed her career plan: "After taking the business course, I started thinking and sharing with my family that I would like to expand our business". Compared to others with different backgrounds, she intended to run an export business and grow her family business in foreign countries. "My parents cannot speak English, and do business only in the local market in Phuket". She affirmed: "As part of the integration of AEC, English would be important for sure. We have to do business with our neighbouring countries. If we do not speak, listen, and understand it, it should not be like that". If she could communicate in English effectively, she perceived it as a strength in helping to achieve her career plan in the future.

However, most of students perceived that passing a high level proficiency test could open the success door for them after graduation. Even so, getting English-speaking jobs is highly competitive and requires physical standards and linguistic assessments. They were well aware that it was challenging to get a high score in TOEIC to apply for their ideal jobs. One participant illustrated that after attending a field trip organised by her school to the aerodrome aviation control centre, she started imagined herself being an officer there. "To work there, I have to meet their requirement by obtaining high TOEIC scores, ranged at around 700-800". Rin said that taking TOEIC was important since "it could prove myself whether what I learned was good enough". No matter how they changed their career plan, all of them were well aware that they needed high scores in order to achieve their goal and meet the employers' compulsory requirements. They were conscious of their current linguistic limitations. They regarded the "one-round listening part" and "error identification" in the TOEIC test sample as "difficult...very difficult". As first-year 
students, they still did not have any concrete and systematic study plan to reach their goals. They remained hopeful, as they still had three more years to improve their linguistic abilities.

In conclusion, their stories echoed that they viewed English as indispensable to their future and they would have to spend time, energy, and effort both in class and out-ofclass to attain their academic and professional goals.

\section{Summary}

This chapter has presented three major themes emerging from the participants' narratives: speaking is our priority, people shaping us from cradle to college, and using English to open our eyes. Similarly, these four participants envisioned themselves as successful language learners and proficient English-users in their imagined communities. However, they held a variety of self-beliefs and perceptions of their intended effort in learning English in their learning environment. Several threads of their narrative data revealed that these participants' L2 self-identities were positively and negatively forged by significant people such as parents, relatives, teachers, peers, and NS and NNS interlocutors from the past, present, and future. Nonetheless, the participants played a pivotal role in regulating themselves to gain exposure of L2 lived and learning experiences, both locally and internationally, and to use English as a medium of communication in their imagined communities. 


\section{CHAPTER 7 DISCUSSION}

In this chapter, I discuss the participants' L2 learning experiences and self-identity based on Dörnyei's (2005, 2009) L2MSS model and Ushioda's (2009) person-in-context approach, as well as imagined communities (Norton, 2000; Wenger, 1998). This chapter develops the themes that emerged in the previous chapter. I capture how the participants extended their learning motivated behaviours and how their notions of L2 self (ideal L2 self and ought-to L2 self) were developed within class and in out-of-class settings. My analysis examines the fine details of learners' interpersonal and intrapersonal perceptions and feelings of their L2 experiences, their immediate learning environment, and an array of sociocultural aspects in the Thai context across time and space.

In addition, I discuss the thematic analysis as it aligns with the theoretical and conceptual framework. I focus on the macro-and-micro aspects of their language learning motivation and experiences.

\section{Tensions and dynamic interplay between their perceived skills and experiences}

In this section, I apply the theoretical framework which aligns with the first theme entitled "Speaking English is our priority". I capture the participants' varied perceptions of their L2 learning motivation and experiences. These reflect their motivated behaviours and the tensions operating among the factors of learning English, social interaction, and identity development in monolingual Thailand.

The participants had different attitudes towards what constituted desirable English pronunciation. There was a dichotomy between participants who strove for Standard English and those who embraced non-standard English norms. The former envisioned themselves speaking fluently like native speakers and aspired to Queen's English or Received Pronunciation. In contrast, the latter seemed to value Thai-English accents so long as their English was intelligible and prioritised this form of English as their medium of communication. They claimed their right to speak English within their national identity, and wished to maintain their "Thainess". However, both groups strongly agreed that currently English is widely used as an international language. They were aware that 
NNS people in expanding-circle contexts use ELF, especially in Asian regions due to the integration of AEC in 2015. This perception contrasts with Jindapitak and Teo's (2013a) findings indicating that the majority of their Thai participants preferred inner-circle accents as a model to upgrade their social status and did not favour localised forms of English. In this study, it seemed that my participants' ideal L2 selves were adapting to the changing sociocultural linguistic landscape of the country.

The participants' differing perceptions of idealised pronunciation had a major impact on the strength of their intended effort and self-efficacy in learning and using the L2. Consistent with Ushioda's (2011b) findings, it could be seen they were motivated to speak L2 by acting on their personal goals and previous learning experiences. The two participants, Nott and Rin, who held up native speakers of English as models, developed clearer ideal L2 selves. For instance, the two students who preferred NS accents could be seen as highly-sociable, cosmopolitan, regulated students, or high achievers, while the other two could be regarded as not very sociable, low achievers, unregulated, or escapist. Those participants who aspired to native speaker accents tried to speak English at school and made more vigorous efforts in diverse contexts than the other two participants. They seemed to try to reduce the discrepancy between their actual self and ideal L2 self. Their perceptions and behaviours were more productive than unregulated students who did not attempt to engage in L2 communicative activities. It appeared that their ideal L2 selves grew stronger than their ought-to L2 selves since they were not afraid of being labelled as "attention-seeking" or "Dadjarit" persons by their school friends. From their viewpoint, speaking with Thai-English accents hindered their goal of becoming a competent speaker of English. They empowered themselves by participating in a range of language successful experiences such as the Speaking Contest or working as an intern and parttime waiter at English-speaking organisations/workplaces.

In contrast, the other two participants aspired to speak their own style of English. They did not seek opportunities to converse with NS interlocutors. Their ought-to L2 selves were more influential than their ideal L2 selves. They seemed to avoid being out of their comfort zones even if they had a chance to mingle with NS and NNS interlocutors. Thus, they could not recount examples of speaking experiences with foreigners at their schools and other non-academic contexts. Interestingly, the participants perceived that speaking 
with NNS interlocutors did not harm their L2 self-identities but could boost their speaking self-efficacy. They valued and prioritised speaking English as a medium of communication, rather than orienting themselves to the target language accent/pronunciation.

The relationship between actual self, ideal L2 self and ought-to L2 self may have been influenced by their local context. Zooming into the sociocultural context in Thailand reveals that these participants studied in the context of an exam-oriented educational system. Throughout their school and university years, they appeared to struggle to pass a series of examinations, accumulated quizzes and achievement tests. The participants reported that the university admission exam in Thailand was the integral motivational element in determining their future success. It appeared that they strove to develop sufficiently strong ideal L2 selves to pass the test and major in English and BE. Gaining entry to prestigious universities as English majors was highly competitive. This situation suggested that institutional assessments directly affected parental, familial, and social expectations that contributed to their ought-to L2 selves. All the participants reported their desire to be academically successful. Also, their ideal L2 self continuously changed over contexts and time. This was particularly evident in their transition from school to university.

\section{Transition from school to university}

During the process of moving from school to university, these participants experienced challenges in becoming language students since all of them failed the written university admission exam. Two students, Nott and Chi, failed English-speaking interview tests at prestigious public universities. Like the marginalised participants in Norton's (2000, 2013a) studies, they seemed to struggle to develop their ideal L2 self and imagined identities that would enable them to improve their L2 learning and social lives. They reported that they could not speak English fluently because, as provincial and rural learners, they had insufficient time and limited opportunities to communicate with native speakers outside of class. However, they still persisted in achieving their academic goals by retaking examinations at other universities. Finally, while the two female participants were admitted as BE-major participants, the other two male participants successfully applied for a scholarship for underprivileged participants and were granted a government 
loan to pursue an English major. It could be seen that all of them imagined themselves enhancing their ideal self at university and improving their English proficiency after graduation. They might construe their majors, curriculum, and universities as "imagined communities" where their L2 self-identities could be forged and developed during the four-year study.

Zooming into these intrapersonal aspects, the findings indicated that all participants prioritised speaking skills and appeared to envision themselves as competent speakers of English. All participants strongly agreed that there was a mismatch between the implementation of the English Speaking Year 2012 policy and their personal motives and aspirations. Their school teachers, like those in other studies of EFL students, continued to use "traditional pedagogical practices and assessments" (Baker, 2015; Choomthong, 2014). In reality, the participants rarely had opportunities to practise speaking English at their school or in their daily lives. Nonetheless, they felt more motivated to study and to engage in a variety of communicative English activities at their universities. This is consistent with Magid's (2009) study which indicated that the university students' ideal L2 selves were likely to be more vivid and concrete than those of school participants. The participants expected that, to become successful language students, they would successfully reduce the gap between their actual selves and future possible selves. Also, they appeared to envision themselves having more frequent opportunities to improve their English proficiency and speaking skills at university in comparison with their time at school.

\section{Interwoven relationship between social and psychological aspects}

In this section, I apply the L2MSS theoretical framework aligned with the second theme entitled "People shaping us from cradle to college". Based on my findings, I discuss the interconnected angles of the participants' ideal and ought-to L2 selves which are considered controversial distinctions in the theoretical framework.

All participants indicated that their previous learning experiences and L2 learning attainment had both positive and negative influences on their present learning experiences. This finding corresponds with Dörnyei' $(2005,2009)$ L2MSS model which indicates that parents, family members, teachers, and peers impact students' L2 learning 
motivation and self-identity. However, these groups of people influenced the participants in contexts which are not entirely consistent with the L2MSS theory.

\section{Parents and familial influences}

The findings of my study show the interconnection between the participants' ideal and ought-to L2 selves in the Thai contexts. Consistent with Teimouri (2016) findings, by adding the actual self, he found that there are the interconnection between the ideal L2 self and ought-to L2 self which leads to links between the promotion-focus and prevention-focus. This does not align with the L2MSS model (Dörnyei, 2005, 2009) which categorises these two aspects of selves separately in positive and negative ways: (1) instrumentality-promotion means L2 learners internalised their intention to learn English for instrumental or pragmatic purposes such as getting a good job; (2) instrumentality-prevention means L2 learners are encouraged to learn English to meet the expectations of others. Interestingly, my findings reveal that the ideal and ought-to L2 selves harmonise and work together in several scenarios. As rural and provincial students, it could be seen that they imagined themselves majoring in English, becoming competent speakers, and getting good jobs. They seemed to struggle to reduce the discrepancy between their current selves and ideal L2 selves. They tended to employ both promotionfocused and prevention-focused motivational strategies to achieve their learning goals in their imagined communities. This affected the strength and frequency of putting forth their intended efforts, boosting their efficacious beliefs, and developing L2 self-system from school to university. The instrumental advantages were internalised as part of their ideal L2 selves. The instrumentality-promotion enabled them to regulate themselves acting on a long-term goal as proficient English-speaking users. They were willing to engineer their own mastery experiences by themselves such as accessing Englishlanguage resources and seeking out English-speaking contexts. Internally, they reported that they felt passionate about learning English without perceiving this process as a burden.

Nonetheless, the participants' ought-to L2 selves seemed to clash with a desirable selfimage. They were afraid of becoming rubber farmers, construction workers or food sellers, tough and low-paid jobs, like their parents. As part of their ought-to L2 selves, they tended to be more agentic and regulate themselves to study harder to avoid getting 
undesirable jobs in the future. In contrast with the findings of other research studies (Papi, 2014; Taguchi et al., 2009), which indicated that the learner's ought-to L2 self clashed with ideal L2 self, the combination of these two aspects of selves appeared to be positively interwoven and harmonised. Since they were well aware that their parents had invested a lot of hard-earned money on their studies, they internalised their families' expectations and sustained their intended effort so as to get secure jobs and support their families' social and financial well-being in the future.

\section{Pedagogical and institutional influences}

Although the participants had a clearer sense of their ideal L2 self after becoming language students, they defined the term "intended learning effort" or "English learning motivation" differently, depending on their previous background and prior learning experiences. Three of them (Nott, Rin, and Chi) affirmed that they tried to do their best to achieve their goals. However, all of them strongly agreed that they could not do their best.

During the critical period from being a spoon-fed learner at secondary school to becoming English-major university students, these undergraduates widened their vision of their L2 self-identities. This may have enhanced or conflicted with their actual self to some degree. With a sense of linguistic self-belief arising from their ideal L2 selves, they had to plan their study, taking responsibility for their own plans and learning to become more autonomous than when they were at school. Their self-beliefs not only related to their language learning motivation to pass the admission examination, but also oriented them to academic success and future careers. However, they needed to move beyond a heavy reliance on their teachers which had developed at school. They had to strive to study by themselves in the university context. To survive there, it could be seen that they had to boost their L2 self-belief and self-regulation to become autonomous learners in class and out-of-class settings. This means that they perceived that, as English-major and Business-English students, if they changed their attitudinal and behavioural perspectives, they could change their L2 self-identity themselves (Boonchum, 2010). That means that their identities were fluid and dynamic and were shaped by social and cultural influences on their L2 learning. 


\section{In-class learning experiences}

The participants reported that they enjoyed having individual speaking tests with their favourite NS teachers. The findings are contrary to previous studies (Khamkhien, 2012), that suggested that Thai participants felt anxious and embarrassed while communicating in English or performing speaking tests. In contrast, the participants revealed that their NS teacher had a positive impact on motivating their learning behaviours and speaking self-efficacy. Thus, teachers' motivational practice appears directly related to increasing the participants' level of language learning motivation in class (Guilloteaux \& Dörnyei, 2008). Despite undertaking tests, the participants felt motivated to speak with a low level of linguistic anxiety. Consistent with Dörnyei and Chan (2013), there was a strong relationship between future self-guide, intended effort, and grades among EFL learners. From the findings, the participants' ideal L2 selves were aligned with their actual selves when they engaged successfully in task-based and communicative speaking tests with their NS teachers. They reported feeling more able to create authentic dialogues and apply grammatical points learned in class. This allowed them to anchor their ideal L2 self within realistic expectations (Dörnyei \& Kubanyiova, 2014) since they visualised themselves speaking in scenarios which could apply to their daily lives and future professions.

However, the major difference was that the two participants, Nott and Ake, preferred fluency-oriented tasks whereas the other group of participants, Rin and Chi, were likely to engage with accuracy-oriented tasks. The first group felt motivated to perform impromptu activities in which they could speak spontaneously. They perceived that their ideal teacher engaged with participants as real people, social beings, rather than simply language students (Ushioda, 2009). When they were not treated as a "language learner", they did not feel forced to perform tedious grammar drills or rote-memory tasks. These demotivating strategies correspond with ought-to L2 self rather than ideal L2 self. That means they were not eager to do activities which did not engage their identity. Rather, they highly valued communicative-based activities which they could connect with their real life outside academic settings. This reflects a positive correspondence between the ideal and ought-to L2 selves of the participants. 
Thus, it could be concluded that their teachers ignited the vision and allowed them to construct an ideal L2 self (Dörnyei, 2009). Despite realising that they used broken English, they preferred to practise speaking English with the teacher with limited interruption or non-threatening instruction. They could then naturally learn from their grammatical mistakes without losing face among their peers because their teacher corrected mistakes indirectly. The teachers' feedback corresponded with the promotionfocused motivational strategies of their ideal L2 self.

In contrast, the other two participants, Rin and Chi, were more concerned about engaging in form-oriented activities. They particularly valued speaking English with correct grammar. The results are in line with Khamkhian's (2012) findings which indicated that memory strategies were the most commonly used strategies for typical Thai participants. In this study, both participants perceived that speaking using rote-memorisation before each test helped them avoid making grammatical errors and getting bad scores or grades. Their ought-to L2 selves were activated to meet their teachers' pedagogical expectations of competence from them. They attempted to regulate themselves to translate, memorise, and rehearse their dialogues with their peers several times before doing the real tests. They wanted to speak English correctly. Without doing so, they were afraid of speaking haltingly, not "Pae" or perfect. They appreciated enhancing their speaking efficacy without any embarrassment and face-losing among their peers. Consistent with Busse's (2013) findings, these L2 students' self-efficacy was interrelated with their ideal L2 self and they exerted intended effort in learning English.

The findings reveal that each participant had different perceptions and responses in comparison to their peers. It appeared that their ideal and ought-to L2 selves closely related to peer group norms, particular adolescents. These two aspects of selves could harmonise and conflict with each other, depending on the participants' perceptions, emotions, and experiences. For example, in the same speaking class, one participant perceived her more competent peers as her models who motivated her to try harder. Her ideal L2 self was activated in line with developing her L2 self-efficacy (Busse, 2013). In contrast, the other participant considered these peers as her competitors in the meansoriented or norm-referenced learning system. Additionally, by comparing them to her English proficiency and GPA, she felt inferior to them. Her ought-to L2 self conflicted 
with her academically desirable self-image and social identity. Similarly, as in Bandura (1997), lower self-efficacy students tend to feel more anxious and helpless than the higher ones.

After studying and completing two academic semesters, three participants, Ake, Rin, and Chi, became worried about their low GPA or becoming "Sil" students. They perceived learning language as an obligation or reported the influence of the ought-to L2 self which regulated them to try harder to avoid getting bad grades. Ideally, language learners should be aware of the gap between their current self and ideal L2 self to motivate them to increase their intended learning efforts. This awareness could drive them to do activities which would help to enhance their competency. However, each learner invested his or her time, energy, and effort differently out-of-class. Dörnyei (2009) points out that some learners may experience the absence of sufficient motivation. This affected their learning outcomes and L2 self-identities. He stated that some learners, despite being able to visualise their self-image as English users, lack a vivid roadmap (Dörnyei, 2009; Dörnyei \& Kubanyiova, 2014) and do not take effective action in reality. In my study, one participant did not report any learning stories that showed his effort and autonomy development outside of class, despite being categorised as a highly-motivated student based on the L2MSS survey. He felt motivated to listen to western music and sometimes downloaded MP3 on his smartphone to learn because these gave immediate pleasure. The self-regulation of his learning behaviour seemed less agentic in the longer term than other participants. With low self-efficacy and agency, he could not remotivate himself to gain self-directed learning experiences in academic and non-academic settings.

To sum up, each participant had different perceptions of their ideal teachers, language learning activities and their peers. They experienced harmony between their ideal and ought-to L2 selves differently while performing speaking tasks. While some participants perceived the rote-memorising activities as tedious and not fruitful, others held different perceptions which were influenced by their varied educational background, language learning motives and previous L2 learning experiences. 


\section{Forging their $\mathbf{L} 2$ self-identity in their imagined communities}

In this section, I discuss the final theme entitled "Using English to open up our eyes". I analyse and capture how their ideal and ought-to L2 selves were forged in their imagined communities in/across time and space. To some degree, their tensions also arose from encountering unexpected experiences in diverse contexts. Also, I discuss changing learning environments which impacted their L2 self and identity development during the transition between being school and university language students.

In this study, three participants realised the importance of AEC integration on their academic and professional paths. They could imagine themselves participating in “imagined communities" (Norton, 2000, 2013a; Norton \& Toohey, 2011). Without any overseas experience, three of them had a chance to have a field trip in Malaysia for the first time with their school teachers. The participants reflected that this opportunity opened up their worldviews and enabled them to share linguistic and cultural competences with their Malay friends. At university, the participants felt integratively motivated to interact with other Asian students and instrumentally work with people in the member states of ASEAN. Two female participants reported that they decided to major in Business English since the curriculum included one year of study in a prestigious Malaysian university. It could be seen that their ideal L2 selves provided the impetus to broaden their linguistic and cultural horizons in doing a variety of activities in Englishspeaking communities. Consistent with Dörnyei (2009, 2010), the ideal L2 self is strongly related to the notion of integrativeness and instrumentality-promotion. The participants seemed to envision themselves acquiring some practically academic and professional advantages of English use in their imagined communities. Hence, all of them strongly agreed that learning English in the classroom alone could not guarantee success in their future jobs. They appeared to struggle to find part-time jobs and imagined that they could practice using instrumental English in their English-speaking workplaces in their local contexts. Most of their ideal jobs were related to service industries such as becoming a tour guide or flight attendant.

However, all of them were concerned that they might not be competitive with other people from the AEC member states due to their limited English proficiency. It appeared that their ought-to L2 selves were highly influential and related to instrumentality- 
prevention (Dörnyei, 2005, 2009b). Their ought-to L2 selves were forged and influenced by their assumptions that other people/applicants from ESL contexts might outperform them. Specifically, they perceived that Thailand was very different from countries like Malaysia which had been a British colony. Consistent with Li's (2014) findings, these EFL participants had a higher level of prevention-instrumentality than ESL participants in other studies. With a low perception of their current competence, the participants decided to major in English or Business English to enhance their English proficiency. Three participants, Nott, Rin, and Chi, believed that they could attain a high score in the TOEIC test. Their ideal L2 selves and self-efficacy were greatly influenced by their relatives and senior friends' shared stories and experiences. In other words, they were exposed to successful models which positively fostered and enhanced their self-efficacy (Bandura, 1997). When they believed that they could learn English like others, they were able to purposefully engage in the self-regulation process and drive themselves towards their desired goals.

After graduation, all of them were aware of the importance of TOEIC and could relate this test to their desired jobs, despite their current position as first-year students. Activating their ideal L2 selves, they aimed to obtain high scores of this test. However, they were still uncertain about their current English proficiency and visualised themselves developing their English proficiency through their own efforts. Otherwise, they could not meet the requirement of their professional goals and would not gain opportunities in English-speaking workplaces. Their ought-to L2 selves were influential and internalized as part of their L2 self-identities. Consistently, the ideal L2 self is reconceptualised as the instrumentality which can be classified as promotion versus prevention, depending on "the extent of internalisation of external incentives" (Taguchi et al., 2009, p. 88). Their different perceptions of their desirable self-image had the potential to have a major impact on sustaining their motivated learning behaviours over time.

They internalised these two aspects of selves. Thus, the notion of instrumentalitypromotion and instrumentality-prevention could not be categorised separately for the participants in this study. The individual participants tended to use instrumental strategies in association with the instrumental orientation. Essentially, the challenge was to solve their puzzle of how to become successful language learners. Each individual participant 
differently exerted persistence and commitment. In addition, they applied different motivational strategies to regulate themselves engaging in English-speaking activities and enhancing their English proficiency. As seen from the findings, they envisioned themselves socially interacting with people in multiple imagined communities both in face-to-face and virtual communication.

\section{Out-of-class learning experiences: face-to-face communication}

The findings indicated that the participants held different perceptions of their selfregulatory activities in non-academic contexts. Two participants unfolded a greater variety of self-directed learning experiences and spent more time and exerted a greater intended effort and investment. They seemed to describe more concrete and meaningful learning processes and experiences than others both in authentic and virtual communication. It appears that the more they felt motivated to enhance their communicative or speaking skills, the earlier and longer they tended to initiate and maintain chatting with their foreign friends. Consistent with Wang and Rajprasit's (2015) findings, these Thai undergraduates strongly agreed that, to become successful language learners, they had to increase their speaking proficiency by expending adequate time and practice, gaining more opportunities to study in native-speaking countries and accessing English resources. As school students, the highly-sociable participants expressed their aspiration to attain fluency and imagined themselves speaking with native-like accents by engaging with virtual communities and identifying themselves as part of their imagined communities (Norton, 2000, 2013a). In light of their narratives, it could be seen that all participants strove to negotiate their L2 identities in their local contexts.

\section{Out-of-class learning experiences: virtual communication}

The act of accessing social networks had a crucial impact on their L2 global identityconstruction and the positioning of the participants in alignment with their language learning processes in imagined communities (Norton, 2000, 2013a). They sought out opportunities to learn English that served their personal needs and aspirations rather than focusing on integrating with any particular native-speaking communities. Interestingly, this scenario leads to new perceptions of ELF. 
Nonetheless, the participants had varied, clear visions of using ELF in diverse learning experiences. The high-sociable or cosmopolitan participants (high achievers) both echoed the positive association between their intended effort and imagination to communicate in English. They tended to make friends from different countries on the Internet in ELF communication. According to Wenger (1998), the concept of imagination refers to "a process of expanding our self by transcending our time and space and creating new images of the world and ourselves" (p. 176) and an "experience of identity" (p.215). Without any familial and institutional influences, they envisioned and regulated themselves to connect with their foreign friends (Murray, 2008b) through an array of social networks such as MSN, Facebook, Tweeter, and Line. They gradually developed a positive self-image and L2 global identity by chatting regularly with their NS and NNS friends. In addition, they felt they had a stronger sense of speaking efficacy after speaking with their foreign friends in face-to-face communication. At school they had very few opportunities to speak English in class. To empower their actual selves, they were agentic and persistent in speaking with their foreign friends through social networks. Eventually they enjoyed chatting, even with NNS interlocutors, maintaining relationships, while exchanging and gaining linguistic and cultural competencies simultaneously with the mobile technology (Ushioda, 2013). In particular, Ake and Chi, exercised a sense of ownership of their Thai-English accent as long as they could make themselves understood clearly and fluently in face-to-face and virtual communication.

The findings revealed that two female participants encountered both positive and negative experiences while accessing social networking. During online chatting, they exercised their agency by screening their chat partners and navigated advantages and disadvantages of accessing English-speaking communities through virtual communication. Yashima (2013a) suggests that, instead of integrating into the NS community, the EFL participants are likely to use English to gain linguistic and intercultural experiences simultaneously. However, these two participants needed to negotiate their L2 self-identities while encountering unexpected stereotyping problems, such as being perceived and treated as a sex worker. Actually, they could have withdrawn from the community but they decided to continue chatting. Maintaining their sense of self efficacy, they strongly believed in seeking foreign friends through social networks. In the virtual community of practice, there is no social class and no particular owner of the English language. The members of 
an online social network or chat rooms felt at ease in speaking and did not experience the high level of stress and linguistic anxiety of face to face communication (Richards, 2014). They were socially equal and had the right to initiate relationships and identify themselves with their NS and NNS friends (Darvin \& Norton, 2015; Norton, 2013a). While chatting online, they were legitimatised to speak as who they were, and they shared cultural and linguistic knowledge, either by verbally chatting or text-based chatting, depending on their preferences at the time. They had the right to make mistakes. It appeared that their ideal L2 selves and their motivated behaviours arising from interaction using technology tended to be sustained continuously and this process was associated with enhancing their autonomous learning (Stockwell, 2013).

To conclude, the individual participants held varied perceptions of and enacted different motivated behaviours during their out-of-class learning experiences. The high-sociable or cosmopolitan participants tended to access more self-directed exposure to English when participating in real and imagined communities of practice. In contrast, the low-sociable or unregulated students were less agentic to socially interact with other member in faceto-face and virtual communication. With limited experiences in non-academic contexts, it seemed that they were not concerned about being peripheral to the target language communities or being accepted by the member of their target language communities.

\section{Summary}

This chapter discusses the dynamic interplay of the four participants' motivated behaviours and L2 learning experiences in class and out-of-class settings. All participants perceived that their family members, teachers, and friends had positive and negative influences on actualising their motivational self-system during their transition from school to university. In aligning with the thematic analysis in the previous chapter, I analysed their motivated behaviours and the interconnection of ideal and ought-to L2 selves in diverse learning contexts. They felt motivated, and envisioned themselves being fluent speakers of English. Despite going through the varied L2 learning process, the participants were well aware of the importance of gaining exposure to L2 learning experiences in the local context and globalising world. 


\section{CHAPTER 8 \\ INTEGRATION OF THE THEORETICAL FRAMEWORK}

\section{Introduction}

In this chapter, I review my findings through the theoretical and conceptualised frameworks of L2MSS, persons-in-context, and imagined communities. Within the lens of SCT, I explore and capture how the Thai university students' identity-oriented components internally shaped and were externally shaped in the linguistic and sociocultural landscape of Thailand. In doing this, I recognise the limitations of my study as discussed in the next chapter and suggest that the theorising of my findings may provide direction for further research. I have adapted Dörnyei's L2MSS and presented persons-in-local-context and persons-in-global context of the Thai university students.

\section{Process of the Thai language learner's L2 motivational self-system}

The findings from my study lead me to propose that there are three interrelating components of the L2 identity. First, the notion of ideal L2 self fits within the boundary of the language learner's “desirable self-image” (Dörnyei \& Ryan, 2015, p.87). All participants aspired to become proficient speakers in English. Second, the notion of ought-to L2 self fits within the boundary of obligations or burdens such as parental and familial influences and expectations. Finally, I propose that the agentic actual self plays a crucial role. It was this that enabled the Thai students in my study to actualise and develop their L2 self-identities. 


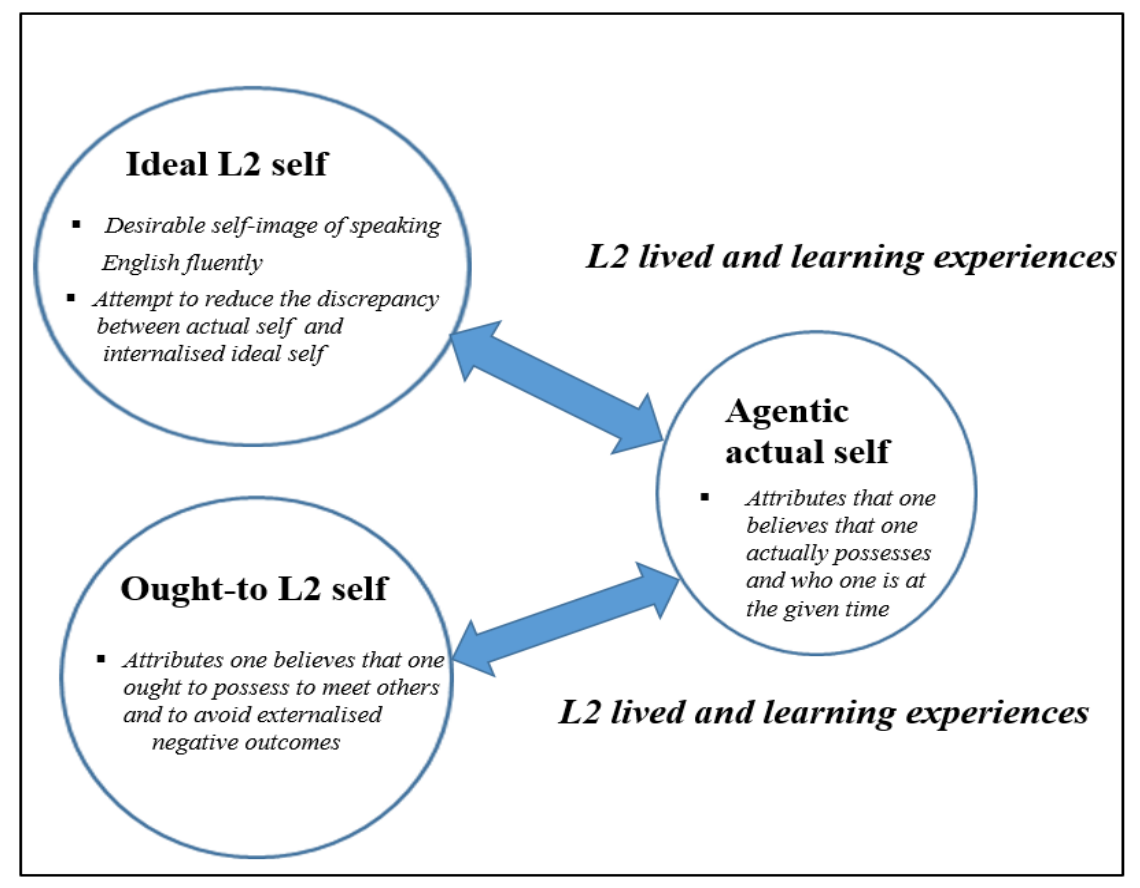

Figure 8.1 Process of the Thai language students' L2 motivational self-system

Dynamic interplay between the notions of ideal and ought-to L2 selves

In this diagram, I present a model that captures the interplay between ideal and ought-to L2 selves of the Thai students that were apparent in their narratives. The balance of these components changed according to whether these two selves were in a state of consonance or dissonance.

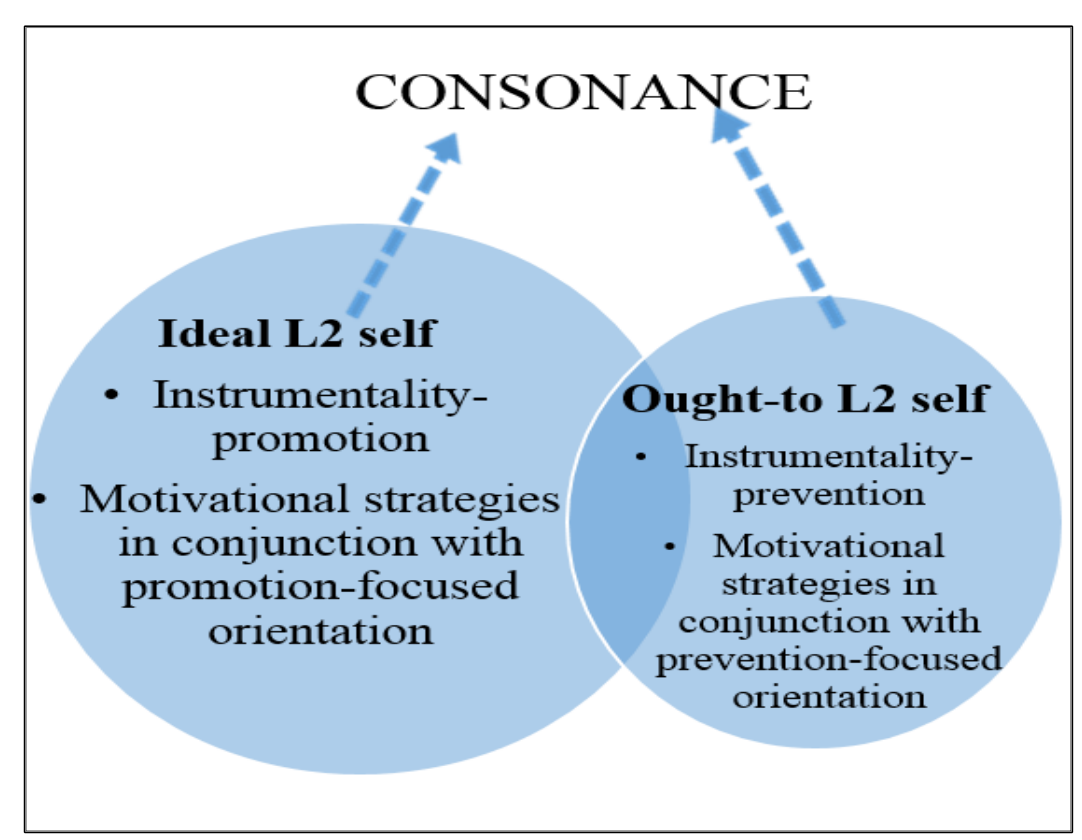

Figure 8.2 Model representing the state of consonance between ideal and ought-to L2 selves of the Thai language students 
As illustrated in Figure 8.2, the notions of ideal and ought-to L2 selves of the Thai participants were dynamically interconnected. When this occurred, the size of the ideal L2 self is bigger than the participant's ought-to L2 self because the level of the learner's motivated learning behaviours was internally stronger than learning to meet others' expectations. Their identities were fluid and fluctuated during the transition from school to university. In other words, my findings presents a new interpretation of Dörnyei's (2009) conception that the learner's ideal L2 self and ought-to L2 self are discrepant and separate. Rather, the evidence from my study indicates that the two notions of selves can coexist, work together, and become potentially productive, thus promoting L2 learning and leading to a state of consonance. The findings suggest that the Thai participants internalised their personal and collective goals to fulfil a desirable self-image as EFL Asian students (Lamb, 2013; Miyahara, 2015; Ryan \& Irie, 2014). This situation reflects a state of harmony between the participants' perceptions of their idealised self and their collective obligations.

The model in the diagram can be redrawn for each participant. Each of the participants recounted different self- regulatory strategies. The proportion of each component in the diagram could depend on the differences how the learners applied self-regulatory strategies to push themselves towards their pursued goal. The promotion-focused participants felt motivated to become proficient speakers of English. Then they told how they regulated themselves to approach desired end-states. They initiated a variety of selfregulatory strategies more intensely than the prevention-focus participants who were likely to avoid engagement.

However, my findings appear to indicate that the aspects of the instrumentality-promotion and instrumentality-prevention are able to coexist because the participants also used strategies associated with instrumentality-prevention to motivate themselves to pursue their goals. In some scenarios, the promotion-focused participants simultaneously used prevention-focused strategies to expend intended effort to avoid negative consequences (see Ake and Nott's in-class learning experiences in the Findings chapter, p. 95, 103). When their promotion-focused strategies increased, they needed to strive harder to complete activities and courses which went against their preferred motivational orientation in order to avoid getting bad grades/GPA or disappointing their parents. This 
may have resulted in a discrepancy between their ideal L2 self and ought-to L2 self to some extent. Consequently, they perceived that they did not do their best in studying English because their ought-to L2 self clashed with their actual self or personal identity. Nevertheless, they successfully harmonised these personal and collective goals as part of their L2 self-identities.

Additionally, there was a relationship between the individual participant's ideal L2 self and self-efficacy. Bandura $(1986,2001)$ recognised that learners could regulate their L2 learning agency, autonomy, and motivation in their learning environment. It is possible to distinguish two sources of self-efficacy arising from the participants' perceptions of their ideal L2 self and their L2 learning experiences. First, they decided to major in English and Business English since they perceived that these courses would enable them to improve their English proficiency. They believed that their teacher's pedagogical practices could enable them to achieve their ideal L2 selves. This sense of their selfefficacy was gradually boosted when they believed that they could enhance their English proficiency during their four-year programme of courses at university. Second, they highly valued in-class communicative and task-based activities. They gained a strong sense of self-efficacy when they performed meaningful linguistic tasks successfully. They attributed their success to ample opportunities to interact with their foreign teachers and international friends. Their efficacious beliefs coexisted with their ideal L2 self.

However, some participants perceived that they strove to learn English to meet social expectations and this coupled with negative learning experiences in their sociocultural contexts negatively impacted their motivational self-system. They did not feel motivated to learn and engage in activities which seemed irrelevant to their academic and professional purposes. 
In this section, I discuss the converse model showing the dynamic interplay between ought-to and ideal L2 selves of the Thai students.

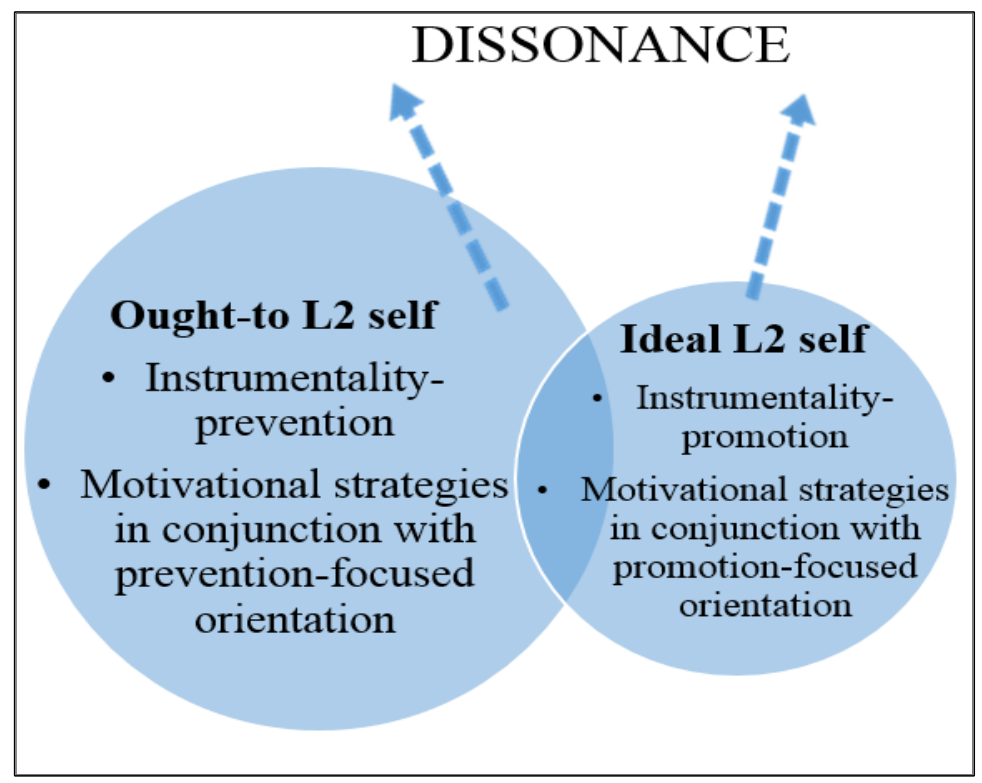

Figure 8.3 Model representing the state of dissonance between ought-to and ideal L2 selves of the Thai language students

On the other side of the coin, the situation was reversed when the ought-to L2 self was more influential than the ideal L2 self, as represented in Figure 8.3. Under this circumstance, the size of the ought-to L2 self is represented as bigger than the ideal L2 self because the participants tended to learn English to meet familial and social expectations, rather than exerting full internal effort on it. Without sufficient passion and motivation, some participants struggled to internalise their ideal L2 self and transform it into agency. The agentic current self then could not be activated and this led to a state of dissonance (see Figure 8.3). A "demotivated" student is one who "was once motivated but has lost his or her commitment or interest for some reason" (Dörnyei \& Ushioda, 2011, p. 138). Based on the findings of the L2MSS questionnaire, all the participants were categorised as highly-motivated students. However, the agentic self-regulation of their English learning was rather different, depending on the extent to which they internally and externally exerted their intended effort as part of their L2 self-identities.

Ake's account (see the section of my goals for learning English and in-class learning experiences in the Findings chapter, p. 84, 93) illustrates how he regarded his goal as an 
obligation. His ought-to L2 self was stronger than his ideal L2 self and was pulled apart his agentic current self. When his agency was declined by studying the grammartranslation method, he seemed unable to motivate himself to achieve his desired endstates or learning goals. In this respect he held prevention focus. Although he was comfortable performing communicative activities or tasks, he tended to avoid extending his full effort to participate in his reading courses. He did not value receptive skills such as reading for his future profession or regard them as an asset. Rather, he tended to apply prevention-focused strategies such as rote-memorisation and grammar-translation in his reading courses. His priority was to avoid failure in performing tasks and tests. By doing that, he realised that he could not do his best since his ought-to L2 self was stronger than his ideal L2 self. Being a risk taker of speaking confidently seems to contradict his wish not to make a mistake. These aspects had a negative impact on his actual self and selfefficacy. He attributed his lack of success in studying English to external or contextual factors such as teachers' demotivating pedagogical practices, rather than his own efforts.

In the Thai context, the sentence "Parents hired me to study" is commonly used to describe the sense of duty or obligation which some undergraduates hold. In contrast with Magid's (2009) findings, it appeared that these Thai students' dreams and ideal L2 self may not have always been consistent with his/her ought-to L2 self or family members' and parents' expectations. If the students decided to study English for solely instrumental reasons such as not failing English proficiency tests or avoiding being unsuccessful in their future career, they held prevention-focused instrumentality. In Ake's case, he could not internalise his instrumental motive and seemed to avoid exerting his full effort in studying all linguistic tasks assigned. Unavoidably, the clash between their personal and social identities may have impacted their L2 identity formation (Dörnyei, 2009). These participants did not gain sufficient opportunities for motivating communicative experiences either in class or out-of-class. They ended up as "Sil" students who obtained a low GPA, changed their major, or were even expelled. Their dreams thus turned into a fantasy. 


\section{Language learners' LLM and experiences in their imagined communities}

Drawing on the L2MSS and persons-in-context models, I will capture how the participants forged their L2 self-identities through socially interacting with interlocutors in their imagined communities. I draw on the notion of investment (Norton, 2000, 2013a) to gain insights into the students' identity development in provincial and rural contexts. In this study, the concept of imagined communities can be identified in relation to three areas: upgrading personal, academic, and social status; integrating into the AEC; and accessing communicative/English-speaking channels via a digital world.

Within the sociocultural landscape of Thailand, the students felt embedded in a hierarchical society which upheld concepts of social superiority and inequality (Baker, 2015). The rural participants perceived themselves to be held back by their social class and as having low proficiency in English and limited access to resources in their community (Baker, 2015; Draper, 2012a, 2012b). They perceived that they did not have sufficient input to become English-speaking users on the global stage.

As language learners, they also envisioned themselves developing communicative skills as part of their L2 identity. To increase their linguistic and cultural capital (Norton, 2000, 2013a), they were agentic in choosing to major in English and Business English which could provide an affordance for academic and professional success. Consistent with Darvin and Norton's (2015) investment model of capital, ideology, and identity, studying English was valued as a symbolic capital. To mitigate against limited resources and opportunities, two participants were agentic and empowered themselves by applying for scholarships and government loans to pursue their English major and participate in their imagined communities. They negotiated a sense of self and constructed their L2 identity by using opportunities to create their own social and cultural capital.

Importantly, the participants' parents were concerned about their future and did not want them to become "low-achieving", "low-cost", students or, even worse, unemployed people. Their parents struggled to provide financial support for their bright future profession. This collective agency appeared to empower these students to become successful language learners, upgrade their social class, and improve their family's well- 
being. English was thus regarded as an asset in a global society. Hence, investment played a vital role in forging these students' imagined identities.

Nonetheless, language learning motivation and L2 self-identity are context-dependent and learners tended to exercise their agency and autonomy differently in non-academic settings. My participants differed from Norton's participants who seemed to make a linguistic and cultural investment in the ESL context (Norton, 2000, 2013a). They felt motivated to learn English and become legitimate members of target language communities. In contrast, the participants in my study tended to focus on accuracy in order to pass tests and examinations and meet the standards set in the national and institutional policy. Thus, their agency, autonomy, sense of ownership were situated in the expanding circle of countries (Bolton, 2008; Kachru, 1998) where they could develop unique forms of linguistic and intercultural competence, rather than the inner circle of Norton's participants. In this study, Nott and Rin aspired to use Queen's English and put their intended effort in speaking English in various contexts. They exercised their power and strongly resisted instruction which they perceived as difficult, impractical, and irrelevant to their communicative goal. They attended class to comply with the university's rules and requirements despite feeling demotivated to engage in lessons. They perceived that their teachers exercised their authority through their institutional power by monitoring attendance. On the other hand, the students also exercised a form of autonomy through their resistance to engaging fully in class activities they did not consider relevant.

Figure 8.4 shows how the students accessed, gained L2 learning opportunities and negotiated their self-identities in their imagined communities. The three connected circles/boundaries could be categorised: persons-in-context, persons-in-global-context (face-to-face), and persons-global-context (virtual) models. The models shed light on language learners' perceptions and emotions regarding the external or sociocultural impact on their L2 self-identities. 


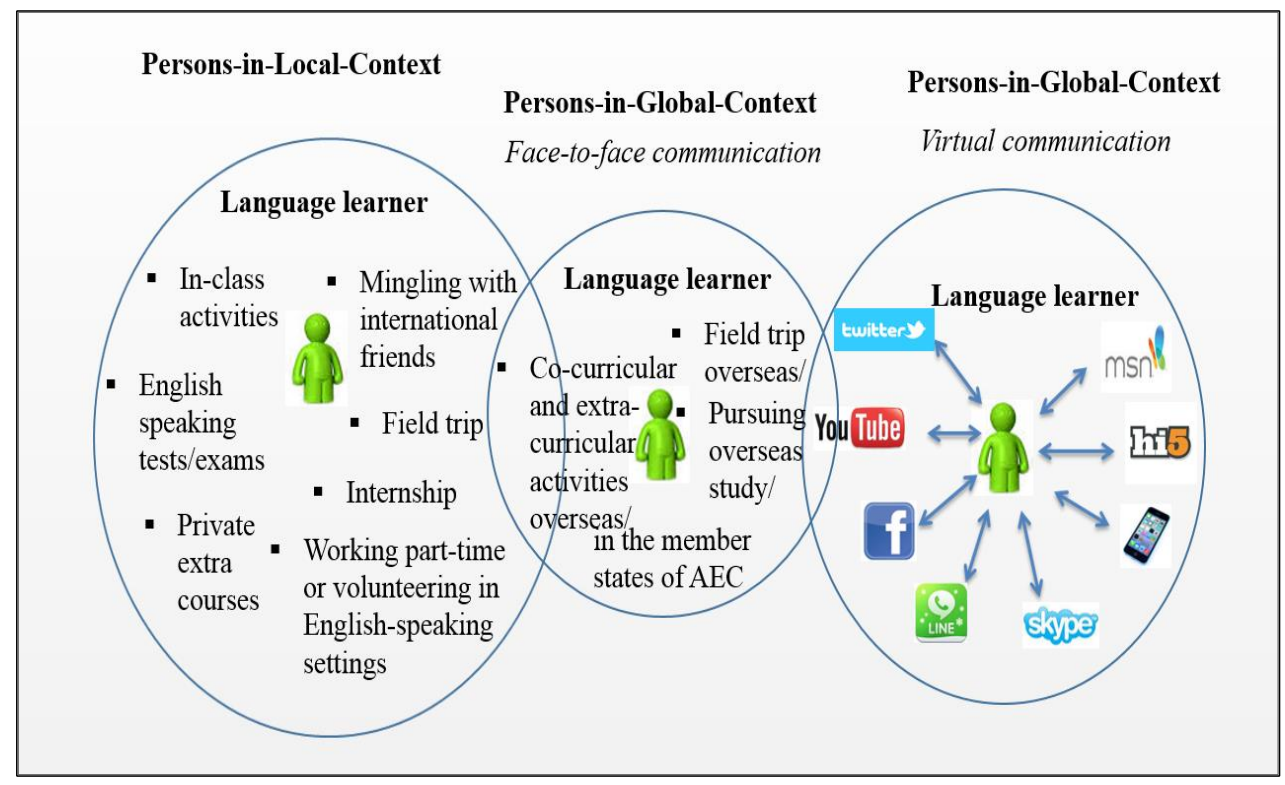

Figure 8.4 Persons-in-local-and-global context and persons-in-global-context models of the Thai university students

As depicted in Figure 8.4, the persons-in-local-context boundary (on the left), shows how the participants were motivated to study English in certain local contexts such as classrooms, field trips, and through a summer internship. The model illustrates that they chose to participate in communicative activities to enhance their L2 lived and learning experiences in their imagined communities. Ushioda (2011c) argued that "motivation is not necessarily achievement-oriented but value-based and identity-oriented" (p. 221). Consequently, social interaction played a vital role in forging the learners' motivation and autonomy as part of their L2 identity. The model therefore offers insights into their local and global learning experiences.

All participants highly valued and felt engaged in performing meaningful speaking activities. It seemed that their identities were stimulated and transported to being part of a community of English speakers during the interaction with their teachers and peers. The term transportable identities refers to the implicit, powerful components of learners' identities that allowed them to imagine themselves using English out-of-class and exert their motivational effort and investment (Falout, 2011; Richards, 2006; Ushioda, 2009, 2011a, 2011b). Apart from being language students, they also had transportable identities as daughters, sons, team leaders, full-time students, part-time hotel staff or volunteers. 
It is useful to revisit how the transportable identities of these L2 learners were constructed and developed in the Thai context. Asian or EFL learners seem to view self as interdependent with external or social relationships with parents, family members, and friends (Besser \& Chik, 2014; Lamb, 2012; Magid, 2009; Marcus \& Kitiyama, 1991). The participants' parents and family members played a vital role in pushing them to exert their intended effort and to become agentic and regulated learners. Despite finding lessons tedious and unproductive because of large classes at school, they strove to gain more exposure to remotivate themselves. They engaged in activities in out-of-class settings such as taking extra courses in English as a result of the influence and support of their families. The L2 learners' and their family's expectations thus coexisted and worked together to produce and develop the learner's agency, self-efficacy, and autonomy. Finally, the personal and collective identity forged their L2 self-identity as shown in Figure 8.4.

These transportable identities have the potential to explain these L2 learner's perceptions of engaging in creating experiential profiles in different contexts. To become language students, all participants realised the necessity of gaining more exposure to Englishspeaking communities. Their accounts reflected the interplay between their academic and non-academic learning experiences in diverse settings. Irie and Brewster (2013) regard the richness of experience as investing in "experiential capital" (p.125). The more they gained successful experiences of communicating with foreigners, the stronger their sense of self-efficacy became and was strengthened in different contexts. The L2 learners tended to be more agentic to speak English and initiated promotion-focused motivational strategies to attain their speaking experiences in out-of-class settings.

\section{Multiple membership and reconciliation in AEC integration}

To deepen an understanding of their L2 collective identity development in the era of ELF, I apply the notions of multiple membership and reconciliation. The term reconciliation means gaining various experiences and engaging in different forms of individuality which are intrinsic to learners' imagined identity (Wenger, 1998, p. 160). Although the process of reconciliation may not always be harmonious, it related to the participants' intended effort to coexist with other people from other countries and transport their L2 selfidentities from one community to another community (p. 160). Based on the persons-in- 
global-context in the middle of Figure 8.4, all students imagined themselves becoming members of the ASEAN community. In the AEC, English is regarded as "the working language" with a motto "One Vision, One Identity, One Community" (ASEAN Secretariat, 2008, p.29). In keeping with this vision, it appeared that the participants sought out opportunities to speak English with NS and NSS interlocutors in face-to-face communication during overseas study and internships. Unlike Gardner's (1985) mainstream concept of motivation in which learners imagined themselves integrating with the target language community. In this case, the community can be seen as the users of ELF in the AEC.

That is why the three circles or boundaries in Figure 8.4 are connected. Becoming motivated and autonomous learners relates to the interaction between the social environment and learners' perceived goals (Bandura, 2001; Murray, 2014; Ushioda, 2009, 2015). The participants were able to envision themselves studying, making friends, and gaining learning experiences at a Malaysian university. Consistently, their ideal L2 selves and imagined identities enabled them to exert effort to learn English and this was congruent with the educational policy and national interest (Islam et al., 2013). Sharing similar beliefs to the EFL learners in Ryan's (2009) study, the participants had a sense of membership of an imagined global community and perceived themselves as Englishspeaking users rather than expressing any desire to integrate with a target language community. In the process of glocalisation, English language has been globalised and increasingly "is being localised" as part of "the expression of local people's hearts and minds" (Schneider, 2011, p.229). The participants expressed a legitimate local and global identity as part of the ASEAN community. They attempted to shift from being the L2 learners to become the proficient English-speaking users. They compensated for a lack of communicative opportunities in their classroom settings and moved their transportable identities from an EFL to ELF context.

Most participants expressed their aspiration to be part of AEC communities integratively and instrumentally. Thus, I argue that these two notions of instrumentality-promotion and prevention could not be separated in practice. Contrary to Hays' (2014) findings, the Thai students did not perceive that English plays a role solely in upgrading their personal employment opportunities. Instead, they highly valued the role of English in achieving 
personal and collective goals. Some participants felt motivated to major in Business English and study in Malaysia. Gaining overseas experiences had the potential to boost their academic, social, and financial status and have a positive impact on their family. These EFL undergraduates strongly believed that gaining overseas experience could forge new social and imagined identities (Yashima, 2013a). This reflected the relationship between their imagined identities and instrumentality-promotion. Their L2 self-identities were mediated by their personal and collectivist goals. They strove to find part-time jobs or become volunteers because they attributed their future success to becoming Englishusers and gaining lived and learning experiences in English-speaking communities.

\section{Persons-in-global-context model (virtual communication)}

The persons-in-global-context model of virtual communication (on the right hand side) in Figure 8.4 has two-headed arrows to show the bi-directorial interaction between the English learners and their NS and NNS social networks on Facebook, Skype, and Line. EFL learners stimulated their own interest and motivation by using technology to support their L2 learning (Stockwell, 2013). They applied technological devices and smartphones as sociocultural tools to develop promotion-focus self-regulatory strategies and improve their English proficiency by themselves (see the Nott and Rin's out-of-class learning experiences in the Findings chapter, p. 106, 128). Despite having no Wi-Fi at home, they still attempted to access social networks at Internet cafes without viewing this as a burden of time and money.

The notion of autonomy can be applied to how the Thai students exercised their agency, engaged in imagined communities and eventually became legitimate members of virtual communities of practice. Their L2 identities were transportable to both in-class and outof-class settings. In this digital world, they exercised agency, initiated relationships and identified themselves with their NS and NNS friends through virtual social networks. They could engage in legitimate interactions in English without worrying about making grammatical errors, unlike in some of their mainstream institutional settings. The participants could expand their identity by "transcending time and space and creating new images of the world" (Wenger, p. 176). Their agentic behaviours exemplified how their transportable identities functioned in the digital world. 
Furthermore, the findings revealed how the learners accessed learning opportunities in their local context. To compensate for communicative constraints in their monolingual physical context, the participants engaged in imagined communities through accessing pop culture, English-language media and resources. The EFL learners' cosmopolitan identity was continuously developed by the impact of their access to social networks and pop culture (Besser \& Chik, 2014; Murray, 2008b). Their ideal L2 selves and transportable identities were embedded within western pop culture and seemed to be interwoven with local and global culture or a "bicultural identity" due to the impact of globalisation (Lamb, 2004, p. 15). Accessing technological devices enhanced their English proficiency and provided a positive link between activating and sustaining their ideal L2 self and intended effort in their imagined communities.

\section{Integrating the Thai Learners' L2 self-identities in their imagined communities through narrative approaches}

By applying the L2MSS and persons-in-context models, the findings of the study appear to add a new dimension to motivation research and L2 self-identity in their imagined communities. In this section, I propose a model to illustrate the dynamic interplay between the internal and external interaction which shapes the language learners' emerging self-identities as illustrated in Figure 8.5. The model is presented as a Concentric Circles diagram. 


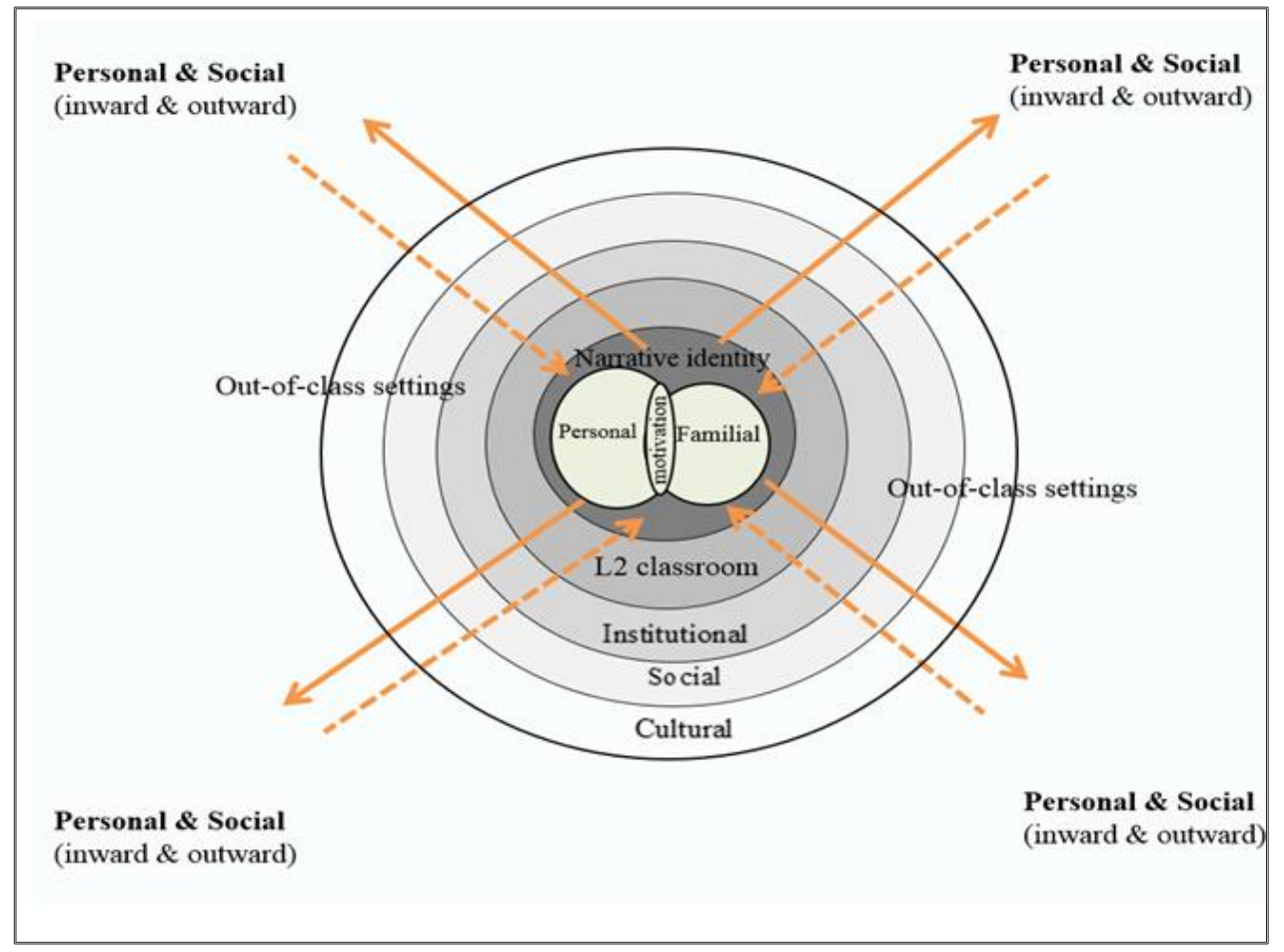

Figure 8.5 Concentric circles diagram of the Thai university students' emerging L2 selfidentities

Figure 8.5 illustrated that the language learners internally shaped and were externally shaped by varied motivational elements to become successful language learners in both in-class and out-of-class contexts. The bidirectional arrow shows the interconnection between a person-to-social and a social-to-person direction of the L2 learners' agency (motivation). As depicted in the centre, I portray the causal relations of the ideal L2 self and ought-to L2 self as the core of the L2 learners' emerging self-identities. Through their narratives, the individual participants shared with me their positive and negative perceptions and self-beliefs from their lived, learning experiences. Each person interpreted and self-evaluated his or her narratives differently in learning English from past, present, and future.

According to Dörnyei and Ryan (2015), L2 narrative identity is the core part of "an individual's ongoing internal narrative" which shapes L2 past experiences and forges future goals (p.202). The Thai university students' perception of their L2 motivation and self-identities was that they did not do their best to learn English. The term doing their best is related to ought-to L2 self or prevention-focus instrumentality often associated with engaging in the rote learning and grammar-translation to pass examinations at their 
school. However, when they entered into the university system and became Englishmajor students, they were encouraged to perform communicative activities or task-based projects to be fluent English-users.

Through their narratives, it was apparent that individual learners held different perceptions of striving for the best. The term what they ought-to be doing does not necessarily match with their ideal L2 self and eventually resulted in the state of dissonance or a mismatch between their self-concept and immediate learning environment. Their negative self-concept may have caused the lack of L2 motivation and affected the way they extended their effort. On the other hand, other students (e.g., Nott and Rin) appeared to feel motivated to study communicative English in class and constantly use promotion-focus strategies by extending full effort in accessing and participating in English-speaking communities such as working part-time or chatting with foreign friends in English-speaking communities. That means, what they ought-to be doing at their university matched with their desirable self-image and self-belief, which results in the state of consonance. However, from Rin and Chi's narratives, despite using promotion-focus strategies, they sometimes could not automatically switch from Englishlearners to English-users in their authentic communication while skyping with NS and NNS interlocutors. These negative experiences may have affected their self-concept to some degree. Thus, they perceived that they could not do their best no matter how hard and frequently they tried, because to them, their best was speaking with perfect grammar and pronunciation.

In this study, the Thai participants revealed intended learning effort, investment, and tensions of shifting from being EFL adolescent learners to proficient English-speaking users in their imagined communities. The Thai participants negotiated their agency and social identity in their sociocultural contexts. Their successes in the particular temporal period stemmed from varied degrees of internalised or externalised factors of motivational sources interacting within classroom and non-academic learning environment. As collectivists, they did not solely attribute their success to their own abilities but also to contextual factors. They tended to expend effort to meet their familial, institutional, and social expectations and norms. As a result, they perceived that, no 
matter what, they could not do their best in studying English due to several surrounding constraints and limited resources in their context.

Applying a narrative approach enabled the participants' perceptions and self-belief of L2 learning experiences to emerge. Their stories illustrate that motivation in L2 development does not relate to fixed individual differences, but it appears to be fluid and responsive to sociocultural factors. The approach has potential to portray the participants' identity construction and development which was highly individualised and contextualised. If the study had been conducted by using a purely quantitative study, the puzzle of the participants' motivational stories and self-identities would have lacked a specific context and remained unresolved. Their particular narratives are dynamically situated in contexts. Thus, contextualising L2 learners' experiences can fill some of the missing puzzle pieces in the participants' motivational stories and emerging self-identities.

\section{Summary}

The chapter has discussed the integration of the theoretical and conceptualised frameworks and presented models to showcase the Thai university students' L2 learning experiences and emerging self-identities in their imagined communities. Integrating the L2MSS and persons-in-context model yielded unique insights on how their perceptions of L2 motivational learning experiences affected their identity shift from being language learners to English-users in local and global contexts. As language students, even if they envisioned themselves being proficient English-users, they seemingly exerted different degrees of intended effort in learning English and gaining communicative experiences through face-to-face and virtual communication. As a consequence, they tended to use a range of motivational strategies according to their promotion-focused and preventionfocused instrumentality to forge their L2 self-identities. This narrative-oriented study illustrated the fluctuation of their agency, motivation, and identity development in their transitional experiences from school to university. 


\section{CHAPTER 9 \\ CONCLUSION}

\section{Introduction}

Constructing the puzzle reveals the participants' journey towards becoming proficient English-users in the era of AEC. This chapter commences with the contributions to the literature. This is followed by the methodological limitations of the study. Finally, the implications for practices, avenues for further studies and my final thoughts are discussed.

\section{Summary of findings}

The online questionnaire was administered to 356 Thai first-year undergraduates from a private and public university in Bangkok and southern part of Thailand. Quantitative data was analysed by using varied statistical approaches to select participants. The results of the findings are presented as follows.

Research question one: a) To what extent do the highly-motivated participants perceive that they exert intended effort and have self-efficacy in learning English?

In terms of the intended effort variable, the four participants were selected and categorised as students who perceived themselves as highly-motivated students. Nott and Chi had similar mean scores of intended effort above the mean score in average. Ake's mean score equated with the score of the average. Rin has the lowest mean score of intended effort.

Then, the four Thai university students were purposely selected and interviewed about their L2 learning motivation and experiences during the critical transition from school to university. The main contributions of this investigation are to reveal the perceptions of the adolescent learners' L2 learning experiences which internally and externally shaped their L2 self-identities. This was achieved through applying narrative approaches which attempted to minimise the power imbalance between the researcher and the students. Qualitative data arising from their individual survey and emerging from in-depth narrative interviews, artefacts, and English Language diary was analysed and summarised as follows. 
Research puzzle two: How do they report their past and present L2 learning motivation and experiences from school to university?

Based on their in-depth interviews, my findings indicate that the four Thai participants perceived that the rote-memorisation, grammar-translation, and examination-orientated approaches practised by their secondary and tertiary EFL teachers impacted their language learning motivation and self-identities. Compared to their L2 learning experiences at their schools, they reported that their NS and NNS teachers at their universities were likely to use authentic learning activities and task-based approaches which matched with their L2 learning motivation, efficacious beliefs, and self-identities. They prioritised speaking skills and felt highly motivated to attain communicative English to become proficient English-users. They perceived that, not only their teachers played a vital role in motivating their English learning, but their parents, relatives, and peers also had positive and negative influences on their L2 learning motivation, experiences, and identity development. Their ideal L2 self and ought-to L2 self seemed to be interconnected and worked together in their motivational system. They perceived that majoring in English and Business English and getting good grades/ GPA at the university could open opportunities for them to improve their English proficiency and communicative skills for academic and professional purposes. By investing their effort and time in these majors, they envisioned themselves improving their parents' and extended family's social status and well-being after graduation.

Research puzzle three: How do they report their in-class and out-of-class learning experiences of their English learning at their university?

Qualitative data in my findings showed that individual participants had varied perceptions of their preferred communicative and tasked-based activities. While some participants preferred the impromptu activities and individual speaking tests, others valued and used rote-memorising strategies to perform role play activities and dialogic tests with their teachers and peers. Despite being categorised as highly-motivated participants, they tended to exert their intended effort differently in learning English in class and out-ofclass contexts. Their ideal L2 self appeared to be strengthened by their sustained efforts to communicate in English in both formal and informal learning contexts. Due to AEC 
integration, they reported that their universities broadened their worldviews of global perspectives. For instance, the students at a public university could envision themselves studying English as junior international students at a Malaysian university in their thirdyear study. In addition, the participant at a private university had a stronger sense of speaking efficacy after communicating in English with NS and NNS interlocutors at International Program or joining a field trip in Myanmar.

\section{Contributions to Literature}

The integration of the results from the quantitative and qualitative study reveals new insights into LLM and L2 identity development. In the previous chapter, I review the contributions of integrating L2MSS and persons-in-context models in the linguistic landscape of Thailand. This section summarises how this study contributes to literature in Chapter three.

\section{Integrativeness and ideal L2 self of the Thai university students}

My study yields insights into these Thai university students' ideal L2 self. Previously, the approach to research conceived of L2 learners as static, rather than social human beings. They were motivated to acquire English by integrating with the target language community (Gardner \& Lambert, 1972). Dörnyei (2005, 2009, 2010) challenged this traditional concept of integrativeness which was mainly tested and validated in ESL contexts and reconceptualised it as the ideal L2 self.

My study suggests that the notion of ideal L2 self has more potential than integrativeness to illuminate the students' intended learning efforts in EFL contexts. The students were motivated to gain access to and communicate with both NS and NNS interlocutors via face-to-face and virtual communication because of the impact of globalisation and advanced digital technologies. I argue that these Thai university students did not aim to integrate in the target language community. Rather, they envisioned themselves belonging to the ASEAN community. Their ideal L2 self and transportable identities were developed to meet Thailand's integration of AEC in 2015 in local and global contexts. They held different perceptions of using a variety of English such as Standard English, functional English, and Thai English (Jindapitak \& Teo, 2013a; Tananuraksakul, 2012) to 
serve their particular purpose of communication both in-class and out-of-class. They exercised their agency to become legitimate members of the ELF community.

\section{Instrumentality and the Thai university students}

Instrumental motivation benefits from a consideration of the impact on the Thai students' L2 self and identity (Gardner \& Lambert, 1972; Gardner, 2001). Dörnyei's (2009) work reconceptualised the notion that instrumentality can be divided into two types. However, the relationship of these types of instrumentality: instrumentality-promotion (ideal L2 self) and instrumentality-prevention (ought-to L2 self), are ambiguous. The L2MSS has potential as a framework for further investigation of learners' intended learning effort in the Thai context.

My study reveals that the Thai university students seemingly exerted varied degrees of intended effort in learning English and gained exposure to face-to-face and virtual communication although they all imagined themselves being proficient English-users. They felt motivated to reduce the discrepancy between their actual self and their other two selves (Higgins, 1987, 1998). As a consequence, they tended to use different motivational strategies in association with promotion-focused and prevention-focused instrumentality to forge their L2 self-identities. By using promotion-focused strategies, some sociable participants regulated themselves to gain more exposure to a variety of learning experiences through face-to-face and virtual communication in their imagined communities. By using prevention-focused strategies, other participants were not likely to capitalise on the access to English resources and they did not participate in Englishspeaking communities of practice.

As discussed in the previous chapter, the interconnection of the ideal L2 self and ought-to L2 self indicated that the learners can apply both promotion-focus and prevention-focus instrumentality, depending on the extent to which they internally and externally exerted intended learning effort. In some scenarios, prevention-focus instrumentality can be used positively for the Thai undergraduates to regulate themselves to become fluent speakers of English. Particularly, they attributed their success to contextual factors and they exerted intended learning effort to meet their parents and family members' expectations and improve their social and familial status in the hierarchical society. 


\section{Inclusion of the self-efficacy in L2MSS}

Since the notion of actual self is not included in the L2MSS model, my study adds the self-efficacy to capture how the Thai students self-evaluate their linguistic capabilities in four skills and actualise their self-system in their immediate learning environment.

From my findings, it appears that L2 Learning experiences constitutes the key component of the tripartite model. Focusing on the Thai university students' narratives using the person-in-context relational view of motivation deepens the comprehension and comprehensiveness of the L2MSS model. SCT reveals how the students' self-efficacy, ideal L2 self and ought-to self were shaped and contextualised by institutional and social practises in classroom and out-of-class settings. Specifically, I could capture how they sustained their L2 motivation and shaped their self-identities from school to university which were situated in the era of Thailand integrating into AEC.

\section{Limitations of the study}

This study has several limitations. First, the qualitative data in this study is based on a small population sample, only four first-year students at two universities. Since the participants were born and grew up in southern Thailand, they may share similar perceptions of their L2 learning experiences and sociocultural impact on their L2 selfidentities. However, it is not generalisable to all English-major students in Thailand as a whole. In this narrative research, I selected to interview only four participants to gain indepth understanding of their L2 learning motivation, experiences, and self-identity. The small number of participants and contextualised nature of their narratives may lack generalisability to L2 learners in other contexts. Instead of making generalisations, the mixed methods sampling design focused on capturing particular students' perceptions and narratives of their L2 identity development within a particular context (Creswell, 2012, 2013).

Second, I administrated the online questionnaire and conducted narrative interviews in the different phases of my study. To some extent, the timing of each phase may have some influence on the learners' perceptions on their LLM and experiences. At the private university, I administered the online survey before they knew the academic results during a summer semester. At the public university, the online questionnaire and interviews were 
conducted in the summer break. The participants already knew their results and were really interested in attending the study and sharing with me their positive L2 learning experiences.

Third, in the beginning stage of interviewing, asking the participants to bring their artefact and share them with the researcher can be problematic in the sense that they may feel familiar with this process. All of the findings are self-reported. My qualitative data was based on the learners' perceptions and self-beliefs of their learning experiences through sharing their story-telling and artefacts with me. Specifically, one of my participants felt reluctant to share his academic failures. To avoid harming his identity, I did not force him to articulate his L2 learning experiences as an English-major student. Consequently, I was not able to restory his L2 learning experiences, compared to others. As an outsider at that university, I also had limited background knowledge about course contents, lecturers' teaching approach, and curriculum.

Finally, due to political unrest happening during my data collection, I could interview only a small number of participants at the private university and could not gain access to one public university in Bangkok. Fortunately, I received the greater cooperation from the participants at the public university because I was a lecturer there and could understand their L2 immediate learning environment as an insider. However, some participants felt uncomfortable sharing their negative stories relating to their teachers and curriculum. Thai students may often pay respect to their teachers and could have avoided discussing unsatisfactory learning experiences with the researcher which is regarded as cultural and ethical constraints in undertaking narrative research.

\section{Implications for practices}

There are implications for educational practices for language teachers, EFL learners, policy makers and parents as follows.

\section{Language teachers and learners}

- Pedagogically, the real challenges for teachers are how to create motivating activities that simulate real communication. How can teachers boost students' confidence and sense of autonomy to continue to enhance their skills by 
themselves? Teachers play a crucial role in engaging students in idealised activities which encourage students to improve their communicative competency. In some cases, teachers and students may frequently work together as co-teachers and co-learners in individualised dialogues, group-based activities, and classroom interaction. Such support may enable them to perform tasks independently in outof-class contexts. Thus, teachers should help them form their ideal L2 selves (Takahashi, 2013) and reinforce the idea that linguistic mistakes in communication often occur. Also, they can help learners boost their ideal L2 self in supported communicative situations (Sampson, 2016). If the students feel unmotivated in class, they can try to reconnect with enjoyable and fulfilling activities outside class as "a strategy for remotivating themselves" (Falout, 2011, p. 27).

- If students felt motivated by examination results or achieving high GPA, teachers may discuss the language students' duty to motivate them further. Teachers may illustrate the consequences of unsuccessful learners who did not put sufficient efforts into learning English and eventually failed to achieve their academic goal. This may help students activate their ideal and ought-to L2 selves and work harder on their studies. Weak students might not feel left behind and, even worse, become "Sil" students in the future (Anonymous, 2014).

- Teachers play a role in creating a practical, plausible roadmap of students' ideal L2 selves and motivating them to use their self-regulatory strategies. They may develop students' efficacious beliefs by integrating the four skills in their taskbased activities, quizzes, and examinations in more practical and meaningful ways. Rather than focusing on tedious grammar-translation activities and tests, teachers created communicative activities which engaged their L2 identity and sustained their learning motivation (Falout, 2011). For example, in reading classes, students could be encouraged not just to read complicated passages and memorise a long list of complicated vocabulary but also to have the opportunity to give a presentation in front of the class and have group discussion.

- One pedagogical possibility would be the application of sociocultural participatory activities in teaching practices to promote the learner's agency, 
autonomy, and motivation. My findings contribute to the implications from Yashima (2013a) who suggests that teachers connect local classroom communities to their L2 communities which encouraged students to use their own imagination and creativity. Engaging in language projects such as role play, drama production and improvisation not only enabled them to integrate with language learning, art, and pop culture in authentic communication but also enhanced fulfilling learning experiences in classroom settings (Nikitina, 2011). In the digital age, teachers may incorporate participating in students' imagined communities of practice by using smartphones and social media.

\section{Policy makers and curriculum designers}

- It is possible for curriculum designers to design pedagogical practices to be more flexible in the ELF era. Because of the AEC integration, English has been the "working language of ASEAN" with a slogan "One Vision, One Identity, One Community" (ASEAN Secretariat, 2008, p. 29). Despite having diversity among the member states of the community in ethnicity, races and religion, English has been widely used as a lingua franca to bridge the differences among us. To achieve their goal, the educators and teachers could design courses and curriculums which open up possibilities for learners to gain more exposure to a variety of English accents, particularly Asian Englishes in ELF, rather than solely focusing on Standard English or American and British accents/pronunciation. It may be time to take the Asian Englishes or Thai English into an account. Learners have their own right to speak as who they are as long as they can be understood (Ushioda, 2011a).

- In the AEC era, schools and universities play role in creating students' imagined communities, broadening their global perspectives, and fully equipping them with appropriate linguistic input and intercultural skills. Provincial and rural students should no longer be marginalised compared with upper-and middle-class groups of students in urban areas (Draper, 2012a, 2012b). To support these goals, educators and curriculum designers can promote collaboration among schools and universities in Thailand and the member states of AEC. For instance, the public university where I worked has adjusted the academic calendar in compliance with 
the ASEAN academic calendar to ensure Thai students can study abroad for one or two semesters without encountering any academic problems. Communicative activities and experiential student projects such as field trips, volunteering, internship, and cultural exchange programmes or "Buddy International Program" benefit the students. By participating in these activities, they will become more confident as English-users, create local and global networks and mutually share linguistic and cultural competences with a circle of Asian friends.

\section{Parents and family members}

- Thai parents are likely to perceive that English is important for their children. This could open the opportunity for their children to get a good job and better standard of life (Choomthong, 2014). In spite of having limited backgrounds in English, it appeared the participants' parents and family members in provincial areas played an important role in creating their children's imaginations from childhood. They provided their children with additional English-edutainment resources such as western DVDs, cartoons, and music. Doing these kinds of out-of-class activities could open up the students' linguistic and cultural competences. Some family members could be perceived as role models of a successful learner. Holding efficacious beliefs is crucial for EFL learners and could lead them to invest their efforts into language learning during their free time. Parents may support their students to take private courses with foreign teachers if they are interested, not under pressure. Parents may support them financially, investing to enrich their English learning experiences. The richness of gaining experiential capital could forge their L2 self-identity in the long run.

To conclude, family members, teachers, and policy makers play an integral role in encouraging Thai learners to take control of their language learning, gaining Englishspeaking experiences, and becoming lifelong, autonomous learners in the globalising world. 


\section{Avenues for further studies}

Further studies may capture the interface between in-class and out-of-class settings. Action research and classroom observation may be one potential way to explore the interaction and dialogue between teachers and students to capture their identities while performing communicative activities. This brings answers to such questions as "Why do students feel motivated or keep silent?" In what scenario or activities do they invest their efforts and time during their free time? How could they forge their L2 identities in faceto-face and virtual communication?

Future researchers may use artefacts such as in-class textbooks, activity tasks, or supplementary which students feel familiar and comfortable to talk about. It is necessary to consider the appropriate time to solicit artefacts. For instance, to establish trust and rapport, researchers build trust and boost participants' confidence to articulate and describe their L2 learning experiences in details. Additionally, students may be invited to bring or take photos while performing their favourite linguistic activities both in class and out-of-class settings (if having). Thus, the photo or personal artefact becomes the starting point of prompting effective narrative interviews which eventually yield processes of their L2 learning experiences in various contexts.

The students' learning motivation and identity gradually changed and developed from the first year to the fourth year through their L2 lived and learning experiences. Further research may investigate learners' efficacious beliefs and changes in their motivated behaviours during different stages of their English learning. Capturing how students use promotion-focus and prevention-focus motivation strategies has potential to create understanding of their engagement in their authentic communication (Higgins, 2012). For future curriculum development, a contextually-rich longitudinal study could be conducted to explore language students' perception of their L2 learning motivation and processes. In this regard, the researcher may collect and analyse their learning stories after completing each semester or academic year. More research needs to be undertaken on the studyabroad of Thai university students. Different methodologies such as using English diaries may have the potential to empower students' unheard voices, and to triangulate with other datasets (Barkhuizen et al., 2014). This may yield insights into the relationships among self-oriented variables which affect learners' L2 identity development. 


\section{Final thoughts}

Reflecting on my previous experiences, I perceive myself as a teacher who taught using textbook-based and grammar-translation approaches. I did not consider students' identities in my teaching. Rather, my concern was to how to teach them to understand key content, pass the course and complete the curriculum. However, my perception changed after undertaking this study. Based on my findings, in spite of being categorised as highly motivated students, they may or may not regulate themselves to focus all English skills in class and out-of-class settings because of their personal and contextual constraints. In the future, I will not make assumptions or jump to the conclusions about my students' LLM because there are culturally-embedded factors that need to be considered. In particular, instead of asking how to motivate students to study English in class, it may be more useful to consider what kinds of tasks motivate students in the L2 learning process and how students can drive themselves to study as lifelong learners. In the future, I will pay more attention to creating communicative activities which boost students' self-confidence and promote their learners' autonomy.

From my perspective, the students' L2 lived and learning experiences are like a drama. Their lives were like a book chapter or a novel. Some parts were complicated and emotional. As a narrative researcher, I tried to find the missing pieces of their puzzle through interview transcripts and their artefacts. It worked very much like a jigsaw puzzle. The pieces of their small stories and experiences were assembled and presented as a big story which represents their collective and social narrative identities. As a narrative researcher, I was delighted to interview a small group of passionate students who dreamed of mastery in speaking English and strove to weave their dreams to be true. Hopefully, I could make some contribution to teaching and learning in my home university in the future. I look forward to seeing my participants in person, having a lively discussion, and gaining profound insights of their two-semester lived, learning experiences while studying in Malaysia. Additionally, I want to be a cultural ambassador in the sense that my thesis could reveal unheard voices and capture a naturalistic picture of the Thai students' L2 personal and collective identity to outsiders and westerners. 


\section{REFERENCES}

Analysing the "Dek Sil" problem: Waste of tertiary education. (2014, June 20-26).

Siamrath Weekly, 61(40), p.40.

Anderson, B. (1991). Imagined communities: Reflections on the origin and spread of nationalism (Revised edition). London: Verso.

Andrews, M. (2007). Exploring cross-cultural boundaries. In D. J. Clandinin (Ed.), Mapping a landscape of narrative inquiry (pp. 489-511). Thousand Oaks, CA: Sage.

Arnett, J. (2002). The psychology of globalization. American psychologist, 57 (10), 774 783.

ASEAN Secretariat. (2008). The ASEAN charter. Jakarta, Indonesia: ASEAN Secretariat.

Retrieved from

http://www.asean.org/storage/images/ASEAN_RTK_2014/ASEAN_Charter.pdf.

Baker, C., \& Phongpaichit, P. (2005). A history of Thailand. New York, NY: Cambridge University Press.

Baker, W. (2008). A critical examination of ELT in Thailand: The role of cultural awareness. RELC Journal, 39(1), 131-146.

Baker, W. (2012). English as a lingua franca in Thailand: Characterisations and implications. English in Practice, 1, 18-27.

Baker, W. (2015). Culture and identity through English as a Lingua Franca: Rethinking concepts and goals in intercultural communication. Boston: De Gruyter Mouton.

Bamberg, M. (2004). Talk, small talks, and adolescent identities. Human Development, 47, 366-369.

Bamberg, M. (2010). Who am I? Narration and its contribution to self and identity. Theory \& Psychology, 2(1), 1-22.

Bamberg, M. (2012). Narrative analysis. In H. Cooper (Ed.), APA handbook of researches methods in psychology. Washington, D.C.: APA Press.

Bandura, A. (1986). Social foundations of thought and action: A social cognitive theory Englewood Cliffs, NJ: Prentice-Hall.

Bandura, A. (1989). Self-regulation of motivation and action through internal standards and goal systems. In A. Pervin (Ed.), Goal concepts in personality and social psychology (pp. 19-85). Hillsdale, NJ: Lawrence Erlbaum Associates. 
Bandura, A. (1993). Perceived self-efficacy in cognitive development and functioning. Educational Psychologist, 28, 117-148.

Bandura, A. (1997). Self-efficacy: The exercise of control. New York: Freeman.

Bandura, A. (2000). Exercise of human agency through collective efficacy. American Psychological Society, 9(3), 75-78.

Bandura, A. (2001). Social cognitive theory: An agentic perspective. Annual Review of Psychology, 52(1), 1-26.

Barkhuizen, G. (2010). Narrative knowledging in TESOL. TESOL Quarterly, 45, 391414.

Barkhuizen, G., Benson, P., \& Chik, A. (2014). Narrative inquiry in language teaching and learning research. New York: Routledge.

Besser, S., \& Chik, A. (2014). Narratives of second language identity amongst young English learners. ELT journal, 68(3), 299-309.

Braun, V., \& Clarke, V. (2006). Using thematic analysis in psychology. Qualitative Research in Psychology, 3(2), 77-101.

Braun, V., \& Clarke, V. (2013). Successful qualitative research: A practical guide for beginners. Thousand Oaks, CA: Sage.

Block, D. (2003). The social turn in second language acquisition. Edinburgh: Edinburgh University Press.

Block, D. (2007). The rise of identity in SLA research, post Firth and Wagner (1997). Modern Language Journal, 91, 861-874.

Bolton, K. (2008). English in Asia, Asian Englishes, and the issue of proficiency. English Today, 24(2), 3-12.

Boonchum, P. (2010). A study of self-identity changes and correlation of influential factors of Thai students studying English. The Buckingham Journal of Language and Linguistics, 3, 35-55.

Bourdieu, P. (1991). Language and symbolic power. Cambridge, MA: Harvard University Press.

Buripakdi, A. (2012). On professional writing: Thai writers' views on their English International Journal of Applied Linguistics, 22(2), 245-264.

Busse, V. (2013). An exploration of motivation and self-beliefs of first year students of German. System, 41(2), 379-398. 
Busse, V., \& Walter, C. (2013). Foreign language learning motivation in higher education: A longitudinal study of motivational changes and their causes. The Modern Language Journal, 97(2), 435-456.

Campbell, E., \& Storch, N. (2011). The changing face of motivation: A study of second language learners' motivation over time. Australian Review of Applied Linguistics, 34(2), 166-192.

Canagarajah, S. (2006a). Changing communicative needs, revised assessment objectives: Testing English as an international language. Language Assessment Quarterly, 3(3), 229-242.

Canagarajah, A. S. (2006b). Negotiating the local in English as a lingua franca. Annual Review of Applied Linguistics, 26, 197-218.

Charmaz, K. (2002). Qualitative interviewing and grounded theory analysis. In J. F. Gubrium \& J. A. HoIstein (Eds.), Handbook of interview research: Context and method. Thousand Oaks, CA: Sage.

Choomthong, D. (2014). Preparing Thai students' English for the ASEAN Economic Community: Some pedagogical implications and trends. Language Education and Acquisition Research Network, 7(1), 45-57.

Chen, S. A. (2012). Motivation and possible selves: An interview study of Taiwanese EFL learners. Language Education in Asia, 3, 50-59.

Choomthong, D. (2014). Preparing Thai students' English for the ASEAN Economic Community: Some pedagogical implications and trends. Language Education and Acquisition Research Network, 7(1), 45-57.

Clandinin, D. J. (2013). Engaging in narrative inquiry. Walnut Creek, CA: Left Coast.

Clandinin, D. J., \& Connelly, F. M. (2000). Narrative inquiry: Experience and story in qualitative research. San Francisco: Jossey-Bass.

Clandinin, D. J., \& Murphy, M. S. (2007). Looking ahead: Conversations with Elliot Mishler, Don Polkinghorne, and Amia Lieblich. In D. J. Clandinin (Ed.), Mapping a landscape of narrative inquiry (pp. 632-650). Thousand Oaks, CA: Sage.

Clandinin, D. J., \& Rosiek, J. (2007). Mapping a landscape of narrative inquiry. In D. J. Clandinin. (Ed.), Handbook of narrative inquiry: Mapping a methodology (pp. 3575). Thousand Oaks, CA: Sage.

Cohen, L., Manion, L., \& Morrison, K. (2007). Research methods in education (5th ed.). London: Routledge Falmer. 
Connelly, F. M., \& Clandinin, D. J. (1990). Stories of experience and narrative inquiry. Educational Researcher, 19(5), 2-14.

Connelly, F. M., \& Clandinin, D. J. (2006). Narrative inquiry. In J. L. Green, G. Camilli, \& P. Elmore (Eds.), Handbook of complementary methods in education research (pp. 477-487). Mahwah, NJ: Lawrence Erlbaum.

Creswell, J. W. (2012). Educational research: Planning, conducting, and evaluating quantitative and qualitative research (4th ed.). Boston: Pearson.

Creswell, J. W. (2013). Qualitative inquiry and research design: Choosing among five approaches (4th ed.). Los Angeles: Sage.

Creswell, J. W. (2014). Research design: Qualitative, quantitative and mixed methods approaches (4th ed.). Thousand Oaks, CA: Sage.

Creswell, J. W., Hanson, W. E., Clark Plano, V. L., \& Morales, A. (2007). Qualitative research designs: Selection and implementation. The Counseling Psychologist, 35(2), 236-264.

Creswell, J. W., \& Plano Clark, V. L. (2011). Designing and conducting mixed methods research. Los Angeles: Sage.

Csizer, K., \& Dörnyei, Z. (2005a). Language learners' motivational profiles and their motivated learning behaviour. Language Learning, 55(4), 613-659.

Csizér, K., \& Dörnyei, Z. (2005b). The internal structure of language learning motivation and its relationship with language choice and learning effort. The Modern Language Journal, 89(1), 19-36.

Crookes, G., \& Schmidt, R. W. (1991). Motivation: Reopening the research agenda. Language Learning, 41, 469-512.

Darvin, R., \& Norton, B. (2015). Identity and a model of investment in applied linguistics. Annual Review of Applied Linguistics, 35, 36-56.

Deerajviset, P. (2014). The ASEAN community 2015 and English language teaching in Thailand. Songklanakarin Journal of Social Science and Humanities, 10(2), 39-75.

Denzin, N. K. (1989). Interpretive Interactionism. New Bury Park, CA: Sage.

Draper, J. (2012a). Reconsidering compulsory English in developing countries in Asia: English in a community of Northeast Thailand. TESOL Quarterly, 46(4), 777-811.

Draper, J. (2012b). Revisiting English in Thailand. The Asian EFL Journal Quarterly, 13(4), 9-38. 
Dörnyei, Z. (1994a). Motivation and motivating in the foreign language classroom. Modern Language Journal, 78(3), 273-284.

Dörnyei, Z. (1994b). Understanding L2 motivation: On with the challenge! Modern Language Journal, 78(4), 515-523.

Dörnyei, Z. (2001). Motivational strategies in the language classroom. Cambridge: Cambridge University Press.

Dörnyei, Z. (2005). The psychology of the language learner: Individual differences in second language acquisition. New Jersey: Lawrence Erlbaum.

Dörnyei, Z. (2009). The L2 motivational self system. In Z. Dörnyei \& U. Ema (Eds.), Motivation, language identity, and the L2 self (pp. 9-42). Bristol: Multilingual Matters.

Dörnyei, Z. (2010). Researching motivation: From integrativeness to the ideal L2 self. In

S. Hunston \& D. Oakey (Eds.), Introducing applied linguistics: Concepts and skills (pp. 74-83). London: Routledge.

Dörnyei, Z., \& Chan, L. (2013). Motivation and Vision: An analysis of future L2 self images, sensory styles, and imagery capacity across two target languages. Language Learning, 63(3), 437-462.

Dörnyei, Z., \& Csizér, K. (2002). Some dynamics of language attitudes and motivation: Results of a longitudinal nationwide survey. Applied Linguistics, 23(4), 421-462.

Dörnyei, Z., Csizér, K., \& Németh, N. (2006). Motivation, language attitudes and globalisation: A Hungarian perspective. Clevedon: Multilingual Matters.

Dörnyei, Z., \& Kubanyiova, M. (2014). Motivating learners, motivating teachers: Building vision in the language classroom. Cambridge: Cambridge University Press.

Dörnyei, Z., \& Ryan, S. (2015). The psychology of the language learner revisited. New York, NY: Routledge.

Dörnyei, Z., \& Taguchi, T. (2010). Questionnaires in second language research: Construction, administration, and processing. London, UK: Routledge.

Dörnyei, Z., \& Ushioda, E. (2011). Teaching and researching motivation (2th ed.). Harlow, UK: Pearson.

Draper, J. (2012a). Reconsidering compulsory English in developing countries in Asia: English in a community of Northeast Thailand. TESOL Quarterly, 46(4), 777-811. 
Draper, J. (2012b). Revisiting English in Thailand. The Asian EFL Journal Quarterly, 13(4), 9-38.

Educational Testing Service (ETS). (2015). 2015 Report on test takers worldwide: The TOEIC listening and reading test. Princeton, NJ: Educational Testing Service. Retrieved from https://www.ets.org/s/toeic/pdf/ww_data_report_unlweb.pdf.

Falout, J. (2011). Pedagogical implications of motivation research: An interview with Ema Ushioda. The Language Teacher, 35(2), 25-28.

Field, A. P. (2013). Discovering statistics using IBM SPSS Statistics: And sex and drugs and rock " $n$ " roll. London: Sage.

Fitzpatrick, D. (2011). Making sense of the English language proficiency in Thailand: An exploration of teachers' practices and dispositions (Unpublished doctorate's thesis). University of Exeter, UK.

Foley, J. A. (2005). English......in Thailand. RELC Journal, 36(2), 223-234.

Fredrickson, T. (2012, January 12). Mission impossible? Getting Thai students to speak English. Bangkok Post. Retrieved from http://www.bangkokpost.com/learning/easier-stuff/275993/mission-impossiblegetting-thai-students-to-speak-english

Fujiwara, T. (2011). Language learning beliefs of Thai EFL university students:

Dimensional structure and cultural variations. Electronic Journal of Foreign Language Teaching, 8(1), 87-107. Retrieved from http://eflt.nus.edu.sg/v8n12011/fujiwara.pdf

Gao, X. (2010). Autonomous language learning against all odds. System, 38(4), 580-590.

Gao, Y., Li, Y., \& Li, W. (2002). EFL Learning and self-identity construction: Three cases of Chinese college English majors. Asian Journal of English Language Teaching, 12, 95-119.

Gardner, R. C. (1985). Social psychology and second language learning: The role of attitudes and motivation. London: Edward Arnold.

Gardner, R. C. (2001). Integrative motivation: Past, present, and future. In Z. Dörnyei \& R. Schmidt (Eds.), Motivation and Second Language Acquisition [Technical Report\# 23]. Honolulu: University of Hawai'i, Second Language Teaching and Curriculum. 
Gardner, R. C. (2010). Motivation and second language acquisition: The socioeducational model. New York: Peter Lang.

Gardner, R. C., \& Lambert, W. E. (1972). Attitudes and motivation in second language learning. Rowley, MA: Newbury House.

Gass, S. M., \& Mackey, A. (2000). Stimulated recall methodology in second language research. Mahwah, NJ: Lawrence Erlbaum Associates.

Geerson, E. B. (2013). The anti-linguistic imperialism of ELF and its implications for English language learning and teaching in Thailand. Thammasat Journal, 31(3). doi:164.115.22.25/ojs222/index.php/tuj/article/download/198/194

George, D., \& Mallery, P. (2011). SPSS for Windows step by step: A simple guide and reference, 18.0 update (11th ed.). Upper Saddle River, NJ: Prentice Hall.

Graddol, D. (2006). English next. Plymouth, UK: The British Council.

Guilloteaux, M. J., \& Dörnyei, Z. (2008). Motivating language learners: A classroomoriented investigation of the effects of motivational strategies on student motivation. TESOL Quarterly, 42(1), 55-77.

Hadfield, J., \& Dörnyei, Z. (2013). Motivating learning. Harlow: Longman.

Hayes, D. (2010). Language learning, teaching and educational reform in rural Thailand: An English teacher's perspective. Asia Pacific Journal of Education, 30, 305-319.

Hayes, D. (2014). The value of learning English in Thailand and its impact on Thai: Perspectives from university students. Asia Pacific Journal of Education, 36(1), 73-91.

Hesse-Biber, S. N. (2010). Mixed methods research: Merging theory with practice. New York, NY: Guilford.

Higgins, E. T. (1987). Self-discrepancy: A theory relating self and affect. Psychological Review, 94(3), 319-340.

Higgins, E. T. (1998). Promotion and prevention: Regulatory focus as a motivational principle. In M.P. Zanna (Ed.), Advances in experimental social psychological (Vol.30) (pp. 1-46). New York: Academic Press.

Higgins, E. T. (2012). Beyond pleasure and pain: How motivation works. New York, NY: Oxford University Press.

Hodal, K. (2012, February 14). Thai schools urged to boost speaking. The Guardian. Retrieved from https://www.theguardian.com/education/2012/feb/14/thailandspeak-english-campaign 
Islam, M., Lamb, M., \& Chambers, G. (2013). The L2 motivational self system and national interest: A Pakistani perspective. System, 41 (2), 231-244.

Irie, K., \& Brewster, D. (2013). One curriculum, three stories: Ideal L2 self and L2-selfdiscrepancy profiles. In M. Apple, D. da Silva, \& T. Fellner (Eds.), Language learning motivation in Japan (pp. 110-128). Bristol, UK: Multilingual Matters.

Jenkins, J. (2000). The phonology of English as an international language: New models, new norms, new goals. Oxford: Oxford University Press.

Jenkins, J. (2006). Current perspectives on teaching world Englishes and English as a lingua franca. TESOL Quarterly, 40(1), 157-181.

Jenkins, J. (2009a). English as a lingua franca: Interpretations and attitudes. World Englishes, 28(2), 200-207.

Jenkins, J. (2009b). Unpleasant? Incorrect? Unintelligible? ELF speakers' perceptions of their accents. In I. A. Mauranen \& E. Ranta (Eds.), English as a lingua franca: Studies and findings. Newcastle: Cambridge Scholars.

Jindapitak, N., \& Teo, A. (2013a). Accent priority in a Thai university context: A common sense revisited. English Language Teaching, 6(9), 193-204.

Jindapitak, N., \& Teo, A. (2013b). The emergence of world Englishes: Implications for English language teaching. Asian Journal of Social Sciences and Humanities, 2(2), 190-199.

Kachru, B. B. (1998). English as an Asian language. Links \& Letters, 5, 89-108.

Kaewmala. (2012, February 23). Thai education failures - part 1: Ridiculous O-NET questions. Asian Correspondent. Retrieved from https://asiancorrespondent.com/2012/02/thai-education-part-1-ridiculous-o-netquestions/

Kanno, Y., \& Norton, B. (2003). Imagined communities and educational possibilities: Introduction. Journal of Language, Identity, and Education, 2(4), 241-249.

Karnnawakul, P. (2004). Summary of research report: Foreign langauge teaching in the southern part of Thailand. Manusya Journal of Humanities, 7, 80-81.

Khamkhien, A. (2012). Proficiency, motivation, and classroom anxiety and their effects on language learning strategies used by Thai EFL learners. Rangsit Journal of Arts and Sciences, 2(2), 85-98. 
Kim, T. Y. (2011). Sociocultural dynamics of ESL learning (de) motivation: An activity theory analysis of two adult Korean immigrants. Canadian Modern Language Review, 67(1), 91-122.

Kirkpatrick, A. (2012). English as an international language in Asia: Implications for language education. In A. Kirkpatrick \& R. Sussex (Eds.), English as an international language in Asia: Implications for language education (pp. 29-43). New York: Springer.

Kongkerd, W. (2013). Teaching English in the era of English used as a lingua franca in Thailand. Executive Journal, 33(4), 3-12.

Kormos, J., \& Csizér, K. (2008). Age-related differences in the motivation of learning English as a foreign language: Attitudes, selves, and motivated learning behaviour. Language Learning, 58(2), 327-355.

Lamb, M. (2004). Integrative motivation in a globalizing world. System, 32(1), 3-19.

Lamb, M. (2012). A self system perspective on young adolescents' motivation to learn English in urban and rural settings. Language Learning, 62(4), 997-1023.

Lamb, M. (2013). 'Your mum and dad can't teach you!': Constraints on agency among rural learners of English in the developing world. Journal of Multilingual and Multicultural Development, 34(1), 14-29.

Lantolf, J. P., \& Pavlenko, A. (2001). (S)econd (L)anguage (A)ctivity theory: Understanding second language learners as people. In M. P. Breen (Ed.), Learner Contributions to Language Learning (pp. 141-158). London: Longman.

Larson, M. (1998). Meaning-based translation: A guide to cross-language equivalence. Oxford: University Press of America.

Lave, J., \& Wenger, E. (1991). Situated learning: Legitimate peripheral participation. New York: Cambridge University Press.

Li, Q. (2014). Differences in the motivation of Chinese learners of English in a foreign and second language context. System, 42, 451-461.

Li, Y. (2011). Translating interviews, translating lives: Ethical considerations in crosslanguage narrative inquiry. TESL Canadian Journal, 28(5), 16-30.

Lincoln, Y., \& Guba, E. (1985). Naturalistic inquiry. Newbury Park, CA: Sage.

Magid, M. (2009). The L2 motivational self system from a Chinese perspective: A mixed methods study. Journal of Applied Linguistics, 6(1), 69-90. 
Markus, H., \& Kitayama, S. (1991). Culture and the self: Implications for cognition, emotion, and motivation. Psychological review, 2, 224-253.

Markus, H., \& Nurius, P. (1986). Possible selves. American psychologist, 41(9), 954-969.

Mercer, S. (2012). The complexity of learner agency. Journal of Applied Language Studies, 2(6), 41-59.

Ministry of Education (MOE). (2008a). The basic education core curriculum B.E 2551 (A.D. 2008). Bangkok, Thailand: Ministry of Education.

Ministry of Education (MOE). (2008b). Towards a learning society in Thailand: An introduction to education in Thailand. Bangkok, Thailand: Ministry of Education.

Miyahara, M. (2015). Emerging self-identities and emotion in foreign language learning: A narrative-oriented approach. Bristol, UK: Multilingual Matters.

Murray, G. (2008a). Communities of practice: Stories of Japanese EFL learners. In V. M. P. Kalaja \& A. M. F. Barcelos (Eds.), Narratives of Learning and Teaching EFL (pp. 128-140). Basingstoke, UK: Palgrave Macmillan.

Murray, G. (2008b). Pop culture and language learning: Learners' stories informing EFL. Innovation in Language Learning and Teaching, 2(1), 2-17.

Murray, G. (2014). The social dimensions of learner autonomy and self-regulated learning. Studies in Self-Access Learning Journal, 5(4), 320-341.

National Identity Board. (2000). Thailand into the 2000s. Bangkok: Office of the Prime Minister.

Nikitina, L. (2011). Creating an authentic learning environment in the foreign language classroom. International Journal of Instruction, 4(1), 33-46.

Noels, K. A. (2003). Learning Spanish as a second language: Learners' orientations and perceptions of their teachers' communication style. In Z. Dörnyei (Ed.), Attitudes, Orientations, and Motivations in Language Learning (pp. 97-136). Oxford: Blackwell.

Norton, B. (2000). Identity and language learning: Gender, ethnicity and educational change. Harlow, England: Pearson Education.

Norton, B. (2001). Non-participation, imagined communities and the language classroom. In M. Breen (Ed.), Learner contributions to language learning: New directions in research (pp. 159-171). Harlow: Pearson Education.

Norton, B. (2013a). Identity and language learning: Extending the conversation (2th ed.). Bristol, UK: Multilingual Matters. 
Norton, B. (2013b, February 4). Investment, identity, and language learning [Blog post]. Retrieved from http://blog.tesol.org/investment-identity-and-language-learning/

Norton, B., \& Gao, Y. (2008). Identity, investment, and Chinese learners of English. Journal of Asian Pacific Communication, 18(1), 109-120.

Norton, B., \& Toohey, K. (2001). Changing perspectives on good language learners. TESOL Quarterly, 35(2), 307-322.

Norton, B., \& Toohey, K. (2011). Identity, language learning, and social change. Language Teaching, 44(4), 412-446.

Office of the Higher Education Commission. (2009). Thai Qualifications Framework for Higher Education. Bangkok: Office of the Higher Education Commission.

Oyserman, D., \& Markus, H. R. (1990). Possible selves and delinquency. Journal of Personality and Social Psychology, 59, 112-125.

Papi, M. (2010). The L2 motivational self system, L2 anxiety, and motivated behaviour: A structural equation modelling approach. System, 38(3), 467-479.

Peirce, B. N. (1995). Social identity, investment, and language learning. TESOL Quarterly, 29, 9-31.

Pintrich, P. R. (2000). Educational psychology at the millennium: A look back and a look forward. Educational Psychologist, 35(4), 221-226.

Raoofi, S., Hoon Tan, B., \& Heng Chan, S. (2012). Self-efficacy in second/foreign language learning contexts. English Language Teaching, 5(11), 60-73.

Richards, K. (2006). "Being the teacher": Identity and classroom conversation. Applied Linguistics, 27(1), 51-77.

Richards, J. C. (2014). The changing face of language learning: Learning beyond the classroom. RELC Journal, 46(1), 5-22.

Riessman, C. K. (2008). Narrative methods for the human sciences. Thousand Oaks, CA: Sage.

Ryan, S. (2006). Language learning motivation within the context of globalisation: An L2 Self within an imagined global community. Critical Inquiry in Language Studies, $3(1), 23-45$.

Ryan, S. (2008). The ideal L2 selves of Japanese learners of English (Unpublished doctorate's thesis). University of Nottingham. Retrieved from http://eprints.nottingham.ac.uk/10550/1/ryan-2008.pdf 
Ryan, S. (2009). Self and identity in L2 Motivation in Japan: The ideal L2 and Japanese learners of English. In Z. Dornyei \& E. Ushioda (Eds.), Motivation, language identity and the L2 self (pp. 120-143). Bristol: Multilingual Matters.

Ryan, S., \& Dörnyei, Z. (2013). The long-term evolution of language motivation and the L2 self. In A. Berndt (Ed.), Fremdsprachen in der Perspecktive lebenslangen Lernens (pp. 89-100). Frankfurt: Peter Lang.

Ryan, S., \& Irie, K. (2013). Imagined and possible self perspectives: Stories we tell ourselves about ourselves. In S. Mercer \& M. Williams (Eds.), Multiple perspectives on the self in SLA (pp. 109-126). Bristol: Multilingual Matters.

Saldana, J. (2013). The coding manual for qualitative researchers. Los Angeles: Sage.

Sampson, R. J. (2016). Complexity in classroom foreign language learning motivation: A practitioner perspective from Japan. Bristol, UK: Multilingual Matters.

Sanonguthai, S. (2014). Ready or not? The state of Thai schools in response to the ASEAN English language policy. Thammasat Review, 16(2), 128-142.

Schneider, E. W. (2011). English around the world: An introduction. New York: Cambridge University Press.

Seidlhofer, B. (2011). Understanding English as a lingua franca. Oxford: Oxford University Press.

Shkedi, A. (2005). Multiple case narrative: A qualitative approach to studying multiple populations. Philadelphia: John Benjamins.

Simpson, A., \& Thammasathien, N. (2007). Thailand and Laos. In A. Simpson (Ed.), Language and national identity in Asia (pp. 391-414). Oxford: Oxford University Press.

Smyth, D. (2001). Thai English. In M. Swan \& B. Smith (Eds.), Learner English (pp. 343-356). Cambridge, UK: Cambridge University Press.

Stockwell, G. (2013). Technology and motivation in English language teaching and learning. In E. Ushioda (Ed.), International perspectives in motivation: Language learning and professional challenges (pp. 118-136). Basingstoke: Palgrave Macmillan.

Taguchi, T. (2010). The L2 motivational self system among Japanese university learners of English: A mixed methods approach (Unpublished doctorate's thesis). University of Nottingham. 
Taguchi, T., Magid, M., \& Papi, M. (2009). The L2 motivational self system among Japanese, Chinese and Iranian learners of English: A comparative study. In Z. Dornyei \& E. Ushioda (Eds.), Motivation, language identity and the L2 self (pp. 66-97). Bristol: Multilingual Matters.

Takahashi, C. K. (2013). Ideal L2 self and university English learners: An interview study. The Language Teacher, 37(6), 3-8.

Tananuraksakul, N. (2012). Psychological and linguistic identities in a Thai EFL/ELF context. International Journal of Language Studies, 6(3), 81-98.

Teimouri, Y. (2016). L2 selves, emotions, and motivated behaviours. Studies in Second Language Acquisition, 1-29. doi:10.1017/S0272263116000243

Trakulkasemsuk, W. (2012). Thai English. In E. Low \& A. Hashim (Eds.), English in Southeast Asia: Features, policy, and language in use. Amsterdam: John Benjamins.

Ushioda, E. (2001). Language learning at University: Exploring the role of motivational thinking. In Z. Dörnyei \& R. Schmidt (Eds.), Motivation and second language acquisition (pp. 93-125). Honolulu: University of Hawai'i, Second Language and Teaching and Curriculum Center.

Ushioda, E. (2008). Motivation and good language learners. In C. Griffiths (Ed.), Lessons from good language learners (pp. 19-34). Cambridge: Cambridge University Press.

Ushioda, E. (2009). A person-in-context relational view of emergent motivation, self and identity. In Z. Dörnyei \& E. Ushioda (Eds.), Motivation, language identity and the L2 self (pp. 215-228). Bristol: Multilingual Matters.

Ushioda, E. (2011a). Language learning motivation, self and identity: Current theoretical perspectives. Computer Assisted Language Learning, 24(3), 199-210.

Ushioda, E. (2011b). Motivating learners to speak as themselves. In G. Murray, X. Gao, \& T. E. Lamb (Eds.), Identity, motivation, and autonomy in language learning (pp. 11-24). Bristol, UK: Multilingual Matters.

Ushioda, E. (2011c). Why autonomy? Insights from motivation theory and research. Innovation in Language Learning and Teaching, 5(2), 221-232.

Ushioda, E. (2013). Motivation matters in mobile language learning: A brief commentary. Language Learning \& Technology, 17 (3), 1-5. 
Ushioda, E. (2015). Context and complex dynamic systems theory. In Z. Dörnyei, P. D. MacIntyre, \& A. Henry (Eds.), Motivational dynamics in language learning (pp. 47-54). Bristol: Multilingual Matters.

Vygotsky, L. (1978). Mind in society: The development of higher mental process. Cambridge, MA: Harvard University Press.

Wang, T., \& Rajprasit, K. (2015). Identifying affirmative beliefs about English language learning: Self-perceptions of Thai learners with different language proficiency. English Language Teaching, 8(4), 1-13. Retrieved from http://dx.doi.org/10.5539/elt.v8n4p1

Webster, L., \& Mertova, P. (2007). Using narrative inquiry as a research method. New York: Routledge.

Wenger, E. (1998). Communities of practice: Learning, meaning, and identity. Cambridge, UK: Cambridge University Press.

Wenger, E. (2000). Communities of practice and social learning systems. Organization, $7(2), 225-246$.

Wongsothorn, A., Hiranburana, K., \& Chinnawongs, S. (2003). English language teaching in Thailand today. In H. W. Kam \& R. L. Wong (Eds.), English language teaching in East Asia today: Changing policies and practices. Singapore: Eastern University Press.

Yashima, T. (2013a). Imagined L2 selves and motivation for intercultural communication. In M. Apple, D. da Silva, \& T. Fellner (Eds.), Language learning motivation in Japan (pp. 35-53). Bristol, UK: Multilingual Matters.

Yashima, T. (2013b). Individuality, imagination and community in a globalising world: An Asian EFL perspective. In P. Benson \& L. Cooker (Eds.), The applied linguistic individual: Sociocultural approaches to autonomy, agency and identity (pp. 46-58). London: Equinox.

Zimmerman, B. J. (2000). Attaining self-regulation: A social cognitive perspective. In M. Boekaerts, P. R. Pintrich, \& M. Zeidner (Eds.), Handbook of self-regulation. San Diego, CA: Academic Press.

Zuengler, J., \& Miller, E. R. (2006). Cognitive and sociocultural perspectives: Two parallel SLA worlds? TESOL Quarterly, 40(1), 35-58. 
APPENDICES 


\section{Appendix A: Ethical approval letter}

TE WHARE WÃNANGA O TE OPOKO O TE IKA A MĀUI

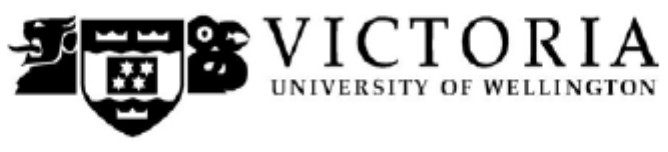

MEMORANDUM

Phone 0-4-4635676

Fax 0-4-4635209

Email Allison.kirkman@vuw.ac.nz

\begin{tabular}{l|l}
\hline TO & Sudatip Prapunta \\
\hline COPY TO & Carolyn Tait \\
\hline FROM & Dr Allison Kirkman, Convener, Human Ethics Committee \\
\hline
\end{tabular}

\begin{tabular}{l|l}
\hline DATE & 11 April 2014 \\
\hline PAGES & 1 \\
\hline
\end{tabular}

SUBJECT

Ethics Approval: 20433

Language Learning Motivation and Identity of Thai University

Students

Thank you for your application for ethical approval, which has now been considered by the Standing Committee of the Human Ethics Committee.

Your application has been approved from the above date and this approval continues until 29 February 2016. If your data collection is not completed by this date you should apply to the Human Ethics Committee for an extension to this approval.

Best wishes with the research 


\section{Appendix B: Questionnaire}

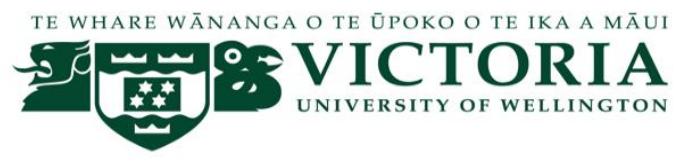

\section{English Learner Questionnaire}

This survey aims to assist the researcher in gaining a better understanding of the thoughts and beliefs of English language learners. This questionnaire consists of three sections. Please read each instruction and write your answer. This is not a test so there are no "right" or "wrong" answers and you do not even have to write your name on it. The results of this survey will be used only for research purpose so please give your answer sincerely. Thank you very much for your help!

\section{Part I}

In this part, we would like to tell us how much you agree or disagree with the following statements by simply circling a number from 1 to 6 .

\begin{tabular}{|c|c|c|c|c|c|}
\hline $\begin{array}{c}\text { Strongly } \\
\text { disagree }\end{array}$ & Disagree & $\begin{array}{c}\text { Slightly } \\
\text { disagree }\end{array}$ & $\begin{array}{c}\text { Slightly } \\
\text { agree }\end{array}$ & Agree & $\begin{array}{r}\text { Strongly } \\
\text { agree }\end{array}$ \\
\hline 1 & 2 & 3 & 4 & 5 & 6 \\
\hline
\end{tabular}

1. My parents encourage me to study English. (PE)

2. If an English course was offered at university or somewhere else in the future, I would like to take it. (CM)

3. Studying English can be important to me because I think it will be useful in getting a good job. (IN_PRO)

4. I can imagine myself living abroad and having a discussion in English. (IS)

5. I have to learn English because without passing the English course I cannot graduate. (IN_PRE) 
6. I study English because close friends of mine think it is important. (OS)

7. My parents encourage me to take every opportunity to use my English (e.g. speaking and reading). (PE)

8. I am working hard at learning English. (CM)

9. Studying English is important to me because English proficiency is necessary for promotion in the future. (IN_PRO)

10. I can imagine a situation where I am speaking English with foreigners. (IS)

11. I have to study English because I don't want to get bad marks in it at university. (IN_PRE)

12. I have to study English, because if I do not study it, I think my parents will be disappointed with me. (OS)

13. I am prepared to expend a lot of effort in learning English. (CM)

14. My parents encourage me to study English in my free time. (PE)

15. Studying English is important to me because I would like to spend a longer period living abroad (e.g. studying and working). (IN_PRO)

16. I imagine myself as someone who is able to speak English. (IS)

17. I have to study English, otherwise, I think I cannot be successful in my future career. (IN_PRE)

18. Learning English is necessary because people surrounding me expect me to do so. (OS)

19. My parents encourage me to attend extra English classes after class (e.g., at English conversation schools). (PE)

20. I think that I am doing my best to learn English. (CM)

21. Studying English can be important for me because I think I'll need it for further studies on my major. (IN_PRO)

22. Whenever I think of my future career, I imagine myself using English. (IS) 
23. Studying English is necessary for me because I don't want to get a poor score or a fail mark in English proficiency tests. (IN_PRE)

24. My parents believe that I must study English to be an educated person. (OS)

25. Studying English is important to me because with English I can work globally. (IN_PRO)

26. The things I want to do in the future require me to use English. (IN_PRO)

27. Studying English is important to me because, if I don't have knowledge of English, I'll be considered a weak student. (IN_PRE)

Part II: In this part, we would like to tell us how much you agree or disagree with the following statements by simply circling a number from 1 to 5 .

\begin{tabular}{|c|c|c|c|c|}
\hline $\begin{array}{c}\text { Strongly } \\
\text { disagree }\end{array}$ & Disagree & So-so & Agree & Strongly agree \\
\hline 1 & 2 & 3 & 4 & 5 \\
\hline
\end{tabular}

How confident are you at the end of this academic year you will be able to?

28. write a short summary of a newspaper article in English? (SE)

29. write your opinion about an article in English? (SE)

30. read and understand a newspaper article? (SE)

31. listen to and understand a lecture in English? (SE)

32. listen to and understand an English native speaker in a tutorial? (SE)

33. listen to and understand an English film? (SE)

34. speak about a film with a native speaker? (SE)

35. discuss a newspaper article with a native speaker? (SE) 
Part III: Please provide the following information by clicking in the box or type your response in the space.

\section{Gender:}

Male

Female

Age: 16 17

18 19

20 or more

First-year student majoring in:

English major/ Business-English major

Non-English major

\section{University:}

Government-run university

Private university

\section{Educational background:}

From what part of the country did you graduate your high school?

Bangkok

Central

Northern

North eastern

Western

Southern

\section{Years of studying English:}

How many years have you been studying English?

6

11
7

12
8

13
9

14
10

15

\section{Overseas experiences:}

Have you spent a longer period (at least a total of three months) in English-speaking countries (e.g. travelling, studying)?

$$
\text { Yes _ No }
$$

\section{Learning experiences with native teachers:}

Have you ever had or do have a native English-speaking teacher?

$$
\text { Yes _ No }
$$




\section{Interested in joining a lucky draw:}

Are you interested in joining the lucky draw of a movie ticket (a total of 20 tickets)? If so, please give your contact details (email address or mobile phone number) in the space given.

\section{Interested in participating in the interview:}

Are you interested in participating in the interview? If so, please give your contact details (email address or mobile phone number) in the space given.

=ニニニ=ニニニ=ニ=-Thank you for completing the questionnaire. 


\section{Appendix C: Preliminary interview questions}

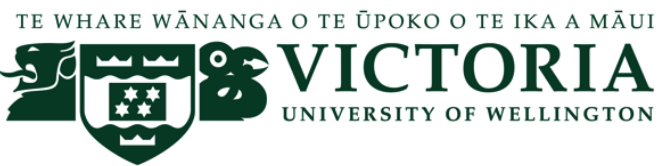

Language Learning Motivation

- Why are you interested in learning English?

- Tell me about your commitment to learning English? Please give examples.

- How do you feel when you are learning English as an EFL undergraduate in

Thailand?

- What is your goal for learning English?

- What are your goals for learning English today?

- What is your long-term goal for learning English?

Language Learning History/ L2 learning experiences in the past and present

- $\quad$ High school L2 learning experiences

- What is the most pleasant memory you have of being a language learner? Please tell me your story, describe it, or show me some related artefacts.

- What is your most unpleasant memory as a language learner?

Please tell me your story, describe it, or share some related artefacts with me.

- $\quad$ University L2 learning experiences

- Who has been the most influential person in your L2 learning? Tell me about him/her.

- Tell me about the personal or family incidents have affected you most in your English learning?

- Motivational changes over time

- How would you describe your present state of motivation for learning English in the university?

- Have you experienced any motivational changes from your high school L2 learning experiences over the past year?

- Have you changed your plans about your future career? Do you think these have had any impact on the way you feel about learning English? 


\section{Learner's self-efficacy}

- Do you relate your reasons for studying to any long-term plans that you might have?

- What do you hope to gain from studying English at university level?

- How do you feel about learning English at university?

- $\quad$ Do you feel confident while performing listening, speaking, reading, and writing activities? Why? Why not? 


\section{Appendix D: Information for the online survey}

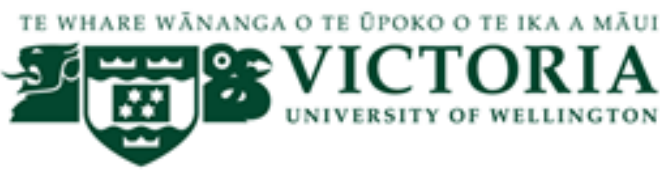

\section{-SURVEY PARTICIPATION- \\ Victoria University of Wellington, New Zealand \\ School of Educational Psychology and Pedagogy, Faculty of Education \\ Information for you regarding the online survey entitled "Language Learning Motivation and Identity of Thai University Students"}

Starting the survey would represent agreeing to take part in the research.

\section{Researcher}

I am Sudatip Prapunta, a PhD student in the School of Educational Psychology and Pedagogy, Faculty of Education, Victoria University of Wellington, New Zealand. I would like to invite you to participate in my research study by responding to an online questionnaire.

\section{Research Project}

My research project is entitled "Language Learning Motivation and Identity of Thai University Students". This study is designed to explore students' perceptions of English language learning motivation through an understanding of Thai university students' language learning identities. It will potentially offer a rich and deep insight into English learners in Thai tertiary education which may inform educational shareholders at Thai universities.

Students in two universities in Bangkok, Thailand are being invited to participate in this project. The questionnaire should take approximately 15-20 minutes to complete. There are no "right" or "wrong" answers and this research will have no impact on your grade. Your name and university will not be identified in any publications resulting from the research. Access to the data is restricted to my supervisors and me. All data will be stored in password protected files and will be kept for 5 years, after which they will be destroyed. 
Participation in the research is on a voluntary basis. If you consent to participate in the research project, please open the link to the online questionnaire. If you complete the questionnaire within (three weeks) __(date)____. You will be eligible to anticipate for the lucky draw for movie tickets. At the end of the questionnaire, you will be asked whether you are willing to be interviewed. If so, you will be asked to provide contact details, and if you are selected for the interview phase, you will be given a separate information and consent form.

If you agree to participate in this research project, you have the following rights:

- to withdraw by not completing the questionnaire;

- to refuse to answer the particular question;

- to ask any additional questions regarding the study at any time;

- to provide the information with an assurance of data confidentiality;

- to be provided with a summary of findings if you wish. The findings will be sent to you by email.

This project has been reviewed and approved by the Victoria University Human Ethics Committee. If you have any questions or you would like additional information, please contact me at Sudatip.prapunta@vuw.ac.nz, sprapunta@yahoo.com or my supervisors, Dr. Carolyn Tait at Carolyn.tait@vuw.ac.nz, telephone +64-4-463-9590 and/or Dr. Margaret Gleeson, at Margaret.gleeson@vuw.ac.nz. If you have any concerns about the ethics of this project, please contact the head of the ethics committee Allison Kirkman at Allison.kirkman@vuw.ac.nz. 


\section{Appendix E: Information sheet for the in-depth interview}

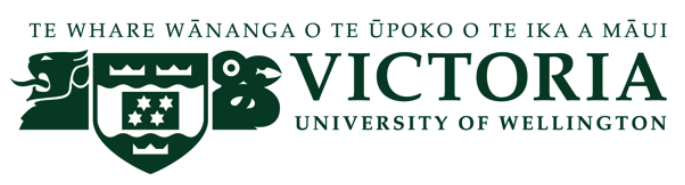

-INTERVIEW PARTICIPATION-

Victoria University of Wellington, New Zealand

School of Educational Psychology and Pedagogy, Faculty of Education

Information Sheet for Interviews with Participants in a Research Study of Language Learning Motivation and Identity of Thai University Students

\section{Researcher}

I am Sudatip Prapunta, a PhD student in School of Educational Psychology and Pedagogy, Faculty of Education, Victoria University of Wellington. My research is designed to explore students' perceptions of English language learning motivation through an understanding of Thai university students' language learning identities. It will potentially offer a rich and deep insight into English learners in the Thai tertiary education which may inform educational shareholders of the universities.

When you volunteer to participate, you will be invited to take part in a face-to-face interview with the researcher which will audio recorded and transcribed by the researcher. The interviews will take approximately 45 minutes to one hour. You may be invited to participate in the follow-up interviews to clarify the different aspects of your stories. Any follow-up interviews will take place via email, phone, or face-to-face-communication, depending on your preference and availability. These interviews are likely to take place within 2 months. All information collected will be strictly confidential. Your identity will be protected using a pseudonym. This study will have no impact on your grade. There is no penalty for participating or not participating in this research. Access to the data is restricted to my supervisors and me. All data will be stored in password protected files and will be kept for 5 years, after which they will be destroyed. 
If you consent to participate in the interview, you have the following rights

- to decline to answer any particular questions;

- to withdraw from the study for any reason within two weeks after interview;

- to ask any questions regarding the study at any time during participation;

- to provide information on the understanding that your name will not be revealed;

- to have the interview transcriptions sent to you by email and have a chance to verify it and change any part of it;

- to be given access to a summary of the study findings when it is concluded if you wish. This will be sent to you by email.

This project has been reviewed and approved by the Victoria University Human Ethics Committee. If you have any questions or you would like additional information, please contact me at Sudatip.prapunta@vuw.ac.nz, sprapunta@yahoo.com or my supervisors, Dr. Carolyn Tait at Carolyn.tait@vuw.ac.nz, telephone +64-4-463-9590 and/or Dr. Margaret Gleeson, at Margaret.gleeson@vuw.ac.nz. If you have any concerns about the ethics of this project, please contact the head of the ethics committee Allison Kirkman at Allison.kirkman@vuw.ac.nz. 


\section{Appendix F: Information sheet for the dean or head of the department}

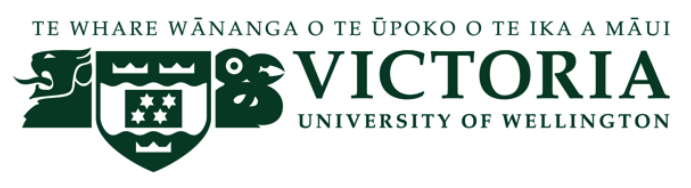

-UNIVERSITY PARTICIPATION-

Dean or Head of Language Centre Information Sheet

"Language Learning Motivation and Identity of Thai University Students"

\section{Researcher}

I am Sudatip Prapunta, a $\mathrm{PhD}$ student in School of Educational Psychology and Pedagogy, Faculty of Education, Victoria University of Wellington. Before doing the $\mathrm{PhD}$, I was a lecturer of................. My doctoral study is designed to explore students' perceptions of English language learning motivation through an understanding of Thai university students' language learning identities. This research has ethical approval from the Victoria University Human Ethics Committee.

This sheet gives you information regarding this study. If you have any questions or would like to receive further information regarding this project, please contact me at Sudatip.prapunta@vuw.ac.nz. You can also contact my supervisors, Dr. Carolyn Tait, Senior Lecturer at Carolyn.tait@vuw.ac.nz, Phone: +64-4-463-9590 and/or Dr. Margaret Gleeson, Senior Lecturer at Margaret.gleeson@vuw.ac.nz. Any ethical concerns regarding the research should be directed to Dr. Allison Kirkman, chair of the Victoria University of Wellington Human Ethics Committee by emailing Allison.kirkman@vuw.ac.nz.

\section{The purpose of my $\mathrm{PhD}$ research}

This research aims to contribute to offer a rich and deep insight into English learners in the Thai tertiary education which may inform educational shareholders of the universities.

\section{Research questions}

1. What kinds of relationship exist between the two L2 "selves" (ideal L2 self and ought-to self) for Thai university students? 
2. How do highly-motivated learners report the past and present influences of their L2 learning environment?

3. How do Thai university students' stories reflect the notion of "self" in their language learning motivation?

\section{Research Process}

My study will be conducted in two universities in Bangkok, Thailand where students study English. To achieve an in-depth understanding of students' perception of English language learning motivation through an understanding of Thai university students' language learning identities, the data gathering in the study is organised into two phrases. In the first phase, data will be collected through online questionnaires. In the second phase of the study, the main data collection of individual interviews will be approximately 45 minute to one hour. The follow-up interviews will be conducted by email, phone, or face-to-facecommunication, depending on the student's preference and availability. The interview will be digitally recorded and transcribed, and the key themes emerging will be translated into English.

\section{Research Participants}

I am sending a link of an online questionnaire to 200-250 first-year students from your university. They are invited to participate in an online survey. At the end of the questionnaire, they will be asked whether they are willing to be interviewed. Those participants and express their willingness to participate will be invited to participate in an in-depth interview. This is an opportunity to ensure all those interested, are encouraged to articulate their deep understanding of their language learning identities.

\section{Participation}

I am seeking permission to access the students' email addresses. Participations may withdraw from the research project for any reason and any data provided would then be destroyed. 


\section{Confidentiality and Access to Information}

The information provided is strictly confidential. Your university and students will not be identifiable. Data and information collected will be kept confidentially by the researcher, Sudatip Prapunta. During and at the completion of the interviews I will collaborate with participants and check with all of them to ensure that the content of interviews are correctly transcribed. If there is any uncertainty, I will ask them for elaboration or further explanation. They will be given the opportunity to change or delete their comments if they wish. Access to the data is restricted to my supervisors and me. All data will be stored in password protected files and will be kept for 5 years, after which they will be destroyed.

\section{The participation for the students would involve:}

- Filling out the online questionnaire.

- Participating in the interviews and being available for follow-up interviews.

- Agreeing that the information given can be used by the researcher, Sudatip Prapunta for the study.

\section{Publications of Results}

The information gained in this research will be used for publication purposes including academic or professional journals, conference papers and appropriate articles and for the deposit of the thesis at the Victoria University of Wellington library.

Your consent for this study is highly valued.

Thank you for your consideration. 


\section{Appendix G: Consent form for the dean or head of the department}

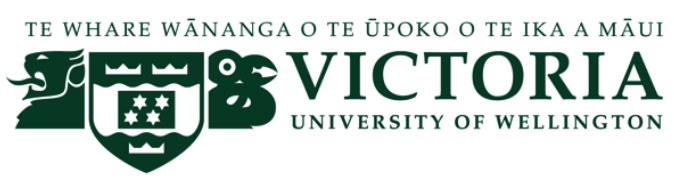

\section{-UNIVERSITY CONSENT FORM-}

\section{$\underline{\text { Research Project - Head of Department Consent Form }}$}

Project Title: "Language Learning Motivation and Identity of Thai University Students" I have read the Information Sheet for students and have understood the nature of research and why the Thai university students have been selected in this study.

- I agree to allow the researcher to access the students' email addresses of the department/language centre for research purposes.

- I agree to allow the researcher to approach undergraduate Thai EFL students from my university for research purposes.

- I understand that participation is entirely voluntary and will take place only with the consent of all participants.

- I understand that data will be kept for 5 years, after which they will be destroyed.

- I understand that the participants can withdraw from the research for any reason within two weeks after interview and that any data provided would then be destroyed.

- I understand that neither the participants' names nor the university's name will be used in any publications or presentations based on the data from this research.

Name:

Signature:

I wish to receive feedback from this project by being sent a summary of the research. This will not be available until (date)

Yes

$\square \quad$ No 
Email address

Signature

Date 


\section{Appendix H: Consent form for students}

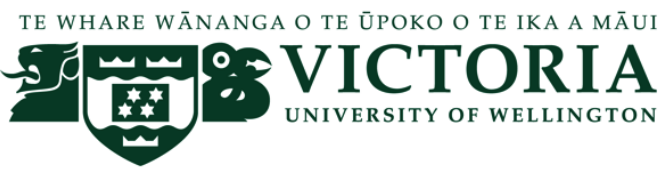

\section{-INTERVIEW CONSENT FORM- \\ $\underline{\text { Research Project-Student Consent Form }}$}

\section{"Language Learning Motivation and Identity of Thai University Students"}

Please read the following:

$>$ I agree to be interviewed by the researcher Sudatip Prapunta.

I understand that interviews will be recorded and transcribed.

I understand that my participation is entirely voluntary.

> I understand that my identity will be protected using a pseudonym. .

I understand that the analysis obtained may be used for a thesis, for conference papers and/or publication by the researcher Sudatip Prapunta.

$>$ I understand that I can withdraw from the research project for any reason within two weeks after interview and that any data provided would then be destroyed.

$>$ I understand that the researcher may ask me for further follow-up interviews to ensure that my stories have been fully understood.

$>$ I understand that the researcher will ask me to share the meaningful artefacts such as diaries, photos, and letters in the interviews.

$>$ I understand that I will have a chance to check the accuracy of the interview/s.

I understand that transcripts and tapes and raw data will be kept for five years, after which they will be destroyed. 
Please indicate your preference for involvement in the research (tick as appropriate):

- I have had the project explained to me and have had the chance to ask any questions. I agree to take part in the above research.

Name

Name of university

I wish to receive feedback from this project by being sent a summary of the research.

$\square \quad$ Yes
$\square \quad$ No

Email address

Signature

Date 


\section{Appendix I: Sample of my research journal}

\section{Excerpt from my Research Journal}

I felt so delighted once Chi, the only one student at my university, replied that she liked learning the Business Grammar course with her NS lecturer. She shared with me that she liked his teaching strategies which he applied the grammatical lessons to real-life activities and speaking tests. Not surprisingly most of our students liked him. Interestingly, sometimes, he played a trick, as a magician, to motivate our students once they got bored.

(Research Journal, July 12, 2014)

Tracing back to the day we had a curriculum-design meeting, we were assigned to brainstorm what subjects we should include or whether to make some changes to our new curriculum. Normally I did not talk much in a meeting, even in the Thai language, as a newcomer. However, I remembered well that I suggested we should change from Grammar I, Grammar II, to Business Grammar I and Business Grammar II. Also, I recommended the textbooks I used as training materials and supplements while working at the company. Even if the commercial textbook I suggested was not selected despite providing a listening CD, I was delighted that I was part of designing this curriculum and the teacher in charge could do his job successfully. This meant we could serve our BE students' language learning needs and motivation to some extent.

(Research Journal, July 30, 2014) 
Appendix J: Sample of the student's English language diary

no.

date.

English Friend : I have $i$ trigtish friend Frame is Tom. is ed

Tom likes boxing and Pinteresting an The Thai language That Tand. He learnst thi language ant Tha culfure. Often he asks me many questions about sentences and I atrays tellteach tote him. I was happy to help his. Tlike I publish T thai language. fom: told me he wants to come to Phoket. $\because$ I want to train boxing at Phecoet he tolds me, and I told him I If be his gutde Two days ago the chatf with

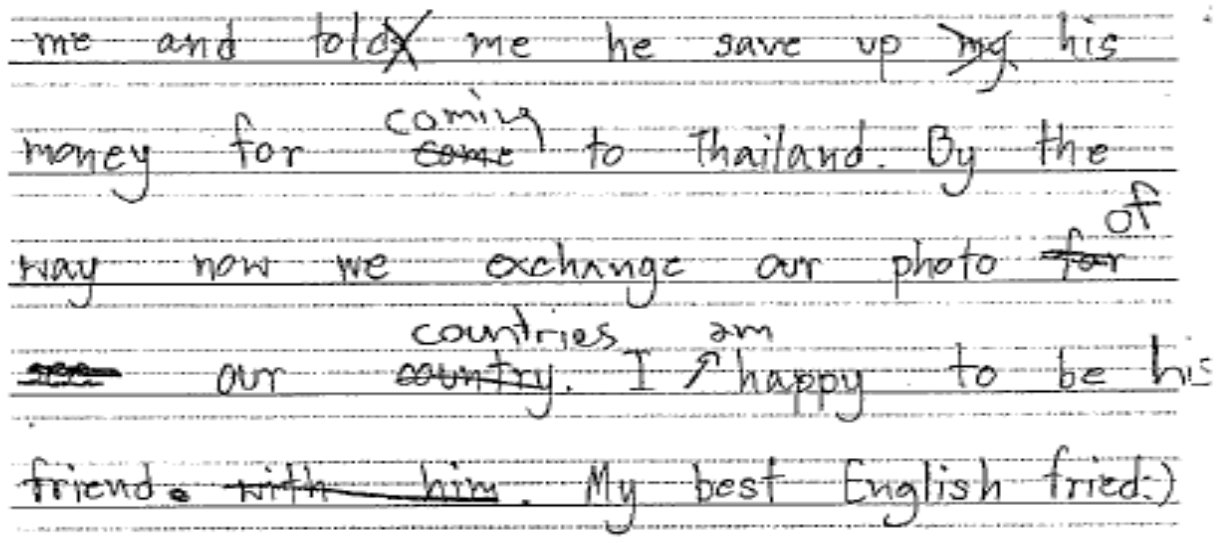
TOM $x$ 
Appendix K: Mean score and SD of the intended effort variable

\begin{tabular}{lcc}
\hline \multicolumn{1}{c}{ Items } & Mean & SD \\
\hline 2. If an English course was offered at university or & 4.89 & .76 \\
somewhere else in the future, I would like to take it. & & \\
8. I am working hard at learning English. & 5.10 & .81 \\
13. I am prepared to expend a lot of effort in learning English. & 4.69 & .93 \\
20. I think that I am doing my best to learn English. & 3.54 & 1.4 \\
\hline
\end{tabular}

